\title{
LA PRODUCCIÓN DE UNA OPORTUNIDAD O ¿LA FRUSTRACIÓN DISOLUTORIA DE LA POSIBILIDAD?
}

La maestría PLANGESCO, cohorte Comodoro Rivadavia, 2003-2013

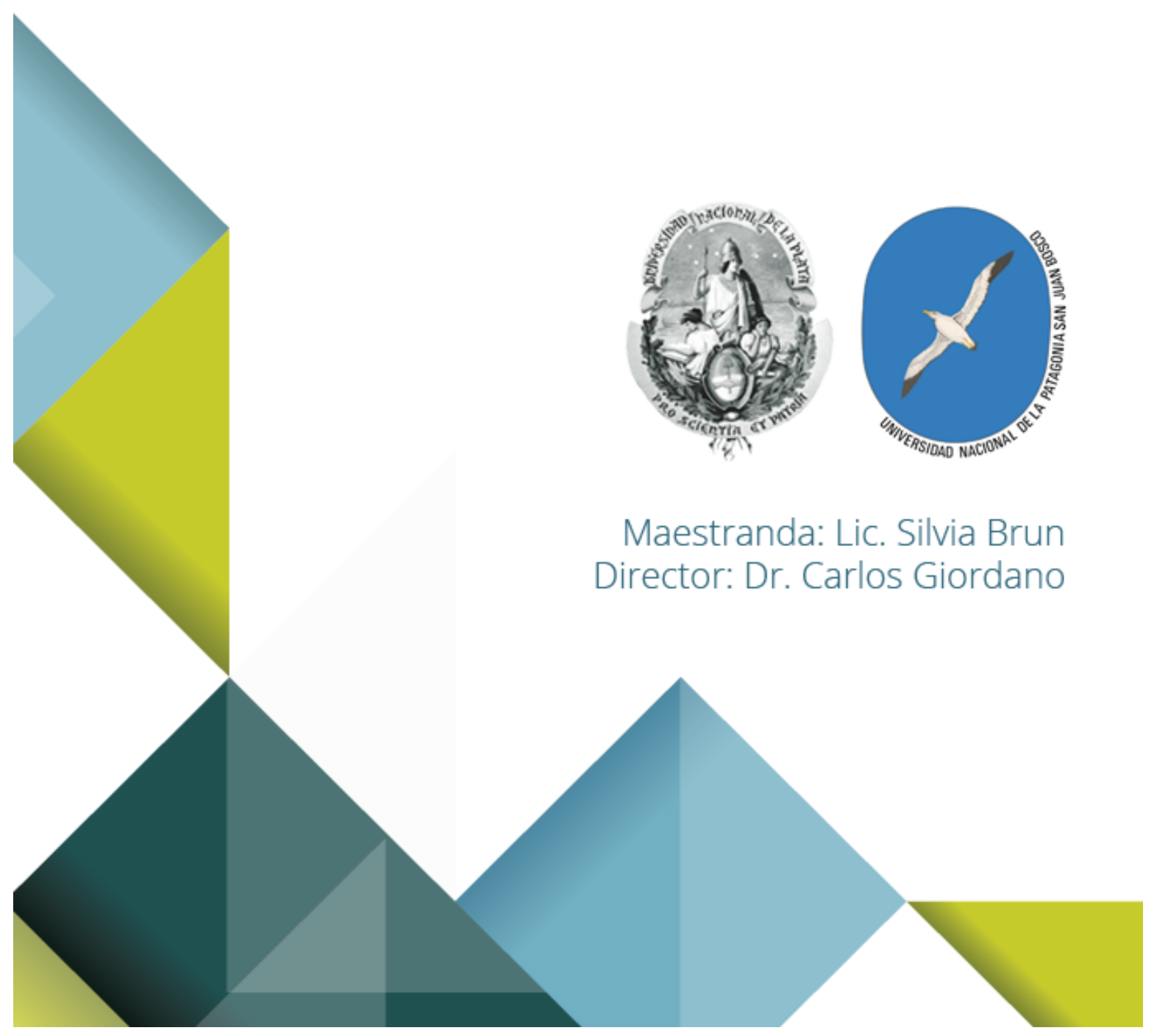


A la memoria de mi padre y de Kira, amiga y compañera

\section{Agradecimientos}

Al primer director de mi primer intento de tesis, Carlos Vallina, maestro y amigo

A mi actual director Carlos Giordano, maestro, amigo, compañero y aliado incondicional

A mis compañeros de PLANGESCO, todos y cada uno por el camino recorrido y a la asistencia especial de cada quien en cada momento

A los profesores, a los que gracias a mi doble rol de coordinadora y alumna, conocí en su faz humana y académica, en especial a Washington Uranga quien se comprometió con el proyecto en un tramo del mismo

A todos los entrevistados que con su disposición ayudaron a la reconstrucción del proceso

A la Facultad de Periodismo y Comunicación Social de la Plata en la persona de Florencia Saintout y a nuestra casa, porque es nuestra y a pesar de todo nos lo permitió

A mis amigas y amigos, por su apoyo y colaboración

A mis hijos Anaclara y Franco por su ayuda y porque le ponen horizonte a mi vida A mi madre Edit

Resumen 
Al reunir los antecedentes de las Facultades de Periodismo y Comunicación Social de la UNLP y de Humanidades y Ciencias Sociales de la UNPSJB se dio marco al caso abordado de constitución de la Maestría PLANGESCO en la sede Comodoro Rivadavia de esta última.

Al reflexionar sobre el modo en que esta experiencia extensa y compleja fue atravesada por la cultura de ambas organizaciones, se analizó la dificultad con que los posgrados han sobrevivido y crecido en nuestro país durante una década, donde las políticas de restauración de derechos fueron construidas en el marco de lógicas desmotivadoras de lo colectivo, herederas del neoliberalismo que la precedió.

Las perspectivas de abordaje político de cada una de las gestiones en ambos decanatos así como de la concepción de la propia maestría que modificó hasta la noción de su temática específica, fueron también producto de esta experiencia desarrollada en un período de casi una década.

La historicidad del proceso destaca los momentos y sucesos que marcaron las condiciones de posibilidad de su desarrollo, así como pusieron en evidencia los obstáculos que fueron producto de un escenario complejo de la educación superior en general y en particular de la universidad receptora.

La fuerza del proyecto colectivo se pone de manifiesto en las apropiaciones y representaciones de los integrantes del grupo que pese a las dificultades reconocen la importancia de haber sostenido el proceso de autogestión y los beneficios que aportó a su propia Carrera de Comunicación Social.

Palabras claves: educación superior- PLANGESCO - posgrado- procesocolectivo

\section{Summary}

Background information was gathered from the School of Journalism and Mass Communication of the University of La Plata (UNLP) and the School of Humanities and Social Sciences of the San Juan Bosco Patagonian University (UNPSJB) to set the framework for the establishment of the PLANGESCO Master's Course at the Comodoro Rivadavia branch of the latter university. Upon reflecting on the way the culture of both organizations pervaded such vast and complex experience, an analysis was made of the difficulties 
postgraduate studies had to endure for one decade in order to survive and grow in Argentina, where restoration of rights policies were built within the framework of collectiveness demotivational logics sprung from a preceding neoliberalism.

Prospects of a political approach to each administration in both deans' offices, as well as to the conception of the master's course itself - which altered even the notion of its specific subjects - were also a result of this experience developed within a period of nearly one decade.

A view of the process through history highlights moments and events that set the conditions for its development, and put in evidence the obstacles that sprung from a complex higher-education scenario, particularly as concerns the receiving university.

The strength of the collective project lies in the appropriations and representations of group members, who, in spite of all difficulties, recognize the significance of having supported the self-management process and the benefits yielded by their own Mass Communication course.

Keywords: higher education - PLANGESCO - postgraduate - process collective*

*translation: Rodolfo Mazzuchi MacSwain

"Se cuenta lo que es utilizado, no las maneras de utilizarlo. Paradójicamente estas se vuelven invisibles en el universo de la codificación de la transparencia generalizada. De estas aguas que se insinúan por todas partes solo son perceptibles los efectos la cantidad y localización de los productos consumidos...". De Certeau Michel. La Invención de lo Cotidiano.

Introducción

Esta tesis tiene como objetivo rescatar y reflexionar acerca de las apropiaciones y representaciones que tuvo para la cohorte de alumnos, en su mayoría provenientes de la Licenciatura en Comunicación Social, la Maestría PLANGESCO de la Facultad de Periodismo y Comunicación Social de la Universidad Nacional de La Plata, que la cursaron en la sede Comodoro Rivadavia de la Universidad Nacional de la Patagonia San Juan Bosco en el 
período 2003-2010. Asimismo, es un propósito rastrear el modo en que esta experiencia atravesó y fue atravesada por la cultura institucional tanto de la Facultad de Humanidades y Ciencias Sociales cuanto de la Facultad de Periodismo y Comunicación Social de la Universidad Nacional de La Plata.

Los siete años que demoró en concluirse el dictado de los seminarios (último encuentro presencial 10/11/2010 Taller de Tesistas) del único ciclo de esta Maestría PLANGESCO -Planificación y Gestión de Procesos Comunicacionalesen Comodoro, anticipan un complejo proceso de implementación empujado por el deseo y atravesado por las dificultades. En la historicidad del mismo, están representados los diferentes momentos, tanto los que posibilitaron como los que dificultaron su consecución. $Y$ en esos momentos destacados, se encuentran las razones que motivaron a cada organización involucrada a favorecer o dificultar el proceso de institución de la Maestría PLANGESCO Comodoro, así como también las condiciones de posibilidad que permitieron gestionar la propia existencia del posgrado.

Así es que el presente trabajo pretende realizar un aporte en el análisis de las percepciones tanto de la cohorte de alumnos de la Maestría PLANGESCO de la FPyCS de la UNLP en la sede Comodoro Rivadavia de la UNPSJB como de referentes clave en el proceso de institucionalización del posgrado en la Facultad Humanidades y Ciencias Sociales de la UNPSJB, proceso en el que tiene a su vez fuerte incidencia la Facultad de Periodismo y Comunicación de la UNLP que opera en este convenio como la universidad tradicional que hace una extensión al sur de su ya consolidado proyecto.

Por último, el trabajo es expresión de la perspectiva de una docente que tomó la iniciativa, de la coordinadora de un proyecto conjunto y de la alumna interesada en desentrañar sus propias disquisiciones.

En este sentido, la investigación estará guiada por la hipótesis de, por un lado, que las dificultades surgidas en su desarrollo pusieron al descubierto las propias dificultades de la Facultad de Humanidades y Ciencias Sociales de la 
UNPSJB para institucionalizar el área de posgrado en el marco de una universidad emergente del contexto nacional, y por otro, que el esfuerzo que la experiencia demandó a sus protagonistas significó un aporte al crecimiento del colectivo en el fortalecimiento de la carrera Licenciatura en Comunicación Social de la UNPSJB.

El primer capítulo La comunicación se abre camino entre las ciencias sociales intenta esbozar una semblanza de las organizaciones involucradas en el dictado de la Maestría objeto de esta tesis, destacando el nacimiento de ambas carreras como marca identitaria de su impronta y devenir. Rasgos propios de las vicisitudes que atravesaron por alcanzar el ideal de la democratización de la enseñanza, el del servicio público de nuestra educación. Por una parte, la Universidad Nacional de la Patagonia que en su nombre 'San Juan Bosco', adopta los orígenes de la institución salesiana y los antecedentes de una organización nacida para apoyar el desarrollo de una región despoblada. Por otra, la Escuela decana de los estudios universitarios de periodismo que hizo gala de su espíritu de asociatividad, con el Círculo de Periodistas de la Provincia de Buenos Aires en su origen y para la constitución de esta Maestría con la Crujía, una organización sin fines de lucro, dedicada a la educación en comunicación.

Todo ello en el marco de un proceso donde la comunicación como disciplina, necesitó abrirse paso entre las más consolidadas de las ciencias sociales. En la Universidad Nacional de la Patagonia fue gestada tempranamente en 1986 por iniciativa de la carrera de Letras, lo que le demandó un esfuerzo extra para posicionarse entre las ciencias sociales, mientras que en la Universidad Nacional de La Plata la carrera, surgida desde el periodismo, integra a la Comunicación Social en la década del '70, pero en el costoso proceso de recomposición de las consecuencias de la Dictadura, que hizo que sea recién en 1989 con el cambio de plan de estudios, que se produzca un crecimiento vertiginoso que se corona en 1994 con el pase a facultad. Esta promoción fortaleció la carrera académica e implicó el cambio del perfil profesionalista por el de una institución que generaba los primeros posgrados de la disciplina. 
El segundo capítulo El posgrado se instala como mecanismo de promoción contextualiza su desarrollo en nuestro país como iniciativa de la incipiente democracia y posteriormente como resultado de las políticas educativas de la década del noventa. Su lento posicionamiento en la Universidad de la Patagonia pone en evidencia la distancia material y simbólica frente a los hitos que señalaron el crecimiento de la Facultad de Periodismo y Comunicación Social de la UNLP, pionera en materia de posgrado. PLANGESCO fue la primera Maestría en Comunicación del país acreditada por CONEAU - Comisión Nacional de Evaluación y Acreditación Universitaria- y categorizada "B" en el año 2011.

En el caso de la Facultad de Humanidades y Ciencias Sociales de la Universidad Nacional de la Patagonia fue necesaria la construcción de un relato que no sólo recuperara los antecedentes previos a la llamada institucionalización del área por parte de las actuales autoridades, sino que articulara los mismos con la confrontación de testimonios y documentos. Este recorrido por los principales antecedentes del posgrado en la Facultad, permitió no sólo la reconstrucción de los eventos y desarrollos en relación al mismo, sino también la comprobación acerca de la falta de reconocimiento institucional a estas primeras iniciativas académicas.

Asimismo se evalúa la importancia de los posgrados en las políticas universitarias de los últimos años, las dificultades y potencialidades para los alumnos que los cursan y las implicancias académicas tanto para las instituciones como para los posgraduados.

El capítulo 3 aborda el Perfil de la carrera y las etapas del desarrollo con la finalidad de conocer en profundidad el origen de la Maestría PLANGESCO, sus características y la evolución en el período correspondiente a la cursada de esta cohorte, así como la de su dictado en la sede Comodoro Rivadavia de la UNPSJB. Este último con el objetivo de evaluar el impacto de los hitos que marcaron su desarrollo, así como para analizar las diferentes etapas que atravesó no sólo en cuanto a la vinculación con las distintas gestiones políticas en ambas universidades, sino a su vez con el contexto que 
condicionaba a las mismas y en consecuencia al posgrado. En particular se visualiza en este apartado la gestión y la planificación del proceso comunicacional en relación a lo colectivo institucional de esta experiencia de posgrado. No obstante, las prácticas destacadas, permiten trazar una línea de tiempo que más que realzar sucesos, colabora con desentrañar parte de la complejidad de los procesos que vinculan a los protagonistas y sus acciones en el contexto.

En el Capítulo 4, El ideal de la construcción colectiva refiere a las percepciones que los alumnos de PLANGESCO Comodoro tienen acerca de su propio proceso, tanto como a la gestión de las relaciones interpersonales que la constitución y mantenimiento de un grupo de estas características demanda a lo largo de una década.

El Capítulo 5 La producción de una oportunidad completa el proceso con el relevamiento de los resultados, no sólo en términos de las tesis concluidas, sino también de los trayectos recorridos por quienes, sin llegar a esa instancia da cuenta de sus transformaciones y consecuencias de las mismas, en su ámbito de aplicación. El resumen de las tesis aprobadas y en vía de defensa, colabora con el necesario mapeo de las variadas temáticas que abordan los comunicadores al momento de reflexionar sobre prácticas sociales, aunque convergentes en la necesidad de visibilizar transversalmente los procesos de la comunicación. La planificación y gestión de los mismos es un área revalorizada por esta Maestría que aporta una mirada que es necesario multiplicar, pese a las dificultades institucionales que haya que atravesar para conseguirlo.

\section{Abordaje Metodológico}

La reconstrucción de la historia de los posgrados en la FHyCS de la UNPSJB fue abordada mediante entrevistas a autoridades actuales y pasadas. Las percepciones extraídas de dichos testimonios fueron comparadas entre sí y con la documentación obrante en la Facultad. Esta última no se encuentra 
sistematizada por proyecto en el área de Posgrado e Investigación sino en notas del Decanato a la que se accedió desde el mismo archivo de la Facultad. Otros datos y referencias pertenecen al Informe de la Comisión de Autoevaluación de la Facultad.

En tanto que respecto a la FPyCS de la UNLP, sobre los posgrados en general los datos fueron extraídos de las publicaciones oficiales y en particular acerca de la Maestría PLANGESCO que es el caso que nos ocupa, de las entrevistas a protagonistas sobre su puesta en marcha y funcionamiento, del documento curricular y de fuentes secundarias.

La instrumentación de las fuentes primarias de datos incluyó: la recolección documental y una serie de entrevistas, además de fuentes secundarias de interpretación de todo el proceso en la fase del encuadre institucional.

Luego de la descripción socio-histórica de las instituciones en el marco del campo político educativo, del resultado de las prácticas que generaron la posibilidad del posgrado en la sede Comodoro de la FHyCS-UNPSJB, se procedió al análisis de las percepciones de los protagonistas del proceso. Se realizan entrevistas a siete maestrandos de PLANGESCO Comodoro entre agosto de 2011 y marzo de 2012. La distribución por sexo resultó de tres mujeres y cuatro hombres y por la adscripción institucional y ubicación geográfica: cuatro docentes de la FHyCS-Comodoro-UNPSJB, una egresada de la carrera de Comunicación Social FHyCS UNPSJB, una egresada de la Tecnicatura en RRPP, FHyCS-Trelew-UNPSJB y un alumno de Puerto Madryn admitido por formación equivalente.

Los estudiantes entrevistados fueron aquellos que mostraron la mayor disposición para concretar el encuentro, que derivó en una entrevista semiestructurada, dado que si bien hubo preguntas constantes, también se sumó la necesaria singularidad de cada uno de ellos en los trayectos y sus visiones. Las entrevistas se realizaron buscando las situaciones más propicias en cada caso, inclusive en los contactos a distancia vía Skype, esperando el momento que propusieran los entrevistados como el más cómodo para su concreción. También se realizó una entrevista a una alumna de PLANGESCO La Plata que por cuestiones de trabajo se encontraba en Comodoro Rivadavia. Con el mismo procedimiento metodológico se desarrollaron las correspondientes a 
las autoridades, sobre un total de ocho entrevistas, dos a representantes de la UNLP, cinco de la UNPSJB, una al coordinador de PLANGESCO Jujuy y al actual co-director del posgrado por intermedio de una fuente secundaria.

Marco Conceptual y antecedentes

En los primeros capítulos orientados a recuperar los orígenes de las carreras de Comunicación Social y de ambas universidades involucradas en el desarrollo del posgrado, colaboró conceptualmente la perspectiva de los estudios regionales tanto historiográficos como socio-políticos, así como las investigaciones puntuales sobre la Universidad en relación a su vínculo con el desarrollo y la evolución política de la Universidad en la Argentina.

En relación a la promoción del posgrado y su expansión, no sólo se apeló a los autores que pensaron a la educación superior como tradición de un campo específico, sino también a aquellos que profundizan en las matrices del pensamiento cultural latinoamericano para develar las vertientes educativas operantes en el país y la región. Así como los resultados de las comisiones de autoevaluación y evaluación externa, producto de los mecanismos establecidos por los órganos de control y acreditación del Estado sobre las universidades abordadas.

En las prácticas que se generaron a lo largo del proceso de desarrollo del posgrado, se diagnosticó, planificó y gestionó desde la dimensión comunicacional construida bajo los conceptos fundacionales de esta propuesta de posgrado.

El análisis de las percepciones de los protagonistas del proceso, los motivos de las acciones pasadas, los modos de relación, así como las comunidades generadas en torno al sentido tienen su fundamento en la fenomenología y los análisis de institucionalistas.

El presente trabajo se plantea como un aporte al campo de la comunicación, en particular por la perspectiva de análisis que ofrece la dimensión comunicativa de todas las prácticas, en este caso aplicada al diagnóstico, gestión y planificación de los procesos comunicacionales de un particular desarrollo educativo. Es el caso de PLANGESCO Comodoro por tratarse de la 
única experiencia de posgrado colectiva en comunicación en la Facultad de Humanidades y Ciencias Sociales de la UNPSJB y la primera edición fuera de la Facultad de Periodismo y Comunicación Social de la UNLP. La fecundidad del mismo reside también en el registro del imaginario acerca de los antecedentes del posgrado en la Facultad de Humanidades y Ciencias Sociales, contexto en el cual se desarrolló esta experiencia y a través de la cual se puso en juego la discusión por la institucionalización de las prácticas. La riqueza de este debate analizado a lo largo del proceso a través de la percepción de los discursos y comportamientos, profundiza la perspectiva comunicacional abordada.

Asimismo un análisis multi-dimensional que compromete tanto la perspectiva de los actores involucrados, desde sus deseos y expectativas, así como la de las estructuras institucionales implicadas, permite una reflexión acerca de la compleja estructuración tanto de esta experiencia como de experiencias similares. En este sentido, el presente trabajo pretende no sólo ser el relato de una experiencia particular, sino una herramienta que despierte nuevos interrogantes y renovadas estrategias para una mejor articulación entre lo político, lo científico y lo comunitario.

\section{INDICE}

\section{Agradecimientos.}

.........2

Resumen.

.......3

Introducción.

.5

Capítulo 1: La comunicación se abre camino entre las ciencias sociales

1.1 UNPSJB. FHCS. Carrera de Comunicación Social

1.1.1 Universidad Nacional de la Patagonia San Juan Bosco........18 
1.1.2 Los orígenes de la UNPSJB ............................................. 19

1.1.2 i) Los Territorios Nacionales, la Gobernación Militar y la Provincia.

19

1.1.3 Un nombre que provoca interrogantes:..............................28

1.1.4 Universidad Nacional de la Patagonia San Juan Bosco........32

1.1 .5

Etapa

democratizadora 35

1.1.6

Comunicación

en

la

FHyCS

38

1.1.7

Carrera

de

Comunicación

Social .40
1.1.8 Un
plan
de larga data. .42

1.1.9 Responsabilidades compartidas....

$1.2 \quad$ UNLP. FPyCS. Carrera de Comunicación Social
1.2.1
UNLP.
Escuela
de

Periodismo .46

1.2.2 Facultad de Periodismo y Comunicación Social 50

1.2 .3

FPyCS/UNLP

Pionera

en

el

campo 54

1.2.4 Comunicación Social UNPSJB. Carrera Emergente. 57

Capítulo 2: El posgrado se instala como mecanismo de promoción

2.1 Los posgrados y su incidencia en la políticas universitarias 
2.1.1 Desde el retorno a la democracia a las reformas neoliberales.....64
2.1 .2
A
partir
del

SXXI

2.1 .3

Posgrados

69

2.1 .4

Algunos

datos

que

marcan

tendencia 70

2.1 .5

Investigación

71

2.1.6 Plan Nacional de Ciencia, Tecnología e Innovación 2012$2015 \ldots . . .72$

2.2 Posgrados en La Plata y en Comodoro. La historia asumida e interpretada por las publicaciones oficiales y por analistas ad hoc

2.2.1 Posgrados en la era de la educación permanente.............................73

2.2.2 Posgrados en Comodoro. Especialización en Docencia Universitaria y Maestría en Educación Superior .78

2.2.3 Especialización y Maestría en Políticas Sociales - Facultad de Humanidades y

Ciencias

Sociales 80

2.2.4 "El Posgrado en la FHCS empieza con la Maestría en Letras (2007)" 83

2.2.5 PLANGESCO y la normalización de la Carrera. .85

2.2.6 Posgrados

en La

Plata. .88 
2.2.7

PLANGESCO

88

2.2.8 El Doctorado, el Posdoctorado y otros posgrados. 92

2.2.9 Posgrados aquí y allá, marcados por la historia 93

\section{Capítulo 3: El perfil de la carrera y las etapas de desarrollo}

3.1 PLANGESCO: En los albores, documento, constitución, características 3.1 .1

En los albores

3.1. 2 Características

del .099

Fundacional 101

3.2 De La Plata a Comodoro: gestiones, protagonistas. Funcionamiento: programas, viajes, reuniones, estructura, sostén económico, reconocimiento/s institucional/es.
3.2.1
De
La
Plata
a

Comodoro. .105

3.2.2

Rumbo

a

la

autogestión

3.2 .3

Jornada

sobre

Políticas

Sociales 118

3.2.4La Maestría como espacio de proyección político-académico.... 121

3.2.5 Proyecto de Especialización en Divulgación Científica 124

3.2.6 Una coordinación atravesada por tres gestiones 126

3.2.7 Última etapa: cuestionados e investigados 131 
3.2.8 Inicio de la de consolidación. .134

\section{Capítulo 4: El ideal de la construcción colectiva}

4.1 Descripción desde el tesista: coro de voces a partir de cuestionarios

4.1.1 Coro de tesistas. 138

4.1.2 Lo individual: motivaciones para empezar. 147

4.1.3 ¿Qué significó

PLANGESCO?. .148

4.1.4

Desde lo

individual...

4.1.5

El

grupo

...151

4.1.6

Desde

lo

grupal.

4.2 Un sentido común, posiblemente colectivo

4.2.1

colectivo

.154

4.2.2

De

10

grupal

a

lo

colectivo 156

4.2.3 Lo individual, el grupo y lo colectivo. 156

4.2.4

Lo

colectivo

institucional. 160

4.2 .5

Desde

el

2003

hasta

hoy. 


\section{Capítulo 5: La producción de una oportunidad}

5.1 El Cierre: las tesis. Los trayectos, las visiones inaufragio o sostén?

5.1 .1

El

cierre,

sus

visiones

165

5.1 .2

Las

tesis

¿Sostenes? 169

a)

Tesis

Luis

Sandoval

16/05/2011 169

b)

Tesis

Celina

Salvatierra

18/12/2012 198

c) Tesis

Diego

Pérez

$01 / 10 / 2013$

5.1 .3

Las

no

tesis

¿Naufragio? 248

5.1.4 Entre tesis: TICs, Autogestión cultural, Radios educativas 253

5.1 .5

Entre

todos .25

6

5.2 Propuesta de convergencia ¿Un futuro posible?

5.2.1

La

Convergencia:

un

futuro

posible .257

5.2 .3

Una

experiencia

en

clave

de

PLANGESCO. 261

Conclusiones. .261

Bibliografía .............270

Legislación consultada. 


\title{
LA COMUNICACIÓN SE ABRE CAMINO ENTRE LAS CIENCIAS SOCIALES
}

1.1 UNPSJB. FHCS. Carrera de Comunicación Social

1.2 UNLP. FPyCS. Carrera de Comunicación Social

\begin{abstract}
"Pensar la universidad como mediadora para que el ser humano pueda desplegar su propia naturaleza como inaugurador, como iniciador, como permanente creador, la coloca como una institución privilegiada en el desarrollo del proyecto de la humanidad y le otorga la posibilidad de ser forjadora de comunidades. Esto implica que a través de la universidad se ponen en juego los sistemas simbólicos, los sistemas normativos y los sistemas de expresión de las diversas localidades donde están insertas; lo que da a los individuos un arraigo y unos fines".

- Restrepo Mariluz
\end{abstract}

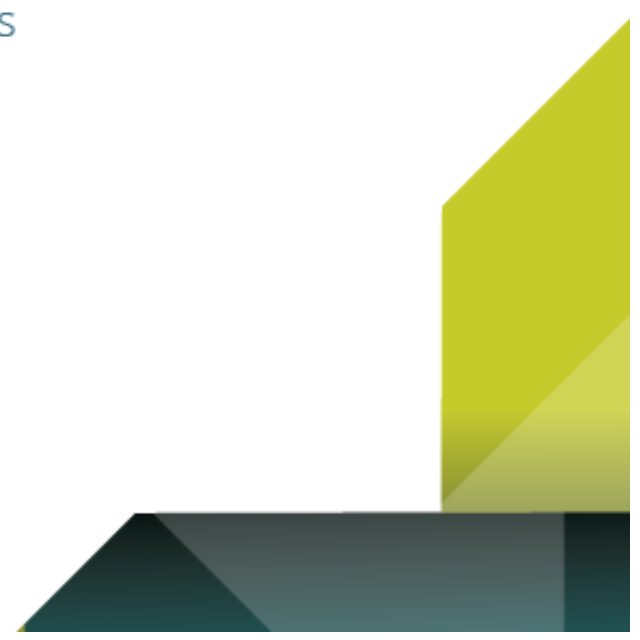

\subsection{UNPSJB. FHCS. Carrera de Comunicación Social}

\subsubsection{Universidad Nacional de la Patagonia San Juan Bosco UNPSJB}


La Universidad Nacional de la Patagonia San Juan Bosco -UNPSJB- fue creada por la ley 22173 del 25 de febrero de 1980, por la que se unificaron la Universidad de la Patagonia San Juan Bosco -1963- y la Universidad Nacional de la Patagonia -1974-. La actual conformación de la Universidad atravesó diferentes etapas, un año después de su creación, se ratificó el convenio suscripto con el gobierno provincial por el cual la provincia de Chubut le transfirió el Instituto Universitario de Trelew. Asimismo se consolidó la sede Esquel que con varias interrupciones había iniciado actividades en la década del '70 y en 1983 se aprobó la creación del Colegio Universitario Patagónico CUP- con asiento en Comodoro Rivadavia. Un año más tarde se abrieron las sedes de Puerto Madryn y Ushuaia, ésta última se convirtió en el año 2011 en la actual Universidad Nacional de Tierra del Fuego, la única de este período, que se organizó sobre la base de una sede de otra universidad nacional.

La creación de esta universidad con el rectorado en Comodoro Rivadavia y tres sedes en distintos puntos de la misma provincia de Chubut: Trelew, Puerto Madryn y Esquel, y hasta muy poco tiempo atrás, otra en Tierra del Fuego, puso en evidencia la necesidad de expandir su posicionamiento en una región escasamente poblada y con distancias que superan los quinientos kilómetros entre sí. Esta decisión se plantea ante la necesidad de brindar "una oferta académica ligada a la explotación económica de las subregiones donde se crean las nuevas sedes universitarias" ${ }^{1}$.

Durante todo el proceso de constitución de la universidad estuvo operando la motivación de articularla con el desarrollo de la región, alineadas las políticas locales con las políticas nacionales que promovían la regionalización de los estudios superiores. En este sentido, básicamente se proponía por un lado, la descentralización del sistema universitario como fuente de desarrollo para las provincias, y por otro lado, la expansión de nuevas carreras como factor de crecimiento de las economías regionales (Pérez Lindo, 1984: 156-157).

Estas ideas acerca de la decisión de crear universidades nacionales con la finalidad de descentralizar y regionalizar, fueron justificadas con Estudios de

${ }^{1}$ Baeza B., La Universidad Nacional de la Patagonia San Juan Bosco como agente de desarrollo (1973-2002). Programa de Evaluación Institucional Permanente Secretaría de Planeamiento Universitario UNPSJB. 
Factibilidad (parte de la política de expansión de universidades del Plan Taquini cuyo objetivo era el de regionalizar la enseñanza), un tipo de diagnóstico que detallaba las características de la zona y planteaba la solución que la institución podía ofrecer a las demandas de la misma. En Chubut se tomaron en cuenta las propuestas de la 'Comisión Promotora'2, integrada por profesionales y empresarios, y las del movimiento estudiantil interesado en la constitución de una universidad nacional.

\subsubsection{Los orígenes de la UNPSJB}

Es preciso ahondar en los orígenes constitutivos de la región a nivel político, económico y social para comprender los antecedentes de la Universidad Nacional de la Patagonia San Juan Bosco a través de una serie de hitos que marcaron el devenir de su institucionalización.

\subsection{2 i) Los Territorios Nacionales, la Gobernación Militar y la Provincia}

A fines del S XIX la Patagonia era un espacio de conquista para el gobierno nacional, las sucesivas autoridades consolidaron el poder central y las tierras incorporadas luego de ese avance colonial interno, se organizaron como territorios nacionales, “...entidades jurídicas que a diferencia de las provincias históricas constituyen meras divisiones administrativas, carentes de autonomía y con directa dependencia del poder central" (Arias Bucciarelli, 2010: 2). Es en 1884 que el Congreso sanciona la ley 1532 por la cual se crean nueve Territorios Nacionales: Misiones, Formosa, Chaco, La Pampa, Neuquén, Río Negro, Chubut, Santa Cruz y Tierra del Fuego. La Patagonia argentina, junto a otros espacios no provincializados del territorio nacional, se mantendrá por un lapso de casi setenta años bajo esta condición y basado en un criterio demográfico las poblaciones irían adquiriendo status de provincias en la medida que alcanzaran una establecida cantidad de habitantes. En esta perspectiva de análisis Arias Bucciarelli (2010: 4) distingue al objeto desde una dimensión espacial como "entes geográficos diferenciados en la

\footnotetext{
${ }^{2}$ Estudio de factibilidad de la Universidad Nacional de la Patagonia. Comisión Nacional, Resolución 2413/72. Ministerio de Cultura y Educación de la Nación. Volumen I. Hemeroteca de la U.N.P.S.J.B.
} 
estructura política del Estado argentino", una dimensión relacional donde "el territoriano es un actor a quien no se le han concedido derechos políticos" y una dimensión temporal considerando un momento o etapa territoriana. La misma se extiende desde la sanción de la ley en 1884 hasta mediados de la década del ' 50 cuando gradualmente se concreta la provincialización.

En el caso de Comodoro Rivadavia entre 1944 y 1955 se estableció una novedosa jurisdicción política denominada Gobernación Militar. Esta zona modificó los límites de los Territorios Nacionales de Chubut, Santa Cruz y Tierra del Fuego para crear un nuevo espacio cuya finalidad explícita consistió en la defensa por parte de las Fuerzas Armadas de los recursos petrolíferos de la Cuenca del Golfo San Jorge. No obstante de acuerdo a Carrizo (2010) fueron las características del movimiento obrero como amenaza para el orden social de los yacimientos el motivo implícito de la militarización de la zona. Sin embargo la defensa del territorio encarnó en la memoria colectiva de sus habitantes, quienes adoptaron el sentido de pertenencia a una región en constante desarrollo, en cuyo proceso fue central la presencia del Estado que creció a medida que adquiría importancia la explotación petrolífera de la zona. Comodoro era la capital de una división administrativa que tomaba parte del territorio de Chubut y de Santa Cruz. Para conformar esta zona les fueron segregados espacios a los entonces territorios nacionales de Chubut y Santa Cruz, cuyos límites originales habían sido fijados en octubre de $1915,55.418 \mathrm{~km}^{2}$ y $42.330 \mathrm{~km}^{2}$ respectivamente (Raffaele, 2012: 47).

La Gobernación Militar creada bajo el gobierno de facto de Edelmiro Farell obtuvo amplias facultades de gobierno y fue resistida inicialmente por la población, "pero gradualmente se ocupó de generar y fortalecer la identidad local, a través de la difusión de políticas culturales y de asistencia social que fueron generando en la población niveles de adhesión hacia el peronismo" (Carrizo, 2007: 8). El autor cita algunos estudios que sostienen que el proceso de provincialización se facilitó en la medida que los territorios fueron siendo peronizados a través de una manifiesta adscripción a sus postulados.

Es en este contexto que se crea la Universidad Popular de la Patagonia, una fundación privada y gratuita que funcionó desde 1943 a 1950 y de la que se 
cuenta con información recabada en el diario El Rivadavia, en una edición especial publicada para su cincuentenario. Es importante vincular el surgimiento de esta institución, nacida de acuerdo al diario El Rivadavia de esa época, "del seno del pueblo merced a la iniciativa de un grupo de vecinos, estimulados por el sentimiento e ideas de bien público", con la constitución de la Gobernación Militar y los fines que perseguía de consolidar un proyecto de desarrollo en esta zona. Señalaba además el diario que tenía como objetivo, contribuir con la acción privada al desarrollo de la instrucción y la educación populares e impartir enseñanza absolutamente gratuita teórico-práctica de conocimientos útiles, consistentes en materias de enseñanza elemental y media. Esta iniciativa de parte de vecinos comprometidos con la acción educativa refuerza la complementariedad de la misma con el espíritu del proyecto político para la región. El nombre asignado a la entidad pone también de manifiesto su intención multiplicadora y la fuerte raigambre de identidad regional que promovía. En este sentido, la página oficial de la UNPSJB destaca que se trató de una institución cuya formación de nivel medio y técnica atendiera también a la especialización en investigación y divulgación de temas patagónicos. El interés por los mismos, destacado en el complemento que para la Escuela de Minería ofrecía en topografía y química del petróleo, señala un importante antecedente de la Universidad y en particular de la necesidad de consolidar los rasgos identitarios de la región que contribuirían también a fortalecer el proyecto político (Diario El Rivadavia, 6/9/49: p.5).

En 1947, a instancias de la Gobernación Militar de Comodoro Rivadavia, se creó el Instituto Superior de Estudios Patagónicos, que cumplió una misión positiva de investigación con publicaciones sobre historia patagónica. Fue creación del General Raggio, gobernador militar, y estaba integrado por gente muy conocida, entre ellos el Dr. Federico Escalada, quien fue el que más produjo en ese Instituto, dedicándose al estudio antropológico de los tehuelches y determinando la tercera etnia de estos indígenas que se llamaban a sí mismos chehuache-ken. Esta fue la base de su obra El Complejo Tehuelche, "valioso aporte al conocimiento de los habitantes originales de 
esta tierra" (Laerte Massari, ex docente y rector de la Universidad de la Patagonia SJB entrevista en Rosales, 2004: 308).

Este es un importante antecedente no sólo por las características de sus estudios regionales que consolidan la idea de pensar la educación orientada al desarrollo de la esta zona, sino también por la activa participación de sus mentores en la gestión de los futuros proyectos.

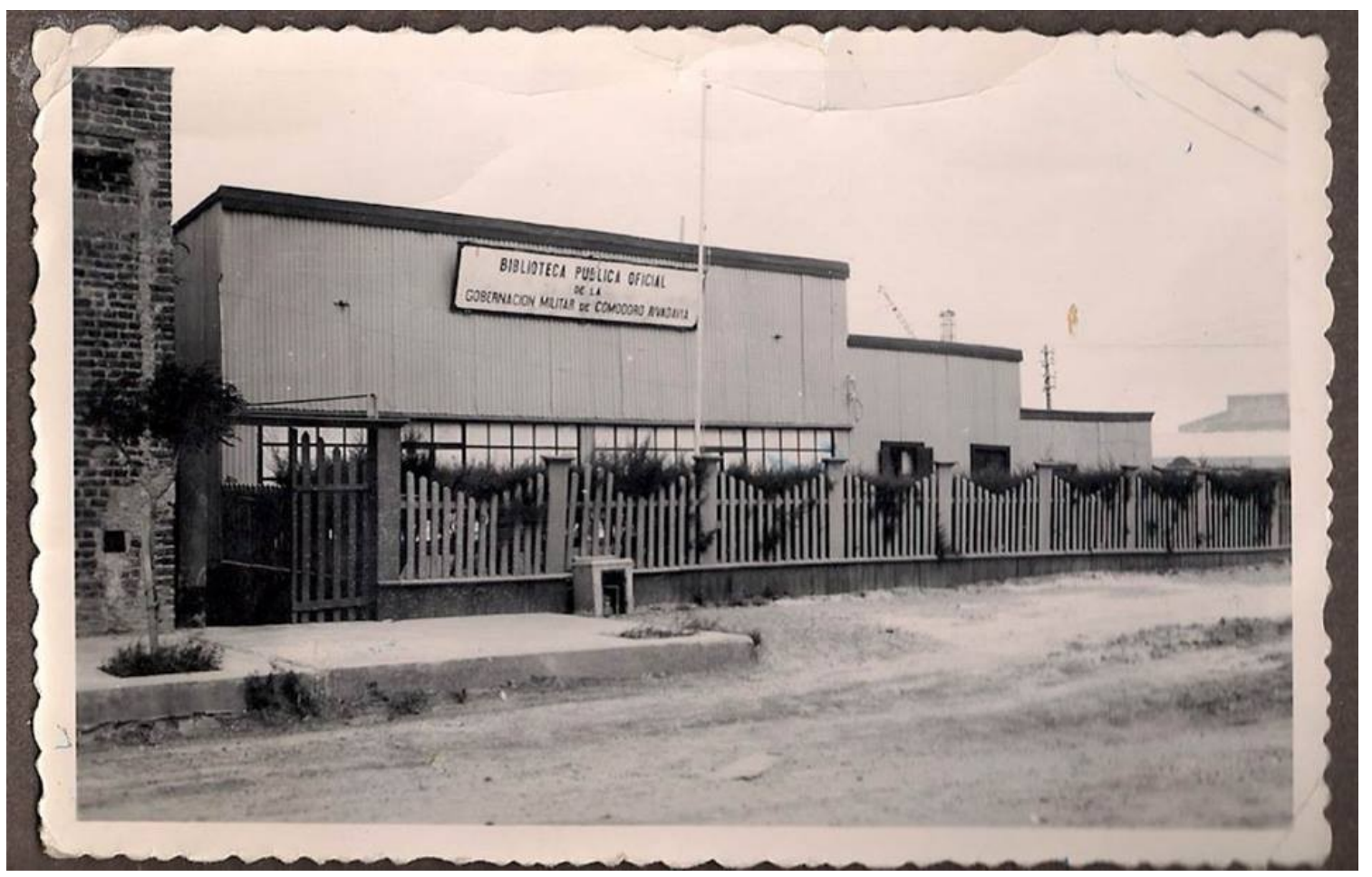

Biblioteca Pública de la Gobernación Militar de Comodoro Rivadavia que se ofrecía ceder para la instalación de la sede de la Universidad Nacional de la Patagonia. Archivo Municipal.

Otro antecedente de la fundación de la casa de altos estudios fue el 27 de septiembre de 1949, cuando el senador contralmirante Alberto Teissaire, vicepresidente primero de la Cámara de Senadores presenta un proyecto de ley para la creación de la Universidad Nacional de la Patagonia. El autor del proyecto al fundamentarlo destaca "la importancia de la Patagonia y su permanente aporte al progreso y a la economía nacionales" (El Rivadavia 28/09/49), una iniciativa que traduce las inquietudes que en torno al desarrollo de la región se orientaban a consolidarlo mediante la educación.

Señalaba que la creación de la universidad completaría el plan iniciado por el Poder Ejecutivo de instalación de otros proyectos educativos y consideraba 
que esta iniciativa constituiría un avance interesante frente a los revelados por las universidades similares ya instaladas de Cuyo y Tucumán. Contemplaba asimismo la creación de pabellones para internado de los estudiantes teniendo en cuenta la fisonomía de la región y finalmente preveía la radicación de la universidad en la margen derecha del Rio Negro al sur.

El proyecto fue aprobado por dicha Cámara pero no prosperó en la de Diputados pese al reclamo de una comisión vecinal que además de su constitución, promovía a Comodoro como asiento de la futura universidad. Esta Comisión Pro Radicación de la Universidad Nacional de la Patagonia presidida por el Dr. Andino Cayelli, primer médico nativo patagónico recibido en una universidad argentina, el Rector del Colegio Nacional Comercial, Ing. Juan Rolando, el Dr. Federico Escalada, en nombre del Instituto Superior de Estudios Patagónicos y el escribano Esteban Salso, entre otros, envió despachos telegráficos con esta solicitud, al presidente de la Nación, Juan Domingo Perón, a los ministros de Educación y Ejército, a los presidentes de las Cámaras de Diputados y Senadores, al presidente del YPF y a los gobernadores militares (El Rivadavia, 6/10/49).

Fue un movimiento importante motivado por la idea de que, de la radicación de la Universidad "derivaría el progreso espiritual y material de toda la población y la elevación de Comodoro a la capital de Patagonia", así da cuenta el diario El Rivadavia de la época, con titulares como "Comodoro Rivadavia debe ser asiento de la Universidad Nacional de la Patagonia" (El Rivadavia: 6/10/49) o "Se realizarán mitines en adhesión a la campaña popular por la Universidad Nacional de la Patagonia" (El Rivadavia: 8/10/49). En este último artículo se menciona que en la asamblea presidida por el Dr. Cayelli se recibió una nota de la Gobernación Militar en la que cedía el edificio destinado para el Museo Regional y Biblioteca para sede de la Universidad Nacional de la Patagonia, en el caso de que el gobierno nacional resolviera su radicación en Comodoro. En la misma crónica se destaca que el Dr. Escalada, en nombre del Instituto de Estudios Patagónicos, se refirió en esa asamblea al plan de acción que se había trazado dicho organismo en pro de la radicación de la casa de altos estudios en la ciudad. 
Todos estos testimonios y acciones, dan cuenta de la convicción detrás del proyecto de la Universidad como símbolo de progreso asociado al desarrollo de la región. En ese mismo ejemplar se publica una nota bajo el título “También en Bahía Blanca piden que en esa ciudad quede radicada la Universidad Nacional de la Patagonia". Esta disputa por la ubicación y el fuerte movimiento de los representantes de todas las fuerzas vivas de la ciudad, demuestra la agitación que provocó el proyecto que finalmente no prosperó, pero que sembró las bases para la futura institución. Asimismo, podemos hallar allí el germen de las disputas que enfrentó Comodoro y la zona del Valle Inferior del Río Chubut por la capital, una vez sancionada la provincialización, ley 14.408 del 15 de junio de 1955, que disolvía la Gobernación Militar y establecía la continuidad de Rawson como ciudad capital. Este movimiento perseguía el fin reivindicativo de una zona que se considera a sí misma autónoma y con capacidad para forjar los destinos de la región. Algunas investigaciones sostienen que este enfrentamiento entre ambas zonas de la provincia, valletanos y comodorenses, aún persiste. La pervivencia de esta disputa es posible de rastrear en el ámbito de la UNPSJB en la escasa vinculación en torno a proyectos entre las sedes de Trelew y Comodoro Rivadavia.

En el marco de la política nacional bajo la cual estas acciones se desarrollaban y más allá de contradicciones que presentaba el gobierno de Perón como la relativa autonomía de las universidades producto de la segunda ley universitaria sancionada en el país que regulaba con máximo detalle el funcionamiento de cada unidad académica, la promulgación del decreto 29337/49 que dispuso la gratuidad de la enseñanza universitaria y el ingreso irrestricto a sus aulas, marcó el rumbo de una política que significó una conquista para la justicia social y la igualdad popular.

Corría entonces el año 1955 y la autodenominada Revolución Libertadora iniciaba otra etapa de facto en la Argentina, la iniciativa del Presidente Perón de masificar la enseñanza pública superior cambió de rumbo con su derrocamiento. Así, "la Universidad quedó en manos de las clases medias y de la burguesía" (Pérez Lindo, 1985:130), la intolerancia hacia todo lo que representara el gobierno anterior se tradujo en reemplazo de profesores y de 
estructuras tanto organizativas como curriculares. Esta etapa que respondió al plan "modernizador" estuvo fundada como lo plantea Buchbinder (2005) más en un proyecto político que institucional, de tal modo que pese a que desde lo académico se sentaron las bases de una organización que retomaba el espíritu reformista, desde lo político se dio una fuerte lucha por la 'desperonización'.

Mientras tanto se produce otro intento frustrado de traer a Comodoro Rivadavia una carrera especializada en petróleo desde la flamante Universidad del Sur con sede en Bahía Blanca (Fundada: 5/01/56). Learte Massari, ex rector de la UPSJB, señala que "el interventor en la Gobernación, capitán de navío Sidders, quería que en Comodoro Rivadavia hubiese una carrera especializada en petróleo, que la Universidad Nacional del Sur estableciese acá una Facultad. "Entonces vino gente de esa universidad e hicieron una asamblea en el Colegio Perito Moreno que terminó en un escándalo" (Entrevista en Rosales, 2004:310). Desde su versión, el proyecto que traían era muy diferente a lo pensado por la gente de la localidad, porque proponían que los alumnos chubutenses cursaran el ciclo básico en Bahía Blanca mediante becas que otorgaría la provincia y que la especialización se hiciera en los laboratorios de YPF. La propuesta no prosperó dado que lo que se perseguía desde la iniciativa local era evitar el éxodo de jóvenes, pero aunque se frustró "quedó picando la pelota" sostuvo Learte Massari. La intención de institucionalizar los estudios superiores en la ciudad y que los mismos estén vinculados a los temas de interés regional y en particular al desarrollo económico de la misma, es recurrente en todos los proyectos que se fueron sucediendo entre los cuales existe este común denominador.

Aquel escenario educativo, con fuerte dosis de elitismo y segmentación de clases, fue propicio para el fortalecimiento de proyectos liberales tendientes a la creación de universidades privadas. En mayo de 1959 se puso en marcha en Comodoro Rivadavia el Instituto Universitario de la Patagonia, autorizado por el decreto ley 6.403. El mismo había surgido de un grupo de vecinos interesados en la educación superior que encontraron en la congregación salesiana el espacio desde donde "dar a la Patagonia los intelectuales, investigadores y técnicos que necesita, además de dotarlos de formación 
cristiana y humanística" (El Rivadavia, 11/02/59). El Instituto se organizó para la docencia con los profesionales radicados en la zona, vinculados la mayoría, a la explotación petrolera, se conformó con un Consejo, un Rector y las Escuelas de Ciencias -geología, bioquímica, farmacia y las ingenierías- y de Humanidades -letras, historia y geografía-.

Las características del mismo marcaron la conformación de la actual Universidad en la zona. Las carreras consideradas en el primer segmento de las ciencias, hoy en la Facultades de Ingeniería y Ciencias Naturales y las segundas en la Facultad de Humanidades y Ciencias Sociales, indudablemente fueron puntales que continúan sosteniendo las bases de su desarrollo. Y a pesar de que, como se describe a continuación, se produjo la unificación de la universidad privada salesiana con la nacional, muchos otros rasgos fundacionales operaron en su evolución.

Como en los proyectos anteriores uno de los móviles fundamentales de este instituto privado y confesional, fue el de frenar el éxodo de los jóvenes a otras zonas del país y evitar así el desencuentro definitivo con la realidad patagónica. Funcionó hasta 1961 en el colegio salesiano Deán Funes, y previo a su traspaso al Obispado se transformó en la Universidad de la Patagonia San Juan Bosco, siendo reconocida como tal por el Poder Ejecutivo Nacional, mediante el decreto 2850 del 18 de Abril de 1963.

\subsubsection{Un nombre que provoca interrogantes}

La denominación San Juan Bosco, puede resultar transparente dentro de la región, pero resulta inquietante entre quienes encuentran una contradicción en los orígenes de sus dos componentes: Universidad Nacional de la Patagonia y San Juan Bosco. El nombre de San Juan Bosco es simple de asociar a la orden salesiana que se expandió por todo el territorio patagónico y con gran influencia en la ciudad de Comodoro Rivadavia, pero extraña su procedencia religiosa vinculada a la universidad pública y laica. Aunque en este sentido, cabe recordar el debate en torno a la ley 1420 de fines del siglo XIX entre los partidarios de la educación laica y gratuita y los que promovían la enseñanza religiosa, sobre todo católica. Dicho debate tendrá su versión 
contemporánea con la sanción de la ley 14557 en 1960 (Ley Domingorena) que autoriza la creación de universidades privadas.

No obstante, la llegada de los salesianos a Comodoro Rivadavia data de 1913 y su participación social y política fue creciendo a medida que incrementaba su obra educativa. Su relación con las fuerzas vivas locales, sobre todo con las autoridades de YPF que, en la década del ' 20 con el general Enrique Mosconi en su presidencia, representaba el motor de la región, inició una vinculación que fue consolidándose en el tiempo. "Estos vínculos cada vez más permanentes motivaron que a lo largo de los años los hechos más significativos de la vida escolar del Colegio salesiano Deán Funes estuvieran unidas indefectiblemente a las acciones de la empresa estatal" (Carrizo, 2007:10).

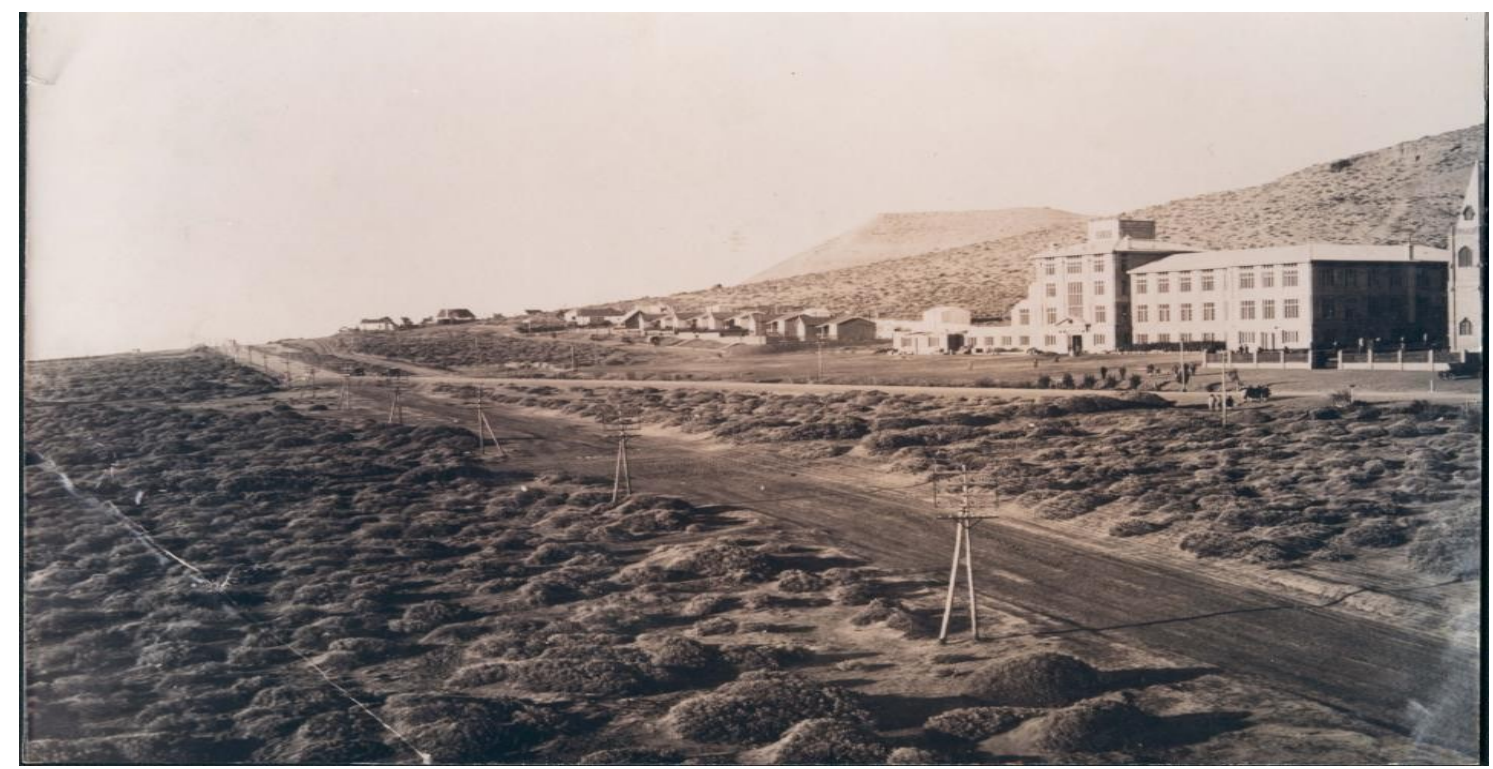

Colegio Deán Funes a comienzo del siglo pasado. Archivo Municipal.

La Universidad de la Patagonia San Juan Bosco fue la primera en fundarse en 1961 y reconocida mediante el decreto № 2850 en 1963. De carácter privado y confesional, surgía del entorno de la congregación salesiana y funcionaba en el Colegio Deán Funes. Se organizó desde el Obispado de Comodoro Rivadavia y se planteó una estructura de corte clerical, en uno de los artículos de su estatuto se dejaba explícita constancia que "la Universidad no podrá por ninguno de sus órganos promover o autorizar manifestaciones de carácter político". El Rector era designado por el Obispado, podía ser reelegido indefinidamente y en caso de licencia lo reemplazaría el profesor 
que designara el mismo Obispo, dentro de sus facultades se encontraba la posibilidad de ejercer el derecho a veto respecto del mismo Consejo Superior. Mientras que en el capítulo destinado a bienes se establecía que los recursos de la Universidad provendrían de la matrícula y cuota que abonaren los estudiantes, así como de los servicios que prestaren, subsidios y frutos de las rentas y bienes patrimoniales de la misma.

En este último sentido, la Universidad local no sólo se solventaba mediante el cobro de matrícula, sino también mediante la vinculación con empresas, sin desdeñar los fondos provenientes de herencias, donaciones, etc. Inició sus actividades con dos facultades: Humanidades con las carreras de Lengua y Literatura castellana y Ciencias con Bioquímica, Geología del Petróleo, Ingenierías Civil, Química y Mecánica.

Paralelamente, en 1960 un grupo de vecinos del Valle Inferior del Río Chubut -Virch- fundó una Asociación, cuyo fin principal era crear una Universidad. Las gestiones realizadas condujeron a la creación en 1965, por Ley de la Legislatura de la Provincia del Chubut, del Instituto de Estudios Superiores (IDES), que en 1966 se adscribió por Convenio a la Universidad Nacional del Sur. El sostenimiento financiero del IDES, que luego se llamaría Instituto Universitario de Trelew (IUT), lo tomó a su cargo la provincia de Chubut con la fiscalización académica la Universidad Nacional del Sur, siendo conjunta la expedición de títulos. Al momento de los primeros egresos del IDES, se firmó un nuevo convenio entre la UNS y la provincia de Chubut, ratificando los términos del anterior y encomendándole la creación de un reglamento propio, acorde con el estatuto de una universidad.

En 1967 tuvo lugar la primera colación de grados y un año más tarde se colocó la piedra fundamental e iniciaron los trabajos en el amplio predio de Km4 donde hoy funciona la Ciudad Universitaria en Comodoro Rivadavia.

“Paralelamente en el orden nacional con el golpe militar de 1966, terminaba una de las etapas más dinámicas de la historia de la universidad argentina. Nuevamente se intervinieron las universidades y se empleó la violencia contra estudiantes y profesores especialmente sostenedores del plan modernizador. Comenzó la radicalización política 
de vastos sectores, que adhirieron a movimientos del estudiantado que expresaban a la izquierda nacional. Un fenómeno recurrente volvió a producirse: la expulsión y posterior emigración de muchos de los más calificados investigadores y profesores" (Rosales, 2004: 313).

Mientras tanto el tema central por el cual comienzan los conflictos con los estudiantes de la institución surge a partir del verticalismo que caracterizaba el manejo gubernamental de la Universidad de la Patagonia San Juan Bosco. Es así que en 1972, en Comodoro Rivadavia, los estudiantes empezaron a reclamar por una mejor formación, mayor nivel de exigencia y apertura al diálogo con las autoridades. En sintonía con la corriente de movimientos jóvenes de Europa, Latinoamérica generaría sus propios reclamos regionales y locales.

Durante el inicio de ese ciclo lectivo, se produjeron una serie de conflictos entre los estudiantes y las autoridades de la UPSJB, que si bien comenzaron por diferentes perspectivas sobre ese manejo burocrático, se transformó en un movimiento estudiantil que cuestionó las bases de sustento de la propia institución universitaria. Hacia febrero de 1973 el conflicto llegó a su punto culminante con la huelga de hambre de un numeroso grupo de estudiantes, quienes fueron reprimidos y desalojados.

Estos acontecimientos convocan al debate de la sociedad civil comodorense, con amplia adhesión no sólo de sectores políticos, sino de toda la comunidad incluida la participación de estudiantes secundarios. El gobierno nacional decide la intervención de la UPSJB que al ser rechazada por sus autoridades resuelven el cierre. Mientras se dirimía su situación en la justicia se pone en funcionamiento la universidad nacional.

Como correlato de ese contexto, se desarrollaron en Comodoro Rivadavia dos movimientos que incidieron en la posterior formación de la Universidad Nacional: la protesta estudiantil y el impulso estatal que operó a favor de la apertura de nuevas casas de estudios superiores (Baeza, 2002).

En relación con este movimiento y en forma coincidente con esa política nacional, se gestó en esta ciudad una Comisión Promotora para la creación de una Universidad Nacional. Finalmente, con fecha 23 de Abril de 1973, se sancionó la Ley 20.296 que estableció la creación de la Universidad Nacional 
de la Patagonia, “...inaugurada el 4 de Mayo de 1974, con la presencia del Ministro de Educación de la Nación, el doctor Taiana, del gobernador doctor Benito Fernández y como rector organizador el ingeniero Silvio Grattoni" (Rosales, 2004: 320).

Entre los objetivos que perseguía estaba el de evitar la migración de los jóvenes, considerados "los futuros protagonistas de la grandeza de la región" (Rosales, 2004). El hecho de contar con profesionales de alto nivel de capacitación para la explotación de los recursos patagónicos y la ocupación estable del territorio regional también se encontraba entre sus misiones. La Universidad como movilizadora de estos fines, fue una constante en todos los antecedentes que pusieron el acento en el arraigo de los jóvenes con la promesa de forjar una región con un alto potencial de progreso y desarrollo. En 1979 se suscribe el convenio de unificación de la U.N.P y la U.P.S.J.B., entre el Ministerio de Cultura y Educación y el Obispado de Comodoro Rivadavia.

\subsubsection{Universidad Nacional de la Patagonia San Juan Bosco}

Hasta que en 1980 fue creada la Universidad Nacional de la Patagonia San Juan Bosco por la que se unificaron la Universidad de la Patagonia San Juan Bosco (1963) y la Universidad Nacional de la Patagonia (1973). Uno de los

entrevistados por Baeza sostuvo que: "Para nosotros no fue fusión sino que la nacional absorbió lo poco que quedaba de la privada" (Alejandro Simeoni citado en Baeza, 2002:13). 


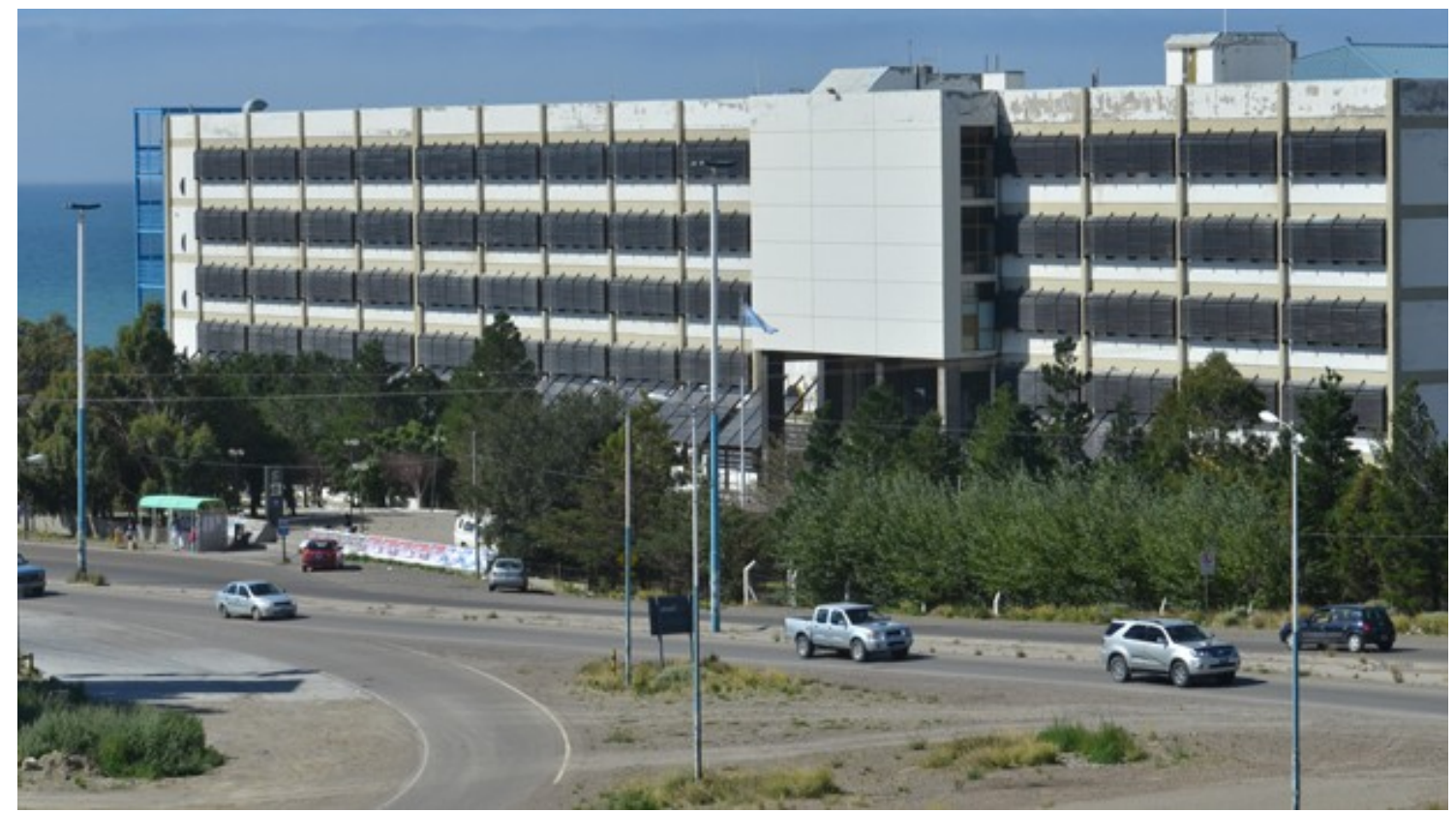

Ciudad universitaria de Km.4, Comodoro Rivadavia.

Sin embargo, la elección como primer Rector del sacerdote Lic. Norberto Sorrentino, da muestra de la fuerte influencia que la Universidad católica todavía conservaba. En el discurso de asunción destacó el hecho peculiar que comportaba la creación de esta universidad "como resultado de la política de redimensionamiento universitario determinada por la Junta de Comandantes en Jefe". Sostenía que como fruto de esa política se había logrado la unificación que daba testimonio del esfuerzo de personas e instituciones entre las que destacaba la iniciativa de la Iglesia por un lado y del Gobierno por otro. $Y$ agregaba que:

"queda como testimonio de un estilo de realización en el país, que superando dialécticas subversivas de los enfrentamientos y de las contradicciones, muestra cómo se pueden lograr objetivos fecundos al servicio del bien común, con ecuanimidad, rectitud de intención, renunciamiento, capacidad de diálogo, entendimiento y grandeza de espíritu". También como parte de ese hecho singular señalaba que "aquí palpita el país que hay que hacer" y hacía hincapié en la necesidad de mantener integrada la Patagonia a la Nación "como símbolo del sentir de nuestra soberanía y nacionalidad" (Sorrentino y Norberto, 19/03/80). 
Señalaba además que el aporte de la Universidad a ese plan de defensa de la soberanía, se debía medir por los logros en el proceso de desarrollo, facilitando la radicación de jóvenes. Estos extractos de su discurso tienen como corolario la alusión a los misioneros y soldados, estos últimos protagonistas de la "gesta colonizadora del desierto" ${ }^{3}$, así denominada por el flamante Rector a la que remite como inspiradora del desafío que le tocaba emprender.

Entre 1971 y 1973 se crean 16 universidades nacionales con el fin de descomprimir las universidades metropolitanas, y promoviendo la regionalización para "brindar al interior mayores posibilidades de desarrollo" (Sorrentino, 1980). Con respecto a las condiciones en las universidades, la primera parte del período constitucional 1973-1976, la que llega hasta la muerte del presidente Perón ( $1^{\circ}$ de julio de 1974) significó la eliminación de los mecanismos selectivos de admisión, es decir el restablecimiento de libre ingreso y la continuidad de la apertura de nuevos establecimientos universitarios en todo el país.

La dictadura militar que se extendió entre marzo de 1976 y octubre de 1983 inauguró un período oscuro de la historia argentina, que impactará fuertemente en las generaciones que hoy transitan las universidades. Profesores y alumnos desaparecidos, listas negras, control y censura, cierre de carreras, un estratégico plan de desmantelamiento y una estrategia para construir un pensamiento acotado por las consecuencias del terror, fueron planificados y ejecutados por el Estado.

\subsubsection{Etapa democratizadora}

Sobre el final de su régimen, los militares mediante la ley de facto 22.207, intentan otorgar a las Universidades un perfil de institución reproductora de valores tradicionales y centro de formación profesional (Pérez Lindo citado en Rosales: 2004). Con la restitución de la democracia se trabaja intensamente en la recuperación de los mecanismos democráticos propios del sistema universitario que evocaba la Reforma del '18, el cogobierno, la autonomía, los

\footnotetext{
${ }^{3}$ Discurso del Rector sacerdote Norberto Sorrentino con motivo de su asunción. UNPSJB. 1980.

http://www.bnm.me.gov.ar/giga1/documentos/EL000022.pdf
} 
concursos docentes, entre otros. La ley 23068 de 1984 establece la normalización que implica la designación de autoridades y la vigencia de los estatutos existentes hasta la ruptura institucional de 1966.

Si bien desde el "estudio de factibilidad" esta Universidad de la Patagonia fue pensada como una institución que debía satisfacer las demandas vinculadas con el desarrollo regional y, por ende, la instalación de diferentes sedes en Patagonia Austral estaba orientada a cumplir dicho objetivo, recién en esta etapa normalizadora -1983/1985- se pudo completar este proyecto. A las sedes de Esquel y Trelew, se sumaron en 1984 las de Ushuaia y Puerto Madryn. El rector normalizador, ingeniero Aldo López Guidi, recuerda su período de gobierno como un momento de muchísima creación, en el cual "todo estaba por hacerse" (Baeza, 2002). Fue convocado por un año a desarrollar la gestión de normalización e implementación de concursos, pero su acción se extendió por el término de tres años, porque en este contexto normalizar era convertir a la Universidad en un agente de desarrollo regional (1983-1985).

Durante este mismo período se reabrieron carreras orientadas a fortalecer la vinculación de las mismas con el desarrollo local, como la Licenciatura en Ciencias Naturales con tres orientaciones: Biología Marina en Puerto Madryn, Desarrollo de Zonas Áridas y Semiáridas en Comodoro y Forestal en Esquel. Esta estrategia se llevó a cabo, aclaró el ex rector, "porque en ese momento, salvo excepciones, no se autorizaban carreras nuevas sino reaperturas y Ciencias Naturales ya había estado en la Universidad. Sabíamos que después de normalizada la Universidad y en ejercicio de la autonomía podríamos transformarlas por ejemplo en Ingeniería Forestal como realmente ocurrió después" (López Guidi citado en Baeza, 2002).

A su vez se inició la carrera de Informática en cuatro Sedes, se reabrieron Geografía y Trabajo Social en Comodoro, Letras en Trelew y comenzaron los estudios de factibilidad para la carrera de Turismo en Ushuaia, que se concretó un año después. En Ciencias Económicas se dio apertura a la carrera de Contador Público en Comodoro y la Tecnicatura en Esquel, además de las Licenciaturas en Administración y Economía. "Y todo eso se pudo hacer porque teníamos un Proyecto importante con un amplio alcance regional y 
que contenía unidades de desarrollo regional que iban de la mano con la actividad académica, por eso lográbamos convencer, por eso y porque conformamos un equipo de conducción que estaba totalmente unido detrás del Proyecto" (López Guidi citado en Baeza, 2002). Para el mismo momento se creó el CIUNPAT -Consejo de Investigaciones de la Universidad- que centralizaba los programas y proyectos de investigación. Los mismos debían organizarse de modo interdisciplinario ya que esa era la forma de lograr más impacto en la región. "Pretendíamos proyectos abarcativos y con firme transferencia a la comunidad (...) Pero con el tiempo se fue desvirtuando y prevaleció el enfoque de considerar a la Universidad como una Federación de Facultades" (Entrevista realizada a Aldo López Guidi en Baeza: 2002).

Dicho planteo se encuentra en sintonía con el concepto del conocimiento como recurso estratégico (Argumedo, 1996) donde el debate reemplaza a la taylorización de los saberes y especialización de las universidades por un conocimiento flexible, abarcador y transdisciplinario. Esta idea es coincidente con el espíritu de aquel período de recuperación de la democracia y de la universidad como herramienta para dotar de sentido a ese propósito. En este dirección, tanto la conformación del CIN-Consejo Interuniversitario Nacionalcomo el SICUN -Sistema Interuniversitario de Cuarto Nivel- (1985) pusieron en evidencia la intención del gobierno de coordinar las políticas universitarias así como la posibilidad de expandir el sistema posgrado. Sin embargo, el entusiasmo de esos primeros años se fue desvaneciendo con la extorsión política financiera que ahogó progresivamente la expansión de los proyectos iniciales.

Desde la asunción del profesor Hércules Pinelli (1986-1989) como primer Rector elegido democráticamente en la UNPSJB y sus sucesores se debió enfrentar el re-encauzamiento de políticas de fortalecimiento institucional, estudios de posgrado en cooperación con otras universidades y seguir las políticas delineadas desde los organismos de financiamiento internacional. 


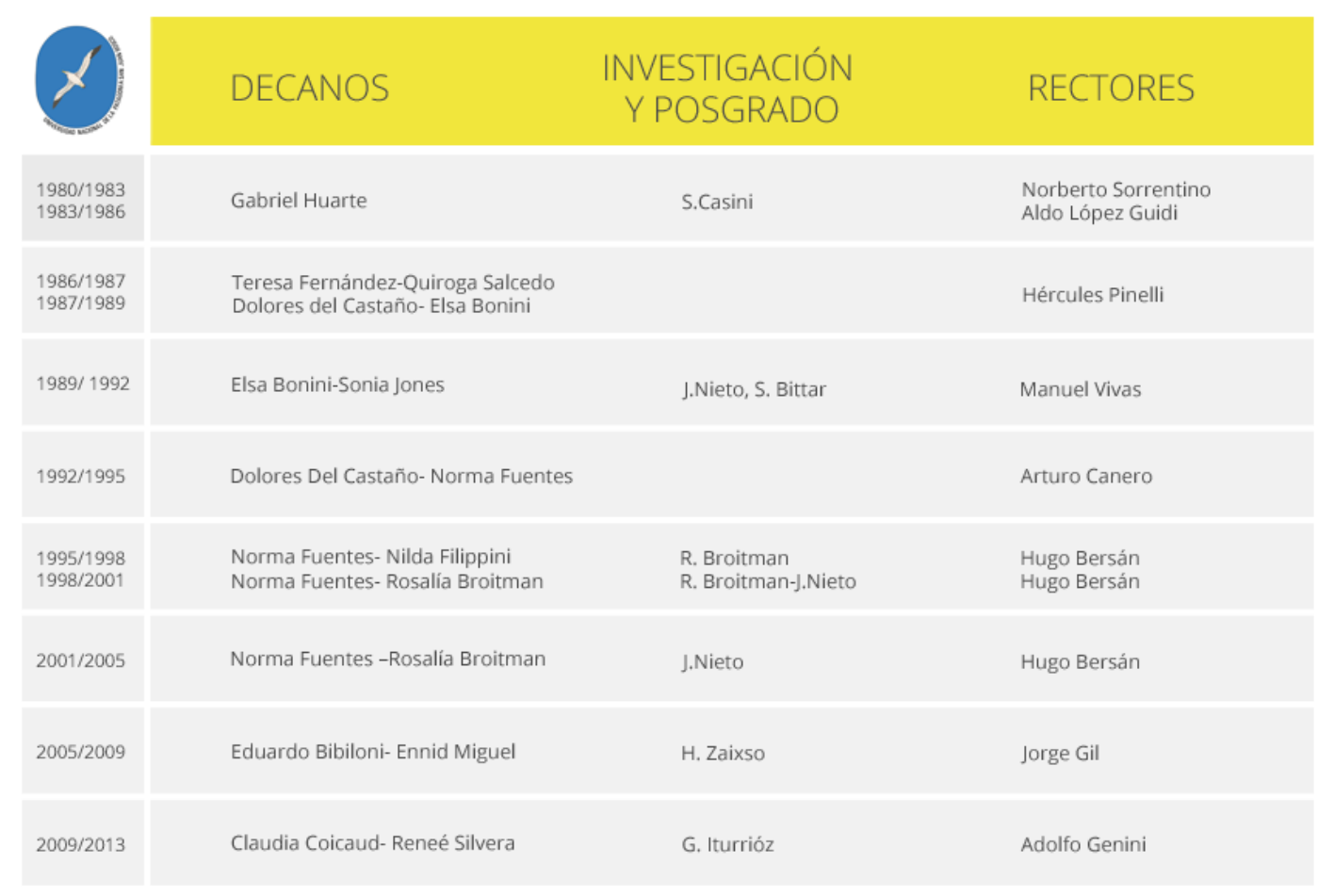

Autoridades del Rectorado de UNPSJB y de la FHyCS desde el inicio de la etapa democrática hasta la actualidad. Cuadro de elaboración propia. Diseño: Franco Raffaele.

\subsubsection{Comunicación en la FHyCS}

La carrera Licenciatura en Comunicación Social, nace en 1986 como una Tecnicatura de tres años de duración y por el interés de la Carrera de Letras de la Facultad de Humanidades y Ciencias Sociales de la UNPSJB. Al finalizar el primer año sus alumnos, interesados en la licenciatura, constituyen una comisión con docentes y autoridades de la Facultad para ampliar la propuesta curricular.

“Los inicios de la Carrera de Comunicación Social de la Universidad Nacional de la Patagonia San Juan Bosco, en la ciudad de Comodoro Rivadavia, despiertan el interés de todos los involucrados pero pocos son los documentos y versiones escritas que lo relaten. Es importante recuperar la memoria de aquellos años dado que en el marco del desarrollo de la comunicación en las ciencias sociales, esta carrera permaneció por más de 20 años con el mismo plan de estudios que la concibió. Este resultado fue producto de numerosas marchas y contramarchas en la gestión política de la Facultad de Humanidades y 
Ciencias Sociales de esta Universidad de la Patagonia" 4 (Rakela y Brun, 2004: 01)

Claudia Coicaud, actual decana y en ese momento reciente egresada de la carrera de Ciencias de la Educación, militante política de Franja Morada y como tal consejera académica en varias gestiones, sostenía que los "Ios planes de estudio y la reforma curricular eran campos de negociación política", entre el '87 y el '90 se instaló una reforma que generó una discusión y a su criterio "produjo el desarme del plan disciplinario hegemónico". Se refería a que en el año 1988 -la carrera de Comunicación nace en 1986- la Facultad aprueba la reforma curricular de los planes de estudio de los Profesorados y Licenciatura en Historia, Geografía y Letras que intentaba complementar el Ciclo Básico Común en Ciencias Sociales vigente en ese momento en la sede Trelew. Para lograrlo establecieron un espacio común a todas las carreras de primer año, denominado módulo en ciencias sociales. De este modo, Comunicación fue parte de la propuesta así como también del cambio de las metodologías por ejes de investigación en todos los años de la carrera, también comunes a otras de la Facultad. "Sin embargo Comunicación fue un foco de resistencia a esa reforma que luego se homologó" interpretó María Rosa Segovia, activa militante de Franja cuando estudiante, luego como docente y con funciones en la secretaría de Extensión años más tarde. "Fue una época de mucha compulsa política por las reformas curriculares generales de los planes, como consecuencia de ella se dieron enfrentamientos académicos e ideológico-políticos por la lucha de espacios de poder, Elsa Bonini (decana en ese momento) no pudo con la reforma completa", concluyó Segovia.

\footnotetext{
${ }^{4}$ La introducción corresponde al trabajo final del seminario de Comunicación en el Marco de las Ciencias Sociales, dictado por la profesora Florencia Saintout en la apertura de la Maestría PLANGESCO, en el que luego de una reseña acerca del origen de la comunicación como disciplina, se contextualiza el nacimiento de la carrera con la percepción de protagonistas de la época acerca del marco de los debates políticos académicos de la Facultad.
} 
Hacia el año 1993 esta reforma se repliega y los ejes, son subsumidos por las metodologías y el conocimiento, sostuvo Coicaud, queda anulado, porque la Facultad no desarrolla actividades de investigación. Se interrumpen, según su impresión, los datos fundantes para la convivencia con los viejos planes, como de investigación y el módulo de ciencias sociales. El levantamiento de las correlatividades o la modificación del programa curricular atenta contra la reforma que se nutrió de esos planes, reflexiona.

\subsubsection{Carrera de Comunicación Social}

Entre los años '80 y '90 cobran protagonismo en la Argentina, las escuelas de periodismo y comunicación tanto en el ámbito de las universidades públicas como privadas. En este caso el estudio universitario de la comunicación surge asociado a disciplinas humanísticas, la carrera nace específicamente, del interés del departamento de Letras por ampliar su campo de acción. "La profesora Norma Narvaiza de Lateulade fue quién ejerció un marcado protagonismo y contó con el decidido apoyo de la decana de esa época profesora Teresa F. de García", recuerda el profesor Juan Carlos Bergonzi, de la Universidad Nacional del Comahue, quien participó de ese proceso y fue consultado al respecto.

En 1986 se inicia el dictado de la Tecnicatura en Comunicación Social de tres años, que estaba armada como un recorte de la Carrera de Letras y era parte de la reforma curricular de esa licenciatura. Como impronta de ese origen los primeros alumnos recuerdan que tenían griego y latín como materias. Cristian Aliaga, docente de la Cátedra de Comunicación Escrita II, uno de los protagonistas de esos momentos opinaba que la Tecnicatura aparecía como una ampliación del territorio de Letras, pero reconocía que gracias al decidido impulso de la profesora Narvaiza se derivó luego en la licenciatura.

Mientras que la actual decana, Claudia Coicaud, sostuvo al momento de redactar este trabajo "que los actos fundacionales de la carrera no han sido modificados y lo más grave - enfatizó- es que tampoco se modificaron las prácticas". Se refiere a su origen y a la orientación aún vigente, pensada en 
la Facultad de Humanidades. Alude a la discusión epistemológica entre el periodismo y la licenciatura la que provocó una interna con dos perfiles: uno en la línea de las ciencias sociales y otro en su relación con las letras, por eso la fuerte influencia de lo escrito, destaca.

A fines de 1986 y a partir del trabajo realizado por una subcomisión, creada por el Consejo Académico e integrada por la Jefe del departamento de Letras y Comunicación Social, profesora Norma Narvaiza de Lateulade, la licenciada en ciencias de la Información Viviana Polli y los alumnos Gustavo Diaz y Luis Sandoval, se elaboró un proyecto del plan de la Licenciatura en Comunicación Social, que es el que actualmente continúa en vigencia. La responsabilidad de la reformulación estuvo a cargo de Norma Narvaiza y de Marta Ardiles del departamento de Ciencias de la Educación.

Como parte de ese proceso y para dar sustento a la nueva propuesta se realizó una reunión de la que participó Juan Carlos Bergonzi como profesor regular de la casa y delegado de la carrera de Comunicación de la Universidad Nacional del Comahue y recordó la presencia del secretario académico de la Escuela de Periodismo de La Plata, un profesor norteamericano de apellido Duncan que desarrollaba tareas de investigación en la Facultad y numerosos alumnos, algunos de los cuales son hoy docentes de la carrera.

En esa reunión, de carácter fundacional, estaban presentes también periodistas de los medios locales con el objetivo de hacerlos partícipes del rol de la Universidad en formación de los profesionales de la comunicación. Era un momento de debate entre los denominados idóneos y quienes defendían la institucionalización de los estudios. Bergonzi recuerda que "las reservas siempre existieron" pero el origen de la formación del periodismo en el campo universitario fue un argumento contundente al momento de conciliar diferencias.

Por su parte, Cristian Aliaga, uno de los primeros docentes de la carrera participó de esa reunión y destacó, no sólo la influencia de su entonces profesor en la Universidad Nacional del Comahue, el Lic. Juan Carlos Bergonzi en el diseño del nuevo plan, sino la orientación del profesor Carlos Duhourq también de la U.N del Comahue- en la definición de contenidos audiovisuales. 
Recuerda que luego a cargo del Departamento de Comunicación, toma la iniciativa de traer profesores de la UBA, y con la coordinación de los prestigiosos Jorge Rivera y Aníbal Ford, Ilegaron a Comodoro: Oscar Landi, Alejandro Piscitelli y Heriberto Muraro, entre otros destacados profesionales recién arribados al país luego de su exilio. La experiencia no pudo continuar por diferencias con la gestión de ese entonces a cargo de la decana Elsa Bonini que consideraba que era anárquica y desprolija la contratación de un docente diferente en cada visita.

Otro de los testimonios, en este caso el de María Rosa Segovia destaca que durante la gestión del rector Manuel Vivas -1989/1992-, se impulsó un proyecto para la instalación de un laboratorio de medios. Sostiene que no llegó a concretarse porque la carrera cuestionaba el origen del financiamiento desde la Fundación Friedrich Naumann. La entrevistada señala que fue lamentable no avanzar en ese sentido y agrega que la siguiente decana Dolores del Castaño -1992/1995- poco tuvo que ver con la carrera de Comunicación y que ni en la anterior, ni en su gestión, se impulsó la implementación de concursos. Mientras que Claudia Coicaud, ex Secretaria Académica de la Facultad, mencionó la decisión de incorporar profesores viajeros para elevar el nivel académico durante la gestión de la mencionada decana Dolores del Castaño. Una medida que continuaba la iniciativa gestora pero que cambia la Universidad con la que se conviene el acuerdo, en este momento con la Universidad Nacional de la Plata.

\subsubsection{Un plan de larga data}

Entre 1985 y 1994 la matrícula de la Facultad fue en crecimiento, Comunicación Social tenía un $19,4 \%$ de los alumnos del total de la misma y había aumentado su matrícula de 54 ingresantes en su apertura a 196 nueve años después ${ }^{5}$. La planta docente de Comunicación Social se componía de 31 interinos y uno ordinario, el $66 \%$ egresados de la carrera más 5 viajeros, docentes de otras universidades que eran contratados para cubrir los espacios curriculares y formar equipos locales. Ningún docente con

\footnotetext{
${ }^{5}$ Informe de la Comisión de Autoevaluación de la Facultad de Humanidades y Ciencias Sociales que en convenio con el Ministerio de Educación se desarrolló entre 1995 y 1996.
} 
dedicación exclusiva, la mayoría con dedicación simple y semi-exclusiva para quienes cubrían por lo menos dos asignaturas.

"Ese mapa estructural cambió poco y muy lentamente, de ese total, tres docentes accedieron a concurso y otros siete recién en este año 2006, los viajeros fueron suprimiéndose también de forma gradual y lentamente, siendo el 2003 el último año en el que se contrató a uno de ellos" (Rakela y Brun, 2004:7). A la fecha se consustanciaron otros cuatro concursos y aún restan tres para completar las materias que forman parte del eje disciplinar específico. No obstante, el plan de la carrera de Comunicación Social aún continúa en vigencia y si alguna cualidad intrínseca se lo permitió "fue más su ambigüedad que la solidez" opina Luis Sandoval quien sostuvo por otra parte que la asistencia de los denominados profesores viajeros, reforzó la condición endogámica de la misma.

\subsubsection{Responsabilidades compartidas}

Así como la Facultad tuvo la intención de crear una carrera de Comunicación Social, que fue al principio lugar de disputa por su perfil - entre "los de Letras" que la pensaron y los visionarios como Norma Lateulade que promovió su desarrollo hacia aquellas nuevas tendencias, también la resistió con la ausencia de políticas de desarrollo, la falta de concursos, la precarización laboral -dedicaciones semiexclusivas afectadas a varias cátedras-, etc.

Si bien la gestión del 99 en adelante intentó algún acercamiento a la carrera con la apertura de un concurso y el ordenamiento del plan que no pasó más que por lo administrativo, también cerró los espacios de los departamentos como sitios de encuentro e interacción de las carreras. La contradicción aparece cuando María Rosa Segovia expresa que "nosotros queríamos tener una facultad de puertas abiertas y teníamos la clara decisión política de que los que tienen espacio son los que producen". Era una intención que se traducía en abrir espacios en gabinetes ubicados en el cuarto piso de la Universidad pero que fue resistida, por lo menos en comunicación, sostuvo. No estaba claro cuál era la producción que se declamaba cuando la investigación no estuvo nunca promovida como política institucional en esa, 
ni en anteriores gestiones. Mientras que la actividad de extensión se concentraba en algunos referentes y en actividades de alcance reducido, cada docente se refugió en su propia cátedra o pequeños grupos de poca incidencia y participación política. Por otra parte las precarias designaciones y la propia modalidad de la práctica profesional del comunicador, alimentó el escaso sentido de pertenencia al espacio académico de los docentes de la carrera.

El Informe de la Comisión de Autoevaluación de la FHyCS en su capítulo "La Investigación en la FHyCS", destaca que "los primeros intentos de fijar y ordenar líneas de investigación en la Facultad parten de la gestión del Rector Hugo Canero -1992-1995- actuando como decana la profesora Dolores del Castaño". No obstante el Informe Institucional de nuestra Universidad elaborado en marzo de 1999 por la comisión evaluadora de la CONEAU sostenía que "en general la investigación está poco desarrollada y no parece representar estímulo alguno en la carrera académica, hasta el momento la Facultad no ha fijado una política de investigación estableciendo prioridades que permitan concentrar esfuerzos y recursos en las temáticas en que sea potencialmente competitiva y/o que tengan relevancia regional". En el apartado de fortalezas y debilidades de la investigación en la FHyCS del Informe de dicha Comisión puntualiza que "los subsidios otorgados en investigación son escasos, así como la interinidad y la baja dedicación de los docentes no constituyen un estímulo para la investigación". En este sentido agrega que "el plantel de investigadores se caracteriza por el escaso número de docentes con posgrado y por bajos porcentajes de aquellos pertenecientes a la carrera del CONICET". Por otra parte también señala que "no existen programas de afianzamiento de los grupos de investigación, ni tampoco hay proyectos de creación de nuevos grupos que utilicen como "difusores" a los docentes investigadores con posgrados que regresan". ${ }^{6}$

La ausencia de gestión producto de esos motivos y aquellos otros relacionados con la falta de entidad para la participación política, fueron la plataforma adecuada para que la carrera flotara sin otro rumbo que aquel

6 Informe de Evaluación Externa de la Universidad. Tomo 1: UNPSJB Informe de la evaluación institucional pág.50, marzo de 1999, citado en el Informe de Autoevaluación. Facultad de Humanidades y Ciencias Sociales. UNPSJB. (1996 y 2009). 
que le permitiera a la Facultad sostener la abultada matrícula que justificaba su existencia.

Al haber fracasado el intento de reunir a las carreras en torno a la producción, en el año 2003 se regresó a la organización departamental de las mismas. A partir de ese momento la responsabilidad por la lentitud de los cambios es compartida merced a las enormes dificultades por establecer acuerdos básicos al interior de la carrera que permitan su crecimiento y desarrollo.

Un logro de factura propia de esta carrera es el convenio con la Facultad de Periodismo y Comunicación Social de la Universidad Nacional de La Plata para el dictado de la Maestría PLANGESCO, que al promover la capacitación del colectivo docente, deja asentado un antecedente democratizador de acceso al conocimiento diferente a las políticas generales de la Facultad de promoción del crecimiento individual.

\subsection{UNLP. FPyCS. Carrera de Comunicación Social}

\subsubsection{UNLP Escuela de Periodismo}

“La Universidad Nacional de La Plata, nacida Provincial allá por 1897 y nacionalizada en 1905, destinó su Futuro bajo el imperio modernista de los estudios científicos, el espíritu asociativo y confraterno entre maestros y discípulos, la preocupación por la difusión social de los conocimientos generados y la formación de docentes para escuelas y colegios científicos para el desarrollo de las ciencias y la industria, y filósofos para la conducción de la República" ${ }^{7}$. En este proceso de modernización ocupó el lugar de las primeras universidades más grandes del país que participó de la apertura a la Reforma de 1918 y cuenta con ese rasgo de identidad así como con esa impronta de un origen que fue consolidándose con acciones como las que acá se destacan.

En 1934 el Círculo de Periodistas de la Provincia de Buenos Aires da apertura a cursos para periodistas en conjunto con la Universidad Nacional de La Plata.

7 Cita de "La Universidad Nacional de La Plata. Memoria sobre su fundación por el Dr. Joaquín V. González". Buenos Aires, Talleres Gráficos de la Penitenciaría Nacional, 1905, en Buchbinder, Pablo. "Historia de las Universidades Argentinas". Buenos Aires, Sudamericana, 2010. 
Un año después la Universidad redacta el nuevo reglamento de la Escuela Argentina de Periodismo, que se convierte en modelo para otros establecimientos en Argentina y el exterior. En 1943, durante el rectorado en la UNLP del Dr. Alfredo Palacios se aprobó la primera reforma al Plan de Estudios de la Escuela, se iniciaron cursos de extensión universitaria y se equipararon los alumnos al régimen universitario. Se montó un taller de imprenta en la escuela y se comenzó a editar "El Iniciador", un periódico escrito por alumnos con el asesoramiento de los docentes. Dicha publicación que hasta 1952 había editado doce números de distribución gratuita, abordaba en general, temas referidos al periodismo y su profesionalización.

Institucionalmente es recién en el año 1954 cuando el Consejo Universitario aprueba el proyecto de creación de la Escuela de Periodismo de la UNLP. Por su parte el Círculo de Periodistas que había participado de la comisión organizadora, facilitó sus aulas y el uso de su taller e imprenta por tres años prorrogables, hasta que la Universidad dispusiera de un presupuesto adecuado a sus fines. Tras haber pasado la Escuela por la modificación de su plan, impuesta por la intervención de la denominada 'Revolución Libertadora' bajo el fundamento de que el plan anterior "además de tener sentido político era inadecuado" ${ }^{8}$, se estableció la obligatoriedad de que los alumnos de tercer año realizaran un trabajo final para optar por el título de Licenciado en Periodismo.

En 1958 la Escuela contaba con un lugar propio y el funcionamiento de una imprenta, además de una pionera biblioteca especializada. Allí se publicó "Ediciones de la Escuela de Periodismo", compuesta de libros que fueron distribuidos a centros de enseñanza especializada del país y toda Latinoamérica.

En 1964 se propone al Consejo Superior la reforma del Plan de Estudios que permitía la enseñanza a nivel superior universitario. A fines de ese año se aprobó dicha iniciativa que convirtió al Instituto en Escuela Superior. Hasta el año 1973, la dirección fue ocupada con cierta continuidad institucional, siendo el Dr. Ataulfo Pérez Aznar el último de este ciclo. A partir de ese año,

8 Giordano, Carlos. El Bicentenario y la Universidad de Cara al Siglo XXI. De riquezas, abandonos y oportunidades urgentes. 
comenzó una serie de conducciones erráticas producto de los vaivenes políticos de la época, el Profesor Juan José Mauro se hace cargo de la Escuela Superior de Periodismo, hasta que la dictadura del autodenominado Proceso de Reorganización Nacional lo destituye al tiempo que designa al psicólogo Daniel Alfredo Pabón como su Interventor.

"La precariedad de los sucesivos edificios ocupados y de los magrísimos presupuestos acordados complicó la situación de un cuerpo docente que contaba con la presencia de Silvio Frondizi entre otros prestigiosos intelectuales comprometidos con ideales de transformación, aún de su propia función. Sin embargo, todos estos límites no fueron superados al pasar al actual edificio de calle $44 \mathrm{~N}^{\circ} 676$, puesto que casi al mismo tiempo que la mudanza, el país comenzó el período más negro de su historia. El 24 de marzo de 1976, una nueva Junta Militar derrocó al gobierno constitucional de entonces y se institucionalizó la política del terrorismo de Estado como norma de convivencia nacional" (Giordano, Libro 70 años FPyCS-UNLP 1934-2004, inédito).

Durante ese primer año del proceso, el Interventor Pabón propone una estructuración de las tareas de docencia e investigación de la Escuela que se contrapone con un proyecto de la Facultad de Ciencias Jurídicas y Sociales de la propia UNLP que quiere anexar la Escuela de Periodismo a su estructura. En diciembre del mismo año el rector interventor de la UNLP aprueba el proyecto presentado por Pabón de implantación de las carreras de Periodismo y de Licenciatura en Comunicación, así como el cambio de Escuela Superior de Periodismo por el de Escuela Superior de Periodismo y Comunicación Social. La misma resolución determina la creación del Instituto de Investigación de la Comunicación Social (IICS) cuyas actividades eran controladas, evaluadas y censuradas por el mismo interventor como parte de la actividad de 'inteligencia del Estado'.

"En toda la década, salvo emprendimientos individuales, la Escuela nunca salió a la calle con ningún producto periodístico ni académico.... Quedan en los pasillos del edificio de 44 las voces de los compañeros muertos y desaparecidos. Y está presente también el testimonio personal de quienes 
recuerdan aquellos días con los ojos mirando el vacío" (Giordano, Libro 70 años FPyCS-UNLP 1934-2004, inédito).

Con el regreso a la democracia en 1983 comienza el período de normalización y asume como director el Profesor Carlos Manuel Bustamante con un reconocido equipo de periodistas cuyas tareas centrales fueron las de la reorganización política para una institución diezmada en sus claustros por el accionar del terrorismo de Estado. Las tareas de recomposición política y de organización académica y científica fueron arduas pero el ejercicio del cogobierno posibilitó la renovación de las cátedras y una incipiente apertura a la investigación específicas.

En el tránsito a un período, cuyo contexto alentaba los ideales de reivindicación y la generación de proyectos, es en 1989 cuando la Escuela Superior de Periodismo y Comunicación Social elige democráticamente a sus autoridades y recae en la figura del profesor Jorge Luis Bernetti, quien durante dos gestiones como director consolidó las bases estructurales de la institución.

El Plan de Estudios fue modificado con la finalidad de adecuarlo a las demandas de la época y para reformar el anterior que respondía al proyecto ideológico de la dictadura militar "contenidos armados desde una concepción lineal del periodismo, que entendía a los medios como aparatos ideológicos de control de los públicos" (Giordano, Libro 70 años: 1934/2004, 27). El plan incorporaba la nueva concepción de la comunicación con un ciclo básico de tres años y uno superior de dos, con las orientaciones de Periodismo y Planificación Institucional y Comunitaria.

\subsubsection{Facultad de Periodismo y Comunicación Social}

Como resultado de ese proceso en la etapa de restauración democrática, es en 1994 cuando el Consejo Superior de la UNLP, por unanimidad, decidió el pase de Escuela Superior a Facultad. "Acompañando este proceso comienza, en todos los niveles institucionales, una preocupación genuina por la 
jerarquización de los estudios, la composición de los planteles académicos, el cogobierno efectivo y la consolidación epistemológica del campo" (Giordano, 2012: 08).

Ante esta nueva instancia, se iniciaron actividades de autoevaluación académica con la finalidad de hacer un análisis del Plan de 1989 y la participación de todos los claustros. Aunque se consideraba que dicho Plan aún continuaba teniendo vigencia en su estructura, las discusiones se orientaron a cambios para el perfeccionamiento y la actualización. Esta iniciativa se materializó en una Comisión que acordó acciones a desarrollar en los próximos años, tales como análisis de las políticas de formación en CS y de diferentes currículas de la especialidad, encuestas diagnósticas a todos los sectores de dicha comunidad universitaria, seminarios, jornadas de reflexión y la evaluación externa de los resultados a cargo de la Dra. Adriana Puiggrós.

De los diferentes tópicos de sugerencias de modificación, producto de todo el desarrollo de ese análisis pueden destacarse desde el punto de vista de su estructura una necesidad de flexibilizar su diseño, incluir las tecnologías de la comunicación y una tesis integradora del conocimiento. En su aspecto epistemológico la necesidad de reconocer la complejización de los perfiles y la transversabilidad del enfoque comunicacional, que exigía no definir a los talleres en función de los medios y evitar que el área comunicacional sea codefinida por las disciplinas tradicionales. Asimismo en una unidad académica en plena transformación de Escuela a Facultad, el desarrollo del grado, el posgrado, la investigación y la extensión debían aparecer como un conjunto teórico y articulado al cual referir los cambios específicos. Es importante destacar que el libro de los 70 años que reseña este proceso aclara que "Las razones institucionales de la reforma de aquel Plan de Estudios estuvieron fuertemente vinculadas con la generación de un marco normativo que permitiera recuperar las prácticas curriculares instituyentes" (Giordano, Libro 70 años: 1934/2004:31).

El Plan de Estudios que finalmente se aprobó en 1998 fundó un nuevo perfil común de la formación, en sus diferentes orientaciones el de un Productor de Comunicación, un agente productor de hechos y procesos socioculturales que 
deben ser interpretados en el marco de relaciones, prácticas y escenarios socioculturales concretos y en determinadas condiciones históricas. Se pensó en un profesional que integre la capacidad de la producción con la de investigación, tanto en la orientación Periodismo como en Planificación Comunicacional, la formación permite al egresado intervenir, desde una perspectiva comunicacional con herramientas inter y transdiciplinarias en procesos variados de comunicación. Asimismo incorporó la carrera de Profesorado en Comunicación para abordar la dimensión comunicación/educación y facilitar el acceso a los sistemas escolares formales y no formales.

La Facultad de Periodismo y Comunicación Social definió a través de la Dirección de Investigación y Posgrado una política de formación permanente que continúe la instancia de grado. Fue así que se sustanció un proyecto en tres escalas: Especializaciones en Comunicación Radiofónica, en Comunicación y Medio Ambiente, en Prácticas Educativo-Comunicacionales, en Comunicación y Salud, en Edición y en Periodismo Cultural; las Maestrías en: Planificación y Gestión de Procesos Comunicacionales (PLANGESCO); Periodismo y Medios de Comunicación; Comunicación y Derechos Humanos; el Doctorado en Comunicación y una instancia Posdoctoral en Comunicación, Medios y Cultura.

En particular y por el ánimo que persigue esta propuesta, es importante referir a la creación de la primera maestría específica dentro de la formación pública en nuestro país, en Planificación y Gestión de Procesos Comunicacionales. Ésta es el resultado de la asociación entre la FPyCS de la UNLP con el Centro de Comunicación Educativa La Crujía, una organización no gubernamental sin fines de lucro dedicada a la educación en comunicación. La denominada alianza permitió la inserción de este proyecto latinoamericano llamado PLANGESCO, del que participaron universidades y centros de comunicación de cinco países de la región. Así fue posible que con la dirección de Washington Uranga y Florencia Saintout, se contara con académicos e investigadores de la talla de Alcira Argumedo, Juan Samaja, Guillermo Mastrini, Daniel Arroyo, Nancy Díaz Larrañaga, Carlos Vallina, 
Héctor Schmucler, María Cristina Mata, Santiago Albarracín, Daniel Prieto Castillo y Eric Calcagno entre muchos otros.

En lo que compete a la investigación propiamente dicha es coherente destacar lo que arrojaba como resultado la reflexión del Informe de Autoevaluación Institucional 2000-2002 ${ }^{9}$, dado que define la impronta de su devenir. "Las prácticas investigativas en la Facultad de Periodismo y Comunicación Social se desenvuelven a partir de políticas científicas establecidas quinquenalmente en áreas de conocimiento de desarrollo prioritario, con una estructura originada en las tradiciones del campo, de nuestra Institución, de la UNLP en general y de las demandas y necesidades indagadas para tal fin".

El documento destaca la importancia de investigar a partir de una problemática latinoamericana y específicamente argentina, asignarle un rol social como productora de conocimientos y no con el objetivo de comprobar teorías generadas en otros lugares. También menciona la necesidad de analizar en torno a qué paradigmas científicos se trabaja el campo de la comunicación y la problemática de la transdisciplinariedad en la investigación. Destaca asimismo que el campo de la Comunicación en la región que surge en la década del '70 desde otras disciplinas sociales, es violentamente interrumpido por la dictadura militar y recién retomado a mediados de la década del ' 80 .

La Facultad decide impulsar líneas de investigación a partir de cuatro opciones estratégicas: la articulación entre lo político y lo científico, la valoración sobre lo investigado, la apropiación de demandas comunitarias y el acento puesto en las matrices epistemológicas de los estudios comunicacionales en Latinoamérica y en nuestro país en particular. En los umbrales de la institucionalización de los estudios de Comunicación, la investigación era vista en la Facultad como el lugar desde dónde intervenir en las discusiones acerca de los saberes, las prácticas, las metodologías y los objetos de este campo. Una plataforma ideológica para la definición de

9 Autoevaluación Institucional en el marco del "Programa para el Diagnóstico, Planeamiento Estratégico y Evaluación de la Universidad Nacional de La Plata", aprobado por el Consejo Superior la coordinación de la Secretaría Académica de la gestión 1998-2000, y continuó en la gestión del período 2001-2004 
políticas científicas de investigación en Comunicación considerando las demandas comunitarias, la cooperación interinstitucional y la concertación política.

Para llevar adelante este proceso, en el año 1995, se aprobó un documento que señalaba qué y cómo había que debatir, en base a estos lineamientos la Secretaría de Investigaciones Científicas y Posgrado planificó el trabajo en tres núcleos: un diagnóstico sobre qué, quién y cómo se investiga en este campo en Argentina y América Latina, el perfil, necesidades, expectativas y análisis de potencial del área de investigación de la Facultad y la recolección de las expectativas y demandas de las principales organizaciones del Gran La Plata. Finalmente se contó con el asesoramiento externo de Guillermo Orozco Gómez y Jorge Rivera.

En sus resultados el tema de la vinculación aparecía como el más destacado, "pensar el proceso investigativo desde las demandas sociales, abre la puerta para profundos cambios en el tipo de vínculos, objetivos y esfuerzos de y entre los sujetos participantes". Las conclusiones elaboradas luego del desarrollo del proyecto para conocer las expectativas y demandas de investigación existentes en el Gran La Plata, permitió una agenda de demandas y expectativas. Aunque es importante destacar que más del $70 \%$ de la población consultada respondió que la Facultad puede desarrollar tareas de cooperación técnica e investigación de sus organizaciones pero menos del $20 \%$ dicen haberla solicitado.

Este replanteo de líneas investigativas derivó según datos del libro de los 70 años de la Facultad del año 2004, en un total de 400 investigadores concebidos a partir de cinco unidades ejecutoras básicas, la individual becarios o tesistas de grado y posgrado-, los proyectos de investigación, los programas de investigación, la Dirección de Investigaciones Científicas y Grado y los Centros de Investigación. A través de estas instancias se pudo dar cuenta de los avances obtenidos entre diferentes publicaciones científicas, entre ellas Oficios Terrestres y Question, se creó la colección Ediciones de Periodismo y Comunicación y se sumó a esta iniciativa una edición específica de Planificación y Gestión de Procesos Comunicacionales, PLANGESCO, como producto de la investigación desarrollada en el posgrado. 
Es importante destacar que la Reforma curricular de Plan de 1998 posibilitó la apertura de las cátedras a los proyectos de investigación, con la tesis como requisito para alcanzar el título de licenciado y su articulación con la política general de investigación de Facultad.

\subsubsection{FPyCS/ UNLP Pionera en el campo}

La UNLP fue pionera en los estudios de periodismo y en su apertura al campo de la comunicación. Es dentro de su historia en la que también se reivindica a los periodistas de oficio a través del Círculo de Periodistas de la Provincia de Buenos Aires que ha tenido la iniciativa de promoverlos. No es sólo en nuestro país la referente en los estudios de periodismo, sino también en toda Latinoamérica se reconoce este antecedente.

Como todos los fundadores señalan un camino, abren mentes y perspectivas para saldar una discusión que permaneció por muchas décadas, aquella de si periodistas eran los de oficio o la formación se volvía necesaria para su legitimación. La asociación entre los mismos periodistas y la Universidad en la consolidación de un espacio de crecimiento, habló a las claras de la necesidad de eliminar la dicotomía. Ni se es periodista por pasar por la Universidad necesariamente, ni deja de serlo quien dedicó su vida al oficio. Sólo que al reconocer el estatus disciplinario en el marco de los estudios superiores, se transforma el oficio en profesión y se habilita al campo más amplio de la comunicación para el desarrollo de una transdisciplina en constante observación.

Con un espíritu expansivo la UNLP, en particular, la Facultad de Periodismo y Comunicación Social mostró su apertura a la construcción de lazos institucionales que se tradujeron en prácticas concretas de asociación y cooperación. "Hemos abierto sedes y extensiones siguiendo la lógica de demandas poblacionales genuinas, capacidad de pago y financiamiento episódico, con propuestas académicas de calidades, recursos y sentidos muy distintas entre sí y respecto a la enseñanza de nuestras sedes centrales" (Entrevista Giordano: 24/11/2011). No obstante que la cita precedente refiere a las extensiones de carreras de grado, en el caso de este análisis, fue la 
Maestría PLANGESCO (Planificación y Gestión de Procesos Comunicacionales) un ejemplo diferente de vinculación, que respondió a una demanda de la Carrera de Comunicación Social de la UNPSJB, con base en la relación establecida con profesores viajeros de aquella Universidad a esta última. La fluida relación con las autoridades que en ese entonces conducían los destinos de ambas organizaciones, posibilitó esta iniciativa surgida de la inquietud de sus bases, docentes de esta casa y docentes formadores de aquella, que supieron interpretar las necesidades de una Carrera emergente en una Universidad lejana de los centros más tradicionales de la educación argentina.

Periodismo y Comunicación Social de La Plata pasó de Escuela a Facultad en 1994 y la Maestría PLANGESCO se crea en 1996, pero ambos hitos empezaron a gestarse a mediados de la década del '80, cuando se discute un nuevo proyecto político académico.

Carlos Giordano ${ }^{10}$ destaca que el primer antecedente de investigación tiene que ver con el Instituto que se creó en la Escuela Superior de Periodismo durante la Dictadura y una vez reinstaurada la Democracia con la figura paradigmática de Juan Magariños Morentín. Menciona que estos antecedentes fueron "combatidos políticamente y discutidos académicamente a partir del año '86" y que terminó este primer período en el '89 cuando se debate el Plan de Estudios.

Sostiene que es en ese documento donde se encuentra el origen de PLANGESCO, el lector del libro "va a descubrir que la Maestría PLANGESCO es parte de la estructura vertical de los estudios en comunicación de la Facultad". Reconoce que inicialmente no había una clara conciencia de la transformación que el posgrado ejercería sobre sus protagonistas. Una vez aceptada no sólo formalmente, sino reconocida por la comunidad universitaria, rescata dos elementos que la distinguían, por un lado la asociatividad con el Centro Cultural Educativo La Crujía y por el otro, la modificación para esta Facultad de la ordenanza de posgrado para el ingreso

10 Giordano, Carlos. El Posgrado como espacio de formación político-académico y su articulación con los programas de becas y las tesis de grado ponencia presentada el Encuentro de Posgrado en Comunicación y Periodismo y II Encuentro de Becarios organizado por la FPyCS de la UNLP, a fines de 2007. 
de alumnos sin título de grado. Este logro era congruente con la asociatividad con la ONG dado que se daba la oportunidad a aquellas personas que no tuvieran título de grado de acreditar la experiencia y los saberes suficientes para acceder al posgrado. Otros logros de esta iniciativa lo fueron: conformar un equipo de gestión, alcanzar los estándares de las demás facultades y el consecuente acceso a los recursos y la calificación de la CONEAU, entre otros. En esta dirección y como lo establece el documento de Políticas Científicas de la Comunicación, los proyectos de investigación se deben inscribir dentro de los programas vigentes y responder a las áreas del conocimiento evaluadas como prioritarias. Esta es una decisión académica y una posición política adoptada por la FPyCS para dar curso a proyectos que se complementen y conduzcan la formación hacia un sentido predeterminado.

Los hitos destacados en el apartado, permiten trazar una línea de tiempo que más que realzar sucesos, colabora con desentrañar parte de la complejidad de los procesos que vinculan a los protagonistas y sus acciones en el contexto.

\subsubsection{Comunicación Social UNPSJB: Carrera Emergente}

Como ya mencionamos el origen confesional de la UNPSJB se vincula a la estrecha relación de la ciudad con la congregación salesiana presente casi desde su fundación. La misma desarrolló una expansiva obra educativa, en alianza con las autoridades de la petrolera estatal YPF y con una fuerte vinculación con el Ejército, así fue consolidándose como rasgo identitario de la ciudad y de su gente. De hecho el colegio salesiano Deán Funés donde se formaron generaciones de comodorenses, nativos y adoptivos, fue sede de la Universidad de la Patagonia SJB.

También la iniciativa pública tiene fuertes antecedentes en la década del '40, tanto con la Universidad Popular de la Patagonia (1943-1950), cuanto con la del Instituto Superior de Estudios Patagónicos (1947). Ambos tenían diferentes objetivos pero coincidían en la necesidad de investigar y divulgar temas de la región, además en el caso del primero, su contribución a la educación popular y gratuita. 
Corrían los años de la Gobernación Militar y Comodoro era su capital. Este proceso que se extendió por más de diez años, modificó, no sólo los límites de los Territorios Nacionales de Chubut y Santa Cruz, sino que constituyó rasgos propios de identidad en los habitantes de esta novedosa jurisdicción política. Producto de la autonomía que alcanzó Comodoro en ese período, hay investigaciones que trabajan sobre las diferencias aún persistentes entre valletanos y comodorenses. Un enfrentamiento que "una vez que la provincialización pareció un hecho, emergió en el debate en torno a qué ciudad sería la capital provincial" (Raffaele, 2012:84).

Comodoro anhelaba su universidad, a estos precedentes mencionados se suma el proyecto que logró su aprobación en la Cámara de Senadores de Nación en el ' 49 y más tarde, en 1955, la iniciativa de traer una carrera especializada en petróleo de la Universidad Nacional del Sur, aunque se frustra por diferencias de proyectos entre aquella institución y el grupo local que tenía el objetivo de evitar el éxodo de jóvenes.

El reconocimiento del gobierno nacional con la sanción de la ley de autorización de creación de universidades privadas (Ley 14.557 en 1960) motivó que el Instituto Universitario de la Patagonia de 1959 se transforme en la UPSJB en 1961.

Entre las carreras que ofrecía se encontraban las facultades de Humanidades (Lengua y Literatura) y ciencias (Bioquímica, Geología del Petróleo, Ingenierías Civil, Química y Mecánica) que eran la base de la educación universitaria salesiana.

El plan modernizador "con una de las etapas más dinámicas de la historia de la universidad argentina" (Buchbinder, 1999) se verá postergado por el golpe de estado de Onganía en 1966. En correlato con la intervención de las universidades, el éxodo de profesores e investigadores, se da la movilización de sectores estudiantiles y militantes políticos en contra del régimen que obstruía el pensamiento crítico y la libertad educativa, entre tantas de las otras limitaciones propias de una dictadura militar. En Comodoro también los estudiantes comienzan cuestionando el manejo burocrático de la universidad privada pero amplían sus reclamos y refuerzan el movimiento estudiantil con la adhesión de otros sectores de la comunidad. Hacia febrero de 1973 el 
conflicto se agudizó con una huelga de hambre de estudiantes que fueron reprimidos y desalojados.

El gobierno decide la intervención de la UPSJB y en forma paralela comienza a gestarse la Universidad Nacional. Es en este período que se amplía la oferta de universidades estatales y en ese marco se sanciona la ley de creación de la UNP en abril de 1973 que a inicios de '74 comienza a funcionar. Finalmente en 1979 se suscribe el convenio de unificación de la UNP y la UPSJB, la influencia de la Iglesia se ve reflejada en la elección del rector, el sacerdote Norberto Sorrentino, quien explicita en su asunción los objetivos que perseguía la Universidad en consonancia con la alianza que existía desde sus orígenes entre la Iglesia y el Ejército, en ese momento el país en manos de la dictadura de Jorge Rafael Videla.

La UNPSJB tenía una impronta sobre fines de la dictadura que estaba marcada por la transmisión de valores tradicionales y centro de formación profesional, pero con la Democracia se recupera la idea del 'Estudio de Factibilidad' que le dio origen al proyecto, de una institución que debía satisfacer las demandas vinculadas con el desarrollo regional. Prueba de ello fue la apertura de las sedes y las carreras asociadas a la potencialidad de cada una de ellas. El Rector normalizador llevó adelante todo este proceso que aspiraba a un proyecto abarcativo, "pero con el tiempo se fue desvirtuando y prevaleció el enfoque de considerar a la Universidad como una Federación de Facultades"- Aldo López Guidi-.

La etapa de democratización y afianzamiento institucional que devino con la primera elección democrática del profesor Hércules Pinelli, fue atravesando diferentes instancias marcadas por la política nacional en torno a las universidades.

La necesidad de encauzar esta investigación hacia la Facultad de Humanidades y Ciencias Sociales y en particular a la Licenciatura en Comunicación Social, para derivar allí en el análisis de la Maestría PLANGESCO en esta sede, nos lleva a una semblanza de los avatares políticoacadémicos de la misma.

La actual decana, Claudia Coicaud, recuerda que entre el 87 y el 90 la reforma curricular de los planes de estudios era el campo de negociación 
política y coincidía en este sentido con la ex Secretaria de Extensión, María Rosa Segovia que sostuvo que la que la decana de ese entonces Elsa Bonini (1986-1989) "no pudo con la reforma completa". Hacían alusión a la creación de un módulo de ciencias sociales común a todas las carreras, así como al reemplazo de las metodologías por los ejes de investigación en todos los años de las mismas.

Hacia el año 1993 esta reforma se repliega de acuerdo al testimonio de Coicaud "el conocimiento, queda anulado, porque la Facultad no tiene investigación" y se interrumpen según su impresión, los datos fundantes para la convivencia con los viejos planes, como eran los ejes de investigación y el módulo de ciencias sociales.

En nuestro caso el estudio universitario de la comunicación surge asociado a disciplinas humanísticas, la carrera nace específicamente del interés del departamento de Letras. Un tecnicatura que aparece como un recorte de la carrera de Letras en lo curricular y como "una ampliación de su territorio" en lo político. A fines de 1986 una comisión conformada por docentes y representantes de los alumnos de la carrera presenta el plan de la Licenciatura que es el que actualmente continúa en vigencia. La Decana Coicaud opina que no sólo no se modificó el plan sino tampoco lo hicieron las prácticas. En este sentido es importante destacar que a fines del año 2012 se presentó el proyecto de un nuevo plan de estudios del se dará cuenta más adelante.

No obstante la visión de las entrevistadas, nuestra carrera en coincidencia con la decana del periodismo argentino como lo es la FPyCS de la UNLP, se planteó la necesidad de zanjar diferencias entre idóneos y profesionales, invitando a los periodistas del medio a participar de la reunión de presentación del nuevo plan. Asimismo la convocatoria a profesores de la UNCOMA -Universidad Nacional del Comahue- colaboró con la perspectiva propiamente comunicacional y la incorporación de lo audiovisual. Más tarde una experiencia con docentes de la UBA, personalidades recién llegadas del exilio, trajeron una mirada más amplia del campo comunicacional y años después profesores de la UNLP recorrieron un largo trayecto de formación en nuestra carrera. A medida que estas ideas comenzaban a sedimentar, más se 
alejó la carrera de aquel "recorte de Letras" y más se adaptó a los cambios y las nuevas prácticas.

Datos del Informe de la Comisión de Autoevaluación de la FHyCS denotan la gran demanda que la carrera tuvo a mediados de la década del '90, un promedio de doscientos alumnos inscriptos, casi un veinte por ciento del total de la Facultad. Sin embargo pese "a la decisión incorporar profesores viajeros para elevar el nivel académico" la carrera presentaba un mapa estructural muy débil y fragmentario. Del total de su planta solo un profesor se encontraba concursado y entre los pocos que contaban con una dedicación semi-exclusiva se hacían cargo de por lo menos, dos materias. La falta de interacción entre los mismos docentes para producir intercambios y consecuentes cambios en su estructura, se vio interrumpida en el ' 99 cuando se eliminaron los departamentos por carrera, también los espacios físicos de contención. Esta decisión, de acuerdo al testimonio de la ex Secretaria de Extensión, María Rosa Segovia, respondía a dar espacio a los que producen, por lo tanto abrirían gabinetes en el cuarto piso, "pero la medida fue resistida, por lo menos en comunicación", sostuvo.

Sin embargo, el Informe Institucional de nuestra Universidad elaborado por la comisión evaluadora de la CONEAU en marzo de 1999 sostenía que "en general la investigación está poco desarrollada y no parece representar estímulo alguno en la carrera académica [...] hasta el momento la Facultad no ha fijado una política de investigación estableciendo prioridades que permitan concentrar esfuerzos y recursos en las temáticas en que sea potencialmente competitiva y/o que tengan relevancia regional".

El denominado Fondo para el Mejoramiento de la Calidad Universitaria (FOMEC), formado con recursos provenientes de préstamos internacionales se utilizó, entre otras funciones, para otorgar becas de posgrados a docentes de la Facultad, quienes en su mayoría, realizaron estos estudios en el exterior.

En el año 2003 con la restitución de la organización departamental, la carrera promueve el dictado de la Maestría PLANGESCO, en convenio con la UNLP, es su intención estimular al cuerpo docente de la misma a participar de una capacitación colectiva. 


\section{EL POSGRADO SE INSTALA COMO MECANISMO DE PROMOCIÓN}

2.1 Los posgrados y su incidencia en la políticas universitarias 2.2 Posgrados en La Plata y en Comodoro. La historia asumida e interpretada por las publicaciones oficiales y por analistas ad hoc

"A nosotros nos toca construir un Espacio Latinoamericano de Educación Superior. Si en 1918 la juventud universitaria latinoamericana emprendió un camino distinto, ¿cómo no podríamos hacerlo casi un siglo después, en una situación donde se han tensionado fuertemente las articulaciones internacionales que subordinaban a nuestros países, sometidos mediante deudas externas impagables, balanzas deficitarias y la lógica de la economía financiera rigiendo sobre nuestro aparato productivo y nuestra vida social? ".

Proyecto Ley Nacional de Educación Superior.

Antecedentes: La modernidad propia: el paradigma Latinoamericano Adriana Puiggrós y otros
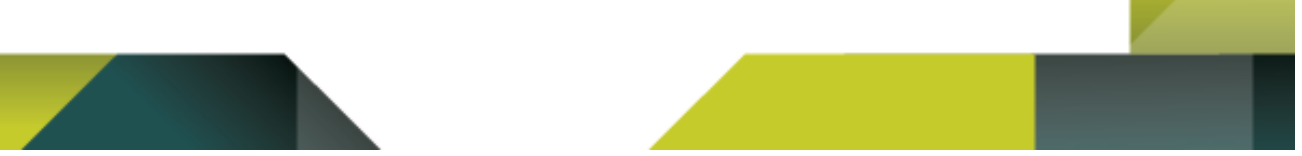

\subsection{Los posgrados y su incidencia en la políticas universitarias}

\subsubsection{Desde el retorno a la democracia a las reformas neoliberales}


A partir de la recuperación de la democracia en los años 80 , el gobierno de Raúl Alfonsín inició una política de democratización de la universidad pública con una etapa de normalización basada en los pilares reformistas de 1918. Este momento estuvo signado por el entusiasmo de toda la comunidad universitaria que a través de los frentes estudiantiles y gremiales de expresión partidaria participaron activamente del proceso.

Hacer frente a las numerosas demandas acumuladas durante el oscuro período de la dictadura, tales como restricciones de ingreso, vaciamiento académico, falta de inversión en el sistema científico, fue un desafío desarrollado en el marco de los avatares económicos que atravesaron todo su gobierno. La pesada herencia del gobierno de facto se tradujo en restricciones presupuestarias, "que sumadas a la decisión política del propio gobierno de no intervenir con políticas activas, terminó delegando en cada universidad las respuestas a estas demandas que se materializaron en diversas soluciones de compromiso" (Suasnábar, 2005). De acuerdo al citado autor, las estrategias implementadas tendieron básicamente a "contener" el exponencial crecimiento de la matrícula de comienzos de los ochenta.

En materia de política educativa, una iniciativa que tuvo que ver con la expansión de la estructura del sistema fue la creación del Consejo Interuniversitario Nacional (CIN) y del Sistema Interuniversitario de Cuarto Nivel (SICUN). Esta decisión también estaba orientada a la promoción del posgrado por la importancia de la coordinación de políticas científicas entre las universidades nacionales. No obstante hacia finales del gobierno de Alfonsín, el endeudamiento externo, la crisis fiscal y el estallido de la hiperinflación provocaron un fuerte descreimiento en la capacidad del Estado para encaminar las políticas públicas en el sentido que venían desarrollándose.

Este escenario generó las condiciones para que el siguiente gobierno de Carlos Menem encare la reforma que gestó el inicio de una etapa que horadó las bases de confianza en lo público-estatal. Así fue que La Reforma del Estado encarada por su gobierno "no sólo señalaba el fin de un ciclo económico sino también la gestación de un nuevo ciclo cultural" (Chiroleu e lazzetta, 2005) porque como lo señalan los autores, la decepción de lo 
público estatal tornó aceptable la privatización de bienes hasta entonces considerados "públicos y comunes". Esta Reforma del Estado impactó en la política educativa y pese a que la Ley de Educación Superior sancionada en 1995 se asentaba en principios democráticos y científicos universitarios, su aplicación estuvo atravesada por la evaluación y acreditación con criterios tecnocráticos, el acceso restricto a la educación superior y el sistema de incentivos a los investigadores mediante evaluación de productividad académica.

"Durante el menemismo la renuncia de responsabilidades educativas por parte del Estado nacional, el abandono que sufrieron las provincias al tiempo de recibir las escuelas transferidas por Nación, la mercantilización de la formación docente, la tercerización de los servicios educativos, la introducción de criterios de mercado en la composición de los salarios docentes, fueron acompañados de una transformación profunda de las conciencias" (Puiggrós, 2007:30). En esta cita la autora describe las causas y consecuencia de un período en el que la sociedad toda aceptó el neoliberalismo con la promesa de que esa política económica, basada en la convertibilidad, sería el pasaporte a la solución de los problemas nacionales. Muchos de ellos docentes, que con su entusiasmo para con estas medidas ayudaron, dice Puiggrós, a la profundidad de la crisis. Esas reformas incluirían el congelamiento de los presupuestos universitarios y la distribución de recursos mediante mecanismos de competencia que respondían a las pautas del programa del Banco Mundial.

Con la creación en 1993 de la Secretaría de Políticas Universitarias (SPU) se comienzan a instrumentar las principales medidas de este plan, un crédito del Banco Mundial financió el Programa de Mejora de la Educación Superior (PRES) que tenía el objetivo explícito de fortalecer el marco legal de la educación superior para introducir al sistema los criterios de calidad y eficiencia como parámetros del modelo. Este programa se transformó en un adecuado mecanismo para motorizar la reforma a través de medidas que tendrán como principales ejes la evaluación de la calidad institucional y promoción de políticas de generación de recursos como el cobro de aranceles o la venta de servicios a terceros. 
La sanción de la Ley de Educación Superior 24521 en 1995, marcará la consolidación del rol de Estado como evaluador y de la evaluación como eje estructurante de las políticas universitarias de esta década (Krostch, 1998). Así como la generación por parte de la SPU de una serie de programas especiales como el Fondo para el Mejoramiento de la Calidad Universitaria (FOMEC) y la creación de la Comisión Nacional de Evaluación y Acreditación Universitaria (CONEAU). Este organismo concentró la acreditación de carreras de grado y posgrado y la evaluación externa de las universidades, luego de sus procesos de autoevaluación, a la vez que se ocupó de dar curso a los proyectos institucionales definidos por el Ministerio de Educación. Mientras que respecto al FOMEC "fueron fondos asignados en su mayor parte a la compra de bienes (54.4\%) y al financiamiento de becas en Argentina y en el exterior (34,5\%) para la realización de estudios de posgrado" (Buchbinder y Marquina, 2008: 59). Los gestores de este programa sostienen que se asoció calidad con financiamiento, pero posiciones más críticas afirman que se abonó una inequitativa distribución de recursos y en consecuencia de poder, entre los diferentes grupos de una misma institución, debilitando inclusive la intervención institucional por el trato directo con los mismos.

Otro de los ejes de esta política estuvo puesto en la necesidad de ampliar la oferta de universidades sobre todo del ámbito privado, para ello se derogó el decreto que impedía su apertura, y posibilitó que entre 1989 y 1995 se crearan 22 universidades privadas. En cuanto a las universidades estatales, la mayoría de las fundadas en este período fueron en la provincia de Buenos Aires. En 1989 se crearon las universidades de Quilmes y de la Matanza, en 1992 las de General Sarmiento y General San Martín y en 1995 las de Tres de Febrero y Lanús. Cercana a la realidad patagónica, en 1994 se crea la Universidad Nacional de la Patagonia Austral en Santa Cruz.

La educación superior en esta etapa siguió los lineamientos de la política externa señalada por los organismos financieros internacionales y revirtió el espíritu de la década anterior, el de recuperar el poder y la autonomía universitaria que se encuentra en las bases fundacionales del sistema. 


\subsubsection{A partir del SXXI}

La ley universitaria de los noventa quedó desactualizada, hay universidades que han reformado sus estatutos fuera de los postulados de esa norma. Durante los gobiernos de Néstor Kirchner (2003-2007) y de Cristina Fernández de Kirchner (2007-2011/ y continúa) se sancionaron la ley de Educación Nacional N² 26206 que derogó la Ley Federal de Educación y estableció la vuelta al modelo de primaria y secundaria, creó el Instituto de Formación Docente y sancionó como obligatoria la finalización de la educación media y la extensión de la jornada completa. Así como también la Ley de Financiamiento Educativo $N^{\circ}$ 26075, que elevó la inversión para el sector de educación, ciencia y tecnología a un piso no inferior al $6 \%$ del PBI, y la Ley de Educación Técnico-Profesional N² 26058 que procuró recuperar y ordenar la modalidad de educación técnica en el nivel medio. Ese incremento sostenido del presupuesto universitario fue el motor que posibilitó la recomposición salarial de los docentes universitarios y preuniversitarios, así como la promulgación de la ley N²6508/09 de Jubilación del 82\% móvil, la continuidad de programas de incentivos a la investigación junto con una revisión normativa orientada a mejorar su productividad. El aumento del presupuesto de Ciencia y Técnica y la conformación del Ministerio de Ciencia, Tecnología e Innovación Productiva, también resultaron políticas que marcaron un avance respecto del período anterior. Aún no se modificó la Ley de Educación Superior, no obstante la Comisión de Educación de la Cámara de Diputados presentó un Proyecto que generó las condiciones de suficiente debate y confrontación de ideas en torno a su futura sanción. Es indudable la necesidad del mismo dado que falta una regulación política integral para la educación superior que organice y de prospectiva a las necesarias transformaciones del sistema.

Es importante destacar también que durante la presidencia de Cristina Fernández de Kirchner se fundaron doce universidades estatales, lo que representa un crecimiento del $12,9 \%$ del área. Otra sanción que interesa a los fines de este trabajo es la de la Ley de Servicios de Comunicación Audiovisual $\mathrm{N}^{\circ}$ 26522/09, que derogó el decreto $\mathrm{N}^{\circ} 22285 / 80$ de la dictadura, cuyo espíritu pluralista y democratizador reivindica las extremas limitaciones a la 
libertad de expresión y derecho a la comunicación de aquél. La batalla judicial de los multimedios que trata de impedir su implementación, pone en evidencia los intereses corporativos que enfrenta en defensa de la libertad de expresión y el derecho a la información de todos los ciudadanos.

\subsubsection{Posgrados}

En el marco de estas tendencias históricas la novedad en el sistema universitario argentino ha sido la "expansión explosiva" de carreras de posgrado que se opera en la década de 1990 en el contexto de las reformas neoliberales. A diferencia de la expansión de la matrícula de grado donde las universidades públicas conservan el predominio sobre el sector privado, la dinámica de crecimiento del posgrado estuvo fuertemente asociada a las tendencias de mercantilización, privatización e internacionalización de la educación superior, comunes a toda la región. La ley de Educación Superior mantenía con reservas la gratuidad de los estudios de grado dejando abierta la posibilidad del arancelamiento y en el posgrado obligaba a las instituciones a autofinanciar las carreras de especialización. Esta política estimuló el fortalecimiento de cada iniciativa en la competencia por la captación de alumnos.

En 1994 había casi 800 carreras y en 2002 superaban las 1.900, Buchbinder y Marquina sostienen que las razones de este crecimiento son diversas, pero en general confluyeron en el proceso exigencias derivadas de la propia evolución del mercado laboral y de las nuevas titulaciones por parte del personal académico.

Entre 1995 y 2009 la cantidad de posgrados creció 230\% (Suasnábar, 2011: 26) sobre todo en especializaciones y maestrías, mientras que muy levemente en doctorados. Esta tendencia a la profesionalización, al igual que la concentración de los mismos en las universidades metropolitanas y más tradicionales, fueron características fundacionales. 
El Fondo para el Mejoramiento de la Calidad Universitaria (FOMEC) destinado a la formación de posgrado a través de becas y equipamiento para maestrías y doctorados evaluadas y acreditadas, fue el pasaporte para muchas iniciativas y de no menos internas entre universidades y al interior de las mismas. "En esa dirección, a partir de 2002, el Consejo Interuniversitario Nacional y la SPU acordaron un modelo consensuado de distribución de los recursos presupuestarios tendiente a mejorar la transparencia y la equidad interinstitucional en el reparto de esos fondos" (Suasnábar, 2005).

En un contexto general marcado por el deterioro de las condiciones de trabajo de docentes universitarios, la expansión del posgrado permitió al segmento de mayores credenciales incrementar sus ingresos, pero también llevó a la naturalización de formas de contratación precarias (De la Fare y Lenz, 2010). “Con todo, las condiciones en que se expandió el posgrado que hemos señalado marcan las fuertes limitaciones de esta política que descarga el financiamiento de los programas en los aranceles de los estudiantes y que se puede apreciar en la baja tasa de graduación. Así, según datos estadísticos de la SPU, en 2008 había 80.160 estudiantes inscriptos en carreras de posgrado públicas y privadas, pero sólo 7.632 se habían titulado" (Suasnábar, 2011: 26).

\subsubsection{Algunos datos que marcan tendencia}

La publicación "Indicadores de Ciencia y Tecnología Argentina 2009" del Ministerio de Ciencia, Tecnología e Innovación Productiva (MINCYT) actualiza datos sobre posgrados en relación a la masa crítica de investigadores. Este relevamiento fue realizado sobre la base de una cobertura completa de los organismos públicos, de las universidades públicas y privadas, así como de entidades sin fines de lucro. En el mismo se destaca que entre los cargos de jornada completa y parcial dedicados a la investigación y desarrollo, y según el grado académico alcanzado, en las universidades públicas se observa que de un total de 32.942 , el $60 \%$ son licenciados, $25 \%$ doctores y el $14 \%$ magisters, el $1 \%$ restante pertenece a profesorados universitarios 0 terciarios. 
Estos resultados señalaban ya, una tendencia en la elección del doctorado como camino superador del grado y la disminución de la opción por las maestrías, contrariamente a lo que sucedía en el período 1995-2009 señalado más arriba. Aunque de acuerdo al análisis de la serie histórica sobresalen los magisters que entre el año 2000 y 2009 aumentaron un 127\% mientras que, en el caso de los doctores el incremento fue del $71 \%$. El salto en la cantidad de doctores se da entre los años 2007 y 2008 marcando la tendencia que se consolida en la actualidad.

Si tomamos como ejemplo la FPyCS de la UNLP aquí analizada, la admisión al doctorado de postulantes que por su proyecto y antecedentes académicos puedan hacer un recorrido de un año más que los egresados de maestría, refuerza la idea de que la formación se encauza en esa dirección.

\subsubsection{Investigación}

El discurso de la modernización en los noventa, se vio traducido en la liberalización de la economía mediante la privatización de las empresas públicas, el tipo de cambio fijo, la desarticulación del aparato productivo y el achicamiento de las actividades de investigación y desarrollo a favor del mercado. Este giro en la política trajo como consecuencia "el abandono del esquema previo centrado en el apoyo del Estado al desarrollo de la ciencia básica, la formación de recursos humanos y la intervención directa en algunos sectores considerados de tecnología de punta o estratégica (cuyo legado más importante fue un conjunto de instituciones como la Comisión Nacional de Energía Atómica (CNEA), el Instituto Nacional de Tecnología Agropecuaria (INTA), el Instituto Nacional de Tecnología Industrial (INTI) y el Consejo Nacional de Investigaciones Científicas y Tecnológicas (CONICET)" (Plan Nacional de Ciencia, Tecnología e Innovación 2012-2015).

En estos años la expansión de las actividades de investigación estaba fundada en la necesidad de promover la resolución de problemas sociales concretos, dando prioridad a la participación de actores del sector privado. La concepción de que eran las empresas las que con la demanda de conocimiento impulsaban las líneas de investigación, exigía a las 
universidades el diseño de estrategias para vincularse con el sector productivo.

De esta manera, la expansión de las actividades de investigación en las universidades fue impulsada por dos vías: por un lado, las políticas impulsadas desde la Secretaría de Políticas Universitarias como el Programa de Incentivos a la investigación, el cual supone un proceso de categorización de los docentes-investigadores en cinco niveles y la acreditación de proyectos para recibir ese plus salarial (Pratti, 2002). Por otro lado, fueron impulsadas por distintas agencias estatales como el Consejo Nacional de Investigaciones Científicas y Tecnológicas (CONICET) y la Agencia Nacional de Promoción Científica y Tecnológica (ANPCyT), primero dependientes de la Secretaría de Ciencia y Técnica, y luego del recientemente creado Ministerio de Ciencia, Tecnología e Innovación Productiva.

\subsubsection{Plan Nacional de Ciencia, Tecnología e Innovación 2012-2015}

Este Plan se basó en el documento "Bases para un Plan Estratégico en Ciencia, Tecnología e Innovación Productiva 2005-2015" y está encuadrado en la ley marco de Ciencia, Tecnología e Innovación $N^{\circ} 25.467$. Persigue los objetivos tendientes a sostener la estructura y planificación de la política científica y tecnológica nacional, las responsabilidades del Estado en el tema y a partir del año 2007 bajo los lineamientos establecidos por el Ministerio Nacional de Ciencia, Tecnología e Innovación Productiva.

La propuesta persigue la creación de un sistema de política de CTI mejor articuladas con el aparato productivo para promover el tránsito hacia una economía basada en el conocimiento. La intención del MINCYT es que el mencionado plan contribuya a la descentralización y arraigo de las actividades de ciencia y tecnología para el desarrollo de esas capacidades en todo el territorio nacional.

Esta reorientación de las políticas públicas para el sector, recoge la necesidad de repensar las formas de intervención frente a la vertiginosidad del cambio tecnológico y su relación con la producción. Abarca el cambio gradual de políticas horizontales hacia políticas diferenciadas y focalizadas, una lógica sistémica de impulso a la innovación y a la importancia de la innovación en 
red. La Argentina ha desarrollado vinculaciones con el resto del mundo en ciencia y tecnología con un fuerte énfasis en la cooperación técnica, que ha logrado su mayor dinamismo en el eje público-público, ya sea a nivel gubernamental, de institutos de investigación o de universidades (Plan Nacional de Ciencia, Tecnología e Innovación 2012-2015).

\subsection{Posgrados en La Plata y en Comodoro. La historia asumida e interpretada por las publicaciones oficiales y por analistas ad hoc}

\subsubsection{Posgrados en la era de la educación permanente}

Hace más de una década Alcira Argumedo en su artículo "El Imperio del Conocimiento, Impacto de la Revolución Científico-Técnica" sostenía que "se calcula que en no más de diez años el $95 \%$ de las tareas normales de una sociedad van a requerir un mínimo de educación de 10 a 12 años con un promedio de ocho horas diarias de estudio" (Argumedo, 1996:1), y por cierto no sólo se alcanzó ese estándar sino que se incrementa progresivamente. Parte de esa demanda de capacitación que en dicho documento estaba centrada en la consolidación de un nuevo modelo de producción económico y social, se concreta actualmente en el predominio del conocimiento como base de las políticas públicas en articulación con el aparato productivo. En ambos sectores de una sociedad, que de la información pasó a valorar el conocimiento, donde se estimula respectivamente, la capacitación y el crecimiento académico, traduciéndose en la categoría de posgrados con diferentes modalidades y sistemas pero con un fin en común, achicar la brecha cognitiva que provocan los nuevos desafíos del desarrollo sustentable. Si bien un principio de institucionalización del posgrado proviene del gobierno radical de Raúl Alfonsín que en 1985 crea un organismo orientado a ese fin, se expande durante el gobierno de Carlos Memen (1989-1999) con los rasgos que la política neoliberal impuso. La LES, sancionada en 1995, sembró sospechas sobre la gratuidad de los estudios de grado pero dejó expresamente ratificada la onerosidad de los de posgrado, convirtiendo a este último en un campo de lucha por la acreditación y autofinanciación de 
sus propuestas en el ámbito público y la fuerte aplicación de estrategias para la captación de alumnos en las iniciativas privadas.

Pese a que el neoliberalismo y la globalización cambiaron las bases estructurales de la sociedad y que en la región los debates por la subsistencia impidieron un análisis integrador de las dificultades y oportunidades, es en América Latina "donde más se avanzó en una educación superadora del modelo normalista liberal europeo, que recibimos como legado" ${ }^{11}$. Las universidades públicas, en la búsqueda de su identidad, fueron desarrollando sus propios rasgos confiadas en el valor estratégico del conocimiento y en la educación como vehículo para la democratización del mismo. Es en nuestro país, que por su carácter de bien público al ser gratuita y obligatoria, - hoy, hasta en los estudios medios- que se la considera un derecho humano personal y social y por lo tanto debe responder a las necesidades y demandas de los jóvenes.

En la medida que fueron expandiéndose y diversificándose las propuestas de posgrado, también se incrementó la preocupación por la calidad y los programas de becas atendieron cada vez más a los parámetros otorgados por las agencias de acreditación.

EI CONICET- Consejo Nacional de Investigaciones Científicas y Técnicas- es el que otorga casi el $60 \%$ de las becas de posgrado en el país y otro porcentaje importante la SECyT -Secretaría de Ciencia, Tecnología e Innovación Productiva- (Barsky: 2005).

Sin embargo, la LES que introdujo el tema de regulación del sistema a través de la evaluación y la acreditación, no lo vinculó directamente a programas de financiamiento o promoción de su desarrollo en áreas de vacancia. En su momento el FOMEC fue un intento para impulsar su desarrollo, pero el destino de fondos para este propósito experimentó un crecimiento en la última década, un factor considerado es el impacto de una agenda internacional de política científica que destaca la escasez de recursos altamente calificados (Luchilo, 2010).

11 Giordano, Carlos. El Bicentenario y la Universidad de cara al Siglo XXI. De riquezas, abandonos y oportunidades urgentes, Facultad de Periodismo y Comunicación Social, UNLP. 
Así el posgrado en un intento por alcanzar los estándares internacionales fue creciendo en términos cuantitativos y con algunos ajustes cualitativos que marcaron transformaciones a finales de la década del '90. Fue creciendo, fundamentalmente por la presión del llamado "credencialismo" (Jeppesen, Neson y Guerrini, 2004) por la desvalorización de la formación de grado y porque las especializaciones y doctorados estuvieron bien definidas desde el inicio en función de su carácter más vinculado a la investigación, no tanto así con las maestrías por su perfil más profesionalista. No obstante su incorporación le dio al sistema un alto grado de fluidez y heterogeneidad, tuvo mayor aceptación en las ciencias sociales porque la estructuración de los posgrados en general fue tardía debido a que se trató del área más castigada por las consecuencias de la última dictadura militar. A pesar de ello existen maestrías como la del caso acá analizado, que tienen un perfil marcadamente académico y que su cursada favorece el crecimiento de quienes continúan el desarrollo de un doctorado, tanto como de los que le encuentran un alto grado de aplicabilidad comunitaria.

En relación a los docentes postulantes a los posgrados, la primera etapa se correspondió con la necesidad de adecuarse a las nuevas exigencias frente a la competitiva carrera por el título. En ese momento, se debatía entre la escasa oferta y la creciente demanda, muchas universidades extranjeras fueron seleccionadas para resolver esta instancia sin que las mismas cumplieran con el mínimo de horas que propone la CONEAU para los posgrados de factura local. Teniendo en cuenta que este organismo además de evaluar a las universidades como tales, lo hace con los posgrados y para salvar esta situación no contemplada dentro de la LES se sancionó de la Ley N 26793 del 2012. La misma establece que las instituciones universitarias extranjeras que aspiren a abrir ofertas académicas en el país deberán radicarse como tales y adecuarse a las normativas vigentes. Hoy los docentes con formación de posgrado superan a los que sólo tienen formación de grado (Jeppesen, Nelson y Guerrini, 2004) y de acuerdo a dicho estudio podría constituirse éste en el primer indicador de maduración de un sistema en creciente desarrollo. 
Este escenario de cambio, debido seguramente a la madurez de las políticas públicas en torno a la educación superior y a la trayectoria de las universidades una vez atravesadas sus primeras experiencias, otorga un mayor nivel de previsibilidad y una oferta más adecuada a las necesidades actuales. De acuerdo a la opinión de especialistas (Follari, 2001), esos primeros momentos de expansión del posgrado en el país no arrojaron una gran cantidad de graduados porque la mayoría no aprobaba la tesis, aunque la experiencia en relación con las tesis era aún germinal. No obstante la relación con esta instancia final continúa siendo conflictiva "es un problema que no está para nada resuelto, sostiene Washington Uranga, ni en los más jóvenes ni en los más experimentados, salvo en aquellos que están presionados por ejemplo con el tema CONICET, que son investigadores y la necesitan para mantener su beca" (Entrevista Uranga: 23/07/ 2012).

Otro problema planteado por ambos especialistas es el hecho de que tampoco hay directores de tesis que puedan dedicarse, esta es una carga "absolutamente honorífica", tiene valor para la calificación en el Sistema Nacional de Incentivos pero una vez alcanzado el máximo eslabón sólo le suma al prestigio académico y reconocimiento institucional. Es por lo tanto una dificultad para los alumnos al momento de buscar director/a para sus proyectos, a raíz de ello ejemplifica Uranga "se generan situaciones en las que yo he dicho muchas veces que no y la gente me lo pide por favor y se producen diálogos casi ridículos donde te dicen 'voy a tratar de molestarlo lo menos posible' cuando en realidad una dirección de tesis debería ser un proceso de enriquecimiento mutuo y de trabajo colectivo" (Entrevista Uranga: 23/07/ 2012).

La falta de directores es parte de una realidad que al momento de ser evaluada por los alumnos es calificada en función de la experiencia. Para Luis Sandoval, el primer egresado de la Maestría PLANGESCO en Comodoro, el rol de su director "fue más bien la de un lector pero aclaró que no hubiese soportado otro tipo de director". Desde su perspectiva hay tres tipos de directores, unos que ejercen la función que la mayoría espera de ellos, otros son los que leen y hacen algunas observaciones y están también, los que no se ocupan (Entrevista Sandoval: 27/08/2011). 
En esta dirección tampoco es menor la responsabilidad que le cabe a las instituciones que hacen un seguimiento pormenorizado durante la cursada pero se desentienden de los procesos de tesis, cuando son las que también padecen los resultados de no contar con una cantidad de graduados que se condiga con la cantidad de cohortes desarrolladas.

De acuerdo a estas cifras tomadas de los anuarios de la SPU citadas por Daniel Lvovich (Luchilo, 2010), los graduados en 2000 fueron el 12,7\% sobre el total de alumnos y en 2007 algo más del 9\%, la leve retracción en este período da cuenta aún de la escasa graduación de los posgrados en general.

Si bien los cambios en las políticas públicas de los últimos diez años dieron un giro en el papel asumido por el Estado frente a la educación superior, Argentina tuvo que superar el lento proceso de inserción de los posgrados si se lo compara por ejemplo, con Brasil y México (Marquís, Spagnolo y Valenti Nigrini, 1998). No obstante cumplida esa etapa, la formación de posgrado fue ubicada en políticas más amplias con una dimensión internacional y la necesidad de identificar capacidades científicas y tecnológicas para vincularlas con los sistemas de innovación.

\subsubsection{Posgrados en Comodoro}

\section{Especialización en Docencia Universitaria y Maestría en Educación} Superior

En una reseña de los estudios del campo específicamente en el terreno de la educación superior en la Argentina, Krotsch y Suasnábar reconocen que desde una perspectiva académica recién se inician en 1985 cuando aparecen las primeras publicaciones concebidas desde la tradición en la investigación social.

En ese sentido la Universidad Nacional de la Patagonia fue pionera cuando en 1989 se crea la primera Especialización en Docencia Universitaria, dependiente de la Unidad de Pedagogía Universitaria de la Secretaría Académica del Rectorado, un objeto de estudio nuevo que se transformó en el primer programa de posgrado de Argentina en el campo de la formación de profesores universitarios para el ejercicio de la docencia. Fue durante la 
gestión del rector Hércules Pinelli (1986-1989) y estuvo concebido y dirigido por el Dr. Cayetano De Lella con su equipo, que además de la especialización, implementó la Maestría en Educación Superior. "Se diseñó una política de formación docente con rasgos propios que, centralmente, apunta a la transformación del ejercicio profesional a través del paradigma de la investigación de la propia práctica"12.

La actual Secretaria de Investigación y Posgrado de la Facultad, Dra. Graciela Iturrióz, se graduó en ambos posgrados que cursó junto a muchos de sus profesores y compañeros, la mayoría de la FHyCS. (Iturrióz, entrevista personal, 27/03/2013) “No sé si la mayoría...- sostuvo Elsa Bonini, alumna de ese posgrado y decana de la Facultad de Humanidades en ese momento-, en la especialización, en los cursos de introducción a la docencia especialmente, hubo mucha gente de otras facultades si eso era lo más rico que tenía" (Entrevista Bonini: 1/07/2013).

"El origen de este ambicioso proyecto se encontró en los SIDU -Seminarios de Introducción a la Docencia Universitaria- cuyo mentor fue el Dr. Cayetano De Lella y a partir de allí se fue gestando esta cadena, SIDU, especialización, maestría, fue como un programa de formación bastante ambicioso que arrojó un importante cantidad de graduados, nos debemos haber graduado 8 o 10". (Entrevista, G.Iturrióz, 27/03/2013). Fue un largo proceso "porque hubo desde razones de orden político vinculadas a los cambios de gestiones, a razones de orden presupuestario calculo, seguramente tenía subsidio de la Universidad para poder brindar una oferta de posgrado de tan alto nivel a tan bajo costo" (G. Iturrióz). La actual secretaria de Investigación y Posgrado, valoró también la importancia de tener un posgrado en la propia Universidad cuando era muy difícil viajar por el costo de los pasajes aéreos y tampoco existía Internet, como lo es hoy, una alternativa para estudiar a distancia. "Nosotros lo financiábamos, aunque debe haber habido una parte que pagaba rectorado, pero los cursos de introducción a la docencia se tienen que haber 'requete' financiado", señala Elsa Bonini, ex vicerrectora en la gestión del rector Jorge

12 Discurso de la vicerrectora Elsa Bonini de la UNPSJB en el acto de entrega del título de Profesor Honorario al Dr. Cayetano De Lella, 2009. 
Gil (2006-2010) y lo decía en relación a la cantidad de alumnos que el posgrado convocó.

Finalmente terminaron la Maestría 15 años después. En ningún momento paramos, recordó Elsa Bonini, "aunque que nos traían un seminario, el otro no, cambiaban la gestión y había que convencerlos de que había que continuar con esto". En este sentido coincidía con la experiencia que atravesó PLANGESCO.

A fines del noventa se graduaron los primeros, entre 2002 y 2003 otro grupo y el tercero, como en los casos de Graciela Iturrióz y Elsa Bonini, actual Secretaria de Posgrado y la ex Decana y Vicerrectora respectivamente, en el año 2005. Además "el problema que tuvo esa maestría es que no acreditó en CONEAU, realmente no sé por qué deberías preguntárselo a la gente de la Unidad de Pedagogía, pero seguramente debería haber tenido que ver con las grandes exigencias de los primeros tiempos de CONEAU, a los cuáles muy pocos llegaban" (Entrevista, G.Iturrióz, 27/03/2013).

2.2.3 Especialización y Maestría en Políticas Sociales - Facultad de Humanidades y Ciencias Sociales-

"En realidad no existía la CONEAU en ese momento, que fue lo mismo que con la especialización nuestra (Docencia Universitaria), tiene reconocimiento del Ministerio de Educación, no de la CONEAU" decía Elsa Bonini respecto a la Maestría en Políticas Sociales que fue la primera que se dictó en esta Facultad, casi en simultáneo con la de Educación Superior, los dos casos se dieron entre el ' 89 y el ' 92 .

Tanto esa Maestría cuanto otras iniciativas a las que aludió Analía Pomés (entrevista 08/08/12) -actual coordinadora local de la Maestría en Trabajo Social, implementada por convenio con la Facultad de Trabajo Social de la UNLP- fueron fuente de formación de muchos de los docentes de la Facultad. Como el caso del Posgrado de Educación de Adultos (PROA), que ella coordinaba y estaba articulado entre el Consejo Provincial de Educación, Ideas (Instituto de Acción Social) de Cayetano De Lella y la UNPSJB, a principio de los noventa. "Fue una semilla muy interesante porque nos orientó a problematizar lo pedagógico incluyendo una dimensión política en 
ámbitos comunitarios, acá había muy poca experiencia en eso". También recordó la Especialización en Análisis e Intervención Institucional, una iniciativa de la Secretaría Académica de Rectorado a fines de los noventa, que era un posgrado de actualización, liderado por Lidia Fernández del cual ella participó y "que colaboró con el análisis de las prácticas en el marco de ámbitos institucionales" (Entrevista Pomés, 08/08/12).

"El desarrollo fue en el Rectorado, pero la mayoría éramos docentes de la Facultad, es decir que el impacto está puesto acá" reconoció Graciela Iturrióz respecto de los proyectos mencionados. En particular y de acuerdo a su testimonio la FHyCS de la UNPSJB tiene una breve historia en esta materia “para mí el origen del posgrado en la Facultad está con la Maestría en Letras en el año 2007, por lo menos de lo que yo puedo informar sino tendría que haber expedientes porque los expedientes no desaparecen, no se archivan mal, los expedientes siguen viviendo" (Entrevista Iturrióz, 27/03/2013). Este comentario de la actual Secretaria de Investigación y Posgrado fue realizado a raíz de la consulta acerca de Maestría en Políticas Sociales mencionada inicialmente por la alumna del posgrado en ese entonces, María Rosa Segovia, y del que después diera cuenta Elsa Bonini, la Decana de ese período entrevistada para este trabajo. También el registro se encuentra en el Informe de Autoevaluación de la FHyCS de 1996 que expresa: "La única oferta de posgrado que ofreció la Facultad fue la Maestría en Política Social en 1992, por diversas razones de tipo administrativos y académicos no fue aprobada por el Ministerio. Hasta el presente se han otorgado títulos de Especialización en Política Social. Los seminarios fueron dictados en su mayoría por profesores visitantes de la UBA". Así como a través de la información brindada por la ex decana Elsa Bonini, en ese momento, miembro junto a Ricardo Sidicaro y Ernesto Isuani del comité académico de dicha Maestría, se accedió al archivo de la Facultad y al expediente que reseña la iniciativa del posgrado (Anexo: Pol. Soc. Expediente 449/91 FHCS “Maestría en Política Social”, folios 1-15).

"Era entre la UBA, CIEP-CISEA y UNPSJB, que fue el primer posgrado que tiene la Universidad en la época de Manuel Vivas, en el año '89, que no nos dieron el título de master porque la CONEAU no la avaló. Esta Maestría en Políticas 
Sociales era un convenio entre el Rectorado y Facultad de Humanidades, o sea que era de la Facultad. Colectivamente llegamos a presentar un recurso de amparo ante el Consejo Superior y ante la CONEAU para que se nos acreditara la maestría, pero después no lo seguimos" (Entrevista Segovia, 20/07/2011).

Casi en simultáneo con esa experiencia, existe un expediente en el archivo de la FHyCS que se corresponde con una iniciativa de Especialización y Maestría en Ciencias Sociales que contaba con la aprobación del Consejo Superior de la UNPSJB (Anexo: Res. 239/91.). De acuerdo a la documentación habría sido gestada en la sede Trelew y contaba con la designación de un Comité Académico constituido por la Lic. Ennid Miguel (Lic. en geografía, responsable en ese momento de la Unidad de Pedagogía FHyCS, sede Trelew), el Dr. Waldo Ansaldi (UBA) y el Dr. Pablo Pozzi (FFyL UBA). El proyecto incluía el plan de estudios de una especialización de cuatro cuatrimestres y para la maestría, la acreditación de este tramo más la tesis, establecía que sería dictada a término en los ciclos académicos de los años 1992 y 1994. El único dato de avance, fuera del proyecto, es un listado de alumnos inscriptos de la Sede Trelew que eleva en el año 1998, la Delegada Académica de dicha sede, al entonces Coordinador del Área Posgrado, Lic. José Luis Nieto, manifestándole que fue extraído de una nota enviada en ese momento a la Decana Dolores del Castaño (1992/1995).

Otro antecedente de posgrado en la segunda gestión de la decana Norma Fuentes (1998/2001) tuvo que ver con la iniciativa del mencionado coordinador, quien comenzó a gestionar un posgrado en educación. María Rosa Segovia su compañera en la gestión recuerda que "cuando lo convocan a José Luis Nieto, él empieza a trabajar y quería tener una línea en cada carrera, o por lo menos una en los profesorados, pensar en una maestría en ciencias sociales, un doctorado en educación o ciencias sociales, otra en comunicación y gestión ambiental que eran diferentes a la naturaleza del resto de la Facultad". Se alcanzaron a realizar las entrevistas de admisión y un encuentro de promoción con el Dr. Ignacio Rivas Flores del Doctorado en Educación que iba a dictar la Universidad de Málaga -España-. "El doctorado quedó trunco, la única posibilidad que teníamos nosotros que ese doctorado 
saliera es que lo diera la Universidad de Málaga, si José Luis no se hubiera muerto, ese doctorado hoy estaría en pie" (Entrevista Segovia: 20/07/2011).

\subsection{4 "El Posgrado en la FHyCS empieza con la Maestría en Letras (2007)"}

“Para mí el proceso de constitución del posgrado en la Facultad empieza con la Maestría en Letras, de ahí en adelante te puedo hablar" reitera Iturrióz y alude al posgrado iniciado en la anterior gestión (Bibiloni 2005-2009) en el marco de la cual también comienza la Maestría en Didáctica, no obstante sostiene que esta secretaría (ahora de Investigación y Posgrado) se llamaba de Investigación y Desarrollo "y no tenía, a mi juicio, una identidad, un lugar específico para el posgrado". Asimismo destaca que desde la Maestría en Letras y todo lo que le sigue son posgrados que fueron presentados a la CONEAU y se encuentran en permanente proceso de acreditación "y eso hace que el desarrollo del posgrado en la Facultad, se inscriba o se encuadre o se integre en un marco nacional de desarrollo del posgrado" (Entrevista Iturrióz, 27/03/2013). Encuentra en este marco institucional de haber ingresado al circuito, la razón de que los posgrados estén vigentes y desarrollándose. Destaca que se encuentran en proceso de acreditación la Carrera de Especialización en Psicología Educacional que se presentó el año pasado, la Maestría en Estudios Socio-territoriales y la Maestría en Geografía de los Espacios Litorales en convenio con la Facultad de Humanidades de la Universidad Nacional de Mar del Plata, ambas por ingresar a CONEAU en este próximo pasado llamado de abril. Así como también agregó la Especialización en Políticas Públicas de la Infancia, Niñez y Adolescencia que dictará la UNER -Universidad Nacional de Entre Ríos- en convenio con cinco universidades, entre las que se encuentra la UNPSJB con financiamiento del Ministerio de Desarrollo de la Nación. Y también la Maestría en Trabajo Social que no enumeró porque la dicta la Facultad de Trabajo Social de la UNPL en la sede Comodoro. "La realidad es que nosotros tenemos muy pocos magisters y doctores como para dar cuenta de una masa crítica, pero así y todo los posgrados están siendo acreditados (...) Todo lo que se está remontando requiere un esfuerzo personal con muy poca estructura, eso también forma 
parte de la historia del posgrado en la Facultad, la falta de claridad respecto de la estructura, porque no existen posgrados que no tengan una Secretaría de Posgrado atrás" (Entrevista Iturrióz, 27/03/2013).

Por su parte la actual Decana Claudia Coicaud en la entrevista realizada a dos años de iniciada su gestión (1/11/2011) valoraba la iniciativa de sostener un proyecto político institucional "que les permite ahora consolidar las áreas de investigaciones y de formación de posgrado". En su opinión la falta de un proyecto político respecto a la formación fue bastante general y recordó "la especialización en docencia universitaria que terminó en una maestría de doce años, la única común a todos y donde mucha gente del ámbito de las ciencias sociales apostó y fue a parar" (Entrevista Coicaud, 1/11/2011).

Y la ex Decana Elsa Bonini considera que al hablar de posgrados "no podemos obviar su historia, en la última década impactaron fuerte las especializaciones y las maestrías, pero los cursos de posgrado sueltos tuvieron su valor" (Entrevista Bonini: 1/07/2013). Pero no adhiere a la opinión de Iturrióz cuando manifiesta que el posgrado comenzó en la Facultad en el 2007 porque opina que hubo antecedentes cuando el área estaba en ciernes en todo el país y rescata la visión del ex Rector Pinelli para poder armar un posgrado y darle continuidad, aquel gestado desde la Universidad en especialización en Docencia y Maestría en Educación Superior, en el que ambas se formaron. La actual Decana Coicaud concluye que la falta de un proyecto político respecto de la formación fue bastante general, se interpreta que refiere a la Facultad, no especifica si a la Universidad en general y Bonini, la ex decana entrevistada, considera que aún no lo hay.

\subsubsection{PLANGESCO y la normalización de la Carrera}

Mientras tanto en el transcurso del proceso relatado, en el año 2003, se firma el protocolo de colaboración mutua entre ambas Facultades en el marco del convenio entre la UNLP y la UNPSJB, que permite el dictado de la Maestría PLANGESCO en la sede Comodoro.

"Nunca se puso en tela de juicio la condición académica de la Maestría con el renombre que tiene la Facultad de Periodismo de La Plata", la actual Decana Claudia Coicaud se refería al hecho de que no se pudieron discutir las 
condiciones académicas de sostén del proyecto, de cuando se replica un posgrado de una Universidad central en otra y que por eso "quedó en manos del grupo autogestionado y el valor de la figura de la coordinación que era la persona que podía sostener, anclar". Para llegar a la conclusión de que lo que se tiene que optimizar, es esta situación de falta de solidez institucional, "porque así lo colectivo en términos políticos tiene que seguir sumando" concluye (Entrevista Coicaud, 1/11/2011).

Por su parte la titular de Investigación y Posgrado, manifiesta que al finalizar su gestión le gustaría saber por qué, exceptuando a nuestro compañero Luis Sandoval, el resto de los docentes de Comunicación no radican proyectos en su secretaría. Y ante la observación de que nuestra carrera considera a este posgrado como uno de los peldaños necesarios para fortalecer la investigación, puntualizó que "no deberían esperarlo solo de eso, de los casos que vos mencionaste habría que ver si están avanzando, no digo por las personas, vos decís que un chico de Madryn mandó su tesis, quién más, no sé Nancy... ojala... pero vos viste cómo son los tiempos, de acá hasta que la terminás y después pasa un año hasta que la institución te genera la defensa" (Entrevista Iturrióz, 27/03/2013).

En parte la respuesta se encuentra en el rol que desempeñó esta carrera en el marco de la Facultad, "puedo decir que Comunicación Social es una carrera que en sus orígenes nace desprendida de letras y que en la discusión de este desprendimiento, este insumo de PLANGESCO después de la época de la normalización y de los viajeros fue como el otro hito respecto de volver a tensar el cuerpo epistemológico específico de la comunicación social". Esto lo afirma la Decana Claudia Coicaud quien reconoce que la época de la normalización y los viajeros se extendió desde su nacimiento en 1986 hasta el año 2003 en coincidencia con el inicio de PLANGESCO. Hasta ese momento la carrera funcionaba con sus cuadros docentes interinos en formación con profesores viajeros, con una situación laboral precarizada y con un fuerte anclaje en la práctica profesional fuera del ámbito universitario.

En este punto y al referirse a la fortaleza del conjunto reconoce que "si no hubiera sido que ustedes como grupo, colectivo, toman la posta de decir esto nos tiene que servir para conformar nuestro jurado y hubo ahí sí un apoyo 
institucional para hacer los concursos en ese momento, más allá de que no había ningún programa de financiamiento como ahora" (Entrevista Coicaud, 1/11/2011). Valora esta acción que permitió en el año 2006 sumar seis profesores ordinarios a una planta que contaba a ese momento sólo con dos en esas condiciones. Lo resignifica desde el rol institucional que hoy asume y recuerda también que "en algún momento con algunos otros colegas consejeros del claustro docente pusimos en tensión esto de decir que la Facultad había tenido un valor agregado, respecto de la normalización de la carrera de Comunicación Social" (Entrevista Coicaud, 1/11/2011).

En el mismo sentido reflexionó acerca de los concursos abiertos que ponen en igualdad de condiciones a profesionales capacitados que recién llegan a la ciudad con "nuestros profesores que hace veinte años que le ponen el hombro a la institución" sin que la Facultad les haya ofrecido ningún programa de capacitación ni recursos para formarse afuera. Por eso reconoce como un punto fuerte y "celebro como capitalizamos la propuesta, sin proponérselo y sin estar escrito en ningún lado, terminó como cumpliendo alguno de estos roles o alguno de estos lugares para los profesores de la carrera" (Entrevista Coicaud, 1/11/2011).

Concretamente desde el año 2003, la Carrera pudo a través de la restitución de los departamentos y con ellos del reconocimiento institucional de la palabra de sus integrantes, señalar sus necesidades más urgentes. Luis Sandoval, docente de Comunicación Social y egresado de PLANGESCO recuerda "que en aquél momento, había una especie de plan estratégico de cuáles eran las cosas por las que la carrera tenía que bregar y había cuatro muy claras: equipamiento, concursos, cambio de plan de estudios y la maestría" (Entrevista Sandoval, 27/08/2011). También agrega que la maestría tenía que ver con un esfuerzo político del Departamento, por eso sostenerla estaba relacionado con la posibilidad de cada uno de obtener el título, pero también del conjunto, porque estaba relacionada con la carrera, con el departamento de Comunicación Social.

\subsubsection{Posgrados en La Plata}


“Nosotros en la Facultad de Periodismo y Comunicación Social estábamos en un proceso inicial de consolidar los posgrados, habíamos pasado hacía poco a ser Facultad eso nos había puesto en el medio de la carrera académica, éramos una institución muy profesionalista y los posgrados sin duda, en todos nosotros en la Facultad de Periodismo, nos estaban impactando de alguna manera, en general positiva" (Entrevista Giordano, 24/11/2011).

Esto sucedió el 24 de octubre de 1994, la Escuela de Periodismo se convirtió en Facultad de Periodismo y Comunicación Social, en el marco de una posición política y de decisiones académicas que también posibilitaron que en 1996 se cree PLANGESCO, la primera Maestría de Comunicación en la Argentina. En realidad la primera presentación de un posgrado en Comunicación ante la CONEAU, además de lo inédito contó con la originalidad de asociar a la FPyCS con una ONG. Y es, de acuerdo al testimonio de Carlos Giordano en la apertura de las jornadas sobre Posgrado en Comunicación y Periodismo (2007), el resultado del debate sobre el Plan de Estudios del año '89, donde se encuentra la génesis de la Maestría que como parte de su estructura incorporaba la nueva concepción de la Comunicación, con la orientación en Planificación Institucional.

\subsubsection{PLANGESCO}

Por su parte la organización no gubernamental denominada La Crujía (nace en 1981 y forma parte de la Asociación Educacionista Argentina, obra de los Hermanos La Salle en Argentina) y se especializa en temas de comunicación, en ese momento específicamente en relación al desarrollo. Corría el año '94 y Washington Uranga se encontraba dirigiendo La Crujía y se planteaba junto a sus colegas cómo introducir el pensamiento latinoamericano al debate de nuestro país. "El auge del debate comunicacional en América Latina fue en la década de los '70, ahí se fue conformando de alguna manera la masa crítica más importante de la comunicación latinoamericana, y Argentina estuvo por fuera de eso, por dos razones, primero porque hay una cuestión histórica de perspectiva cultural, de Argentina mirando mucho más Europa que a América 
Latina y por otro lado porque eran los años más duros de la dictadura y eso también generaba un aislamiento grande de Argentina, en realidad de todos los países " ( Entrevista Uranga, 23/07/2012).

En ese sentido la Maestría fue concebida como un proyecto que más allá de formar alumnos en el posgrado perseguía la finalidad de construir conocimientos y "lograr aportes de docentes y maestrandos a la problemática de la planificación y gestión de la comunicación en diversas instituciones y prácticas sociales en el país y América Latina. Para ello se trabaja sobre la base de un modelo pedagógico centrado en el interaprendizaje, la multidisciplina y la transdisciplina" ${ }^{13}$.

Y para la concreción de esta asociación "hubo gente que hizo los puentes, yo creo que Claudia Villamayor tuvo ahí un papel muy importante, porque ella era la que tenía más contactos con la gente de La Plata, Laura Moreno que también era en ese momento parte del equipo de La Crujía y yo fuimos los que establecimos mayores contactos con un equipo en el que estaba el nuevo decano de la Facultad, Luciano Sanguinetti, Walter Miceli que fuera el vicedecano y la actual directora de la Maestría que es Cecilia Ceraso" (Entrevista Uranga, 23/07/2012).

La idea original de acuerdo a los testimonios y al documento curricular, era la de vincular el pensamiento latinoamericano de comunicación/educación cuanto el de planificación, con el ámbito académico. Dado que, pese a que la gran mayoría de los países de América Latina padecieron dictaduras militares en las décadas anteriores, también se habían sembrado las bases para una comunicación democratizadora, sobre todo en las prácticas de resistencia. Muchos de esos espacios estaban vinculados a la radio, y esas experiencias que conocemos bajo el nombre de comunicación alternativa, tuvieron actores que se convirtieron en autores del relevamiento de las mismas. Esos comunicadores fueron los primeros docentes de la Maestría PLANGESCO.

La comunicación democrática como perspectiva y la planificación de la comunicación como estrategia para el desarrollo "se expresó en lo que eran los primeros docentes, Daniel Prieto Castillo, fue de alguna manera la expresión de esa confluencia de corrientes, Rosa María Alfaro, la peruana,

${ }^{13}$ Documento curricular PLANGESCO 
Marita Mata, Alcira Argumedo, expresaban estas dos vertientes, la suma de estas miradas. Daniel Prieto y Marita Mata fueron muy determinantes en cuanto a la mirada comunicacional. Rosa María Alfaro, que te mencionaba, pero también Rossana Reguillo, la mexicana, Jesús Martín Barbero que también estuvo en el comienzo haciendo aportes, tuvimos algunos seminarios con Héctor Schmucler el aporte epistemológico de Esther Díaz, una filósofa de la UBA esa mirada o la de Silvia Delfino también" (Entrevista Uranga, 23/07/2012).

Por su parte el profesor Carlos Giordano reconoce que al momento de su constitución la presencia de Washington Uranga como eje de vinculación entre las dos organizaciones le daba a PLANGESCO un sentido "donde la planificación tenía que ver con algunas concepciones del desarrollo, pero sobre todo de la administración de políticas públicas relacionada a procesos de integración continentales con un planteo crítico funcional".

Esta impronta "empezó a ser debatida por otros que empezaron a ver la planificación como una planificación para el desarrollo ligado a los procesos de liberación nacional y social, en lo discursivo digamos, hay que ver si después las técnicas y las tácticas dan cuenta de esto, pero me parece que en lo discursivo esto empezó a disputarse y hubo un cambio objetivo en la dirección de la PLANGESCO, que pasó en un primer tiempo de Washington Uranga a Cecilia Ceraso y ahora Germán Retola, que es parte del mismo equipo de Cecilia y profundiza de alguna manera las concepciones productivistas de la planificación".

Tal como lo expresa Giordano en la visión de Germán Retola ${ }^{14}$ de los diferentes enfoques con que puede ser abordada la planificación, "nosotros pensamos un desarrollo que tienda a revitalizar estratégicamente las fuerzas endógenas territoriales de transformación, un planificador que se acerque y parta de los otros para pensar juntos el deseo y desde ahí pensar procesos de comunicación con énfasis en lo local". Plantea la idea de una universidad que

14 Entrevista realizada a Germán Retola por Marcelo Brunet y Franco Aguirre para la revista digital Difusiones $\mathrm{N}^{\circ} 1$ del área de investigación UCSE-DASS. Universidad Católica de Stgo del Estero, sede San Salvador de Jujuy, donde se desarrolló por convenio la Maestría Plangesco, 2011. 
se involucre con las prácticas sociales e intervenga a través de esta propuesta.

Hay una diferencia respecto del planteo inicial, la Maestría Plangesco "tiene otro sello, tiene otro sello de origen y esa primera identidad que le dio Washington y que le dieron los docentes del inicio, sigue teniendo la totalidad de la formación más allá de que hubo en el medio un proceso de intervención del segundo equipo por decirlo de alguna manera" (Entrevista Carlos Giordano, 24-11-2011).

Mientras que Washington Uranga, quien a partir de este año (2012) no forma parte del plantel docente del posgrado, ya que, de acuerdo a su testimonio, su materia era muy troncal y no garantizaba la perspectiva políticoinstitucional del mismo, opina que PLANGESCO tiene vigencia en su sentido. Sin embargo considera que habría que modificar el plan de estudios "porque pasaron casi veinte años y el escenario cambió", haciendo referencia a desarrollos tecnológicos impensados en aquél momento y al creciente interés por la comunicación en todos los ámbitos. Tampoco ve en la actualidad la fortaleza de los primeros años en cuanto a la construcción colectiva del equipo docente aunque sostiene que esta falta de interacción se replica hoy en todos los posgrados.

\subsubsection{El doctorado, Posdoctorado y otros posgrados}

El crecimiento y la complejización que implicó la institución de la Facultad se vio reflejada en la actividad del área de Investigación y Posgrado. Así como PLANGESCO se distinguió por su particular asociación con una ONG, la Maestría en Periodismo y Medios de Comunicación hizo lo propio con la UPTBA (Unión de Trabajadores de Prensa de Buenos Aires). En los dos casos y merced a esa asociatividad, se consiguió la modificación de la ordenanza de posgrado que posibilitó el ingreso de personas que sin tener título de grado se les permitiera el ingreso acreditando los saberes suficientes de sus propios procesos y experiencia. Ambas maestrías fueron las primeras en su género en el país y consiguieron una alta acreditación de la CONEAU.

Posteriormente la implementación de la Maestría en Comunicación y Derechos Humanos salda una necesidad de establecer desde una perspectiva 
comunicacional, la construcción de un campo que favorezca la indagación y producción de conocimiento en esta área. En la línea de las anteriores cuenta con un sistema de becas para integrantes de organizaciones sociales. Por último, la flamante Maestría en Comunicación y Criminología se propone convertir en un espacio de formación y reflexión respecto del fenómeno que involucra a la comunicación en el proceso de expansión del poder punitivo.

En orden creciente fueron las especializaciones las que continúan la escalada de formación académica de posgrado en Comunicación Radiofónica, en Prácticas Educativo-comunicacionales, Comunicación y Salud, Edición, Periodismo Cultural, Género y Comunicación, Comunicación y Medio Ambiente. Esta última será parte de un análisis detallado ya que surgió de la inquietud de un alumno de PLANGESCO Comodoro y fue luego institucionalizada por la FPyCS. También posibilitó su dictado inicial en nuestra ciudad, luego de una asociación con la Fundación Patagonia Natural, con sede en Puerto Madryn (Anexo: Especialización).

Es el Doctorado en el año 2003 el que ofrece, como se describe en la página oficial de la FPyCS, un ámbito de excelencia académica para la formación de investigadores "que contribuyan al mejor conocimiento de los procesos y las estructuras comunicacionales que afectan el desarrollo de nuestras sociedades".

Finalmente en este ciclo se propone una Estancia de Investigación Posdoctoral en Comunicación, Medios y Cultura "cuya intención es la de abordar el estudio y profundizar el debate sobre la complejidad que encierra la trama de la Comunicación, el Poder y los Derechos Humanos", destinado a doctores en ciencias sociales y humanas (http://www.perio.unlp.edu.ar/node/3078).

\subsubsection{Posgrados aquí y allá, marcados por la historia}

Con la reapertura democrática de 1983, comienza la normalización de las universidades públicas con una amplia agenda de restituciones y modificaciones. Todas necesarias para compensar los graves perjuicios de la Dictadura y reencauzarla hacia los pilares reformistas fundacionales. La 
intención se tradujo en políticas concretas de apertura, recepción de docentes que volvían del exilio, fortalecimiento académico y todas las medidas indispensables para contener el necesario proceso de recomposición de la institución. No obstante ello, las masivas inscripciones y el respaldo popular no lograron impedir el impacto que las presiones político-económicas de una década compleja, le imponían a la política educativa de esta democracia en ciernes.

En relación al posgrado las bases para su fortalecimiento se sentaron con la creación del SICUN (Sistema Interuniversitario del Cuarto Nivel) orientado a su expansión y consolidación mediante la cooperación entre las distintas universidades.

Al tiempo que sobre fines de esa década, en la FPyCS de la UNLP se debatía la reforma del Plan de Estudios con la finalidad de adecuarlo a las demandas de la época y revertir la impronta de la línea ideológica de la Dictadura. El plan incorpora la nueva concepción de la comunicación en la Licenciatura en Comunicación Social, donde como parte de la estructura de la misma se encuentra la génesis de la Maestría PLANGESCO.

En la UNPSJB se consolidaba en esa etapa normalizadora el proyecto de una institución destinada a satisfacer las demandas del desarrollo regional con la instalación de diferentes sedes en la Patagonia Austral. Se crea el CIUNPAT (Consejo de Investigaciones de la Universidad) con el objetivo de que los primeros proyectos de carácter interdisciplinarios ayuden a concretar ese mismo objetivo en la región. A nivel de posgrado fue pionera cuando crea la Especialización en Docencia Universitaria y Maestría en Educación Superior, de la mano de Cayetano De Lella en 1989, un proceso que se extendió por más de una década, pero que formó a muchos de los docentes de la FHySC protagonistas de su conducción a finales de los noventa.

La reforma del Estado encarada por el gobierno de Menem señaló la constitución de un nuevo escenario económico que afectaba toda la estructura sociocultural. La misma impactó en la política universitaria por la ruptura con el modelo democratizador del gobierno radical, fue atravesada por la evaluación y acreditación, el acceso restricto a la educación superior y el sistema de incentivos mediante evaluación de productividad académica y 
también por el fuerte desarrollo del posgrado. La SPU (Secretaría de Políticas Universitarias) es el organismo creado para promover entre otras, la evaluación de la calidad institucional, el cobro de aranceles y la implementación de la venta de servicios a terceros. La Ley de Educación Superior 24521, sancionada en 1995, consolida el rol de Estado como evaluador a través de la CONEAU, encargada de acreditar las carreras de grado y posgrado.

La Escuela de Periodismo de la UNLP adquiere el carácter de Facultad en 1994 y la Maestría PLANGESCO se crea en 1996, pero ambos hitos comenzaron a gestarse a mediados del ' 80 cuando se discutía aquél nuevo proyecto político académico. Hacia finales de la nueva década otro cambio de Plan de Estudios, orienta un perfil de egresado que pone el acento en la formación de un productor de comunicación que debe ser interpretado en el marco de los procesos socioculturales y de sus condiciones históricas. Esta Reforma curricular de 1998 posibilitó la apertura de las cátedras a los proyectos de investigación, con la tesis como requisito para alcanzar el título de licenciado y su articulación con la política general de investigación de Facultad.

La falta de un proyecto político respecto a la formación fue bastante general, así opina la actual decana de la FHyCS de la UNPSJB, dando cuenta del dificultoso proceso de constitución del posgrado en la misma. De hecho la Dra. Iturrióz, Secretaria de Posgrado de su gestión, considera a la Maestría en Letras iniciada en el año 2007 como la que da origen al posgrado en la Facultad. Los antecedentes anteriores son ignorados por su falta de institucionalización, dado que a ella no le constan tanto la Maestría en Políticas Sociales (1991) que no ha otorgado títulos más que en la especialización, la iniciativa de la Maestría en Ciencias Sociales de la sede Trelew que no llegó a implementarse así como tampoco el doctorado en Educación que tampoco prosperó. En opinión de la ex decana Elsa Bonini, no se recuperan la gran cantidad de seminarios de posgrado que a su criterio fueron las iniciativas de la época, en la que era difícil tener la visión de dar continuidad a los mismos en un posgrado como lo hizo en el aquel entonces el Rectorado con la Maestría en Educación Superior. El dictado de 
PLANGESCO a partir del año 2003, es soslayado en los relatos porque no es de factura local, por la extensión de la cursada y sobre todo por la autogestión de su proceso. Quizás también por la instancia actual de realización de tesis que ubica a los alumnos en un lugar de invisibilidad hasta su graduación. Tanto como aquella Maestría en Educación Superior que iniciada en el año 1988 tuvo tres camadas de graduados, 1999, 2002 y 2005. En tanto que la Facultad de Periodismo y Comunicación Social de la UNLP definió a través de la Dirección de Investigación y Posgrado una política de formación permanente que continúe la instancia de grado. Fue así que se sustanció un proyecto en tres escalas: especializaciones, maestrías, doctorado y una instancia posdoctoral, una estrategia pionera en el campo de la comunicación en la Argentina que responde a marcos de formación nacional y latinoamericano.

Por su parte la Facultad de Humanidades y Ciencias Sociales de la UNPSJB a través de su Secretaría de Investigación y Posgrado, destaca que actualmente se encuentran en proceso de acreditación la Carrera de Especialización en Psicología Educacional que se presentó el año pasado, la Maestría en Estudios Socio-territoriales y la Maestría en Geografía de los Espacios Litorales en convenio con la Facultad de Humanidades de la Universidad Nacional de Mar del Plata. Así como también, la Especialización en Políticas Públicas de la Infancia, Niñez y Adolescencia que dictará la UNER (Universidad Nacional de Entre Ríos) en convenio con cinco universidades, entre la que se encuentra la UNPSJB con financiamiento del Ministerio de Desarrollo de la Nación y la Maestría en Trabajo Social que dicta la Facultad de Trabajo Social de la UNPL en convenio con esta Facultad.

Finalmente es importante destacar las tendencias mencionadas en el capítulo, respecto a los datos que señalaban que en el período 1995/2009 la cantidad de posgrados creció el 230\% (Suasnábar, 2011: 26) sobre todo en especializaciones y maestrías y muy levemente en doctorados, que esa tendencia se revirtió entre los años 2007 y 2009 marcando la línea que se consolida en la actualidad en la elección directa del doctorado.

La apuesta de la Carrera de Comunicación a la Maestría PLANGESCO y la opción doctoral que ofrece la beca del PROSOC II (Proyecto de Apoyo a las 
Ciencias Sociales) para algunos docentes, entre ellos un maestrando de PLANGESCO y otro egresado, consolida un proceso de crecimiento para una carrera que con muchas dificultades se abre campo en una Universidad emergente del sur argentino. 


\section{PERFIL DE LA CARRERA Y LAS ETAPAS DEL DESARROLLO}

3.1 PLANGESCO: En los albores, documento, constitución, características.

3.2 De La Plata a Comodoro: gestiones, protagonistas.

Funcionamiento: programas, viajes, reuniones, estructura, sostén económico, reconocimiento/s institucional/es.

“El nuevo comunicador debe entender profundamente que la comunicación para el cambio social trabaja esencialmente con culturas y que se necesita una sensibilidad muy especial para apoyar el proceso de cambio social en el mundo en desarrollo, que no tiene nada más a que aferrarse que a su identidad cultural. Desarrollo y cambio social deben ser posibles dentro de un proceso de intercambios culturales horizontales y respetuosos".

Alfonso Gumucio- Dragón
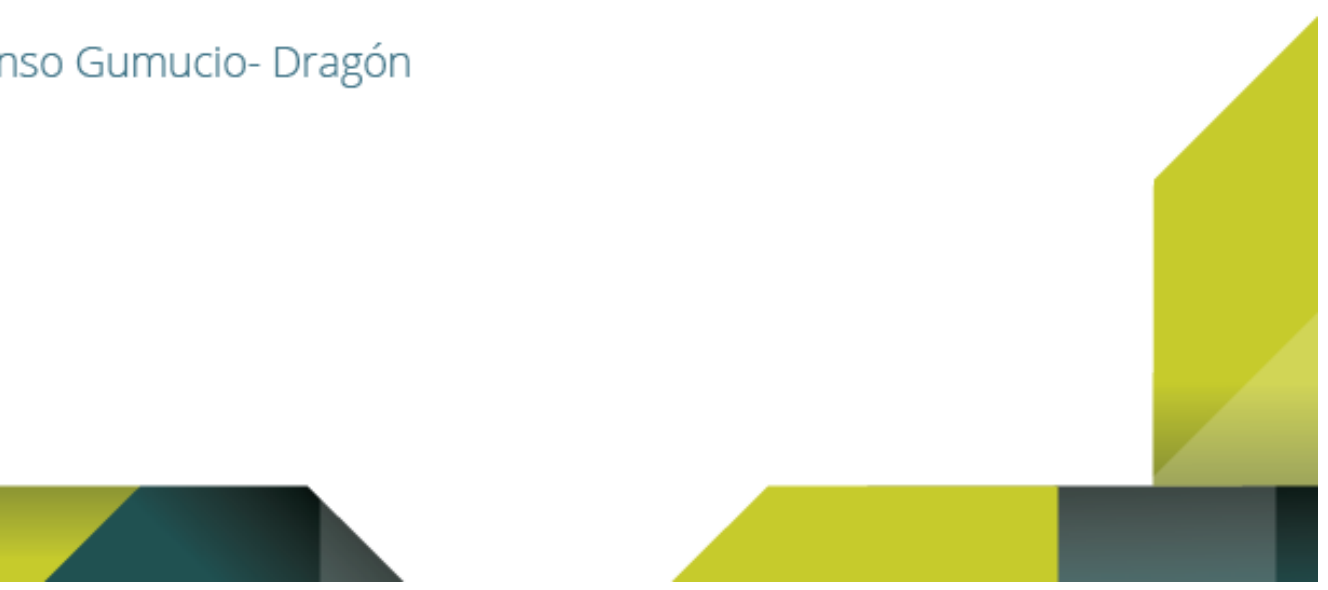

\subsection{PLANGeSCO: En los albores, documento, constitución, características}

\subsubsection{En los albores}


Al finalizar la Segunda Guerra Mundial se abrió una etapa en la que el equilibrio de poder se definió en las hegemonías de EE.UU y la URSS. Este período se caracterizó por un crecimiento sostenido en los países del norte y un desplazamiento entre ambos hacia regiones de Asia, África y América Latina.

Como culminación del mismo, en el año 1973 dos acontecimientos marcarán la política internacional en las décadas subsiguientes, tanto la derrota de EE.UU en Vietnam como el aumento que impone la OPEP (Organización de Países Productores de Petróleo) en los precios del crudo y el embargo petrolero a las naciones que apoyen a Israel. Este declive del predominio norteamericano, llevará a la creación de la Comisión Trilateral entre América del Norte, Japón y Europa Occidental con el objetivo de coordinar las políticas de los tres referentes principales del capitalismo central.

No obstante la llegada de Carter al gobierno de EE.UU en 1976, va a redefinir la estrategia trilateral por la fuerte crisis económica que atraviesa y la lucha entre regiones de la periferia, en contra de sus intereses dominantes. Esta reformulación de poder en Medio Oriente, África y Asia Menor enfrentada por Carter, se compensa con la relativa estabilidad alcanzada en América Latina donde gobiernan dictaduras militares pro-norteamericanas ejerciendo una represión que aniquila cualquier tipo de cuestionamiento.

Pese a ello los jóvenes investigadores de la comunicación en Latinoamérica comienzan a denunciar las desigualdades de la región en el marco de estas sangrientas dictaduras militares. Así fue como sumaron sus aportes a la propuesta de la UNESCO de plantear Políticas Nacionales de Comunicación, traducidas en las recomendaciones de la Declaración de San José de Costa Rica "que vino a constituir una suerte de credo oficial de la comunicación alternativa para la construcción democrática" (Beltrán, 2005:18) .

En 1980 Reagan gana las elecciones presidenciales y las corporaciones internacionales son los actores principales del predominio estadounidense en el mercado mundial. Los recursos que los anteriores gobiernos destinaban a las políticas sociales, serán derivados a las empresas, consideradas las únicas capaces de generar empleo. Así como en el marco del enfrentamiento EsteOeste, se plantea una nueva etapa de Guerra Fría, donde se establecerán 
relaciones bilaterales con los distintos países para evitar los ámbitos de negociación multilateral. La política de derechos humanos que, aunque bastante contradictoriamente había intentado promover el gobierno de Carter, es eliminada en el contexto de las hipótesis de guerra donde las "terceras posiciones" pasan a ser caracterizadas como sospechosas de conspiración comunista internacional.

Se habló entonces de los ochenta como de la 'década perdida', con el afianzamiento del neoliberalismo y la globalización que cambiaron las bases estructurales de la sociedad. La demoledora crisis oprimió los intentos de desarrollo pero provocó la esperanzadora restitución de gobiernos democráticos en la región. Pero como plantea Beltrán, no fue perdida en la reflexión y acción de comunicadores latinoamericanos que continuaron ocupando otros espacios académicos, educativos y comunicacionales y comenzaron a pensar la comunicación más allá de los medios.

Más tarde el NOMIC (Nuevo Orden Mundial de la Información y la Comunicación) fue un hito en la resistencia a la comunicación vertical de los países hegemónicos, pero pese a estos esfuerzos no se logró alterar el orden establecido. No obstante la traducción de estas ideas en el concepto de democratización de la comunicación, dejó sentadas las bases para el fortalecimiento de un movimiento latinoamericano de comunicación. "Sólo en los noventa un grupo de académicos y estudiosos de la comunicación, por una parte, y organizaciones sociales que habían desarrollado experiencias de comunicación popular, se unieron para pensar en la coordinación de esfuerzos partiendo de la base de que del intercambio y la tarea común podría redundar en un mayor beneficio tanto para la academia como para el campo de la comunicación popular y en las organizaciones" (PLANGESCO Documento curricular y Plan de Estudios -DCyPE-,2001:21).

América Latina desarrolló interesantes experiencias de comunicación alternativa y popular, algunas de neta factura local que intentaban hacer su aporte a proyectos políticos liberadores. En el libro de PLANGESCO se rescatan entre otros, los proyectos de investigación y sistematización de procesos educativos que provinieron de esas prácticas tales como ALER (Asociación Latinoamericana de Educación Radiofónica), la experiencia 
formadora de José Ignacio López Vigil y la investigación de un grupo de comunicadores de toda la región coordinado por María Cristina Mata, entre otros.

\subsubsection{Características del Documento fundacional}

El libro mencionado, a modo de documento curricular y pedagógico de PLANGESCO, define el proyecto educativo de la Maestría como un proyecto y no la suma de iniciativas individuales de docentes y alumnos, cada uno limitándose a cumplir sus propios roles, por el contrario se sostiene que "tiene una vocación social e institucional indiscutidas, tanto por la propuesta misma como por el tipo de maestrandos que ha convocado" (DCyPE). Sobre sus características sostiene que no persigue sólo los objetivos obvios de ampliar conocimientos y alcanzar una formación profesional, sino que busca enriquecer la ciencia de la comunicación al promover el análisis de diversas instituciones desde la planificación y gestión comunicacional.

Así planteada la Maestría nace en el 1996 mediante la asociación entre la FPyCS de la UNLP y el Centro de Comunicación Educativa La Crujía. Pionera en el campo y sobre todo en la propuesta que intenta articular las reflexiones teóricas, metodológicas y epistemológicas de la comunicación en América Latina, con las prácticas sociales de la región. Convencidos sus mentores que la sistematización de esos conocimientos, alimentados de la diversidad de prácticas locales, daría como resultado la formación superior de gestores de procesos comunicacionales. Plantean la necesidad de no reducir la comunicación a los medios como única problemática de análisis y posicionar a esta transdisciplina entre los actores y sus prácticas sociales.

Queda expuesto en todo el documento, entre las características y propuesta pedagógica-metodológica, que a esta Maestría la distingue el hecho de considerarla un espacio de confluencia de la investigación, producción y gestión. Destaca la integración de la educación con la sociedad y la articulación de la teoría y la práctica al forjar el aprendizaje sobre la base de los problemas.

El Plan de Estudios está concebido en áreas: Contextual, Planificación y Gestión, Investigación, Multimedial y Seguimiento y cada una de ellas cuenta 
con un conjunto de temáticas que se organizan en cursos, seminarios y talleres. La vinculación entre las áreas está pensada como un proceso dialéctico que confluye en el Taller Permanente de Tesis. No obstante por fuera de la currícula concreta se establecen interesantes planteos respecto al tipo de formación que persigue, menciona a Jesús Martín Barbero cuando señala "debemos dar forma a demandas de comunicación mediante la formación de profesionales mediadores" (DCyPE). Aboga por un proceso que exceda el plan de estudios para estimular la reflexión que tienda a la generación de producciones y modelos propios.

Desde la perspectiva pedagógica destaca que "interesan no sólo los estudios, sino también los estudiosos" (DCyPE) haciendo referencia a esa vertiente que considera que quien se involucra en una maestría de este tipo lo hace desde su historia y expectativas con el fin de concretar sus sueños y su modo de proyectar el futuro.

Lo expuesto se corresponde con la experiencia de PLANGESCO en la Universidad Nacional de La Plata desde su implementación en 1996 hasta el año de edición de ese libro en el año 2001. "Por las aulas de la PLANGESCO pasaron en los últimos cinco años las personalidades más relevantes del campo académico y profesional de la comunicación y de las ciencias sociales del continente: Rosa María Alfaro, Regina Festa, Néstor García Canclini, Jorge González, Francisco Gutiérrez, Jesús Martín Barbero, Ernesto Laclau, Guillermo Orozco Gómez, Mabel Piccini, Rossana Reguillo, entre otros. También se sumaron entusiasmados a este proyecto, investigadores con reconocida trayectoria como Alcira Argumedo, Daniel Arroyo, Jorge Luis Bernetti, Silvia Delfino, Esther Díaz, María Cristina Mata, Daniel Prieto Castillo, Juan Samaja, Héctor Schmucler, Washington Uranga, Carlos Vallina. Asimismo, una mención especial a Victor Bronstein, Jorge Capitanich, Oscar Cuattromo, Aníbal Ford, Daniel García Delgado, Damián Loreti, José Pasquini Durán, Antonio Presern y Ana Wortman, quienes también brindaron su apoyo a la propuesta. Además, la Maestría se ha transformado en un lugar de confluencia de colegas graduados de Chile, Colombia, Cuba, Honduras, México, Paraguay, Perú, Uruguay y de numerosas universidades argentinas" (PLANGESCO DCP, 2001:14). 
PLANGESCO nace un año después de sancionada la LES y se desarrolla en ese convulsionado período que atraviesa los últimos tiempos del segundo gobierno de Carlos Menem y la corta experiencia de la Alianza en el gobierno, que finaliza trágicamente el 20 de diciembre de 2001.

La brutal crisis desatada en ese momento, hizo pensar que no era posible la recuperación, sin embargo luego de la forzada sucesión presidencial, la elección de Néstor Kirchner con sólo el $22 \%$ de los votos y su asunción en mayo del 2003, no vaticinaba la progresiva mejoría que alentaban sus políticas de reestructuración económica, social y sobre todo cultural. En el marco de un contexto pos neoliberal el desarrollo retorna al espacio público y al debate político y académico (García Delgado, 2006), se registra un crecimiento económico, un descenso gradual del desempleo, pobreza e indigencia y la salida del default, como la apertura a un modelo de protección nacional y defensa de los intereses colectivos, que contrasta fuertemente con el utilitarismo y pragmatismo de los noventa. Se destaca también en este primer período la clara política desplegada en el sentido reivindicatorio de los derechos humanos y la administración de justicia. Desde la imagen del retiro del cuadro del ex presidente de facto Jorge Videla de la galería de fotos de primeros mandatarios, hasta medidas como la renovación de la Corte Suprema, acompañadas de un discurso militante de reconocimiento a la diezmada generación a la que él representaba.

En materia educativa se sancionan la Ley de Educación Técnica y Profesional, la ley de Financiamiento educativo que eleva el presupuesto al $6 \%$ del PBI, la ley Nacional de Educación que estableció la obligatoriedad del nivel secundario y una reforma del sistema educativo similar a las vigentes antes del menemismo. No obstante las urgencias asumidas en los gobiernos Kirchneristas (2003-2007: Néstor Kirchner, 2007-2011: Cristina Fernández de Kirchner y 2011 hasta la actualidad: Fernández de Kirchner) la política universitaria también fue abordada con cambios, "un seguimiento exhaustivo de los programas especiales parece dar cuenta de una política incremental antes que global y coherente hacia el sector" (Suasnábar y Rovelli, 2012: 40). No obstante este parecer, de los programas desarrollados en el ámbito de la SPU, el de Voluntariado Universitario, ni bien iniciado el gobierno de Néstor 
Kirchner, significó un acercamiento a la comunidad mediante la promoción de proyectos que tienen el objetivo de mejorar su calidad de vida. Otros vinculados a fortalecer proyectos bilaterales y multilaterales de asociación especialmente con países del MERCOSUR, así como el de Promoción de la Universidad Argentina en el Exterior, dan cuenta del estímulo a la constitución de redes.

Una novedad en el sistema a nivel de política universitaria son los programas especiales orientados al mejoramiento de disciplinas, carreras e instituciones. $\mathrm{Si}$ bien los que continuaron fueron, el de Apoyo y Desarrollo de las Universidades Nuevas (PROUN), el de Incentivos a Docentes-Investigadores (PROINCE) y el Sistema de Información Universitaria (SIU), se agregan los especiales por disciplina que en el caso de esta Facultad de Humanidades y Ciencias Sociales de la UNPSJB se beneficia tanto por el Proyecto de Mejoramiento de la Enseñanza en Ciencias Sociales (PROSOC) como por el de Humanidades (PROHUM).

Sumado a que, en 2005, la SPU introduce un nuevo instrumento de distribución de fondos denominado "contratos-programa plurianuales". Este nuevo instrumento que implica distribución de recursos, implementa, sobre todo en las universidades más acotadas por las restricciones de su presupuesto, una salida para la regularización de su planta docente.

\subsection{De La Plata a Comodoro: gestiones, protagonistas, funcionamiento.}

\subsubsection{De La Plata a Comodoro}

En este escenario de transformaciones, donde a nivel nacional se inicia un proceso de cambios que redundarán progresivamente en la política universitaria, los posgrados que se consolidan en las universidades tradicionales todavía son una asignatura pendiente en las universidades nuevas.

Un aspecto de la hipótesis de esta tesis plantea que las dificultades surgidas en el desarrollo de PLANGESCO en Comodoro, pusieron al descubierto las propias dificultades de la Facultad para institucionalizar el área de posgrado 
en el marco de una universidad emergente del contexto nacional, así como también rastrear el modo en que esta experiencia atravesó y fue atravesada por la cultura institucional tanto de la Facultad de Humanidades y Ciencias Sociales y cuanto de la Facultad de Periodismo y Comunicación Social de la Universidad Nacional de la Patagonia San Juan Bosco.

Así se pone de manifiesto en todo el proceso que se relata a continuación y que comienza cuando en octubre de 2003 se presenta la Maestría PLANGESCO en la Facultad patagónica, a propuesta del profesor Carlos Giordano de la FPyCS de la UNLP y como parte del acuerdo con las autoridades de la FHyCS de la UNPSJB, representada por el Secretario de Planeamiento y Posgrado de ese entonces, José Luis Nieto, quien eleva al Consejo Académico la nota 725/03 (Anexo: Expediente PLANGESCO, FHyCS 2635/03 PLANGESCO, folio 16) mediante el cual se promueve la firma del convenio que permite su dictado. A esa documentación se agrega el Plan de Estudios adecuado a la modalidad semi-presencial que se adopta y el plan de costos que implica la puesta en funcionamiento de la misma.

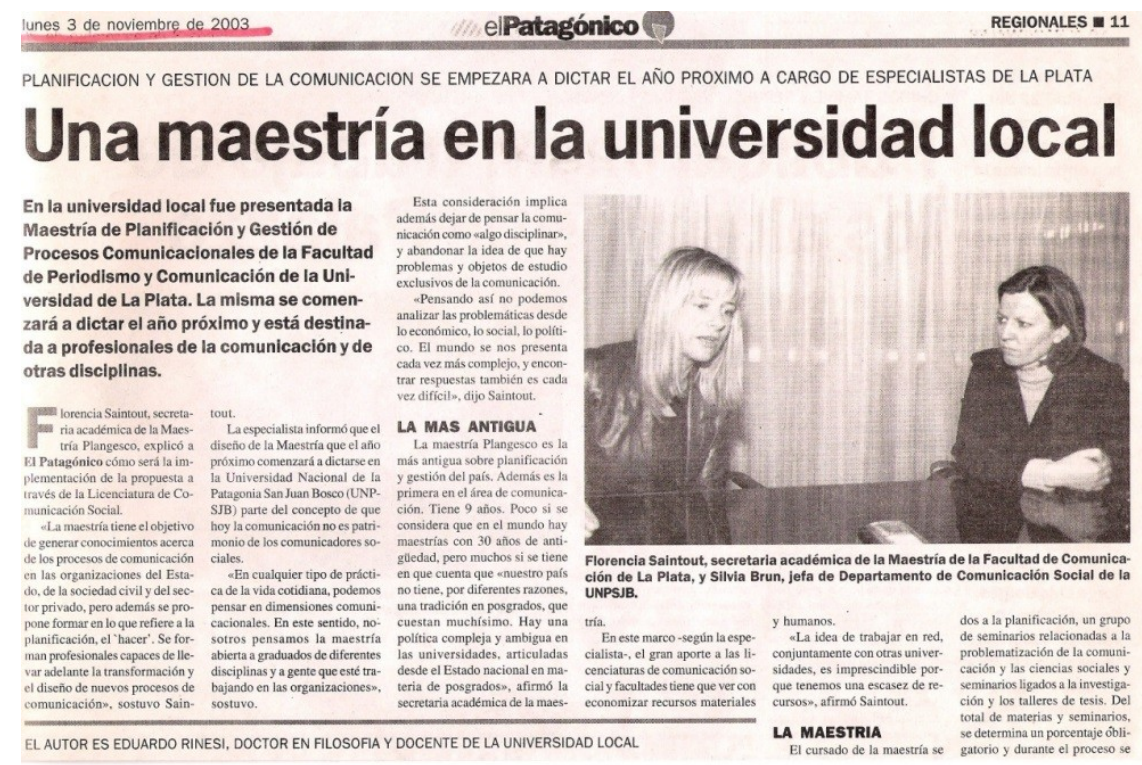

El profesor Giordano se desempeña como docente viajero de esta casa desde mediados del noventa, cuando merced a criterios establecidos por el Consejo Académico, se propone contratar a profesores que posean categorización en investigación y posgrados, con la expectativa de ofrecer esa formación a docentes de la Facultad (Res. CAFHCS $\mathrm{N}^{\circ}$ 001/96). Esta medida es consecuente con las demandas de la LES, para que las universidades 
adecuen sus plantas docentes a estos parámetros y también con la necesidad de jerarquizar esta Carrera que se constituía en una de las de mayor matrícula de ingresantes de la Facultad. Norma Fuentes desarrolla en ese momento, el primero de los tres períodos frente al decanato de la Facultad de Humanidades y Ciencias Sociales, al igual que el ingeniero Hugo Bersán en el Rectorado de la UNPSJB y deben dar respuesta, entre otros, a los requerimientos de la comisión evaluadora de la CONEAU que en marzo de 1999 sostiene sobre esta Universidad, que en general no se fijaron políticas para la investigación ni acciones que estimularan su desarrollo en la perspectiva regional.

Esta tesista como ayudante de una de las materias a cargo del equipo de los profesores de La Plata, establece los vínculos que promueven el diálogo necesario, para transmitir las expectativas de los docentes de la carrera de Comunicación Social sobre su formación pos gradual. Los docentes de Comunicación Social no acceden a las becas de posgrado provenientes de recursos del FOMEC- Fondo para el Mejoramiento de la Calidad Universitaria-, una de las razones las expone María Rosa Segovia cuando recuerda que en la gestión de la decana Norma Fuentes de la que participó como funcionaria de Extensión primero, luego también de Posgrado, "la primera cosa que nos damos cuenta, es que había que concursar para que nuestros profesores pudieran hacer posgrados porque si no, no eran admitidos en ningún posgrado, por lo menos en ninguno de excelencia de las universidades grandes" (Entrevista personal: 20/07/2011). Menciona que por ese motivo, se crea la oficina de concursos y que coincidentemente con su partida a España para hacer una maestría con recursos FOMEC, se llama al segundo concurso de la carrera desde su creación en 1986. Era el año 2000 y esta tesista accede a la titularidad de la cátedra Publicidad y Propaganda, pasan seis años más para que se convoquen a otros seis concursos de la carrera.

No obstante en el año 2003, con la restitución de la organización de carreras por departamento, cerrados a fines de la década del noventa, Comunicación Social accede a la conformación de su Consejo Consultivo y nombra como coordinadora a quien relata. Este rol habilita las gestiones para procurar los objetivos que el Departamento en ese entonces se propone, traer un 
posgrado, concursar los cargos docentes, reformar el plan de estudios y adquirir equipamiento para las prácticas. Se cuenta tanto con la convicción acerca de esas prioridades como con la consciencia de las dificultades. Pese a conocer la realidad de esta Facultad y en especial de esta Universidad en un período en que la oxigenación de la política nacional contrasta con el enrarecimiento del escenario local, no se prevé que serían diez años los necesarios para todo este proceso.

Mientras tanto, comienza el dictado de PLANGESCO en la sede Comodoro de la UNPSJB, en el mes de octubre del año 2003, la decana Norma Fuentes se dirige al Consejo Académico informándole que el expediente de la Maestría cuenta con el aval del Departamento de Comunicación y que está prevista para noviembre la visita de la Secretaria Académica de la Maestría para dictar un seminario y firmar los convenios correspondientes (Anexo: Expediente PLANGESCO, FHyCS 2635/03, nota 727/03, folio 17).

Como está planeado viaja a Comodoro, Florencia Saintout, Secretaria de Investigación Científica y Posgrado de la FPyCS y Secretaria Académica de la Maestría PLANGESCO, quien dicta la primera parte del Seminario "La Comunicación en el marco de la Ciencias Sociales" y conviene con las autoridades la firma por parte de su decano del Protocolo de Cooperación y Colaboración Mutua entre las Facultades. Dicho documento, suscripto por los decanos Carlos Guerrero y Norma Fuentes e inscripto en el marco del Convenio entre ambas Universidades, posibilita la preinscripción de los interesados en el dictado de la Maestría y la promoción de la misma (Anexo: Expediente PLANGESCO, FHyCS 2635/03: Resolución CAFHCS No 424/03folio18, Protocolo-folio 26, artículos periodísticos, publicidades: folios 29 al 32).

El Seminario de Posgrado también cuenta con el auspicio de la Secretaría de Extensión y convoca a más de sesenta interesados. En el mes de diciembre 27 de los mismos se inscriben para el cursado de la maestría, mientras que en marzo del año siguiente ya sumaban 40. La segunda parte del Seminario se dicta en el mes de abril del año 2004 y también se realizan las entrevistas de admisión a los pre-inscriptos (Anexo: Primeros Seminarios: listado de 
inscriptos, seminario y maestría. Nota 89. FHCS: 27/10/03. Resol. 434/03 Aval académico. Segundo seminario y promoción del posgrado).

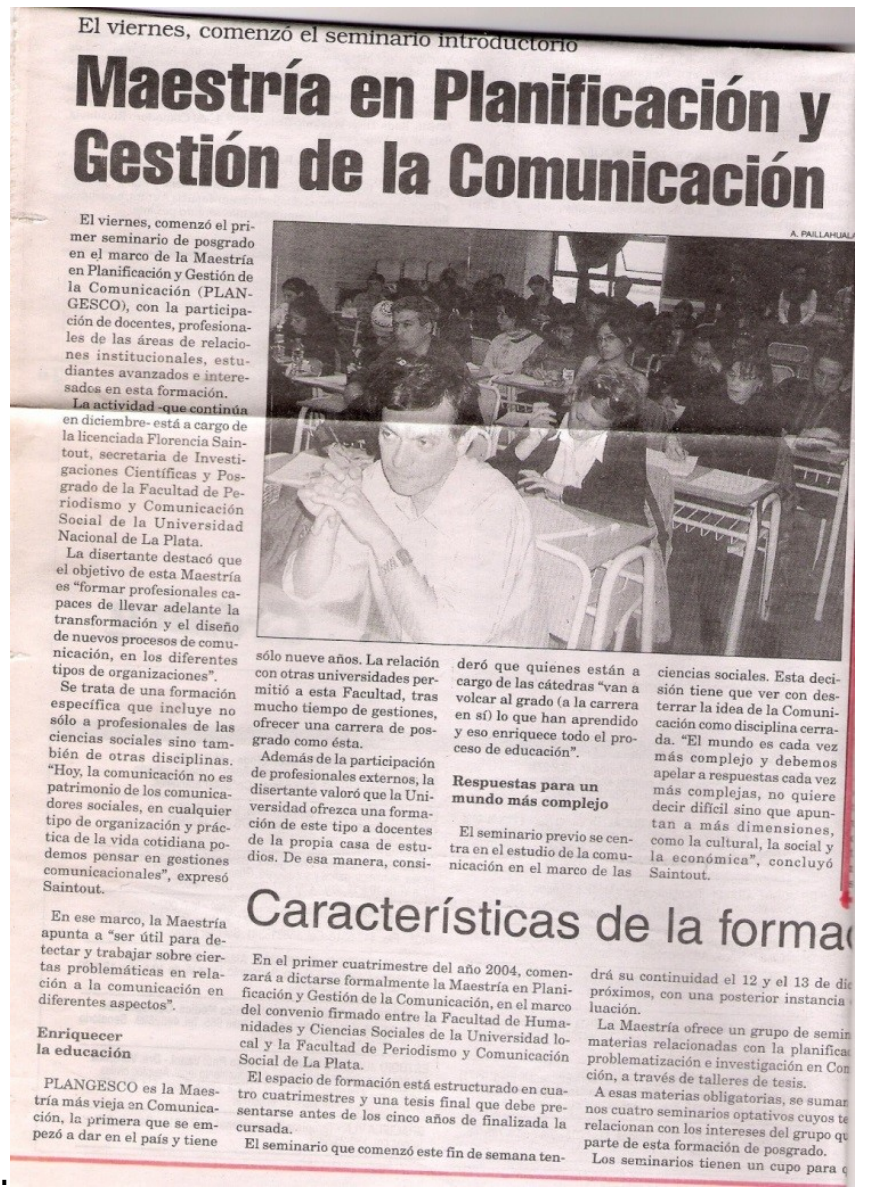

\subsubsection{Rumbo a la autogestión}

En diciembre de 2003, asume como gobernador de la Provincia del Chubut, el candidato justicialista Mario Das Neves, que rompe con la continuidad de dos gestiones radicales (Maestro 1995-1999 y Lizurume 1999-2003). En este sentido es evidente el alineamiento con las políticas públicas nacionales, no obstante la Universidad acentúa su carácter autónomo con la política del rector Hugo Bersán, quien atraviesa su tercer mandato cuestionado por mal manejo de los recursos presupuestarios de la Universidad.

Mientras tanto en la Facultad, al momento de los primeros acuerdos por la instrumentación de PLANGESCO, se incluye en la elevación del proyecto, un Plan de Costos con dos opciones (Anexo: Expediente PLANGESCO, FHyCS 2635/03 Estructura operacional y plan de costos. Folios: 11-15). En dicho documento se considera el dictado de 14 talleres y seminarios obligatorios y 3 seminarios optativos, distribuidos en cuatro cuatrimestres. Se prevé el cobro de una inscripción cuatrimestral (matrícula) de $\$ 200$ por cuatrimestre y 
una cuota mensual por cada alumno de $\$ 200$, lo que hubiese dado un total por maestrando de $\$ 4000$ al finalizar la cursada. Se considera un pago de $\$ 800$ mensuales para el coordinador de la Maestría (provisto por la FPyCS de la UNLP) durante toda la cohorte y se deja constancia que el personal administrativo sería dispuesto y solventado por la institución donde se dicte la misma. Se establecían $\$ 1500$ de honorarios para los profesores de los seminarios o talleres obligatorios, y de $\$ 1000$ para los docentes de los seminarios optativos. También se contemplan los viáticos que incluían los pasajes desde La Plata a Aeroparque (en el caso que correspondiera), los pasajes ida y vuelta de avión, el alojamiento y las comidas. Para posibilitar el dictado de modo semi-presencial se establecen dos viajes por cada seminario y/o taller de cada docente y tutorías a distancia. Se levanta el régimen de correlatividades para permitir alterar el orden establecido de modo que se pueda acordar con los profesores los viajes a esta ciudad en función de la disponibilidad de su agenda.

En esa estructura se indica que para cubrir los costos eran necesarios 13 alumnos, se aclara que si se superaba esa cantidad la recaudación quedaba para la FHyCS hasta un límite de 26 alumnos. Superado el mismo y hasta 30 alumnos se compartirían las ganancias entre las dos instituciones.

Al mes de mayo del año 2004, ya realizado el primer Seminario y las entrevistas de admisión, 13 interesados completan los pasos estipulados en ese momento. El coordinador por la UNLP, Carlos Giordano, envía esta nota a cada alumno admitido y en ella advierte sobre las dificultades que sobrevendrían de mantenerse este número de participantes del posgrado. No era difícil de prever dado que como se adelantara en la estructura de costos, este era el número base para sostener las erogaciones que implicaba su implementación.

"Estimado....: Luego de haber leído tu propuesta de trabajo y las justificaciones, el Comité de Grado Académico de la Maestría en Planificación y Gestión de Procesos Comunicacionales (PLANGESCO), ha determinado la aceptación de tu inscripción como maestrando.

De acuerdo a los requisitos formales, deberás completar la documentación faltante y estaremos en contacto para precisarte los pasos materiales de aquí en adelante. Como pudimos conversar personalmente al momento de la entrevista, la viabilidad de la instalación de la Maestría en la UNPSJB depende 
del interés de un conjunto de aspirantes debidamente calificados. Hasta el momento han completado los pasos requeridos 13 profesionales. Estimo que esto crecerá al momento de cierre de la inscripción. De no ser así, creo que los costos serán difíciles de cubrir más allá de los deseos y la voluntad que todos pongamos en la implementación.

Si está en tus posibilidades y deseos, te pido que pienses en alternativas de viabilidad y las hables con Silvia Brun, José Luis Nieto y/o conmigo para lograr este objetivo que todos nosotros estamos construyendo.

Te envío un saludo afectuoso, te felicito por la aceptación y quedamos en contacto".

Nota enviada a cada alumno admitido a la Maestría. Carlos Giordano, 26/05/04.

En el mes de agosto se desarrolla el segundo seminario obligatorio Comunicación en las Organizaciones y las Instituciones dictado por Nancy Díaz Larrañaga. En esta oportunidad se hace publicidad de la Maestría en los diarios Crónica y El Patagónico de Comodoro Rivadavia y El Chubut con alcance en la zona del Valle. De hecho esta iniciativa logró despertar el interés de tres alumnos, dos de la ciudad de Trelew y uno de Puerto Madryn, quienes completaron todo el proceso (Anexo: Primeros seminarios).

\section{3/2004*}

El cronograma enviado por el profesor Giordano, coordinador de la FPyCS, incluye para este año 2004, la segunda parte del Seminario de Larrañaga recién mencionado, el Taller de Tesis y Epistemología y Procesos Científicos, ambos con dos encuentros. El Taller de Tesis reprograma el segundo encuentro para febrero de 2005.

1. La Comunicación en el marco de las Ciencias Sociales. Optativo Florencia Saintout, 7,8 y 9 de octubre de 2003/ Abril de.2004

2. La Comunicación en las Organizaciones y en las instituciones. Nancy Díaz Larrañaga, 12, 13 y 14 de agosto / 17 y 18 septiembre de 2004.

\section{Seminario de Epistemología y Procesos Científicos, Juan Samaja.} 28, 9 y 30 de octubre/ 3y 4 diciembre 2004.

4. Taller de Tesis I, Carlos Giordano, 23,24 y 25 de septiembre 04/febrero 2005 
En el mes de septiembre de este año 2004 se designa a esta tesista, coordinadora académica por la sede Comodoro, se solicita a modo de reconocimiento por la actividad que desarrolla desde el inicio de la gestión del posgrado. Parte de los acuerdos mencionados ya no tenían correlato en la realidad del posgrado y ante la incertidumbre que se vislumbra, una de las tareas que sugiere la Secretaría de Planeamiento y Posgrado de la FHyCS de la UNPSJB es la de gestionar recursos ante organizaciones de la comunidad. A la distancia se puede interpretar esta medida como un resabio de la institución de políticas de los noventa que con la implementación de la figura de 'servicios a terceros' intenta recaudar fondos para compensar los debilitados presupuestos universitarios que por falta de financiamiento y por la tendencia a la privatización de algunas áreas, sedimentaron en el proceder de aquellas autoridades.

La primera gestión se inicia con el Banco Credicoop (Anexo: Gestiones ante la entidad) que luego de una entrevista con el gerente del mismo, deriva el contacto a la Fundación de la entidad crediticia. Pedidos del mismo tenor con notas y entrevistas se concretan con los propietarios de los diarios locales Crónica y El Patagónico, con los responsables de Empresur, una tarjeta de crédito local, y con la Fundación OSDE. En el caso de esta última y como parte de las conversaciones entabladas, se organiza en la FHyCS como una actividad de extensión de la Maestría, una charla con Luis Alberto Quevedo, sociólogo de FLACSO, que llega a la ciudad invitado por la Fundación para una actividad promovida por la misma. En ese momento Quevedo propuso la temática "La política y los medios en la Argentina de hoy". Es el mes de octubre del 2004 y el ambiente en la Universidad está enrarecido, a la conferencia asisten pocas personas.

El escenario es complejo y dificultoso y no solamente para el desarrollo de esta Maestría sino en la Universidad toda. Se atraviesa la tercera gestión (1995/2005) tanto de la Decana Norma Fuentes en la FHySC como del Rector Hugo Bersán en la UNPSJB. Pesa sobre la gestión del Rector una denuncia penal, realizada en el año 2001 por él, en ese entonces, auditor contador 
Carlos Padín, por contratar fraudulentamente cuatro obras por más de seis millones de pesos.

Se inicia el año 2005, un año electoral en la Universidad y en la Facultad, "el secretario de Posgrado, José Luis Nieto se va a la secretaría Académica del Rectorado, entonces era poco el tiempo que le podía dedicar dejan a Silvia Martínez que era la persona que trabajaba, porque se había ido Paulina Uviña, con Rosalía en el Vice-decanato en la parte de investigación, se separa investigación de posgrado, pero Silvia se queda más abocada a trabajar la parte administrativa de la investigación que le llevaba un montón de tiempo en posgrado" (Entrevista Segovia, 20/07/2011).

En la misma entrevista Segovia sostiene que luego del cargo que toma Nieto en Rectorado ella asume la responsabilidad de integrar Posgrado y Extensión en una sola Secretaría, "José Luis [Nieto] no se podía dedicar y yo veía que faltaba pro-actividad en la Secretaría de Posgrado" y reconoce que "ya el último tiempo de la gestión, antes que se partiera el equipo de gestión, él ya casi no se ocupaba de los temas de la Facultad". Se vive una época donde el agotamiento de las gestiones y las compulsas políticas por el reacomodamiento provocan fuertes resistencias, que en el caso de los estudiantes derivó en una toma de la Universidad que se inició a principios de abril y se prolongó por más de un mes. Los alumnos acompañados en esta medida por algunos docentes y no docentes, solicitan entre otras demandas el aumento del presupuesto indexado a la inflación, subsidio al comedor universitario, becas para fotocopias y pago de otras adeudadas, apertura de los libros de servicios a terceros y la constitución de la Facultad de Derecho ${ }^{15}$. En este marco, el interés institucional por la Maestría se debilita, el último encuentro se concretó entre las autoridades de la secretaría de Extensión y Posgrado, la coordinación de la Maestría y los representantes de la Fundación del Banco Credicoop. En dicha oportunidad la Fundación se comprometió a otorgar dos pasajes aéreos con la contraprestación de una actividad por parte de la Maestría para los asociados de dicha entidad crediticia. La propuesta consistió en una charla del profesor Washington Uranga en su proyectado 
viaje para el mes de junio de ese año. Dicho compromiso no pudo hacerse efectivo porque el periodista y profesor es internado de urgencia y se suspenden tanto esas actividades como las clases programadas.

En todo el año se completan dos seminarios, el optativo de un solo viaje dictado por el profesor Schmucler en el mes de mayo, el del profesor Carlos Vallina entre abril y mayo, y la primera parte del taller de Tesis a cargo de Silvia Delfino en agosto, en pleno paro docente. Esta medida de fuerza extiende por más de veinte días a raíz de fuertes reclamos salariales con un gran nivel de adhesión.

El posgrado comienza a 'des-institucionalizarse' si se utiliza el término con el que las autoridades locales lo calificaron, no voluntariamente sino como parte de la supresión de los soportes administrativos y financieros básicos con los que se habían comprometido ambas universidades. Así es como esas carencias, concentran gran parte de la energía que los maestrandos, restaban a su actividad docente, práctica profesional y dedicación familiar.

A estas dificultades se suma que los alumnos se atrasan en el pago de las cuotas, como es necesario adquirir los pasajes con antelación y la coordinación de esta sede asume el compromiso frente a los proveedores y docentes, convoca a una reunión de maestrandos para analizar la situación. En esa oportunidad todos coinciden en la necesidad de solicitar el otorgamiento de becas a la Facultad, ante la compleja situación que atraviesan. La mayoría de los alumnos, docentes de la carrera de Comunicación Social, consideraban un derecho reclamar por ayuda para sostener el posgrado. Con nota elevada a la Decana, se cursa el pedido mencionado (Anexo: Expediente PLANGESCO, FHyCS 2635/03. Nota 7531/05, Folio 45) y en esa reunión se lee una carta recibida por mail del profesor Giordano, en la que alienta la prosecución del posgrado y ratifica los compromisos asumidos por la Facultad de Periodismo de La Plata (Anexo Dificultades: Carta a Plangesco Comodoro, 19/05/05).

La Resolución del Consejo Académico 190/05 de la 3ra Sesión Ordinaria del 5/07/2005, firmada por la decana Norma Fuentes, adjudica media beca a cada maestrando (la suma de 6500 pesos en total) y solicita a las secretarías de Posgrado y Extensión iniciar gestiones para la obtención de fondos que 
permitan completar lo solicitado (Anexo: Resolución 190/05 en Expediente PLANGESCO, 2635/03 FHCS, folios 39-40). En el Anexo (Dificultades) se puede consultar la reproducción de la grabación de la sesión del Consejo en la que se trató el tema, es importante tener en cuenta que algunos consejeros mencionan el hecho de que la Facultad ha ayudado a docentes con becas, además de mantenerles el cargo mientras cursaban sus posgrados fuera de la ciudad. También se discute la decisión en función del estado de quebranto en el que se encuentra la institución en ese momento, aunque reconocen que se trata de 13 docentes y que quedaría trunco el proyecto. Finalmente deciden otorgar la mitad de lo solicitado y le encomiendan a las autoridades de las secretarías involucradas que presenten opciones de financiamiento en la próxima reunión del Consejo.

Ese compromiso nunca se efectiviza, pese a las reiteradas notas y reuniones mantenidas por esta coordinadora con los funcionarios salientes. El 31 de octubre de 2005 asumen las nuevas autoridades: el profesor Eduardo Bibiloni como Decano de la Facultad y el Lic. En Zoología Héctor Zaixso como secretario de Investigación y Desarrollo, a quienes se les solicita el cumplimiento de aquel compromiso. La respuesta llega de a través de la nota 1401/05 con fecha del 17 de noviembre de ese año, firmada por el decano Eduardo Bibiloni, por la cual se informa que no se efectuará el pago de la resolución 190 hasta tanto no se presente un informe sobre el estado de la Maestría. Es importante destacar que al momento de elevar la solicitud de becas al Consejo Académico, se adjunta un informe con el estado de situación del posgrado.

Evidentemente en ese documento no se da respuesta a las demandas de las autoridades que ponen el acento en la falta de un anclaje académico del proyecto. "Sin la fortaleza académica de algunos que de este lado puedan sostener, queda como a la deriva...Creo que la institución tiene que poder tener ahí una contraparte interesante de discusión." (Entrevista Coicaud, 1/11/2011), así lo expresa la actual Decana, en ese momento como consejera académica de la Facultad. Aunque reconoce que "hubo ahí un momento de crisis institucional a partir del 2004 y 2005 que nadie sabía hacia dónde iba, esto se vivió y fue volver bastante hacia atrás". En consecuencia admitió esa 
difícil situación por la que atravesaron los maestrandos haciéndose cargo de la autogestión del posgrado cuando, deberían haber sido sólo alumnos de una maestría.

A esta altura del relato es importante articular la demanda de un anclaje académico al colectivo de PLANGESCO en Comodoro, con el reconocimiento a la falta de todos los otros aspectos que sostienen el desarrollo de un proyecto de esta naturaleza.

\section{5*}

4. Taller de Tesis I, profesor Carlos Giordano, segundo encuentro 04/febrero 2005

5. Seminario Optativo. Comunicación y Cultura. Profesor Héctor Schmucler. 12, 13 y 14 Mayo

6. Taller Multimedial I y II, Profesor Carlos Vallina. Primer encuentro abril, segundo: mayo

7. Taller de Tesis II, Profesora Silvia Delfino. Primer encuentro agosto

*Seminarios y talleres desarrollados durante este ciclo.

\subsubsection{Jornada sobre Políticas Sociales}

En marzo de 2006 se concreta el postergado Taller de Planificación y Gestión I, que por la enfermedad del profesor Washington Uranga se suspende el año anterior. En el segundo encuentro en el mes de mayo, el profesor Uranga completa la asignatura, y como contraprestación a la Fundación del Banco Credicoop que colaboró con sus pasajes para la Maestría, brinda un asesoramiento a la Comisión de Socios de dicha entidad crediticia en reemplazo de la charla abierta organizada el año anterior.

Washington Uranga se encuentra en ese momento a cargo de la dirección de Fortalecimiento de Espacios Asociativos del Ministerio de Desarrollo Social de la Nación y se ofrece a gestionar la llegada a nuestra sede del profesor Daniel Arroyo, en su doble carácter de profesor y Vice-Ministro nacional. La 
propuesta del profesor Uranga consiste en organizar una Jornada sobre Políticas Sociales que acerque a Daniel Arroyo a Comodoro y pueda en ese marco, dar el seminario de Estado y Procesos Sociales, a los alumnos de PLANGESCO.

Desde la coordinación se realizan las gestiones necesarias para organizar conjuntamente con el Ministerio de Desarrollo Social las jornadas denominadas: "Otras Iniciativas, más actores: políticas sociales para el desarrollo". El evento planificado para el 17 y 18 de agosto de 2006 contó con el auspicio y corresponsabilidad del Gobierno Provincial y de la Municipalidad local. Con el fin de organizar la logística quince días antes viajan a esta ciudad representantes técnicos del Ministerio que mantienen reuniones con miembros de la FHyCS y esta coordinación. Se encontraba frente al decanato el profesor Eduardo Bibiloni y en el Rectorado el contador Jorge Gil.

Además de la participación de los gobiernos provincial y municipal, se diseñan mesas de trabajo con representantes de empresas, cooperativas y académicos de esta Facultad. Finalmente se concreta el 18 de agosto durante esa sola jornada, sobre la base de una metodología combinada de conferencias y mesas de trabajo, el Ministerio de Desarrollo Social aporta sus propios expositores, la Universidad sus académicos y la coordinación de la Maestría la logística del encuentro e invitación a los representantes de las organizaciones de la comunidad.

En la conferencia inaugural el Lic. Daniel Arroyo, viceministro de Desarrollo Social de la Nación, aborda la temática en torno al aporte que los nuevos diseños de políticas sociales hacen al desarrollo. Washington Uranga, titular del área de Espacios Asociativos del Ministerio expone acerca de la incidencia de las estrategias de comunicación en la construcción de políticas públicas y hacen lo propio desde su especialidad, Adriana Clemente, directora del Área Pobreza y Desarrollo Social, Instituto Internacional de Medio Ambiente y Desarrollo - América Latina IIED-AL- y José Bereciartúa, Secretario de Hacienda de la Confederación Argentina de la Mediana Empresa (CAME).

Entre los referentes provinciales tanto el Ministro de la Producción, Martín Buzzi como el de Familia y Promoción Social, Adrián López, exponen sobre las 
políticas sociales en la provincia del Chubut. Las mesas con los invitados de la comunidad se conforman con Miguel Angel Tunik, titular del Servicio Municipal de Empleo de la Municipalidad de Comodoro Rivadavia, Iris Pacheco, docente de la Carrera de Ciencia Política y Tecnicatura en Turismo, Fabricio Feliceti, docente de la Carrera Ciencia Política, Gabriela Derbes, empresaria, Antonio Frey de la Comisión Socios del Banco Credicoop, Jorge Corcoy, Jefe de RR.PP y relaciones institucionales y Laura Cambareri, coordinadora en Comunicación, ambos de la SCPL -Sociedad Cooperativa Popular Limitada- (Anexo: Jornada: folletería de promoción y notas de organización).

Una vez finalizada la jornada, el profesor Arroyo dicta la primera parte del Seminario Estado y Procesos Sociales, cuyo segundo encuentro recién se concretaría dos años más tarde con el profesor Jorge Tirenni. En esa oportunidad el profesor Washington Uranga también establece los contactos necesarios para que llegue a esta ciudad María Cristina Mata, con quien resulta complicado establecer contacto.

Esta actividad y ese pedido de intermediación, dan cuenta de la orfandad en la que se encuentra en ese momento, el proyecto PLANGESCO en Comodoro, ahora también desde el punto de vista de la responsabilidad de la FPyCS de la UNLP en la gestión de los seminarios. La necesidad de organizar una actividad de tamaña magnitud, para que un docente de la propia Maestría brinde una clase a los alumnos de esta cohorte, no parecía desmedido en ese marco. En perspectiva, si bien tuvo el impacto de colocar a la PLANGESCO Comodoro como protagonista de un evento que convocaba a representantes de los gobiernos nacional y provincial en el ámbito de la Universidad y el beneficio de contar con la experiencia de un funcionario de esa jerarquía en el seminario, no sólo no era la función de un posgrado sino tampoco, la de una gestión solitaria que ya llevaba tres años de supervivencia.

El ministro provincial de la Producción, Martín Buzzi, en ese momento como parte del gobierno de Das Neves, el que ya comienza a evidenciar su diferencia con el gobierno nacional de Néstor Kirchner, se presenta en la Jornada luego de asistir, también como invitado, a la asamblea del Consejo Superior de la Universidad en la que se debatía en el nuevo estatuto. 
Taller de Tesis II, profesora Silvia Delfino febrero segunda parte

8. Planificación y Gestión I, profesor Washington Uranga, primera parte: marzo y segundo encuentro junio.

9. Estado y Procesos Sociales, profesor Daniel Arroyo. Primera parte, agosto

10. Comunicación, Modelos y Perspectivas para su análisis, profesora María Cristina Mata, primera parte octubre.

*Seminarios y talleres desarrollados durante este ciclo.

\subsubsection{La Maestría como espacio de proyección político-académico}

\section{Encuentro, cursos y especialización}

A principios de noviembre de 2005, la coordinación de PLANGESCO colabora con Diego Pérez, alumno de la Maestría, quien a su vez se encuentra al frente del área de Comunicación de la Fundación Patagonia Natural de Puerto Madryn, en la promoción del II Encuentro de Periodistas Patagónicos. Esta actividad organizada por dicha Fundación convoca a periodistas de toda la región y cuenta con la coordinación de Daniel Santoro, especialista en investigación del diario Clarín. A instancias de las gestiones realizadas por la Maestría, este evento se desarrolla en la sede Comodoro de la UNPSJB los días 4 y 5 de noviembre ${ }^{16}$.

A raíz del interés de Diego Pérez en los temas ambientales y como miembro de la Fundación Patagonia Natural el marco del proyecto PNUD-GEF ARG/02/ G31, desarrolla su proyecto de tesis de PLANGESCO en torno a los procesos comunicacionales de los conflictos ambientales y la formación de una red de periodistas que diera cuenta del vínculo comunicación/ambiente en la actualidad regional. Su directora por ese entonces, la profesora Nancy Díaz Larrañaga, secretaria en ese momento, de Investigación y Posgrado de la FPyCS de la UNLP, viaja a Comodoro Rivadavia al acto de apertura del encuentro y para avanzar con la Fundación Patagonia Natural en un proyecto de posgrado sobre Comunicación y Ambiente. En oportunidad de su visita y por intermedio de la coordinación de la Maestría, se reúne con el decano 
electo Eduardo Bibiloni para interesarlo en que la FHyCS sea sede para el desarrollo del proyecto, basado en la tesis del maestrando Diego Pérez.

Un mes después la Facultad de Periodismo de la Plata, con la decisión de su decano, Alejandro Verano, presenta al Consejo Académico la creación de la Especialización en Comunicación y Medio Ambiente y designa como director interino al Lic. Edmundo Ferreti. De esa gestión no participa de ningún modo el alumno de PLANGESCO que desarrolló el proyecto como base para su propia tesis, ese hecho modificó la perspectiva no sólo del alumno sino de esta tesista que encontró en esa actitud una diferencia con la gestión de la FPyCS de ese momento.

Un año más tarde Diego Pérez deja su cargo de coordinador del área comunicación de Fundación Patagonia Natural en discrepancias con la orientación del proyecto, pero quedan establecidos los acuerdos institucionales para el avance de la Especialización.

En junio del año 2007, como última gestión luego de este desenlace, la coordinación de PLANGESCO Comodoro presenta a la directora del Departamento de Comunicación Social, una nota donde reseña las gestiones llevadas a cabo para promover el dictado de la Especialización en la Facultad local y da cuenta del origen de dicha iniciativa. Menciona como antecedentes el taller de Periodismo de Investigación del año 2005 y el taller de Ética Periodística, a cargo de Javier Darío Restrepo de la Universidad Javeriana, realizado en noviembre de 2006. Este último también promovido por Diego Pérez como integrante de la Fundación y de FOPEA (Foro de Periodistas de la Argentina) y con la coordinación de PLANGESCO Comodoro. Se realizó en la UNPSJB y convocó a numerosos periodistas, docentes y alumnos de la casa.

El Decano Eduardo Bibiloni en respuesta a la solicitud de la coordinadora PLANGESCO Comodoro respecto de la necesidad de suscribir los convenios pertinentes para iniciar la especialización en el 2do cuatrimestre, envía la nota 454/07 a su nombre para dar su respaldo a "la posibilidad de avanzar en un acuerdo con la Fundación Patagonia Natural y la UNLP a fin de participar en la implantación del Posgrado de Especialización en Comunicación y Ambiente". 
En sendos avisos y afiches publicitarios se difunde la apertura de la cursada en la sede Comodoro el 24 agosto de 2007, de su desarrollo pueden dar cuenta las autoridades de las tres instituciones involucradas. PLANGESCO Comodoro no tuvo más participación en este proceso, eran tiempos de consolidar el propio, ya demasiado postergado por innumerables circunstancias que se continúan reconstruyendo en este documento (Anexo: Especialización: notas de gestión, aviso publicitario y nota de prensa).

\section{7*}

Comunicación, Modelos y Perspectivas para su análisis, profesora María Cristina Mata, segunda parte febrero.

11. Economía y Administración, profesor Eduardo Alegre Gálvez, primera parte junio y segunda parte: septiembre.

12. Procesos Políticos y Medios de Comunicación en Argentina, profesor Guillermo Mastrini, julio (único encuentro)

13. Planificación y Gestión de la Comunicación II, profesora Claudia Villamayor, Primer encuentro: 14 y 15 de diciembre de 2007 -

*Seminarios y talleres desarrollados durante este ciclo.

\subsubsection{Proyecto de Especialización en Divulgación Científica}

En diciembre de 2007 asume la presidencia Cristina Fernández de Kirchner, la primera mujer elegida para el cargo en nuestro país y la segunda en ejercerlo. Continúa con el autodenominado Modelo Nacional y Popular que se inicia con el gobierno de su esposo Néstor Kirchner y que en materia universitaria, significó aumento del presupuesto, una creciente política de becas y programas, y una importante inversión en infraestructura. La creación del Ministerio de Ciencia y Tecnología como uno de los primeros anuncios de la Presidenta representa un aliciente para el sector que recibe una señal de interés en esta política que coloca al conocimiento como un factor estratégico para el desarrollo.

Atravesados sus primeros meses de gestión por el conflicto con el campo ${ }^{17}$, esas secuelas y la crisis mundial postergaron en materia universitaria la 
anunciada revisión de la LES. De acuerdo a Chiroleu y Marquina (Chiroleu, Marquina y Rinesi ed., 2012: 24) en el Congreso había 10 proyectos en Diputados y otros 2 en Senadores y se esperaba que al iniciar el período de sesiones del 2009 el oficialismo presente el propio pero, en el discurso inaugural de sesiones ordinarias del Congreso la Presidenta no menciona el tema universitario. Es el año en el que oficialismo pierde las elecciones legislativas pero también el de la sanción de la Ley de Servicios de Comunicación Audiovisual y del programa de Asignación Universal por Hijo que está destinado a abordar la promoción de un sector postergado de la población y su relación con la educación.

Mientras tanto en Chubut, el gobernador Mario Das Neves, enemistado con Néstor Kirchner, se aleja del gobierno nacional y lanza su candidatura a presidente para las elecciones del 2011. "El lanzamiento de mi candidatura es una puesta en escena para debatir lo que no se discute: la pobreza y la educación como pilares fundamentales" (Mario Das Neves, diario La Nación, 28/10/2009) sostiene mientras en la provincia los docentes son reprimidos bajo su mandato por reclamar la apertura de la paritarias.

En este contexto PLANGESCO Comodoro continúa en su intento de posicionarse desde varios frentes. A principios del año 2008, el maestrando Daniel Pichl, a cargo de la Dirección de Prensa de la UNPSJB, presenta la inquietud del Rector en ese entonces contador Jorge Gil de generar una Especialización en Divulgación Científica. Ya había mantenido comunicación con la Universidad de Morón para traer la Diplomatura con la que ellos contaban, pero la oportunidad de dar una respuesta desde la Carrera de Comunicación la brindan los contactos establecidos a través de PLANGESCO. Desde esta coordinación se mantienen reuniones con Silvia León, en ese momento Secretaria General del Rectorado, encargada de articular esa idea con las posibilidades que PLANGESCO ofrece a través de la Facultad de Ciencias Sociales de la UBA, representada en el posgrado por el profesor Washington Uranga. Tanto la Maestría en Periodismo como la Especialización en Planificación y Gestión del Periodismo, de las cuales Uranga es profesor y 
miembro de la comisión académica, brindan potencialmente los recursos necesarios para constituir un posgrado en esa dirección. Junto a Daniel Pichl, en base a los programas con los que se cuenta y en articulación con la oferta académica de estos posgrados de la UBA, se confecciona una propuesta de Plan de Estudios de una Especialidad en Periodismo y Divulgación. Las gestiones avanzan con la mediación del profesor Uranga quien propicia una reunión de la Coordinadora de PLANGESCO con el Dr. Pablo Alabarces, Secretario de Posgrado y la subsecretaria Dra. Silvia Faraone en la sede de la Facultad de Ciencias Sociales en Buenos Aires. De ese encuentro quedan formalizados los contactos para que se avance en los convenios necesarios para su implementación. Un mes más tarde el Rector Jorge Gil solicita la organización de un seminario con tema específico de la especialidad que dé cuenta del número de interesados en la misma.

En el mes de septiembre de ese año 2008, la coordinadora de PLANGESCO toma una licencia por enfermedad y esas gestiones quedan en manos del Rectorado.

La mínima estructura con la que cuenta el posgrado le impide proyectar más allá de la voluntad y posibilidad de quien tiene la responsabilidad de la función, en este caso sólo la coordinadora local.

\subsubsection{Una coordinación atravesada por tres gestiones}

Como se menciona bajo el subtítulo "Rumbo a la Autogestión" el decano Eduardo Bibiloni, ni bien asume y ante el reclamo de esta coordinación para que la Facultad efectivice las medias becas aprobadas por el Consejo Académico en julio de 2005, solicita un informe de gestión. Informe que se había entregado al momento de solicitar el auxilio económico que colaborara con el fortalecimiento del posgrado.

El grupo de alumnos incluidos en el pedido de becas está compuesto en ese momento, en su carácter de docentes de la FHyCS: Mónica Baeza, Osvaldo Bonino, Gabriel Carrizo, Adrián Duplatt, Beatríz Escudero, Marcelo Hernández, Fernando Krebs, Vanina Perera, Luis Sandoval, Nancy Sáez, Kira Rakela, Martha Soto y Miguel Ángel Becerra, completan la cohorte dos egresadas de Comunicación Social: Cecilia Farías de Esquel y Celina Salvatierra, los 
maestrandos de Trelew: María Dilys Vales y Nidia Do Paso y Diego Pérez de Puerto Madryn.

Es importante recordar que durante el segundo cuatrimestre de ese año (2005) no hubo responsable en el área dentro de la Facultad, el titular pasa al Rectorado y la administrativa se encuentra con licencia por enfermedad. Ante esta situación el colectivo de maestrandos decide la autogestión de su funcionamiento al movilizarse tras la necesidad de concretar los seminarios faltantes. El momento de suscribir los acuerdos son los encuentros para los seminarios, la cadena de mails y todas las comunicaciones necesarias para consensuar lo relativo al interés del grupo. Iniciado el próximo ciclo lectivo (2006) se eleva nuevamente al Consejo Académico el resumen del estado del posgrado con el fin de reclamar por las medias becas aprobadas por la gestión anterior, la supervivencia del posgrado exigía urgentes definiciones (Anexo: Beca, Dedicación, Fondos Semilla).

Si bien en el año 2004 la resolución que designa a la coordinadora local señala que dicha función se prorrogaría hasta la finalización de la cohorte, en los hechos cada año a partir de esa fecha, son necesarias gestiones para la renovación de ese compromiso. La extensión de los plazos en la concreción de los seminarios respondía a innumerables factores, que hasta de condiciones extremas dependen, por ejemplo el Seminario Paradigmas Sociales y Matrices Culturales de Alcira Argumedo previsto para el 2 de junio de 2008 es postergado porque se suspenden los vuelos a causa de las cenizas del volcán Chaitén. Durante ese cuatrimestre se mantienen esas condiciones que impiden realizar los seminarios previstos, además del de Argumedo, el de Planificación y Gestión II y el de Estado y Procesos Sociales, eso motiva una nota a la Secretaria Académica; Patricia Pichl, en la que se le solicita la extensión de la dedicación y se le presenta el cronograma de los seminarios que se dictarían en ese ciclo.

La última designación para la coordinación es requerida hasta julio de 2008 (Res. 034/07) con la expectativa de finalizar en ese período. Un fenómeno de la naturaleza como el que impide concretar los viajes no se puede prever, no obstante ni bien recuperado el tráfico aéreo se dictan dos seminarios en el mismo mes. El Taller de Planificación II como último encuentro y el Seminario 
a cargo de Alcira Argumedo que se abre a Extensión para posibilitar que otros docentes de la Facultad puedan cursarlo, al igual que en su momento se hizo con el del profesor Juan Samaja.

Por licencia de salud en el segundo cuatrimestre del 2008 no se cuenta con la presencia de la coordinadora, pero Luis Sandoval, compañero alumno de PLANGESCO, se ocupa de la logística del seminario de Jorge Tirenni que reemplazaba a Daniel Arroyo, aún con tareas de funcionario.

\section{8*}

Planificación y Gestión de la Comunicación II, profesora Claudia Villamayor. Segundo encuentro: 7 y 8 agosto

14. Paradigmas Sociales y Matrices Culturales, profesora Alcira Argumedo, único encuentro 26 al 29 de agosto

Estado y Procesos Sociales, profesor Jorge Tirenni, segundo encuentro 19 y 20 septiembre

*Seminarios y talleres desarrollados durante este ciclo.

En febrero de 2009 se solicita nuevamente la dedicación simple al cargo de la coordinadora y al mes siguiente, se presenta también un aval de la directora de la Maestría, Cecilia Ceraso. La resistencia a concederla era tanto por el cuestionamiento a la dilación de los plazos cuanto a la postura imperante de que "la renovación del cargo del coordinador terminaba siendo administrativa y burocrática, sin una discusión académica del proceso" (Entrevista Coicaud, 1/11/2011). Así lo expresa la actual decana quien resume la opinión del Consejo Directivo de la FHyCS de cual formaba parte en ese momento "cualquier proyecto de formación que uno embarque institucionalmente debe presentar esta doble faceta, no sólo tiene que tener la banca política sostenida en el tiempo, sino cierta fortaleza que haga a su implementación en términos académicos" (Entrevista Coicaud, 1/11/2011).

(Anexo: Beca, Dedicación y Fondos Semilla: 15/10/04; 9/06/08; 6/02/09; 12/03/09 y 5/04/10).

En este reclamo apela a poner en escena los resultados parciales que la cursada iba expidiendo, dado que en varios tramos de la entrevista, la 
Decana alude por ejemplo, a ese valor agregado que implicaría la presencia de nuestros maestrandos en la FPyCS de La Plata o la presentación de artículos de los seminarios en alguna publicación. No obstante reconoce la importancia de que haya concluido el dictado de los seminarios porque admite que se atravesó un tiempo institucional no muy claro "donde el área de posgrado de nuestra Facultad no existió ni como política, ni aún en la persona que estaba designada que ni siquiera era del campo de las ciencias sociales, mucho menos iba a estar interesada por la comunicación social" (Entrevista Coicaud, 1/11/2011). Se refiere a la segunda gestión (Bibiloni 2005-2009) de las tres que comprendieron la consecución de PLANGESCO en la sede Comodoro, período en que, paradójicamente se cuestiona la falta de posicionamiento de PLANGESCO en la discusión política-académica de la Facultad. De hecho en ese lapso la Secretaría, antes de Planeamiento y Posgrado (2001-2005), pasa a denominarse de Investigación y Desarrollo, subsumiendo posgrado a la categoría de pro-secretaría.

También María Rosa Segovia, quien fuera parte del equipo de la primera gestión en el marco de la cual se gestó PLANGESCO destaca que "se convirtió en una secretaría de investigación y de servicios a terceros, que después termina finalmente Eduardo Bibiloni pidiéndole la renuncia -se refiere al Secretario de Investigación y Desarrollo Héctor Zaixso- cuando se entera que se llevaban adelante los servicios a terceros solamente de Gestión Ambiental y de Geografía" (Entrevista Segovia, 20/07/2011).

En este escenario y con fecha del 27 de abril de 2009 se da curso a la última designación de la coordinadora de PLANGESCO en Comodoro, que se extiende hasta el 29 de febrero de 2010 (Res. 84/09).

En el mes de abril, se desarrolla el Taller de Tesis III a cargo de Germán Retola que se encuentra en ese momento en el equipo de gestión del posgrado en la FPyCS y desde ese rol suscribe con los alumnos un compromiso mutuo para la entrega y corrección de trabajos hasta fin de ese año. Ese compromiso es respaldado con el trabajo operativo de la coordinación local en viajes periódicos a la ciudad de La Plata (mayo, julio y septiembre). En el último de estos encuentros en la FPyCS se realizan acuerdos con el profesor Carlos Giordano, quien se compromete con el 
seguimiento del proceso de tesis del conjunto de la cohorte de maestrandos. Como resultado de ello, se organiza una Jornada de Tesistas con su coordinación para el 27 y 28 de noviembre de ese año. En su mail a los alumnos el profesor Giordano expresaba:

"La idea es juntarnos con todos los que puedan y quieran en dos jornadas el 27 y 28 de noviembre próximos donde revisemos puntualmente cada proceso de tesis y veamos las cuestiones materiales concretas que las operativicen y permitan culminarla.

Para esto, la Facultad, a través de la Secretaría de Investigaciones y la Dirección de la Maestría, me financia el viaje y dispuso el acuerdo para que con la cátedra y los equipos de investigación que dirijo (Seminario Permanente de Tesis y diversos equipos enfocados en cuestiones epistemológicas, gnoseológicas y pedagógicas de los procesos de investigación y producción de conocimiento) desarrollemos este acompañamiento final" (9/10/09).

Esta comunicación se publica en un espacio virtual generado por el maestrando Diego Pérez donde además de archivar los programas de las asignaturas, materiales de las mismas y la relatoría del último taller, se constituye en un nuevo espacio de comunicación grupal ${ }^{18}$.

\section{9*}

15. Taller de Tesis III, Germán Retola, optativo, abril.

Jornadas de tesistas, profesor Carlos Giordano. 27/28 noviembre

*Seminarios y talleres desarrollados durante este ciclo.

\subsection{7 Última etapa: cuestionados e investigados}

En abril de 2010 en la provincia del Chubut comienzan las actividades de la Tecnicatura en Enfermería con la que se da por inaugurada la Universidad Provincial del Chubut. Iniciativa del Gobernador Mario Das Neves que tiene

18 http://grupopatagonia.pbworks.com/w/page/16296105/FrontPage 
fuerte resistencia en la comunidad de la Universidad Nacional, pero que tenazmente desarrolla como parte de su solitaria y ya lanzada campaña presidencial. "Posiblemente orientar el ingreso de dinero proveniente de la extensión de los contratos petroleros para el objetivo -por cierto loable- del desarrollo regional, y en especial de la potenciación de un espacio urbano rezagado de la actual explosión de crecimiento: Rawson". ${ }^{19}$ Una de las razones esgrimidas por Becerra Artieda, docente de la carrera de Comunicación Social de la UNPSJB, para interpretar el interés manifestado por el entonces gobernador en la adopción de esta medida. Este motivo se vincula con lo expuesto en el capítulo 1, acerca de la histórica puja entre las dos zonas de la provincia: sur -Comodoro Rivadavia y aledaños- y la región del VIRCH (Valle Inferior del Río Chubut) que se manifiesta en las decisiones de los gobernadores, históricamente representantes de esta última región.

En la UNPSJB a comienzos de 2010 asume como decana en la FHyCS, Claudia Coicaud, quien era Secretaria Académica al momento de suscribirse los convenios para la implementación de PLANGESCO. Mientras que en la FPyCS de la UNLP es en el mes de mayo de este mismo año, cuando designan a Florencia Saintout en el mismo cargo, quien se desempeñara en aquel momento como Secretaria Académica de la Maestría y que oficiara de representante del decano en los actos protocolares para la constitución del posgrado en esta sede.

De aquél momento Giordano recuerda cierta resistencia de la actual decana cuando estaba a cargo de la Secretaría Académica y festeja lo que considera un cambio de actitud en la actualidad "que supongo tiene que ver con un cambio de contexto, Argentina ha cambiado políticamente, ha cambiado contextualmente, la importancia que se le da a la comunicación es otra..." (Entrevista Giordano, 24/11/2011). Desde su posición la Decana sostiene que como Secretaria Académica en el momento del diálogo para iniciar el proyecto "fui una de las personas que más contribuí a formular los protocolos para la firma del convenio" (Entrevista Coicaud, 1/11/2011).

19 Becerra Artieda, Fernando. UNPSJB vs UPCH: un falso debate. Diario Crónica Comodoro Rivadavia, 25/02/10 
Pero es a comienzos del año 2010, ya en función la flamante Decana Lic. Claudia Coicaud, cuando ante la solicitud de esta coordinación para continuar en el cargo y acompañar el plan propuesto por el profesor Giordano de la FPyCS, encomienda a la Secretaría de Investigación y Posgrado investigue sobre aspectos de su desarrollo. En particular solicita 'información sobre el trayecto de formación académica de los matriculados', un análisis del expediente académico-administrativo e 'incorporar los actos resolutivos por los que se designaron a la profesora Silvia Brun como coordinadora y una vez analizados enviarlos para su tratamiento al Consejo Directivo de la Facultad' (Anexo: Beca, Dedicación, Fondos Semilla, Nota 282/2010).

Cuando la Decana solicita la documentación mencionada, desde la Secretaría Técnica de Posgrado, Silvia Martínez, quien se encontraba en esa misma función en el año 2005, responde con una nota de 8 puntos en los que detalla (Anexo: Expediente PLANGESCO 2635/03 FHCS. Nota, folio 64) el proceso del que fue partícipe hasta el uso de su licencia, aunque ella sostiene que fue hasta la finalización de aquella gestión política (2005). En dicha nota expresa que pese a la designación de la coordinadora académica "el manejo de la Maestría pasaba fundamentalmente por la Secretaría", pero luego manifiesta que en la dependencia "obra documentación anexa de los gastos de los años 2004 y 2005, fichas de preinscripción y legajos de los maestrandos" que no constan en el expediente que actualmente se halla en la Secretaría de Posgrado. Dice que es de suponer que ya debiera haber culminado con el proceso de formación y sugiere solicitar la explicitación de tal situación a la coordinadora académica. El tono de la nota induce a la sembrar sospechas sobre la actuación de la coordinadora y sobre los destinos de este posgrado que se dio en Ilamarlo: 'desinstitucionalizado'. Este calificativo no quedó plasmado en ningún documento pero se infería de los comentarios y de la insistencia de varios actores en cuestionar la legitimidad del mismo.

Al poco tiempo de este episodio, Carlos Giordano viaja a Comodoro Rivadavia para una actividad académica no vinculada a la Maestría y mantiene junto a la coordinadora una reunión con la Decana Claudia Coicaud, y de la entrevista con el profesor se deduce que no fue del resultado esperado en términos de la importancia que para el colectivo de alumnos tiene la Maestría. No 
obstante en ese año 2010, dos fuertes acciones colaboran para continuar sosteniendo al grupo de maestrandos, desde lo institucional una completa respuesta a ese pedido de informes sobre el estado del posgrado y la organización de un taller de tesistas con la gestión del Programa Fondos Semilla, solicitados a la Secretaría de Ciencia y Técnica de la Universidad (Anexo: Beca, Dedicación y Fondos Semilla). Este último persigue la finalidad de apoyar la prosecución de las tesis y mantener la cohesión del grupo de alumnos del posgrado. Los recursos provenientes de ese programa solventan los viáticos y el profesor Carlos Giordano no percibe honorarios por la actividad.

2010*

30 abril : Reunión del profesor Giordano con la Decana Lic. Claudia Coicaud

10 y 11 de Diciembre: Taller de Tesistas, coordinador por Carlos Giordano.

*Actividades desarrolladas en este ciclo.

\subsubsection{Inicio de la etapa de consolidación}

El 27 de octubre de 2010, el día en que se realiza el Censo Nacional en el país, se anuncia el repentino fallecimiento del ex presidente y en ese momento diputado nacional, Néstor Kirchner. La población del país asiste consternada a las imágenes de su sepelio, su esposa y presidenta Cristina Fernández recibe un fuerte respaldo anímico en ese momento y en las urnas al año siguiente, cuando es reelegida como presidenta con más del $54 \%$ de los votos. En la provincia, Martín Buzzi llega a gobernador por el Modelo Chubut -Dasnevismo- en pugna con el Frente para la Victoria representado por Eliceche. Ni bien asumido Buzzi se alinea con el gobierno nacional y en las vueltas políticas, los integrantes de la fórmula derrotada pasan a formar parte del gabinete ministerial.

En ese escenario, entrado el año 2011 se inician nuevamente las gestiones para conseguir recursos que permitieran desarrollar el plan de acción propuesto por el profesor Giordano, se presenta una nueva solicitud al 
programa de Fondos Semilla, pero en esta oportunidad es denegado. La actual secretaria de Investigación y Posgrado, Graciela Iturrióz, solicita a la coordinación ad hoc de PLANGESCO que la petición se haga a través de la Facultad y no en forma directa a la Secretaría de Ciencia y Técnica del Rectorado como el año anterior, informa que los criterios aplicados en esta oportunidad para la distribución de dichos fondos pasan por priorizar las jornadas y seminarios de posgrado y/o extensión.

Ante la imposibilidad de concretar un encuentro en esta sede, se organizan conferencias por skype con el mismo profesor Carlos Giordano. En tres oportunidades durante los meses de agosto y septiembre se habilitan estos espacios virtuales para evacuar dudas acerca de las respectivas tesis, independientemente de los procesos que cada maestrando desarrolla con su director/a. Diego Pérez, de Puerto Madryn, María Dilys Vales y Nidia Do Paso de Trelew, Celina Salvatierra desde México, Cecilia Farías desde Esquel, Nancy Sáez y Silvia Brun en Comodoro y Carlos Giordano desde La Plata se conectan a la videoconferencia grupal. Este espacio no sólo fue productivo en el proceso de cada uno de los participantes por su diálogo con el profesor, sino en especial para el necesario aliento, que en esta etapa de mayor soledad de redacción de la tesis, significa la reunión con los compañeros de cursada.

Cierto es que la graduación de Luis Sandoval -16//05/11-, estimula las expectativas acerca de las condiciones de posibilidad sobre el necesario cierre del proceso que cada uno debe dar. La expectativa del resto de los maestrandos es continuar ese camino, pese a las marcas de ese atravesamiento institucional o mejor aún, motivados por la necesidad de superación de las mismas.

En octubre del año siguiente, en el 2012, Celina Salvatierra, defiende su tesis de PLANGESCO vía Skype desde México donde fue a hacer su experiencia de vida cuando terminó de cursar este posgrado.

\section{1*}

Solicitud de Fondos Semilla para nuevo encuentro de tesistas: no otorgado.

16/05 Luis Sandoval, primer alumno de PLANGESCO COMODORO que defiende su Tesis "Tecnología, comunicación, ciudadanía. Una aproximación a los usos políticos de las tecnologías de comunicación en Argentina" 
Skypes grupales con el profesor Carlos Giordano: 20/08 - 27/08 y 17/09

2012*

18/10 Celina Salvatierra defendió su tesis de PLANGESCO "Autonomía en la Ciudad de México, comunicación y gestión en el Centro Cultural La Pirámide 2010-2011" online desde México, vía Skype con el jurado

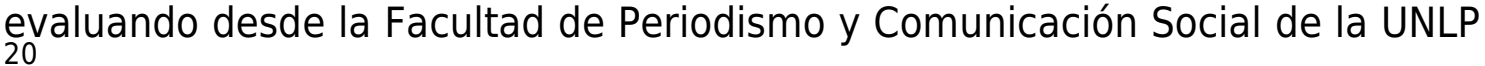

*Eventos y actividades de estos ciclos.

20 http://www.clasesdeperiodismo.com/2012/10/15/argentina-facultad-de-periodismopermite-sustentar-tesis-usando-skype/ 


\section{CAPITULO 4}

\section{EL IDEAL DE LA CONSTRUCCIÓN COLECTIVA}

4.1 PLANGESCO: En los albores, documento, constitución, características.

4.2 Un sentido común, posiblemente colectivo

“...Nosotros tenemos que saber que en esta revolución, en esta profunda transformación en el campo del conocimiento y en el campo de la democratización del conocimiento, hay un desplazamiento de la idea de calidad tecnocrática, meritocéntrica, hacia una nueva plataforma sostenida por la igualdad..."

Florencia Saintout 
En este capítulo es importante destacar que la tesis tiene como objetivo reflexionar acerca de las apropiaciones y representaciones que tuvo para la cohorte de alumnos, en su mayoría provenientes de la Licenciatura en Comunicación Social, la Maestría PLANGESCO de la Facultad de Periodismo y Comunicación Social de la Universidad Nacional de La Plata, que la cursaron en la sede Comodoro Rivadavia de la Universidad Nacional de la Patagonia San Juan Bosco en el período 2003-2010 y develar si el esfuerzo que la experiencia demandó a sus protagonistas significó un aporte al crecimiento del colectivo en el fortalecimiento de la carrera Licenciatura en Comunicación Social de la UNPSJB.

Que para tal propósito se realizan entrevistas a siete maestrandos de PLANGESCO Comodoro entre agosto de 2011 y marzo de 2012, sobre un muestra aleatoria que resultó de tres mujeres y cuatro hombres y por la adscripción institucional y ubicación geográfica: cuatro docentes de la FHyCS Comodoro-UNPSJB, una egresada de la carrera de Comunicación Social FHyCS UNPSJB, una egresada de la Tecnicatura en RRPP FHyCS Trelew UNPSJB y un alumno admitido por formación equivalente de Puerto Madryn. Con el mismo procedimiento metodológico se desarrollaron las correspondientes a las autoridades sobre un total de ocho entrevistas, dos a representantes de la UNLP, cinco de la UNPSJB, una al coordinador de PLANGESCO Jujuy y al actual co-director del posgrado por intermedio de una fuente secundaria.

\subsection{Descripción desde el tesista: coro de voces a partir de cuestionarios}

\subsubsection{Coro de tesistas}

En el caso de los alumnos, la entrevista mantiene un conjunto de preguntas que aluden a información biográfica-académica, de su práctica profesional y situación respecto del posgrado, en relación a su motivación, desarrollo (seminarios- proyecto de tesis), resultado de la experiencia y su opinión respecto del grupo y de las instituciones involucradas.

Las percepciones y representaciones de los maestrandos se contrastan luego con las de las autoridades y desde el encuadre socio histórico y a partir de la 
dimensión comunicacional, se analizan las condiciones y procesos dentro de las cuales se encuadraron las prácticas de los alumnos y sus discursos.

ALUMNOS PLANGESCO COMODORO

\begin{tabular}{|l|c|l|}
\hline Alumnos & $\begin{array}{l}\text { Fecha } \\
\text { entrevista }\end{array}$ & de \\
\hline Luis Sandoval & $27 / 08 / 2011$ & $\begin{array}{l}\text { Comodoro } \\
\text { Rivadavia }\end{array}$ \\
\hline Kira Rakela & $17 / 09 / 2011$ & $\begin{array}{l}\text { Comodoro } \\
\text { Rivadavia }\end{array}$ \\
\hline María Dilys Vales & $28 / 09 / 2011$ & Trelew \\
\hline Marcelo Hernández & $18 / 11 / 2011$ & $\begin{array}{l}\text { Comodoro } \\
\text { Rivadavia }\end{array}$ \\
\hline Daniel Pichl & $20 / 12 / 2011$ & $\begin{array}{l}\text { Comodoro } \\
\text { Rivadavia }\end{array}$ \\
\hline Celina Salvatierra & $29 / 12 / 2011$ & $\begin{array}{l}\text { Comodoro } \\
\text { Rivadavia }\end{array}$ \\
\hline Diego Pérez & $29 / 03 / 2012$ & Puerto Madryn \\
\hline
\end{tabular}

ALUMNA PLANGESCO LA PLATA

\begin{tabular}{|c|c|c|}
\hline Alumna & $\begin{array}{ll}\begin{array}{l}\text { Fecha } \\
\text { entrevista }\end{array} & \text { de } \\
\end{array}$ & Lugar \\
\hline Gabriela Chavez & 20/02/2012 & La Plata \\
\hline
\end{tabular}

AUTORIDADES FHyCS - UNPSJB

\begin{tabular}{|l|c|l|}
\hline Autoridades & $\begin{array}{l}\text { Fecha } \\
\text { entrevista }\end{array}$ & de \\
\hline María Rosa Segovia & $20 / 07 / 2011$ & $\begin{array}{l}\text { Comodoro } \\
\text { Rivadavia }\end{array}$ \\
\hline Claudia Coicaud & $01 / 11 / 2011$ & $\begin{array}{l}\text { Comodoro } \\
\text { Rivadavia }\end{array}$ \\
\hline Analía Pomés & $08 / 08 / 2012$ & $\begin{array}{l}\text { Comodoro } \\
\text { Rivadavia }\end{array}$ \\
\hline Graciela Iturrióz & $27 / 03 / 2013$ & $\begin{array}{l}\text { Comodoro } \\
\text { Rivadavia }\end{array}$ \\
\hline Elsa Bonini & $01 / 07 / 2013$ & $\begin{array}{l}\text { Comodoro } \\
\text { Rivadavia }\end{array}$ \\
\hline
\end{tabular}

\section{FPyCS- UNLP}

\begin{tabular}{|l|lr|l|}
\hline Autoridades & $\begin{array}{l}\text { Fecha } \\
\text { entrevista }\end{array} \quad$ de & Lugar \\
\hline
\end{tabular}




\begin{tabular}{|l|c|l|}
\hline Carlos Giordano & $24 / 11 / 2011$ & La Plata \\
\hline Marcelo Brunet & $14 / 06 / 2012$ & Jujuy \\
\hline Washington Uranga & $23 / 07 / 2012$ & La Plata \\
\hline Germán Retola* & $27 / 03 / 2013$ & La Plata \\
\hline
\end{tabular}

* Revista Difusiones (primer ejemplar junio de 2011)

\begin{tabular}{|c|c|}
\hline Estudiantes & Perfil \\
\hline $\begin{array}{l}\text { Luis Sandoval } \\
47 \text { años. Casado. } 3 \text { hijas } \\
\text { Vive en Rada Tilly } \\
\text { Licenciado en Comunicación Social } \\
\text { UNPSJB }\end{array}$ & $\begin{array}{l}\text { Trabaja desde que era estudiante de } \\
\text { comunicación en las dos materias de } \\
\text { las que ahora es titular (Teorías y } \\
\text { Modos de la Comunicación), aprobó } \\
\text { la PLANGESCO y actualmente cursa } \\
\text { el doctorado en la UNLP. Considera } \\
\text { ecléctica su carrera y cree que lo fue } \\
\text { para la mayoría de los de su } \\
\text { generación, al completarla con } \\
\text { trabajos afuera y con pocos maestros } \\
\text { y referentes en esta Universidad. Se } \\
\text { dedicó a trabajar en la Municipalidad } \\
\text { de Comodoro en un área vinculada a } \\
\text { la comunicación institucional y el } \\
\text { desarrollo local. Sólo en los últimos } \\
\text { tres años se cruzaron esta práctica } \\
\text { profesional con la académica en el } \\
\text { ámbito de las políticas públicas y las } \\
\text { TICs. } \\
\text { PLANGESCO se le presentó como una } \\
\text { instancia de crecimiento, aunque } \\
\text { frente a la única oferta, no tenía un } \\
\text { pleno convencimiento por la } \\
\text { temática. }\end{array}$ \\
\hline
\end{tabular}




\section{Kira Rakela}

63 años. Casada. 2 hijos

Vive en Comodoro Rivadavia

Licenciada en Comunicación Social UNPSJB
Cursó tanto la primaria como la secundaria en Punta Arenas (Chile) de donde es oriunda. Como era muy difícil hacer la reválida en nuestro país, ya en Comodoro Rivadavia, decidió rendir la primaria y cursar el secundario de adultos, esa fue la etapa que marcó el curso de su vida profesional. Ya tenía sus dos hijos cuando estudió Comunicación Social. Vino a la Argentina a inicios de los '70 pero recuerda con nostalgia las luchas estudiantiles por un mundo mejor, dice sentirse orgullosa de los estudiantes chilenos y su actual movimiento por la conciencia de una educación pública para todos.

Es docente en Problemática de la Comunicación y quiso hacer PLANGESCO porque era una cuenta pendiente y otra porque había tenido una mala experiencia en la Maestría anterior de Gestión de la Información, cursó todos los seminarios pero no pudo terminar la tesis. Se trataba de la base de datos de la Facultad, "hoy con los años de experiencia en la Comisión de Autoevaluación, considero que la 


\begin{tabular}{|c|c|}
\hline & tengo aprobada". \\
\hline $\begin{array}{l}\text { 3. María Dilys Vales } \\
\text { Vive en Trelew } \\
55 \text { años. Casada. } 3 \text { hijos. } 3 \text { nietas } \\
\text { Técnica Universitaria en RRPP } \\
\text { UNPSJB. Sede Trelew }\end{array}$ & $\begin{array}{l}\text { Terminó su secundaria en la escuela } \\
\text { comercial nocturna, tenía } 24 \text { años y } \\
\text { sus dos hijos más grandes. Al mismo } \\
\text { tiempo había hecho el profesorado } \\
\text { de inglés que le sirvió para dar clases } \\
\text { particulares hasta que su hijo mayor } \\
\text { se recibiera y se fuera estudiar. } \\
\text { Decidió hacer la Tecnicatura en } \\
\text { Relaciones Públicas en la sede Trelew } \\
\text { de la UNPSJB, como se quedó con } \\
\text { ganas de más, intentó en Ciencias } \\
\text { Políticas, como no le convenció se } \\
\text { contactó con la Universidad del SXXI } \\
\text { en Córdoba porque pretendía la } \\
\text { licenciatura. Llegó un momento en } \\
\text { que económicamente no lo pudo } \\
\text { solventar, desde la Facultad } \\
\text { organizan una unidad ejecutora para } \\
\text { trabajar en capacitaciones sobre } \\
\text { comunicación y optó por este } \\
\text { desarrollo. En ese marco se presentó } \\
\text { la Maestría PLANGESCO. }\end{array}$ \\
\hline $\begin{array}{l}\text { 4. Marcelo Hernández } \\
\text { Vive en Rada Tilly } \\
49 \text { años. Viudo. } 2 \text { hijos } \\
\text { Licenciado en Comunicación Social } \\
\text { UNPSJB }\end{array}$ & $\begin{array}{l}\text { Su carrera de comunicación está } \\
\text { atravesada por su trabajo en el } \\
\text { Banco Nación, donde trata de } \\
\text { incorporarla desde diferentes } \\
\text { proyectos, especialmente en el en } \\
\text { área de capacitaciones. Su interés } \\
\text { pasa por articular comunicación con }\end{array}$ \\
\hline
\end{tabular}




\begin{tabular}{|c|c|}
\hline & $\begin{array}{l}\text { la institución y la sociedad. La } \\
\text { docencia hoy es un espacio de } \\
\text { confluencia con la escuela desde el } \\
\text { Derecho a la Información y como } \\
\text { ayudante de Metodología de la } \\
\text { Investigación. } \\
\text { "En PLANGESCO vi la oportunidad de } \\
\text { crecer académicamente”, ante la } \\
\text { imposibilidad de viajar a Bs As para } \\
\text { perfeccionarse. }\end{array}$ \\
\hline $\begin{array}{l}\text { 5. Daniel Pichl } \\
\text { Vive en Comodoro Rivadavia } \\
44 \text { años. Casado. } 3 \text { hijos } \\
\text { Licenciado en Comunicación Social } \\
\text { UNPSJB }\end{array}$ & $\begin{array}{l}\text { Se recibió de técnico mecánico, luego } \\
\text { de su paso por la carrera de } \\
\text { ingeniería, decide que la } \\
\text { comunicación podía encauzar su } \\
\text { gusto por la escritura y la lectura. } \\
\text { Trabajaba de electricista mientras } \\
\text { estudiaba, hasta que ingresa como } \\
\text { no docente en la UNPSJB, cuando } \\
\text { finaliza la carrera pasa de Personal al } \\
\text { sector de Prensa y comienza como } \\
\text { auxiliar docente de profesores } \\
\text { viajeros de las cátedras de } \\
\text { Actualidad Informativa I y II. Cursa la } \\
\text { Maestría de Gestión Universitaria, no } \\
\text { termina la tesis. Cuando finaliza ese } \\
\text { posgrado empieza PLANGESCO. } \\
\text { “Llegué cansado” a este posgrado, } \\
\text { sostiene. }\end{array}$ \\
\hline $\begin{array}{l}\text { 6. Celina Salvatierra } \\
\text { Vive en Comodoro Rivadavia }\end{array}$ & $\begin{array}{l}\text { Termina el secundario e ingresa a } \\
\text { Comunicación, en el último año de la }\end{array}$ \\
\hline
\end{tabular}




\begin{tabular}{|c|c|}
\hline $\begin{array}{l}37 \text { años. Soltera } \\
\text { Licenciada en Comunicación Social } \\
\text { UNPSJB }\end{array}$ & $\begin{array}{l}\text { carrera comienza a trabajar en el } \\
\text { diario El Patagónico y se dedica diez } \\
\text { años al periodismo. Si bien siempre } \\
\text { le interesó la carrera académica, } \\
\text { intentó estudiar letras y abogacía, los } \\
\text { tiempos del diario se lo impidieron. } \\
\text { Pero su interés por la formación le } \\
\text { hizo estar atenta a la oportunidad y } \\
\text { finalmente empieza PLANGESCO. Se } \\
\text { fue a México con la idea de hacer su } \\
\text { tesis y algo de periodismo digital. }\end{array}$ \\
\hline $\begin{array}{l}\text { 7. Diego Pérez } \\
\text { Vive en Puerto Madryn } \\
53 \text { años. Divorciado. } 5 \text { hijas } \\
\text { Historia UBA incompleto }\end{array}$ & $\begin{array}{l}\text { Estudió la especialidad electrotécnica } \\
\text { en la secundaria, ingresó a la UNLP } \\
\text { para estudiar ingeniería aeronáutica, } \\
\text { luego motivado por su historia } \\
\text { familiar vinculada al periodismo y la } \\
\text { militancia política en el partido } \\
\text { comunista, se hace cargo de } \\
\text { publicaciones y de la tarea docente } \\
\text { dentro de la organización. Más tarde } \\
\text { en el periodismo en general, hasta } \\
\text { que en el año '91, una crisis de orden } \\
\text { ideológico- existencial lo lleva a } \\
\text { emigrar de Buenos Aires a Puerto } \\
\text { Madryn tratando de encontrar una } \\
\text { nueva forma de vivir. Después de } \\
\text { avanzar en la carrera de historia en } \\
\text { la UBA y tratando de comprender a } \\
\text { través de la lectura de los } \\
\text { posmodernistas el espíritu de la }\end{array}$ \\
\hline
\end{tabular}




\begin{tabular}{|l|l|}
\hline nueva época. Llegó a Puerto Madryn \\
con su hija mayor y la mamá de las \\
mellizas de quien se separó luego de \\
dos años en esa ciudad. \\
Trabajó en los medios y en un tiempo \\
consiguió un posicionamiento, luego \\
con las limitaciones del entorno \\
comienza a buscar alternativas y en \\
esa búsqueda aparece PLANGESCO. \\
Lo tienta antes que nada la \\
bibliografía, ya que el nombre -dice- \\
es una rara especie de galimatías.
\end{tabular}

Para plantear el proceso que atravesó el grupo de maestrandos en el decurso de los diez años de desarrollo es preciso utilizar categorías que ayuden a desentrañar aquello que aparece como título de esta tesis y está centrado en la necesidad de conocer si para sus integrantes PLANGESCO representó una oportunidad o la frustración de una posibilidad. En cada uno de los miembros del grupo que finalmente terminó de cursar los seminarios y en particular de los entrevistados, hay percepciones de lo que el proceso arrojó en la escala de lo individual, lo grupal y lo colectivo. Entendiendo a esta última dimensión como la que representa a las organizaciones que promovieron el lanzamiento del proyecto y a la institución educativa que atraviesa a cada una ellas.

\subsubsection{Lo individual: motivaciones para empezar}

Para Luis Sandoval, profesor de Teorías y Modos de la Comunicación, PLANGESCO se presenta como una instancia de crecimiento, aunque no tenía un pleno convencimiento por la temática, era la única oferta y no la pensaba desechar. Para Kira Rakela, también docente de la carrera de Comunicación, era una cuenta pendiente en gran parte porque había tenido una mala experiencia 
en la Maestría de Gestión de la Información. Una oferta de Posgrado que junto a la de Gestión Universitaria que cursó Daniel Pichl, otro profesor de Comunicación, trajo en ese momento Rectorado de la UNPSJB aprovechando los recursos del FOMEC. Cuando termina de cursar ese posgrado empieza PLANGESCO ante la necesidad de alcanzar la titulación. Marcelo Hernández, también ve en PLANGESCO la oportunidad de crecer académicamente ante la imposibilidad de viajar para perfeccionarse.

Para María Dilys Vales PLANGESCO coincide su necesidad de seguir estudiando con la inquietud de adquirir nuevos conocimientos para el trabajo, que sobre comunicación, había comenzado a desarrollar con la Unidad Ejecutora en capacitación de la Provincia del Chubut y desde allí se sumó Nidia Do Paso y comenzaron a viajar desde Trelew.

Mientras que Diego Pérez viene desde Puerto Madryn motivado por la búsqueda de nuevos horizontes, se había agotado su interés por el periodismo tal como se lo concebía allí. Celina Salvatierra empieza PLANGESCO, luego de trabajar diez años en periodismo gráfico y con deseos de acercarse a la investigación científica.

\subsubsection{Qué significó PLANGESCO}

Una instancia de crecimiento, desde la sistematización, la lectura de producción, "que capaz que uno las podía hacer de otra manera pero en concreto estuvieron forzadas por el marco institucional, que aunque fuera débil existía, de estar haciendo una maestría", sostiene Luis Sandoval quien pese a no estar convencido, ni de la planificación, ni de la perspectiva comunicacional, reconoce que en los últimos años logra consolidar un espacio de preocupaciones académicas más específicas y "la Maestría es parte de eso".

Kira Rakela sostuvo que se inscribió interesada en ampliar sus conocimientos en esta materia, sobre todo para fortalecer la cátedra de Problemática de la Comunicación que dicta en la carrera. $Y$ manifiesta que le sirve no sólo en el andamiaje teórico de los contextos con los que trabaja en la cátedra, sino en la profundización de sus reflexiones. 
María Dilys Vales comenta que volvería hacerla porque le resultó muy enriquecedora pero la desanimaron los inconvenientes para concretar la cursada, lo complejo de todo el proceso, la distancia "Muchas cosas, pero como podés ver no me desanimó".

Para Marcelo Hernández el desgaste del proceso desalentó su continuidad. Lo vencieron los materiales, las horas dedicadas al estudio, más su trabajo en el banco, la docencia, "y no conté que a los cuarenta y pico no iba a tener la fuerza que me motivó a iniciarla". Reconoce que nunca mermó su interés en la Maestría, sino en avanzar hacia la titulación, también cree que no se estaba tan lejos del conocimiento pero que esta experiencia le sirvió para ordenarlo, organizarlo y abrió una expectativa para encauzar "ese pensamiento que uno tiene de lo social".

Daniel Pichl se presenta en PLANGESCO, pero ya venía cansado y propone un reconocimiento de materias del otro posgrado, como no lo consigue retoma la cursada. Le interesa la gestión y la vincula con su trabajo de comunicación periodística en el área de Prensa de la Universidad, desde donde también trabaja el tema de la divulgación de la ciencia.

Mientras que Celina Salvatierra tenía claro que deseaba hacer la tesis afuera y dedicarse a alguna actividad vinculada con el periodismo digital. Terminó de cursar algunos seminarios que le faltaban en La Plata y se fue a México, "yo sentía que tenía que reivindicar lo que había visto en PLANGESCO" con la idea de que "la teoría tiene que estar trabajada en la calle".

Después de leer la gacetilla con la información de PLANGESCO y sobre todo motivado por la bibliografía Diego Pérez viaja a Comodoro. No tener un título le generaba mucha ansiedad pero la entrevista de admisión le da la confianza necesaria para encarar el proceso. $Y$ destaca que su balance es muy positivo, agradecido de ponerle "andamiaje a sus dudas", de sentirse en algún campo de debate compartido, de retomar lecturas de modo colectivo, discutir ideas y "reencontrarme con autores que de alguna manera yo había defenestrado desde una lectura más dogmática". 


\subsubsection{Desde lo individual}

Las motivaciones si bien estrictamente no coinciden, tienen un común denominador que es la necesidad de iniciar una formación de posgrado. Para algunos como una instancia de crecimiento o una oportunidad para reivindicar una mala experiencia anterior; la imperiosa necesidad de la titulación en otros; el fortalecimiento de un proyecto laboral, la búsqueda de nuevos horizontes o la ocasión para acercarse a la investigación académica.

Estas motivaciones provocaron diferentes modos de involucramiento en relación a su propio desarrollo y se traducen en los argumentos con los que cada uno sintetiza su paso por PLANGESCO. Luis Sandoval ya graduado al momento de concretar la entrevista, pondera la importancia del posgrado en su fortalecimiento académico y Kira Rakela ingresada con deseos de mejorar la cátedra que dicta en comunicación, reconoce que le ha dado profundidad teórica y reflexiva. Tanto Daniel Pichl como Marcelo Hernández, plantean la necesidad de alcanzar una postitulación pero ambos con una cursada irregular, Pichl retoma cuando no logra las equivalencias de las materias del posgrado anterior y Hernández abandona luego de cursar casi todos los seminarios, abatido por el desgaste del proceso, pero con la convicción de que le abre un horizonte para encauzar su pensamiento de lo social. Por su parte Celina Salvatierra con la idea de reivindicar PLANGESCO en una experiencia de comunicación alternativa en México -ya graduada al momento de redactar esta tesis- y Diego Pérez satisfecho de haberle dado andamiaje a sus dudas y de reencontrarse con autores que había leído desde una perspectiva más dogmática. María Dilys Vales en una línea más pragmática, encuentra lo que buscaba en términos del enriquecimiento que la Maestría le ofreció para fortalecer su trabajo de capacitaciones, pero desanimada por los inconvenientes que se presentaron para concretar la cursada.

\subsubsection{El Grupo}


Luis Sandoval cree "que ahí se armó finalmente un grupo humano muy rico y por un trayecto muy largo y también muy importante que yo creo que sería algo que no deberíamos perder". Aunque agrega que "incluso restringiéndolo al dato de que una parte importante de los que cursábamos éramos docentes de la carrera y siendo que la PLANGESCO nos obligaba a un ámbito de relación que sino no nos dábamos, tampoco lo aprovechamos cien por cien".

Kira Rakela sostiene que el grupo nunca actuó como grupo, "siempre fuimos entes individuales, no hubo un... "bueno sentémonos a leer", como pasa en otros grupos nosotros en la otra maestría nos sentábamos a leer y hacíamos tarea juntos, porque realmente actuábamos como grupo, esto fue muy individual". Sostuvo que nunca hubo intercambios y que "para mí como grupo no funcionó...contigo tuvimos algunas discusiones para hacer algo, trabajamos con el seminario de Saintout, Diego y las chicas de Rawson van y vienen, pero a excepción de ti y Luis no tengo más referencia, las otras son personas que como uno no se lleva ni se llevó tampoco".

Recordó el espacio Wiki en el entorno virtual como una instancia de intercambio, "pero quedó... a todos nos ha pasado lo mismo pero no sé por qué no pudimos destrabar eso, sacar esa cortina que nos impide ver al otro".

María Dilys Vales dice que "en realidad las relaciones que más fortalecí son las que teníamos acá, por la poca distancia y porque compartimos el trabajo, era con Nidia y con Diego.... Y después lo que nos sorprendió, como nosotros veníamos de otra carrera que nada que ver con comunicación, "que nuestros compañeros eran muy teóricos, para mí demasiado teóricos y como nosotros veníamos de la práctica nos preguntábamos por qué se embrollan tanto entre la práctica y la teoría, en la práctica no es así. Pero hoy que lo tengo que bajar a papel y a teoría me cuesta, me cuesta bajarlo al papel y ponerlo a teorizar".

Para Marcelo Hernández "el grupo tuvo cosas muy positivas, pero todos escondían algo a la larga, no fue muy explícito cada proyecto, me parecía que tenían miedo de compartirlo, salvo uno o dos casos, que desde el principio siempre hicieron lo mismo y siempre apuntaron a lo mismo porque ya venían trabajando con eso, pero después el resto no lo ponía en claro... daba esa 
sensación, capaz que fue una sensación mía o era una timidez natural para no pasar el ridículo ante la presentación de un proyecto".

Manifiesta no haber visto intercambios más que entre algunos y que en su hipótesis eran los que tenían una formación más sociológica, que de acuerdo a su percepción respondía a la línea del posgrado, mientras que el resto con una base más comunicacional pura, no hacía aportes sino que se encontraba más en el papel de receptor. "Los pocos que sí tenían ese conocimiento cuestionaban más que preguntar o eliminar dudas".

Aunque no cursó regularmente, Daniel Pichl comparó con la otra maestría en la que formaban grupos aunque la mayoría de los alumnos eran de Ciencias Económicas y en PLANGESCO eso no sucedió. "Y a mí eso me enriqueció mucho y en PLANGESCO siempre que trabajaba estaba solo, me ponía a leer solo, por ahí te consultaba a vos o a Luis, pero en la soledad absoluta y digo somos de Humanas y estamos solos y en la otra maestría que era de Económicas buscaban la integración, que los grupos sean interdisciplinarios".

Celina Salvatierra primero valoró que se haya hecho una extensión al sur, agregó que comprende que hay muchos factores que influyen en la conformación de un grupo y en particular "hice la PLANGESCO con muchos que fueron mis profesores, y muchos que fueron mis compañeros, entonces es como que ya nos conocíamos", reconoció que la gente está grande y en esta etapa de su vida la mayoría atravesados por el trabajo, las obligaciones y la familia. Satisfecha de haber cursado los seminarios, reconoció que le dio mucho placer hacerlos. "Como debilidad, me hubiera gustado que hubiera más intercambio, pero me parece que todo está funcionando así porque en la UNAM -Universidad Nacional de México- de dos años pasaron a cuatro y te ponen un tutor, ya no cursas seminarios, tenés que desarrollar tu proyecto y el tutor va haciendo el seguimiento de tu trabajo". No obstante sostiene que en la Academia los trabajos tienen que dialogar más porque es allí donde se encuentra la posibilidad de crecer.

Diego Pérez encuentra en PLANGESCO, "encuentro en los profes, encuentro en ustedes, en vos, una gran apertura, contrariamente a lo que me decía Giordano, 
esta función de venir desde afuera sin cargas previas al grupo, a mí me liberó, me dio la posibilidad de decir más tranquilo lo que se me ocurría frente a lo que pasaba". Se siente muy agradecido, reconoce que aprendió, reorganizó los conceptos, debatió consigo mismo y con los demás una gran cantidad de ideas.

\subsubsection{Desde lo grupal}

La percepción de Luis Sandoval, ya egresado al momento de la entrevista, es uno de los pocos que valora la calidad humana del grupo, aunque reconoce que pese a ser la mayoría docentes de la carrera de Comunicación no se explotó al máximo esa condición. La mirada de Kira Rakela es más crítica hacia el interior del grupo, calificándolo de individualista pero sobre todo vinculándolo con la imposibilidad de armar cadenas de producción, por ejemplo en torno a la lectura. Daniel Pichl comparte este último testimonio pero en relación a las dificultades para intercambiar ideas y compara esta debilidad con su positiva experiencia en el anterior posgrado que cursó. Por su parte Marcelo Hernández si bien reconoce cosas positivas, destaca la mezquindad de los integrantes del grupo para compartir sus proyectos y sostiene que los intercambios fueron solamente entre algunos, aquéllos formados en una línea más sociológica, que de acuerdo a su criterio era la del posgrado, pero afirmaba que cuestionaban más que preguntar o eliminar dudas.

Tanto María Dilys Vales como Diego Pérez pertenecientes la zona del Valle (Trelew-Puerto Madryn), tienen un planteo diferente, inclusive entre ambos. En el caso de Vales tiene que ver con la diferencia en el modo de encarar el posgrado, según ella los compañeros de la Carrera eran muy teóricos, aunque reconoce que ahora es ella la que tiene dificultades para bajar la práctica al papel y ponerla a teorizar. Diego por su parte sintió una buena recepción en el grupo y considera que el hecho de venir de afuera lo liberó para expresar libremente su punto de vista, se muestra satisfecho y agradecido con la experiencia. 


\subsection{Un sentido común, posiblemente colectivo}

\subsubsection{Lo colectivo}

"Tampoco lo aprovechamos cien por cien, por ahí hubiera sido mucho más fructífero si hubiera habido una apertura mayor de las cosas de cada uno como puesta en común y discusión, pero parece en todo caso como que la imposibilidad es externa, no es algo que no hizo la Maestría, creo que viene de esta carrera, de la universidad, de la facultad..." (Entrevista Sandoval, 27/08/2011).

“No, nunca estuvo presente ese pensamiento, esa idea de que sea un desarrollo para la carrera, nunca lo verbalizamos... Ojala hubiese sido, pasa que nosotros somos absolutamente individualistas en la carrera, esto tiene que ver también con una cuestión institucional...institucionalmente tampoco se promueve esto, a nadie le interesa" (Entrevista Rakela, 17/09/2011).

"No creo que haya sido un excelente grupo en general, como un grupo de construcción a futuro, de transformación, no" (Entrevista Hernández, 18/11/2011).

"Pero creo que aun así hay que buscar espacios para que se dialogue, cuando digo dialogar digo leernos, darnos opiniones, volver a construir proyectos y me parece que de ahí sale también, salen cosas interesantes, que también se pueden hacer propuestas a la calle que es lo que en definitiva vale". (Entrevista Salvatierra, 29/12/2011).

"Yo creo que hubo un intento inicial de transformar esto en un proyecto colectivo que fue la idea original, pero la no continuidad de Giordano y de las políticas de Giordano en todo caso, la variación de las miradas en la política institucional, hizo que no fuera posible constituirlo como un proyecto colectivo, me parece que no se logró. Hubo objetivos parciales que son básicamente un grupo de personas que quedamos vinculadas a esta idea de PLANGESCO y que seguimos trabajando, de las 18 quedamos cinco o seis, con distintas miradas y la 
idea de constituir nuestros propios proyecto. Pero yo no llego a ver, por lo menos hasta ahora, un proyecto más colectivo" (Entrevista Pérez, 29/ 03/2012).

\subsubsection{De lo grupal a lo colectivo}

Cuando se alude a lo colectivo como la posibilidad de proyección hacia una escala superior al grupo, Luis Sandoval considera que la imposibilidad de haber logrado otra trascendencia es externa, no provocada por la Maestría sino en todo caso que viene de la carrera, de la Facultad, de la misma Universidad.

En esa misma línea Kira Rakela que pondera al grupo como individualista, lo atribuye también a una cuestión institucional, que es desde donde esta integración no se promueve.

Para Marcelo Hernández no fue un grupo de construcción de futuro, de transformación. Sin embargo Celina Salvatierra con la perspectiva que le da hacer su experiencia en México, sostiene que esta falta de intercambio y de diálogo entre proyectos no fue privativa de nuestro posgrado, sino que lo ve en las universidades de allá y lo señala como una tendencia, aunque no por serla la valora positivamente.

Otro que se refiere al tema pero desde otra perspectiva directamente vinculada al proyecto es Diego Pérez, que ve dos etapas con un intento inicial de transformación que lo asocia a la activa participación del coordinador de La Plata, Carlos Giordano y una segunda con la falta de continuidad de esas políticas. Logra rescatar objetivos parciales aludiendo a los que aún se encuentran trabajando.

\subsubsection{Lo individual, el grupo y lo colectivo}

Estas tres dimensiones permiten diferenciar en el relato de los alumnos sus motivaciones individuales, su percepción de lo grupal y la escala de lo colectivo. Las razones no difieren seguramente de las de otros maestrandos de la generación intermedia, que iniciaron sus estudios de posgrado muchos años después de finalizar su carrera de grado, con experiencia profesional y cargas de familia propia de esta etapa. 
Cuando en las entrevistas, los maestrandos responden acerca del grupo, en general se refieren a lo que fue la integración dentro la cursada de los seminarios, en torno al concepto de grupo como asociación, "como un número de personas que interactúan unas con otras sobre una base regular" y con expectativas de ciertas formas de conducta recíproca ${ }^{21}$. El mayor reclamo pasaba en las entrevistas por la imposibilidad de "hacer grupo" en el sentido de reunirse para estudiar o realizar trabajos, por la dificultad para compartir los proyectos de cada uno o simplemente por la falta de discusiones o puestas en común en el marco de los encuentros. Son los alumnos que no pertenecen a la carrera los que opinaron en otra dirección, más como observadores y sin la carga de la historia compartida, en un caso se cuestionó la preponderancia de la postura teórica en alumnos locales, aunque en otro se manifestó el agradecimiento por la oportunidad de formación.

Es Luis Sandoval que al momento de consultarlo ya se encontraba graduado, a quien probablemente ese punto de vista le permitió valorar el grupo humano que se conformó, más allá de reconocer que no se explotó en toda su capacidad, siendo la mayoría docentes de la misma carrera.

Y fue Celina Salvatierra otra graduada al momento de la redacción de esta tesis, pero aún en México en ese entonces, quien opinaba que le "hubiera gustado que hubiera más intercambio, pero me parece que todo está funcionando así". Se refería a su conocimiento de lo que estaba sucediendo en la UNAM (Universidad Nacional de México) donde el doctorado de dos años pasó a cuatro sin cursar seminarios y con la figura de un tutor que va haciendo el seguimiento del desarrollo del proyecto de cada alumno. Para Marcelo Hernández no fue un grupo de transformación y es Diego Pérez, quien señala un intento inicial de transformación y que pese a la falta de continuidad de esas políticas, reconoce que se alcanzaron objetivos parciales, con los que quedaron hoy cerrando el proceso.

21 Giddens, A. Sociología. Alianza. Madrid, 1991. Capítulo 9: Grupos y Organizaciones 
Y al pasar a la escala de lo colectivo, la asociación se realiza con lo institucional, con el respaldo que la Universidad haya podido representar para cada integrante de este conjunto, primero de alumnos, luego de maestrandos, finalmente de sostenes y compañeros de un proyecto educativo que hubo que empujar en condiciones, en muchas circunstancias, extremas.

Luis Sandoval considera que la imposibilidad de haber logrado otra trascendencia es externa, no provocada por la Maestría sino en todo caso que viene de la carrera, de la facultad, de la misma universidad. En esa línea Kira Rakela que califica al grupo como individualista se lo atribuye también a una cuestión institucional que es desde donde esta integración no se promueve.

Por su parte, María Dilys Vales tiene una percepción diferente por provenir de otra ciudad y encontrar en la coordinadora la representación de la UNPSJB, tampoco cuenta con un respaldo de la Facultad de Trelew, "no es una sede que se sintiera parte de ésta, mi idea es que acá no hay registro de que la Maestría existió -se refiere a la sede Trelew de la FHyCS-". Respecto de FPyCS de La Plata se quedó con la sensación de que el entusiasmo inicial no se puso de manifiesto en la realidad.

En torno al apoyo institucional Daniel Pichl no cree que esta facultad ayude a la capacitación, "considero que vos (se refiere a esta tesista en su rol de coordinadora) hiciste gestiones por eso llegó donde llegó, pero desde la Facultad no hay apoyo, no hay estímulo. Es una institución imposibilitadora, te pone muchas barreras, hay mucho de quinta cerrada".

Lo que pasa es que en estos ocho años la situación ha cambiado, la historia nos ha modificado, sostiene Marcelo Hernández para quien la razón de la falta de respaldo para esta Maestría estaba en una universidad desbastada, sin presupuesto, con gestiones mediocres desde el punto de vista del fortalecimiento que deberían haber recibido las carreras aunque más no sea en un crecimiento paulatino. No había, de acuerdo a su criterio, una decisión de respaldo a este proyecto porque no prometía mucho en cuanto a resultados, aunque aclaró que cree "que desde Nieto para acá, hubo una intención de que esto continuara, más allá de algunos palos en la rueda, pero hubo muchos celos 
de a quién le pertenecía la gestión. Institucionalmente no creo que hayamos tenidos una Universidad facilitadora de este proceso, para nada, lejos, más bien una Universidad de derecha, para denominarla, no sé si privada, de derecha". Mientras que Celina Salvatierra tiene una mirada más despojada, en parte por una cuestión generacional, sólo mantenía con la institución su vínculo como ex alumna y al cursar con la mayoría de los que habían sido sus docentes y algunos de sus compañeros, estaba ubicada en un lugar de contención, tanto es así que para ella la gestión de PLANGESCO Comodoro, estuvo representada solo por la figura de la coordinación y de sus propios compañeros.

Diego Pérez encuentra en PLANGESCO Comodoro una gran apertura y se siente agradecido por la oportunidad de aprender y de ponerle andamiaje sus dudas que el posgrado le ofreció. Aunque también puntualizó aquellas cosas que no le gustaron, hizo referencia a la mala experiencia con su primer proyecto de tesis que quedó como germen de la especialización en Comunicación y Ambiente, pero con el que no pudo continuar porque el tema del proyecto pertenecía a la Fundación Patagonia Natural de la cual también fue desafectado. "Creo que tiene que ver con cierto desconocimiento mío, que me retrasó en el proceso de la tesis, pero que también me enseñó que la Universidad no está exenta de estos debates, ni aun en estos sectores ideológicamente más afines". Le costó dos años presentar un nuevo proyecto de tesis y admite que, quizás ingenuamente, confió sin reparos en la Universidad y sintió ese episodio como una traición, aunque a pesar de la decepción pudo evaluar que la institución estaba atravesada por un debate de época que padecía las consecuencias de las privatizaciones, de la disgregación, de factores políticos que alcanzaron a todas las instituciones. Su visión se modificó con el retorno de Carlos Giordano a respaldar fuertemente la finalización del proceso "me parece que le volvió a poner un criterio, yo no sé cómo estarán ellos ahora, lo que pasa es que Carlos representa otra cosa".

En la perspectiva de Luis Sandoval, la Facultad en La Plata es muy posibilitadora, "tienen tendencia a tratar de que las cosas salgan, antes que poner obstáculos para que no salgan". Este comentario que pareciera destacar una cualidad, es a 
su vez utilizado para mencionar la impresión "de que también en relación a la Facultad no estuvimos muy institucionalizados". Puntualmente hizo referencia al poco conocimiento que se tenía en aquella institución de PLANGESCO Comodoro y presume que su paso por todo el proceso con la defensa incluida, puede haber servido para ordenar algunos problemas aún no resueltos en torno a esta cohorte.

\subsubsection{Lo colectivo institucional}

"Los anhelos de la organización cobran sentido y se constituyen en la construcción colectiva y solidaria de quienes la integran" (Entrevista Uranga, 2003:10). Por eso es fundamental considerar a las instituciones involucradas, el lugar desde dónde se emprendió la experiencia, las circunstancias y la modalidad.

Desde la iniciativa surgida de una carrera no hegemónica pero con una matrícula que representa un aporte fundamental al conjunto de la Facultad, con, en ese momento, docentes no concursados y visibilizados más por su desempeño profesional que académico, pero conscientes de su necesidad de formación y de pasar a otra instancia con la carrera de grado. El diálogo entre ambas instituciones tuvo vaivenes pero hubo voluntad de institucionalización, la Facultad de Periodismo de La Plata estaba en el proceso de consolidar los posgrados y la Facultad de Humanidades y Ciencias Sociales no podía desechar la oportunidad de estrechar lazos con la UNLP y de atender a la preocupación de los docentes en su necesidad de formación. "En un contexto nacional difícil, donde el país entero estaba en crisis, donde la educación superior estaba cuestionada", PLANGESCO en Comodoro pasó a ser rápidamente "una acción de autogestión de los interesados" (Entrevista Giordano, 24/11/11). Desde la perspectiva de Giordano esta impronta en el desarrollo fue desalentando a los que menos involucramiento tenían e hizo que el grupo actual, que termina el proceso, se consolide en la resistencia.

Dicho ahora desde su lugar de decana, Claudia Coicaud opina que fue la propuesta colectiva la que permitió sostener y "sobreponerse a los avatares 
institucionales" (Entrevista Coicaud, 1/11/11) la que posibilitó la finalización de los seminarios. Aunque también realza la necesidad de que todo proyecto de formación que uno emprenda institucionalmente tiene que tener "un contralor académico". Y este cuestionamiento a la debilidad en la instrumentación de PLANGESCO fue uno de los avatares institucionales que el grupo tuvo que enfrentar. Ese argumento de la debilidad en su anclaje académico, aunque pueda ser explicado en términos concretos de ausencia de acciones que el posgrado debería haber generado, expresa la incertidumbre que genera un comportamiento no institucionalizado. No sólo para las autoridades porque como lo enuncian Berger y Luckmann "cuando más se institucionaliza el comportamiento más previsible y controlado se vuelve" (Berger y Luckmann, 1994: 85), sino para toda la cohorte que tuvo que doblegar esfuerzos para sostenerse y neutralizar las resistencias. No obstante, de esta experiencia se produce una "sedimentación intersubjetiva" (Berger y Luckmann) que le permite al grupo que la compartió recordar aspectos comunes y sensibles de la misma. Y dar cuenta del proceso permite explicar y justificar, lo que constituye la “legitimación" del mismo.

\subsubsection{Desde el 2003 hasta hoy}

Entre los hechos y los discursos, entre las sucesiones de aconteceres y pareceres, en ese contexto en el que este proceso se desarrolló se encuentran sedimentos de un período que la actual decana de la Facultad de Periodismo y Comunicación Social de La Plata, resume en "una profunda transformación en el terreno simbólico de la ciencia". Se refiere a la ciencia que pretende asumir el "desafío de construir un mundo mejor" y oponerse a la idea los poderes únicos. Manifiesta que en la larga década neoliberal se fue perdiendo esa pasión por hacer ciencia "y en todo caso lo que fueron quedando de esta época, fueron la epistemología de los curriculums, la ciencia de los expertos al servicio de cualquier poder". Plantea como respuesta la necesidad de recuperar la pregunta de para qué, para quiénes y con quiénes hacemos ciencia, la respuesta en su reflexión apunta a pensar las diferencias entre quienes cuestionan la calidad no 
advirtiendo el desplazamiento de "calidad tecnocrática, meritocéntrica hacia una nueva plataforma sostenida por la igualdad".

Desde este planteo las políticas científicas deberían sostener la idea de asociar calidad a inclusión, desarrollo y soberanía, memoria, verdad y justicia. Todos valores indispensables para vivir estos procesos de cambio personal, grupal y colectivo.

“El individuo puede hacer complicadas conexiones lógicas e iniciar y controlar secuencias diferenciadas de acción, sólo si él o ella es capaz de hacer uso del acervo de experiencia disponible en el contexto social" (Berger-Luckmann, 1997:34).

Florencia Saintout, encarna en este discurso ${ }^{22}$ el espíritu de la época que gestiona en su Facultad de la Universidad Nacional de la capital de la Provincia más grande y central del país y cuya reverberación se insinúa en algunos discursos e iniciativas en esta emergente Universidad, también nacional, pero de una región alejada y poco poblada del país.

22 Jornada "Universidad, Ciencia y Territorio en la Década Ganada", organizada por la Subsecretaría de Gestión y Coordinación de Políticas Universitarias del Ministerio de Educación de la Nación- 01/08/2013 


\section{CAPITULO 5}

\section{LA PRODUCCIÓN DE UNA OPORTUNIDAD}

5.1 El Cierre: las tesis. Los trayectos, las visiones, naufragio o sostén?

5.2 Propuesta de convergencia. Un futuro posible?

"Si construir es construirse, la Maestría tiene el propósito de colaborar en la construcción personal y profesional de un grupo de seres que avanzará en ese intento a través de esfuerzos individuales y del espacio de la interacción grupal."

(Maestría en Planificación y Gestión de Procesos Comunicacionales, Documento Curricular y Plan de Estudios)
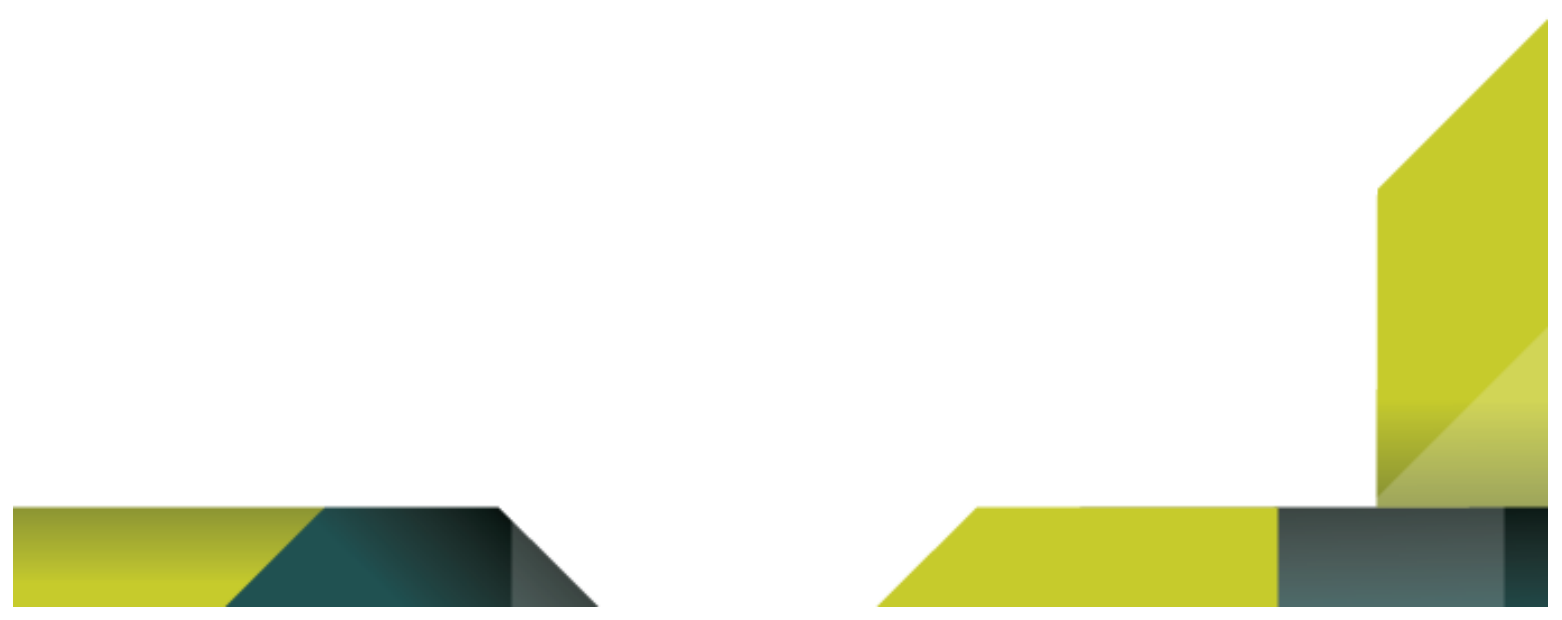


\subsection{El Cierre: las tesis. Los trayectos, las visiones inaufragio o sostén?}

\subsubsection{El cierre, sus visiones}

Éstas que se resumen son las tesis de los maestrandos de PLANGESCO Comodoro que al momento están entregadas, las de Luis Sandoval y Celina Salvatierra se encuentran aprobadas y la de Diego Pérez a la espera de su defensa. Este resumen que puede resultar poco sintético para preciarse de serlo, sirvió parar captar el sentido más profundo de las motivaciones que las impulsaron. No es sencillo llegar a esta instancia cuando el escrito académico tiene características que dificultan este objetivo. No obstante el documento fundacional de la Maestría, en un párrafo ya citado en el capítulo anterior, sostiene que "no se busca sólo enriquecer la ciencia de la comunicación, sino también, y de manera fundamental, enriquecer el conocimiento sobre diferentes instituciones y sobre los posibles espacios de trabajo en planificación y gestión de la comunicación". Y en este sentido los procesos de los alumnos citados se adentran en las instituciones elegidas, sea a través de las organizaciones que las representan o mediante su perspectiva analítica de los hechos, los discursos y las interacciones.

La dinámica de "Las TICs en la sociedad contemporánea" de Luis Sandoval concentra el interés de diferentes disciplinas del conocimiento, pero en esta tesis el estudio de la apropiación y la significación en el uso político de las mismas arroja resultados inéditos porque es abordado desde la mirada de un comunicador al que le interesaron, en el marco normativo internacional y nacional, los casos de organizaciones digitales de la sociedad civil y de sitios contra-hegemónicos en la red, para el análisis de su producción social de sentido. En su desarrollo se interroga acerca de cómo esos objetos se convierten en sede de negociaciones simbólicas y entre sus principales hallazgos reconoce su condición instrumental respecto a movimientos de cambio social y hacia adentro de su propia organización y que pese a que son diferentes en los 
contenidos respecto de los medios tradicionales, no lo son en cuanto a sus modos de producción y en relación a los destinatarios que son considerados como lectores -visitantes y no como parte de la experiencia colaborativa que hoy promueve la red. Sin embargo destaca el tema de la "desconexión" ya que de las respuestas deduce, que si bien coincide con la exclusión social, varios de los entrevistados opinan que la inclusión digital debería concentrarse en la capacitación para la producción de contenidos.

En el registro teórico señala que las categorías de la teoría política crítica contemporánea que utilizó para interpretar su proceso le resultaron productivas para un análisis de las tecnologías de comunicación y que por el campo de los usos cotidianos de las nuevas tecnologías pasa su interés en la investigación.

Para Celina Salvatierra el primer planteo en torno a la tesis fue hacer algo con comunicación alternativa en Latinoamérica, se mudó a México y sentía que era el aspecto más susceptible de ser abordado a nivel regional. Su tema fue la autogestión, en particular sobre la definición que grupos artísticos como La Pirámide tienen sobre esa noción. Tenía necesidad de reivindicar lo que había visto en PLANGESCO en el sentido de que la teoría debe estar trabajada en la calle. "A mí me gustó mucho la Maestría, de hecho por eso quiero seguir estudiando", afirma mientras ya se encuentra cursando el doctorado en la FPyCS de la UNLP.

El objetivo general del trabajo consistió en diagnosticar para comprender el proceso comunicación de La Pirámide, una organización que se define como autónoma y autogestiva; a fin de reconocer los modos en los que se comunica y elaborar una propuesta de planificación. El interés de la autora, sobre todo en su condición de extranjera, tuvo que ver con la necesidad de pensar y conocer estos espacios, donde confluyen subjetividades y formas de organización colectiva en el marco de la sociedad capitalista.

Encontró un conjunto de debilidades -un esquema comunicacional vertical, falta de acuerdos entre actores en torno a roles y tareas; desconocimiento de los interlocutores y consecuentes representaciones - que formaban parte de un mapa más amplio, no referidas exclusivamente a lo comunicativo pero que le 
permitieron ver una disociación entre gestión/proyecto político y comunicación. Como consecuencia de ello, proyectó una planificación que podría facilitar el proceso de democratización de la comunicación en la organización, ponderando el concepto de diálogo entre comunicación y arte para pensar la práctica como propuesta política al interior del proceso de comunicación integral. En las conclusiones destaca que la autonomía y la autogestión son construcciones sociales mediadas por procesos de comunicación, por lo tanto para pensar un proceso de planificación de la comunicación participativa, es necesario trabajar en la transformación de todos los niveles comunicativos para que sirva de incentivo a otras OSC.

La tesis de Diego Pérez abordó la utilización de las radios en el proceso educativo en el contexto actual del desarrollo de los medios y la comunicación, apostó con la experiencia concreta a que el aprendizaje pasara por un diálogo de saberes escolares y sociales.

El objetivo que se planteó fue el de desarrollar procesos de inclusión de la radio en los contextos educativos, con el desafío de pensar la educación desde una mirada comunicacional y no solo desde la mediación tecnológica de la radio. Esta tesis incluye una descripción de la experiencia, de las reflexiones y conclusiones de un proceso de capacitación de docentes que se desempeñaron como mediadores en la realización de proyectos institucionales de radio. Estos procesos de planificación de la comunicación en los ámbitos escolares, se desarrollaron con niños y niñas de establecimientos ubicados en diferentes sectores de la provincia de Chubut en 2010, 2011 y 2012.

La experiencia de los tres años relevados le permitió al autor comprobar la viabilidad para proyectar una red de radios escolares en una modalidad de wiki radios educativas, así como la incorporación del equipo inicial de Escuelas al Aire Libre al Plan Provincial de Lectura.

En las conclusiones Diego Pérez destaca el aporte original de este proceso en la utilización de la tecnología radial derivada de la Web 2.0 como un instrumento de transformación del proceso tradicional de la enseñanza áulica, así como la riqueza de la mirada comunicacional de los procesos, que le permitió articular 
saberes y disciplinas diversas para construir y dar cuenta del estado de la cuestión en este campo específico.

Reflexiona que en esta experiencia le fue imprescindible sostener la tensión entre las miradas pedagógicas/educativas y la mirada comunicacional, que no fue solo epistemológica o teórica, sino metodológica en la búsqueda de respuestas a la creciente complejidad del proceso. En este sentido destacó que producto de la experiencia pudo comprobar que plantear objetivos y gestionar procesos para llevarlos a cabo, está más en la línea de la orientación que de una planificación concreta, por lo menos en estos casos que involucraron a comunidades enteras y diversas.

\subsubsection{Las tesis. ¿Sostenes?}

a) Tesis Luis Sandoval 16/05/2011

Tecnología, comunicación, ciudadanía. Una aproximación a los usos políticos de las tecnologías de comunicación en Argentina

El director de la tesis fue Eduardo Rinesi y la redacción se desarrolló durante el año 2010. En la tesis "se identifican, relevan y diagnostican algunos usos políticos de las tecnologías de información y comunicación en Argentina, especialmente en lo que hace al uso de Internet" y se analiza el modo en que distintos actores sociales las utilizan y resignifican. Asimismo teniendo como campo de estudio el amplio abanico que generan las TICs como herramienta política fundamental en el marco de la Sociedad de la Información, Sandoval circunscribe su investigación a los marcos normativos que estableció el gobierno nacional, la visión y posicionamiento de organizaciones de la sociedad civil con actuación en el ámbito SIC/e-gov (Sociedad de la Información y el Conocimiento Gobierno electrónico -e-goverment-), y en las experiencias de los grupos de 
acción contra-informativos que traducidos en portales o sitios web "se enmarcan en la tradición de la comunicación popular y alternativa de América Latina".

\section{Índice de contenido}

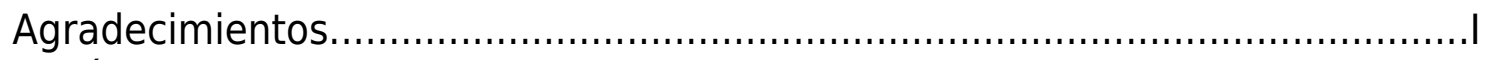

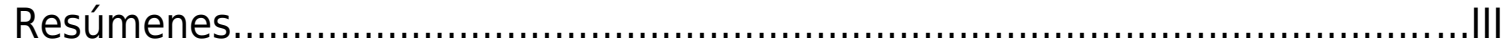

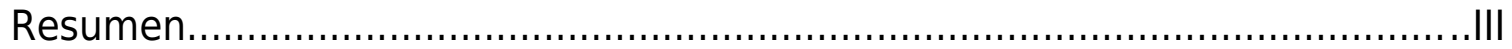

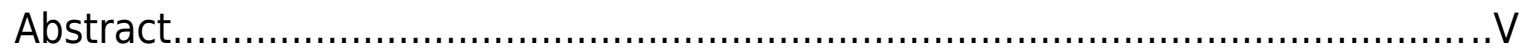

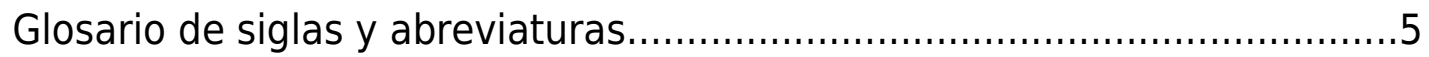

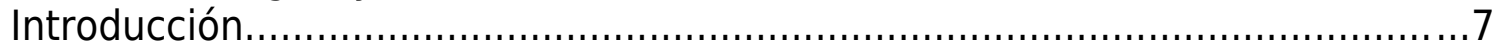

1. La política del signo ¿sociedad de la información? ¿sociedad del conocimiento? ¿sociedad de los saberes compartidos?..........................15

1.1. Desregulación de los mercados y modernización tecnológica: el proyecto europeo de la Sociedad Global de la Información.....................17

1.2. La Cumbre Mundial de la Sociedad de la Información.......................21

1.3. De la información al conocimiento: la intervención de la UNESCO en el

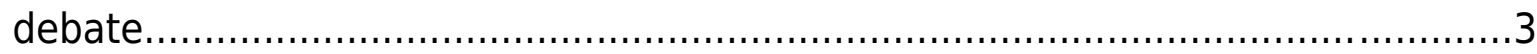

2

1.3.1. Cuestiones cruciales en las sociedades del conocimiento..............35

1.4. Del conocimiento a los saberes compartidos.

1.5. Addendum: sobre el origen del concepto de información

2. Las políticas del Estado Nacional sobre SIC/e-gov en Argentina (19972009)

. .52

2.1. Un recorrido por la normativa argentina sobre SIC/e-gov. 54

2.1.1. Infraestructura y acceso.

2.1.2. Internet: derechos y garantías.

2.1.3. Gobierno electrónico.....

2.1.4. Promoción de actividades económicas.

2.1.5. Promoción de contenidos culturales y educativos

2.2. La Agenda Digital Argentina: intento de política integral...... 66

2.3. La Ley de Servicios de Comunicación Audiovisual: más acá de la

SIC.

73

2.4. La normativa sobre SIC/e-gov: una evaluación de conjunto 75

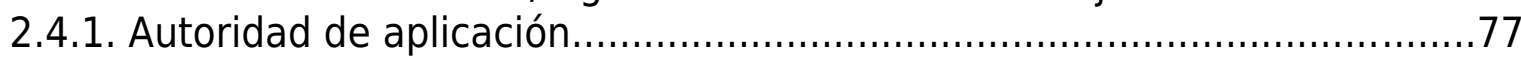

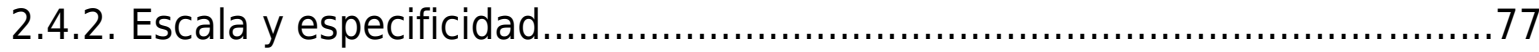

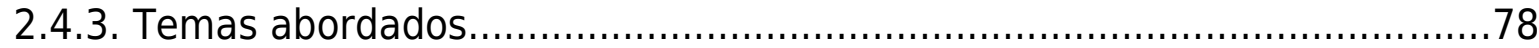

2.5 .

Conclusión

3.0 El punto de vista de la "sociedad civil"

3.1. Cuestiones metodológicas y delimitación del corpus.

3.2. Descripción general de las organizaciones 
3.2.1. Asociación Civil Actuar.

3.2.2. Asociación Civil Nodo Tau.

3.2.3. SOLAR Asociación Civil Software Libre Argentina.

89

3.2.4. Fundación Gestión y Desarrollo.

3.2.5. Fundación Compañía Social Equidad.................................................90

3.2.6. Fundación Evolución.

3.2.7. Sociedad de la Información para las Américas Capítulo Argentino (e-

Américas).

3.2.8. Otras organizaciones.

3.3. El campo de las OSC "digitales": descripción inicial.

3.3.1. Diseño de variables.

3.3.2. Dimensión: organizaciones pequeñas y medianas 95

3.3.3.

Antigüedad

3.3.4.

Localización 100

3.3.5. Relación con gobiernos y empresas

3.3.6. Promoción del software libre.

3.3.7. Orientación temática.

3.4. El campo de las OSC "digitales": topografía

3.4.1. Construcción de indicadores

3.4.2. Relaciones entre indicadores.

3.5. Posicionamientos y evaluaciones

112

3.5.1. Las políticas del Estado Nacional: evaluación general y participación ciudadana.

3.5.2. Las políticas del Estado Nacional: la Agenda Digital.

115

3.5.3. Comparación con otras experiencias

3.5.4. La inclusión digital y los modelos la1....

120

3.5.5. Las redes entre organizaciones y el software libre. 122

3.6. Conclusión.

4.0 Más allá del marco institucional: experiencias contra-hegemónicas en

red.

4.1. Cuestiones metodológicas y delimitación del corpus. 132

4.2.

Análisis

4.2.1. Definición y articulación

4.2.2. Contenido, referentes

4.2.3. Sistema de publicación

4.2.4. Referencias al software libre y a la tecnología....

2.5. Participación y articulación en red.

5.0 Hacia una teoría político-comunicacional de los usos tecnológicos 
5.1. Los dos momentos de la política.

5.1.1. Jacques Ranciére, o de cómo se transforma el ruido en palabra.

5.1.2. Toni Negri: la potencia creativa de la multitud............................169

5.1.3. Claude Lefort: la exterioridad del poder

1.4. Ernesto Laclau: el populismo como lógica política

5.1.5. Michel de Certeau: las artes del débil

5.2. Intermezzo: para una lectura política de las tecnologías de comunicación.

5.3. Lecturas, audiencias, usuarios: cuestiones comunicacionales para el análisis de los usos tecnológicos.

5.3.1. La herencia de los estudios críticos de audiencias. 205

5.3.2. De las audiencias a los usuarios, de los medios a los ensamblajes sociotécnicos 211

Conclusiones 219

Bibliografía. 229

Anexos. .24 5

El objetivo general propuesto consistió en analizar el uso social de las tecnologías de información y comunicación como espacio de lucha política.

Metodológicamente se realizaron análisis de documentación normativa, encuestas, entrevistas semiestructuradas y análisis cualitativo de sitios web. De los mismos se analizaron, entre otras cuestiones, sus modos de producción y los contratos de lectura que postulan hacia sus lectores y usuarios, las posibilidades de participación de éstos y el tratamiento de las temáticas vinculadas a las mismas tecnologías de comunicación.

En el registro teórico, este trabajo estudia "el modo en que el uso de las TICS puede considerarse un espacio de tensión política y socio-comunicacional entre el momento institucionalista y el momento creativo/productivo. Busca delimitar si esta distinción, proveniente de la teoría política crítica contemporánea, posee alguna productividad teórica para explicar los procesos de significación y apropiación de las TICs".

Lo hace a partir de un conjunto de autores que abordan dicha tensión y de la contrastación con los resultados de la propia investigación. 
Desde este lugar concluye que su productividad deviene de una marcada homología entre los problemas a los que atendió esa reflexión y los abordados por la tradición de los estudios críticos de audiencias y por las actuales investigaciones sobre Internet y los medios digitales.

Así como también se encuentra entre las principales conclusiones la inexistencia, para el período analizado entre 1997 y 2009 de un plan integral del Estado nacional vinculado a las cuestiones de desarrollo de la SIC. Esta ausencia se desprende del conjunto normativo analizado (donde son escasas las leyes y predomina el desarrollo de infraestructura en detrimento de las cuestiones sociales y culturales), pero también es señalada por las organizaciones de la sociedad civil con actuación en las problemáticas aludidas, aunque no son en absoluto homogéneas. Otro resultado de la investigación es la caracterización de este campo, a partir del delineamiento de una topografía del mismo.

\section{Aportes}

El campo de estudio de esta tesis hace eje en la interfaz entre Estado y sociedad civil, en particular, en el modo en que dispositivos de comunicación se convierten en objetos de apropiación y disputa. La mirada que propone la PLANGESCO, no se encontrará en esta tesis tanto en que trate de Internet o de las TICs, sino en que se interroga acerca de cómo esos objetos se convierten en sede de luchas y negociaciones simbólicas, vale decir en lugares de producción social de sentido.

Aportes de cada capítulo

La política del signo ¿Sociedad de la información? ¿Sociedad del conocimiento? ¿Sociedad de los saberes compartidos?

En el primer capítulo analiza un conjunto de documentos que delimitaron el campo internacional de comprensión de la actual transformación del capitalismo transnacional, vinculada a la digitalización de los procesos económicos y sociales. 
Toma como ejes de este capítulo las recomendaciones al Consejo Europeo de la comisión presidida por Martin Bangemann (1994), los documentos de la Cumbre Mundial de la Sociedad de la Información (2003-2005) y el Informe Mundial de la UNESCO de 2005. Alude a la construcción de estas sociedades y a las disputas por la nominación como claros indicadores de los procesos y conflictos del campo. Lo cierra con una reflexión acerca del modo en que los mismos conceptos de información y comunicación en los estudios sobre comunicación, muestran cómo las "palabras operan como cristalizaciones de entramados de intereses económicos, opciones políticas, horizontes ideológicos y elecciones filosóficas".

El término "Sociedad Global de la Información" adquirió visibilidad a partir del informe de la comisión presidida por Martin Bangemann entonces vicepresidente de la Comunidad Europea y Comisario Europeo de Mercado Interior, Empresa e Industria para la modernización de las infraestructuras de comunicaciones. Presentado en 1994 tenía como eje las decisiones que debía tomar la Unión Europea para el aprovechamiento de las tecnologías de información como motor de desarrollo económico a partir de la liberalización extrema de los mercados.

La propuesta del Informe era la desregulación de los mercados de telecomunicaciones, el apoyo de los gobiernos a las empresas europeas del sector como vía de ingreso y expansión de la "nueva revolución industrial". El acento estaba puesto en las infraestructuras de telecomunicaciones: "Ios elementos constitutivos de la sociedad de la información" como lo indica la Red Digital de Servicios Integrados (RDSI), la banda ancha, la telefonía móvil y los satélites de telecomunicaciones y no, el desarrollo de contenidos o los usos de la tecnología.

El informe fue contemporáneo a la propuesta norteamericana de "autopistas de la información", presentada por Al Gore como candidato demócrata a la vicepresidencia en 1992 e impulsada durante el gobierno de Bill Clinton, como modernización de las infraestructuras de trasmisión de datos, proyecto que asumía como marco necesario la desregulación de los mercados y la privatización del sector de las telecomunicaciones. La denominada Global 
Information Infraestructure fue comunicada por Al Gore en marzo de 1994 durante una conferencia plenaria de la Unión Internacional de Telecomunicaciones (UIT) realizada en Buenos Aires. "Nada de esto puede ser tomado como casual: ni el momento, ni el ámbito, ni el lugar del anuncio", la ofensiva de EE.UU por liderar los negocios mundiales derivados de la revolución científico-técnica, la idea de hacerlo a partir de sus componentes "duros" (el hardware y las redes de telecomunicaciones) y como lugar, el país que había asumido el desguace del Estado como una política pública ejemplar, con un resultado muy visible en ese momento como era la privatización de la telefónica estatal EnTel.

Compara los resultados de Cumbre Mundial de la Sociedad de la Información que en dos etapas se reunió en las ciudades de Ginebra (2003) y Túnez (2005). Destaca que aunque se reconoce a la comunicación como una necesidad humana básica, la tendencia planteada para alcanzar ese objetivo fue el fortalecimiento de la infraestructura desde la lógica implantada por el mercado. No obstante siendo ese el planteo, valora que las ONGs de todo el mundo acordaran propuestas comunes y desarrollaran un papel análogo al que los gobiernos tercermundistas habían tenido dos décadas antes en la Comisión Internacional de Estudio de los Problemas de la Comunicación de la UNESCO (la famosa Comisión McBride). Finalmente expone que la Cumbre de Túnez no constituyó un real avance en la democratización del acceso a las TICs pero supuso alguna contención de las tendencias más liberalizantes del sector de las telecomunicaciones, que venían avanzando desde los noventa.

Por su parte la Organización de las Naciones Unidas para la Educación, la Ciencia y la Cultura (UNESCO) presentó un "Informe Mundial” en el que sentó su posición y diferencias en los ejes planteadas por la Cumbre. No más la denominación de Sociedad de la Información que se asocia a progresos tecnológicos cuando el concepto de sociedades del conocimiento abarcaría aspectos sociales, éticos y políticos más vastos.

La UNESCO apunta a un cambio en el eje de las políticas públicas relacionadas con las tecnologías de comunicación, que ponga foco en las cuestiones 
culturales, educativas y del desarrollo científico. Alude en el documento al concepto de brecha cognitiva más que al de brecha digital, que además del acceso a las TICs favorezca la utilización amplia de los conocimientos para alcanzar el desarrollo sostenible.

Entre algunos de los temas del documento mencionado que destaca y sobre los que se extiende el autor se encuentran: la libertad de expresión frente a los regímenes de seguridad a ultranza; optar por la noción de sociedades del aprendizaje; la ciencia y la privatización del conocimiento.

Mientras que las Organizaciones de la Sociedad Civil en el proceso de la cumbre consolidaron el trabajo en red y uno de los resultados de este trabajo fue la publicación del libro: Palabras en juego: enfoques multiculturales sobre las sociedades de la información, impulsado por tres organizaciones no gubernamentales abocadas a la promoción de usos sociales y cívicos de las TICs. En el sentido de las nominaciones, en el libro se hace referencia a la necesidad de reemplazar sociedad del conocimiento por "sociedades de los saberes compartidos", si bien la intención de tomar distancia de término "knowledge management" apropiado por las corporaciones empresarias, no consideró que knowledge no distingue entre información y conocimiento. En cuanto a los principales temas abordados se encuentra el de la gobernanza de Internet, planteada como un todo que pase a ser "efectivamente global, democrática, transparente y pluralista. Tema finalmente postergado en la Cumbre ya que el actual sistema del ICANN está concesionado por el gobierno de Estados Unidos, "sujeto de hecho a las leyes de ese país y dependiente en su funcionamiento del negocio de delegación y redelegación de nombres de dominio".

En torno a la brecha digital, se propone que para hablar del tema y de las estrategias para enfrentarla se parta de la sociedad que soñamos y no de la tecnología. Y que una vez definida la utopía se reflexione en cómo las tecnologías pueden contribuir para alcanzarla. Por ejemplo, se habla de la solidaridad digital como estrategia de reducción de la misma y del concepto de acceso universal como un derecho de todos los ciudadanos del mundo. 
Finalmente a partir del significado de información, reseña la teoría matemática de la comunicación de Claude Shannon cuya ambición era subsumir bajo su modelo todo tipo de procesos comunicativos, ya sea entre máquinas, hombres o animales y que demostró ser tan exitoso porque planteaba un máximo aprovechamiento de transmisión de información a bajo costo. Su modelo fue clave para el futuro rol de la comunicación en la sociedad contemporánea, su traslado a las ciencias sociales pese a las críticas que cosechó tuvo un alto impacto como base de las teorías de autores fundacionales del campo.

Plantea el autor que el concepto shannoniano de información resulta la base teórica de los esfuerzos por implantar la Sociedad de la Información, desde las coordenadas históricas e ideológicas mencionadas. El acento en la infraestructura que proponen los países centrales y las empresas del sector de telecomunicaciones, y que ha sido incorporado de un modo amplio en las políticas de los países no desarrollados, se justifica al fin por la indiferencia respecto al contenido y la cultura.

\section{Las políticas del Estado Nacional sobre SIC/e-gov en Argentina (1997- 2009)}

El eje del segundo capítulo pasó por las políticas del Estado Nacional sobre Sociedad de la Información y gobierno electrónico en el período que va de 1997 a 2009. Para ello analizó un conjunto de normativas, a partir de una caracterización por las temáticas u objetos de interés de cada una, la autoridad de aplicación y el momento o período de su aprobación, así como una evaluación general de las políticas llevadas adelante en dicho período.

Para abordar el tema, el autor comienza por un repaso de las iniciativas del Estado nacional, a partir de los marcos normativos y para la delimitación del corpus de instrumentos legales a analizar, toma como base inicial la enumeración que realiza Cristian Jensen (en su contribución a las jornadas de discusión que organizó en 2005 la Fundación Friedrich Ebert) y como punto de inicio el Decreto $N^{\circ}$ 554/97, que declaró “de Interés Nacional" el acceso a Internet. 
No obstante comienza por destacar la importancia de la sanción de la Ley $\mathrm{N}^{\circ}$ 26522 de Servicios de Comunicación Audiovisual, calificándola como un hecho político de gran dimensión y como la propuesta legislativa del gobierno de Cristina Fernández de Kirchner que más debate generó en la sociedad argentina. No obstante reconoce que esta ley no aporta mucho a las definiciones del tema motivo de esta tesis, aunque admite que es una constante en los marcos normativos sobre la SIC. Es en su fundamentación y declaración de principios donde se encuentra una vinculación mayor con el tema y en los tramos del Plan de Acción referidos a la diversidad cultural, los medios de comunicación y la dimensión ética de la SI.

Destaca que varios autores coinciden en que no se pueden comparar los marcos regulatorios de los medios denominados tradicionales, que cuentan con la limitación del espectro radioeléctrico, con la digitalización completa que es el motivo de análisis de las SIC. Por este motivo plantea que no considerará la LSCA en el análisis de este capítulo.

Como parte del mismo toma en cuenta las Normas que estarían comprendidas dentro de esta temática, Tipo, Fecha, Escala (se refiere al universo al que apunta la norma), Especificidad (se refiere a si la norma realiza una apreciación general o si detalla caminos de acción) y Gestión.

Y en cuanto a los temas:

Infraestructura y acceso

Promoción Económica

Gestión gubernamental

Participación ciudadana

Software libre

Diversidad cultural y lingüística

Delitos y cuestiones penales

Privacidad de datos y derechos del usuario

Promoción social y lucha contra la pobreza

Medio ambiente

Educación y calidad educativa

Dominio público

Esta sistematización le permite empezar con el análisis de los datos en el período bajo análisis: concluye que entre 1997 y 2001 el desarrollo de 
infraestructura ocupa todo el espacio de las acciones gubernamentales, con sólo dos excepciones: la creación de Educ.ar y la Ley de Habeas Data, ambas bajo el gobierno de De la Rúa. Es justamente durante el breve gobierno de la Alianza cuando se realiza el pasaje a una segunda etapa, donde los temas dominantes serán el gobierno electrónico y la promoción de la industria del software. Finalmente, en el último tramo del período se dio el -al menos por ahora frustrado- intento de impulsar una Agenda Digital de carácter integral.

Concluye del análisis de las normativas relacionadas con la SIC en nuestro país que las mismas se caracterizan por su parcialidad, no existiendo un plan integral que las contenga. "Las pocas leyes (apenas 6) que el Congreso ha sancionado sobre el tema se refieren a cuestiones muy específicas (el habeas data o la firma digital) 0 , en el otro extremo, realizan declaraciones generales. Tal vez la excepción sea la Ley $N^{\circ} 25.922$ de promoción de la industria del software, que puede constituir un instrumento promocional apropiado, aunque se concentra solamente en los aspectos de desarrollo productivo del sector".

"Al menos para el período estudiado, un señalamiento hecho hace varios años parece seguir vigente: "No existe, en la Argentina, un plan estratégico de la Sociedad de la Información, y algunas de las acciones o políticas aprobadas están poco desarrolladas o inconclusas" (Jensen, 2006: 30). Dada la complejidad de la problemática, resulta imprescindible que este vacío sea colmado a partir de políticas con contenido social y democrático".

\section{El punto de vista de la "sociedad civil"}

En el capítulo 3 contrastó el mapa trazado por los pronunciamientos internacionales y las políticas gubernamentales, con la evaluación y opiniones que tienen al respecto las organizaciones de la sociedad civil en Argentina, que asumen como eje de trabajo el desarrollo social de las TICs. Para llevar adelante esta tarea delineó una topografía del campo de las organizaciones de la sociedad civil "digitales" y relevó sus puntos de vista.

Inicialmente reseñó el origen de la denominación, destacando que la complejidad del campo no se limita solo a la definición del mismo, sino que se 
profundizó al momento de realizar una tipología que ordene su heterogeneidad. Decidió que como unidad de análisis quedaran definidas como organizaciones de la sociedad civil de alcance nacional e incluyó como eje de trabajo el desarrollo social de la TICs y las políticas gubernamentales sobre SI y gobierno electrónico, cuyo conjunto llamó OSC digitales.

A partir de las enumeradas en el plan de tesis y de las que el autor conocía alguna información previa, utilizó la técnica de bola de nieve de dos maneras complementarias: indagando en los sitios web de las organizaciones para localizar referencias a otras, e incluyendo una pregunta específica en la Ficha de Identificación de Organizaciones No Gubernamentales. Identificó en total 13 OSC dentro los requisitos pautados y pudo obtener respuesta de 11 , con las cuales concretó encuestas y entrevistas en profundidad con más de la mitad de las mismas. La indagación se desarrolló entre diciembre de 2008 y diciembre de 2009 , los datos obtenidos en las encuestas y entrevistas se complementó con la obtenida en los sitios webs correspondientes.

Las siguientes fueron las OSC que dieron respuesta: Asociación Argentina de Teletrabajo. Asociación Civil Actuar. Asociación Civil Links. Asociación Civil Nodo Tau. SOLAR Asociación Civil Software Libre Argentina. Fundación Gestión y Desarrollo. Fundación Compañía Social Equidad. Fundación Evolución Fundación Vía Libre. Res Non Verba. Sociedad de la Información para las Américas Capítulo Argentino.

Luego de una caracterización de cada una de ellas, el autor centra su análisis en las relaciones entre las organizaciones y en la búsqueda de regularidades para la interpretación. Definió un conjunto de variables descriptivas de cada organización que puso luego en relación con los posicionamientos y evaluaciones realizadas en torno a las políticas gubernamentales del sector. Estableció dimensiones, por ejemplo de cantidad de miembros (mediana: más de 10 integrantes y pequeñas: menos de 100 con despliegue territorial acotado) de las tres medianas, dos son fundaciones y una, asociación civil. Con el objeto de avanzar en el análisis del campo de las organizaciones de la sociedad civil "digitales", desarrolló tres indicadores que combinan varias de las variables 
descriptivas: escala, articulación política-institucional y tendencia de acción (este índice es una operacionalización de las variables relacionadas con la orientación temática de la acción de las organizaciones, interesado en describir puntualmente la intervención técnico- científica de las mismas).

Al poner en relación dichos indicadores comenzó a desarrollar la topografía del campo y estableció regularidades que luego relacionó con las opiniones y posicionamientos de las distintas organizaciones frente a las políticas gubernamentales sobre el sector.

En la primera relación entre indicadores, la que cruza los valores de la escala y de la articulación político-institucional determina que una escala mayor implica una también mayor capacidad de articulación con gobiernos y empresas.

En la segunda relación contrastó la escala y la tendencia a la acción, un indicador que sitúa en un eje donde los polos son el trabajo en territorio (capacitación, promoción del desarrollo, etc.) y las actividades "de gabinete" (investigación académica, consultoría). Así visto, las organizaciones que privilegian el trabajo en territorio también tienden a tener una escala mayor.

En la última relación, entre la Tendencia a la acción y escala, obtiene lo que a su criterio es el gráfico más interesante para el análisis dado que ambos indicadores se relacionan negativamente. "Sin que ello sea contundente, puede decirse que las organizaciones con mayor capacidad de articulación con el gobierno y las empresas, y tal vez por ello, con mayor capacidad de incidir en las políticas gubernamentales del sector, no son las que despliegan más tareas de capacitación, concientización o promoción del desarrollo".

Al hacer un análisis topográfico de conjunto, encuentra tres grupos de organizaciones, el primero -Nodo Tau, SOLAR y Actuar- cuya característica más saliente es que son las organizaciones que promueven el uso y adopción de software libre y que están menos articuladas con el sistema político institucional. El segundo -Gestión y Desarrollo, Links y Sociedad de la Información para las Américas- que son organizaciones pequeñas y con capacidad importante de articulación con el sistema político-institucional. $Y$ el tercero -Fundación Evolución y Compañía Social Equidad- organizaciones medianas y abocadas de 
forma excluyente o prioritaria al trabajo en territorio, especialmente en capacitación.

En relación a los posicionamientos respecto a las políticas del Estado Nacional sobre desarrollo de la Sociedad de la Información, indaga en torno a tres ejes: a) evaluación general de las políticas y espíritu de las normativas existentes; b) evaluación de políticas y acciones de gobierno electrónico, especialmente respecto al uso de las TICs para el favorecimiento de la participación ciudadana y c) posición respecto al proceso de la Agenda Digital y al Documento Base resultante.

La evaluación que hacen las distintas organizaciones sobre las políticas que el Estado Nacional ha llevado adelante en el campo de las tecnologías de información y comunicación y la Sociedad de la Información es llamativamente uniforme, pese a que en otras cuestiones existen marcadas divergencias.

Se resalta la falta de continuidad en las políticas del Estado y atribuyen los avances en la incorporación inclusiva de las TICs a la dinámica del mercado, antes que a políticas gubernamentales. Estas últimas llegan a ser vistas como abiertamente incoherentes, para lo cual se esgrime como ejemplo -en los casos de Actuar, Evolución y e-Américas- el hecho de que al mismo tiempo se haya impulsado la Agenda Digital y el "impuestazo tecnológico".

Respecto a la evaluación de las acciones de gobierno electrónico y su orientación, las opiniones también son coincidentes en cuanto a que los avances son relativos aunque los que están vinculados a la modernización de los procesos administrativos en algunos sectores o temas son exitosos, pero es escasa o nula la promoción de programas de participación ciudadana. Coinciden en que Las razones de este "retraso" en el uso de las TICs como herramienta de participación no son tecnológicas, sino más propiamente políticas.

Finalmente en relación a la valoración de la Agenda Digital se diferenciaron nítidamente las organizaciones que participaron del proceso, de las que no lo hicieron, incluso entre las primeras predomina una mirada negativa o escéptica. Es vista como una misión de un plan, sin la presentación de acciones concretas. De acuerdo a algunos testimonios, las organizaciones que estuvieron son socias 
de empresas del sector, mientras que observaron la poca participación de la sociedad civil y la ausencia de aquellas vinculadas al mundo de la cultura y el software libre.

Del campo analizado en esta tesis -las organizaciones de la sociedad civil abocadas al desarrollo social de las TICs- sólo las que integran RODAR fueron invitadas a participar en el proceso de la Agenda Digital, quedando afuera las reunidas en el Grupo 1 que son las que promueven la adopción de software libre y que -justamente- parecen tener menor capacidad de articulación político institucional.

En función de estos datos, el autor plantea la existencia de una red de asuntos en torno a las políticas del Estado Nacional sobre el sector SIC/e-gov, que se puso en evidencia en el proceso de elaboración de la Agenda Digital. Esta red, presenta a modo de hipótesis, "es la que vincula a las cámaras empresarias de la industria del software (donde tienen representación particularmente las grandes transnacionales y las empresas locales que -en muchos casos- son partners de las mismas), las OSC que reunimos en los Grupos 2 y 3 y funcionarios de la Administración Pública Nacional (la ONTI de modo formal, los funcionarios que integran el Foro Informático Argentino de una manera más informal). Fuera de esta red quedan las organizaciones que promueven el uso del software libre y que tienen sedes y radios de acción en el interior del país, aun cuando algunas de ellas -es el caso de SOLAR y Vía Libre- incluyen la incidencia política -de manera explícita- como uno de sus ejes de trabajo".

Cuando de comparar experiencias se trata para las organizaciones que no promueven el software libre el modo de licenciamiento es instrumental respecto a otros objetivos, mientras que para las que lo promueven, se trata de una característica central. En consecuencia, para las últimas el "avance" refiere casi exclusivamente a medidas de apoyo específico al desarrollo y uso de software libre; en tanto que para las primeras implica cuestiones más diversas: la expansión del uso de las TICs, las políticas de superación de la brecha digital, la incorporación masiva en la gestión gubernamental, las políticas industriales del sector, etc. 
En cuanto a la inclusión digital las respuestas provocaron la mayor dispersión para algunos el desarrollo de infraestructuras sigue siendo un elemento a considerar de modo importante, ya que la "desconexión" coincide con la exclusión social. Pero más allá del acceso, para varios de los entrevistados la inclusión digital debe concentrarse en el favorecimiento del uso, y en este sentido son importantes dos aspectos: la formación y capacitación y la producción de contenidos.

Respecto a la incorporación masiva de computadoras móviles (netbooks) en las aulas hubo coincidencia en cuanto a valorar la importancia del equipamiento, pero acordaron también en que no se sabe si implica un mejor proceso de enseñanza aprendizaje.

\section{Más allá del marco institucional: experiencias contra-hegemónicas en la red}

El capítulo 4 refiere a la problemática que tiene su tradición en la comunicación popular y alternativa latinoamericana respecto del posicionamiento de los actores y movimientos sociales a partir del análisis de un conjunto de sitios web contra-informativos.

En este capítulo el autor aborda las experiencias de uso de las tecnologías de información y comunicación desde el punto de vista de los movimientos que impugnan el orden hegemónico vigente. Sostiene que las experiencias de uso de Internet vinculadas a movimientos sociales que aquí analiza, encuentran sus antecedentes en la historia de la comunicación popular y alternativa en América Latina. Si bien no es su objetivo analizar su historia, encuentra que estos casos comparten algunas de esas problemáticas. Luego de revisar las diferencias y tensiones entre contra-información y alternatividad, se refiere al uso de Internet como un medio que "vuelve mucho más explícitos los vínculos entre opciones técnicas y prácticas políticas". El acceso a internet implica no sólo la disponibilidad física sino también las competencias para su uso, por consiguiente 
"si en otras épocas la comunicación era un medio más en la lucha, hoy la apropiación de las TICS es también parte de los fines por los que se emprenden esas luchas". En este mismo sentido, el actual reconocimiento de la importancia del control de bienes intangibles ganó espacio en los movimientos contrahegemónicos con luchas sociales que van desde el medio ambiente hasta la propiedad intelectual. Asimismo destaca como una de las consecuencias de la evolución de Internet hacia el concepto de 2.0, la popularización de las herramientas para publicar que permiten la participación horizontal y la difuminación de la tradicional distinción entre emisor y receptor.

Desde esta perspectiva el autor plantea dos preguntas de investigación en este tema:

- ¿Qué relaciones se establecen entre los movimientos políticos alternativos y las TICs? ¿Son éstas visualizadas como lugares estratégicos de lucha, o predomina una mirada instrumentalista que los limite a un rol difusor de luchas consideradas más reales o efectivas?

- ¿De qué manera las opciones políticas de los movimientos alternativos con actuación en la web se articulan con la flexibilidad interpretativa de los dispositivos técnicos? ¿Estas opciones se trasladan a usos u opciones técnicas específicos identificables, por ejemplo el uso de software libre o GNU, o plataformas colaborativas de producción de contenidos, etc.?

Metodológicamente tomó como unidades de análisis portales o sitios web de internet vinculados a movimientos sociales contra-hegemónicos, establecidos según un muestreo teórico que diferenció:

a) Sitios orgánicos de movimientos político-sociales definidos.

b) Sitios autónomos impulsados por grupos determinados, de características cerradas

c) Sitios autónomos de tipo colaborativo, relevando sitios impulsados por grupos o colectivos y no blogs individuales

La recopilación de información y análisis de los sitios se realizó entre setiembre y diciembre de 2009, de los 41 sitios contra-informativos encontrados se trabajó con una muestra final de 15 y la misma fue analizada con una ficha que contenía 
los siguientes parámetros de información: autodefinición, articulación con organizaciones o movimientos, identificación de los referentes, sistema de publicación, tratamiento de los artículos, cantidad de artículos publicados, comentarios y vías de contacto, referencias al software libre y a la tecnología como tema y links, enlaces a otros sitios contra-informativos.

Acta - Agencia de noticias de la CTA Agencia de Noticias Pelota de trapo Agencia Rodolfo Walsh

AnRed

Correpi

Darío vive

Enredando

Equipo de investigación Rodolfo Walsh Iconoclasistas

Indymedia Argentina

La colectiva

La fogata

La vaca

Metrodelegados

Prensa de frente http://www.agenciacta.org.ar

http://www.pelotadetrapo.org.ar

http://www.agenciawalsh.org http://www.anred.org

http://www.correpi.lahaine.org http://dariovive.org

http://www.enredando.org.ar

http://www.rodolfowalsh.org

http://iconoclasistas.com.ar

http://argentina.indymedia.org

http://www.lacolectiva.com.ar

http://www.lafogata.org

http://lavaca.org

http://www.metrodelegados.com.ar

http://www.prensadefrente.org

Un primer análisis pasó por distinguir los sitios que se reivindican como proyectos orgánicos y los que no lo hacen, el relevamiento de 41 sitios arrojó que 8 (20\%) mostraban vinculaciones orgánicas, mientras que 29 (71\%) no lo hacían. Por lo tanto no está comprobada en esta muestra, esa relación que en la literatura del tema se considera una característica definitoria de los movimientos contra-informativos. La relación orgánica con proyectos político-sociales definidos abarca a una minoría de los sitios web analizados. Esta definición no inhibe el carácter oposicional de estos movimientos, en todo caso reflexiona el autor, se debe a que las condiciones actuales son muy diferentes a las del contexto de las radios mineras bolivianas $u$ otras experiencias alternativas reconocidas.

Luego de caracterizar a cada uno de ellos, los distingue por el grado de autonomía de los proyectos comunicacionales, utilizando la diferenciación entre: proyectos comunicacionales autónomos, sitios web componentes de proyectos 
comunicacionales de mayor escala, complementarios de otras vías de difusión/información o integrados a estrategias de acción directas.

Luego en materia de contenidos y referentes detecta que en los sitios analizados existe una marcada heterogeneidad en cuestiones como la cercanía respecto a los estándares periodísticos profesionales o la utilización solvente de recursos multimedia. También en cuanto a disparidad en la cantidad de material y frecuencia de actualización del mismo, así como en el uso de fuentes externas. Para definir una tipología de clasificación utilizó las siguientes variables: sitios de opinión, servicios informativos, blogs y órgano interno y luego tomó como ejemplo, un caso para cada categoría.

Posteriormente analizó las herramientas de software utilizada por cada colectivo, consciente de que esta elección condiciona o dificulta el alcance de determinados aspectos. Diferenció los sitios que utilizan sistemas de gestión de contenidos (CMS) de los que no lo hacen, dado que el primero permite la publicación, actualización y personalización como una tarea sencilla, así como la publicación colaborativa descentralizada y la interacción con los usuarios y los que no utilizan este sistema no cuentan con más ventaja que el control total de la plataforma. Aclara que algunos proyectos son anteriores a que los CMS se popularizaran y que por distintas razones no migraron a plataformas actualizadas. También encuentra diferencias entre dos tipos de CMS, el tipo blogs o tipo portal y las plataformas bajo las cuales fueron diseñados que todas se corresponden con la utilización de software libre. En este punto comienza a dar respuesta a la pregunta acerca de si las TICS son visualizadas como lugares estratégicos de lucha o desde una mirada instrumentalista sólo desde su rol difusor. Solo con la excepción de EnREDando, en el resto de las organizaciones la tecnología no es tratada como tema y tampoco problematizada como un factor de lucha contra-hegemónica.

Casi todos los sitios analizados priorizan el control del contenido, evitan dar a los visitantes alternativas de colaboración directas y se inclinan por formatos tradicionales. 
En este capítulo el autor concluye que los sitios web contra-informativos son una expresión actual que hunde sus raíces en la comunicación popular y alternativa de América Latina. Actualizan así dos tensiones centrales: la condición instrumental respecto a proyectos de cambio social y hacia adentro de su propia organización. Además de las problematizaciones que agrega Internet como plataforma para su comunicación.

Los principales hallazgos que el autor reconoce es que la mayoría de los sitios analizados no son proyectos orgánicos de movimientos u organizaciones y que pese a que los contenidos, las agendas y el punto de vista que sostienen son diferentes a los de los medios tradicionales sus modos de producción y negociación con el lector/visitante no muestran mayores diferencias con aquellos. Que pese a que las experiencias colaborativas dejaron de ser marginales, no son parte de este colectivo de experiencias, por lo que el autor manifiesta "la falta de correspondencia entre las posiciones enunciadas y el dispositivo comunicacional utilizado para hacerlo". Es posible -reflexiona-que la problematización más amplia de estas cuestiones conlleven una readecuación de esta realidad.

Hacia una teoría político-comunicacional de los usos tecnológicos

El quinto y último capítulo en una relectura de esos hallazgos, conceptualiza el modo en que las TICS pueden considerarse espacios de lucha política. Para cumplir con ese objetivo realizó una revisión de fuentes provenientes de la teoría política crítica, los estudios de audiencias y los estudios de construcción social de la tecnología.

El autor plantea que al momento de iniciar esta tesis, "uno de los objetivos del trabajo era analizar el modo en que el uso social de las TICs puede considerarse un espacio de tensión política y socio-comunicacional entre el momento institucionalista y el momento creativo/productivo, buscando delimitar si esta distinción posee alguna productividad teórica para explicar los procesos de significación y apropiación de las TICs". En este capítulo espera por lo tanto dar 
cuenta de las categorías y lecturas desde las que obtuvo respuesta y nuevas preguntas para sus indagaciones.

Lo hace desde la teoría crítica contemporánea y apela a la existencia en los fenómenos políticos y culturales de la tensión entre dos momentos: uno institucionalista de administración de lo existente, y otro radicalmente innovador y creador de nuevas posibilidades. Todo ello para saber si las TICs son un espacio de lucha política, para conocer cómo se conceptualizaría esa lucha y si enseñan algo sobre estas cuestiones la incursión en las políticas gubernamentales sobre SIC, la acción de la sociedad civil relacionadas con las TICs y las experiencias contra-informativas en la red.

A partir de diferentes autores planteó esos dos momentos de la política, echó mano al libro El Desacuerdo de Jacques Ranciére, que se constituye como el principal aporte del autor a la filosofía política, para comprender a partir de esta relación, la filosofía de la política. En Toni Negri la relación entre el momento institucionalista y el creativo-productivo de la política se asocia a un proyecto filosófico que rompe con el trascendentalismo y asume la contingencia de las luchas históricas. Mientras que en la obra de Claude Lefort apeló a la interrogación sobre lo que llamó "el modo de institución de la sociedad", aquello que hace que se mantenga como tal a lo largo del tiempo más allá de las transformaciones y que al mismo tiempo la distingue de otras tanto en sentido diacrónico como sincrónico.

De la teoría política de Ernesto Laclau se centró en su modelo general de análisis político basado en las diferencias que a juicio del autor mantiene el discurso institucionalista con el populista, reafirmando que sólo el segundo es político en la medida que se constituye desde la demanda social como expresión de una necesidad y de reclamo.

Finalmente toma a Michel De Certeau, en especial a partir de su obra La Invención de lo Cotidiano en su reflexión acerca de los márgenes "que tienen los dominados para no hacer exactamente lo que los poderosos pretenden, para no estar precisamente en el lugar que se les ha asignado". 
En el cruce de estas lecturas con la política en materia de tecnologías de comunicación, reconoce que es precisamente este último autor quien más recursos ofrece al momento del análisis, dado que su perspectiva es útil para pensar en el conjunto de prácticas de la vida cotidiana, el matiz de no sujeción al orden que siempre presentan ese aspecto que se suele denominar politicidad. Tanto así como el punto de vista de Negri desde dos perspectivas, la primera en la necesidad de permitir la intromisión de lo sorprendente en nuestros propios esquemas analíticos y la segunda es el vínculo que establece entre el poder constituyente e insurrección, el primero dando forma, creando alternativas allí donde la segunda ha abierto cauces a espacios de innovación.

Una conclusión similar a la que arriba en relación a Lefort podría ser el resultado de su lectura de Laclau, si sólo toma nota de la distinción que establece entre lo social y lo político (que podría considerar equivalente a la distinción lefortiana entre lo político y la política). Destaca que el centro de atracción del autor argentino es el opuesto: si para Lefort se encuentra en el primer polo de ambas dicotomías, para Laclau está en el segundo, en lo aún no sedimentado.

De Rancière localiza una escala que busca registrar el conflicto, tal como la experimentan los seres humanos en su propio acaecer histórico, la claridad de ese concepto se fortalece en su idea de que sólo hay política "pocas y raras veces" dado que su existencia exige la interrupción del "orden natural de la dominación".

Como la riqueza de la palabra política reside en su ambigüedad -define citando a Rinesi- se propone mapear la tensión entre la política como práctica institucional de administración de las sociedades y la idea de la política entendida como antagonismo y lucha.

Lecturas, audiencias, usuarios

En los últimos ítems de este capítulo el autor analiza cuestiones comunicacionales en el análisis de los usos tecnológicos, la herencia de los estudios críticos de audiencias y el tránsito de la noción de audiencia al concepto de usuario, así como de los medios a los ensamblajes socio-técnicos. 
La fecundidad de estas temáticas residen no sólo en la estrecha relación entre el objeto de análisis y estas teorías abordadas, sino en la claridad conceptual del autor en tanto comunicador y especialista en tecnologías de la información y la comunicación.

\section{Conclusiones}

A partir del significado de información, el autor reseña la teoría matemática de la comunicación de Claude Shannon cuya ambición era subsumir bajo su modelo todo tipo de procesos comunicativos, ya sea entre máquinas, hombres 0 animales y demostró ser tan exitoso porque planteaba un máximo aprovechamiento de transmisión de información a bajo costo. Su modelo fue clave para el futuro rol de la comunicación en la sociedad contemporánea, su traslado a las ciencias sociales pese a las críticas que cosechó tuvo un alto impacto como base de las teorías de autores fundacionales del campo.

Plantea el autor que el concepto shannoniano de información resulta la base teórica de los esfuerzos por implantar la Sociedad de la Información, desde las coordenadas históricas e ideológicas mencionadas. El acento en la infraestructura que proponen los países centrales y las empresas del sector de telecomunicaciones, y que ha sido incorporado de un modo amplio en las políticas de los países no desarrollados, se justifica al fin por la indiferencia respecto al contenido y la cultura, que se condice con el planteo de aquella teoría fundacional del campo.

Destaca que es en ese proyecto de la Sociedad de la Información donde aparecía fuertemente ligado el avance mundial del neoliberalismo, las Naciones Unidas proponen la realización de la Cumbre Mundial de la Sociedad de la Información. Los debates entre gobiernos, empresas y organizaciones de la sociedad civil no fueron tan exitosos como las expectativas generadas pero permitieron la aparición de "la sociedad civil mundial" un actor muy importante que planteó críticas a las tendencias hegemónicas.

Pone en valor también la importancia que adquirieron los estados nacionales, con particular fuerza en América Latina contra los agoreros que vaticinaban su 
extinción en aras de la tan mentada globalización. A partir de este convencimiento aborda las políticas del Estado Nacional sobre Sociedad de la Información y gobierno electrónico en el período que va de 1997 a 2009 analizando un conjunto de normativas que le permiten delimitar un estado de la cuestión en nuestro país. Explicita que le interesaba indagar si las políticas del Estado argentino vinculadas a las SIC y al gobierno electrónico apuntaban a la utilización de las TICs con un objetivo democratizador o privilegiaban la búsqueda de una gestión administrativa más eficaz.

Encuentra que en el período mencionado no existió un plan integral que contuviera al conjunto de normas vinculadas con el tema de análisis.

Menciona no obstante la ley de Servicios de Comunicación Audiovisual № 26522 que si bien da cuenta de los debates internacionales en su fundamentación, tiene por objetivo la regulación de los servicios de radiodifusión tradicionales. Asimismo destaca que los variados decretos del PEN, objeto de esta sistematización, apuntan casi excluyentemente al desarrollo de la infraestructura de telecomunicaciones, y que una línea que se fortaleció fue la incorporación de TICs a la gestión gubernamental.

Sobre este punto se pregunta si debemos conformarnos con una conclusión pesimista acerca de la cuestión de las políticas sobre el tema en nuestro país y de inmediato responde que como lo adelantara en la introducción de la tesis, la delimitación del corpus documental llega hasta el 2009 pero que otros anuncios y concreciones posteriores a esta fecha -el conjunto de iniciativas gubernamentales abarcadas por el Plan de Televisión Digital Abierta, el Programa Conectar Igualdad y el Plan Quinquenal de Telecomunicaciones "Argentina Conectada"- parecen alentar un plan estratégico para la sociedad de la información.

No obstante como los frentes de lucha son múltiples el autor plantea que sería un reduccionismo limitarse a los debates en los foros internacionales o las normativas nacionales y refiere a la irrupción de los formatos colaborativos como la profunda transformación en Internet, que no fue prevista ni planificada por los grandes aparatos comerciales ni institucionales. 
En su análisis de las organizaciones de la sociedad civil con actuación en el campo de apropiación de las TICs y la inclusión digital, comprobó el alto grado de diversidad, aun cuando en sus opiniones existieran coincidencias.

Al contrastar los pronunciamientos internacionales y las políticas gubernamentales nacionales con la evaluación y opiniones que tienen al respecto este tipo de organizaciones de la sociedad civil, encuentra una clara división de opiniones. Por un lado están las que promueven el software libre que consideran indispensable como medida de apoyo a su desarrollo y el resto que destaca que los intereses son más diversos: la expansión del uso de las TICs, las políticas de superación de la brecha digital, la incorporación masiva en la gestión gubernamental, las políticas industriales del sector, etc.

En general de las respuestas deduce que la "desconexión" coincide con la exclusión social pero varios de los entrevistados opinan que la inclusión digital debe concentrarse en la capacitación para la producción de contenidos. Respecto a la incorporación masiva de computadoras móviles (netbooks) en las aulas hubo coincidencia en cuanto a valorar la importancia del equipamiento, pero acordaron también en que no se sabe si implica un mejor proceso de enseñanza aprendizaje.

Su hipótesis inicial lo llevó a abordar el análisis de los sitios web contrainformativos, considerados a priori como una expresión actual de la comunicación popular y alternativa de América Latina. Un sector que estaba "claramente fuera del espacio institucional, el de los grupos y movimientos alternativos o contra-hegemónicos que tienen a las TICs como campo de intervención".

Y que luego de la pormenorizada sistematización actualiza dos tensiones centrales hacia el interior de estos sitios y portales: la condición instrumental respecto a proyectos de cambio social y hacia adentro de su propia organización.

Los principales hallazgos que reconoce son: que la mayoría de los sitios analizados no son proyectos orgánicos de movimientos $u$ organizaciones y que pese a que los contenidos, las agendas y el punto de vista que sostienen son 
diferentes a los de los medios tradicionales, sus modos de producción y negociación con el lector/visitante no muestran mayores diferencias con aquellos y que, pese a que las experiencias colaborativas dejaron de ser marginales, no son parte aún de este colectivo de experiencias. Asimismo en los casos que releva el autor, a estas tensiones mencionadas se suman las cuestiones que la especificidad de Internet como plataforma técnica agrega.

Finalmente destaca que las categorías de la teoría política crítica contemporánea que utilizó para interpretar su proceso, resultaron productivas para un análisis de las tecnologías de comunicación. Si esto es así, -reflexiona el mismo autor- lo es porque estas categorías presentan una marcada homología con los resultados a los que han arribado, tanto la tradición de los estudios críticos de audiencias, como las actuales investigaciones sobre Internet y los medios digitales inspiradas en la corriente de los estudios de construcción social de la tecnología.

Al concluir el proceso el autor plantea la necesidad de nuevos interrogantes como una vía para la continuidad del tema en nuevas investigaciones, es el campo de los usos cotidianos de las tecnologías, lugar en donde éstas son domesticadas y reapropiadas por los usuarios, sin perder de vista -advierte- que se trata de un lugar de negociaciones, un campo de lucha por la producción de sentido.

“De este modo, podremos comprender mejor los complejos modos en que las tecnologías de información y comunicación, lejos de ser epifenoménicas respecto a las luchas por el prestigio, el poder y el acceso a los recursos materiales y simbólicos, son -en nuestras complejas sociedades de comienzos del siglo XXI- sede y botín de esas luchas" concluye.

b) Tesis Celina Salvatierra 18/12/2012

Autonomía en la ciudad de México 2010-2011: Comunicación y gestión en el centro cultural "La Pirámide" 
La directora de tesis fue la Mgter. Nancy Díaz Larrañanga y se desarrolló durante el período 2010-2011 en el Distrito Federal, ciudad de México.

Índice de contenido

Presentación

1. Antecedentes $\mathrm{p}-7$

1.2 Tema $p-11$

1.3 Referente empírico $\mathrm{p}-12$

1.4 Problema de investigación p-12

Marco teórico referencial

2 Los estudios culturales $p-13$

2.1 Estudios culturales latinoamericanos p-14

2.2 Comunicación en las organizaciones $p-15$

2.3. Diagnóstico de la comunicación $p-15$

2.3.1 Diagnóstico participativo $p-16$

2. 4 Comunicación y complejidad p-17

2.5 Diagnóstico y planificación $p-19$

2. 5.1. Significación e indicios $p-20$

2.6 Tipos de organización $\mathrm{p}-21$

2.7 Misión y visión p-22

2.8 Organización e institución $\mathrm{p}-24$

2.8.1 Organización, discurso y poder p-25

2.8.2 Prácticas y roles $\mathrm{p}-27$

2.9 Noción de autonomía $\mathrm{p}-29$

2.9.1. Comunicación participativa y democrática p-31

2.9.2 Noción de ciudadanía comunicativa p-33

2.9.3 Articulación comunicación y arte p-33

Contexto socio-político en el que se ejerce la práctica

3 Introducción p-36

3.2 Arte y cultura como campo estratégico p-36

3.3 El aparato cultural estatal $p-39$

3.4 Visibilidad en el marco legal de la cultura $p-40$

3.5 El Estado administrativo $\mathrm{p}-41$

3.6 Una matriz mercado-céntrica p-42

3.7 De colores políticos en el mismo territorio $p-44$

3.8 El Estado y la cultura en las periferias $p-45$

3.9 Los espacios autónomos y auto gestionados p-47

3.9.1 Mapa de la autogestión en la Ciudad de México c/ metro p-48

3.9.2 Auto-representación de la autonomía p-49

Referente empírico. El caso La Pirámide p-55

4 .1 Centralidad del edificio en forma de pirámide $p-55$

4.2 Figura legal y naturaleza del vínculo entre la Asociación de Escritores y el 
centro cultural $p-67$

4.3 Documentación de referencia $p-69$

4.4 Características de los actores $p-72$

4.5 La propuesta cultural por la que se evidencia el proyecto político p-77

4.6 "Aquí y ahora" de la organización p-78

4.7 Productos comunicacionales, situaciones de comunicación en la organización p-79

Diseño metodológico p-86

5 Estrategias $p-88$

5.2 Técnicas p-89

5.3 Información relevada en las entrevistas a actores externos de la autogestión y de la autonomía p-90

5.4 Productos comunicacionales $p-91$

5.5 Lista de entrevistas a informantes clave -91

Diagnóstico comunicacional del centro cultural "La Pirámide" p-92

6.1 De la autonomía y de la autogestión p- 94

6.2 Una mirada Comunicacional p-95

6.3 Modelos de gestión en La Pirámide p-97

6.4 De los roles atribuidos y asumidos $p-101$

6.5 De los productos mediáticos ¿para públicos o para ciudadanos? p-107

6.6 Massmedia p-109

6.7 Misión y visión en un proceso identitario p-111

6.8 Un proceso crítico y reflexivo $p-112$

6.9 Trayectos causales decisivos p-114

7. Planificación. Líneas de acción posibles para la autonomía y autogestión. P115

Referencias bibliográficas $p-120$

Anexos

El objetivo general del trabajo consistió en diagnosticar para comprender el proceso comunicación en una organización que se define como autónoma y autogestiva; a fin de reconocer los modos en los que se comunica y elaborar una propuesta de planificación.

Los objetivos específicos plantearon diferenciar los elementos constitutivos de situaciones de comunicación en referencia a la cultura organizacional:

- Las estrategias comunicacionales entre modelos de gestión (2010-2011) y los cuerpos informacionales que las sustentan.

- Un esquema de poder, un discurso enunciativo que lo hace posible. 
- Los modos particulares de construcción del orden simbólico.

\section{Presentación/ Antecedentes}

A modo de introducción, la autora detalla una síntesis de los antecedentes de la Maestría de Planificación y Gestión de Procesos Comunicacionales -PLANGESCO-, a fin de comprender la pertinencia de este estudio de caso. Aclara la perspectiva de investigación que propone la Maestría, consistente en un acercamiento a las organizaciones y sus procesos de comunicación desde una mirada puesta en las experiencias, los modos de vinculación e incidencia con los procesos socioeconómicos, políticos y culturales.

El caso abordado se sitúa en México y está vinculado a modos de hacer propios de la autonomía y la autogestión en ese país. Por lo tanto los antecedentes relevados tienen que ver con los procesos de comunicación que suscitan sentido colectivo en dicho contexto. Menciona la autora que la relación Estado-sociedad civil se ha deteriorado todavía más en el último sexenio, sin modificaciones en el modo de hacer política tras 70 años sin alternancia, mucho menos en sus maneras de comunicarse. Las políticas públicas se sostienen más que nada en el asistencialismo y se profundiza la impunidad de crímenes y desapariciones.

La propuesta académica de PLANGESCO es vista por la autora como un aporte pertinente para que las organizaciones de la sociedad civil entiendan a la comunicación como un proceso clave para comprender la cultura. En particular, refiere al centro cultural auto gestionado La Pirámide, organización que tuvo un papel fundamental en el debate sobre este tipo de prácticas culturales. En el momento de realización de esta tesis, la organización atravesaba un proceso de crisis entre un nuevo modelo de gestión democrático o un repliegue sobre sí misma volviéndose más hermética. El interés estuvo puesto en esta definición, en la posibilidad de facilitar procesos para proponer el cambio o como inspiración para otros espacios culturales que quisieran diferenciarse en su contexto. 
Tema -Referente empírico - problema de investigación

El interés de la autora, sobre todo en su condición de extranjera tuvo que ver sobre todo con la necesidad de pensar y conocer estos espacios considerados como diferentes, identificados desde la autogestión y autonomía, donde confluyen subjetividades y formas de organización colectiva en el marco del capitalismo.

El centro cultural La Pirámide es definido por la autora como un espacio que vuelve visible la oferta cultural alternativa en México. No obstante menciona que del relato de los actores emerge la dificultad de no contar con leyes que los legitimen, lo que condiciona estructuralmente la autogestión. En el caso mexicano esta omisión no refiere a desinterés por parte de los gobiernos que han visto a la cultura como una herramienta estratégica y de cohesión, sino como un modo específico de control. En este marco el vínculo entre autogestionados y el gobierno adopta diferentes modalidades. Otro condicionante es el lugar de funcionamiento, que en el caso de La Pirámide ha marcado la historia de la organización sobre todo en la división de sus fuerzas. Antes de que el centro cultural se constituyera como tal había sido casa de cultura, hasta que ese año la Asociación de Escritores de México propuso la acción colectiva que significó la

toma del edificio. En los documentos de ese debate se dio cuenta de la necesidad de contar con edificios propios y de un marco legal que todavía no existe pero que ha generado distintas estrategias de gestión y permanencia de los espacios culturales.

En torno al problema de investigación la autora esbozó tres preguntas ¿Cuáles son las situaciones de comunicación en el momento actual de la organización? ¿Qué mapa de poder develan? y ¿Cuáles son las condiciones que permitirían a los actores reflexionar en torno a ellas? Interrogantes que se formularon en la relación de conocimiento/acción y que permitieron la realización del diagnóstico comunicacional. 


\section{Marco teórico referencial}

En el capítulo siguiente la autora da cuenta de los materiales que dieron andamiaje a su proceso de análisis de dicho referente y al diagnóstico que realizó mediante la observación de situaciones de comunicación.

Los estudios culturales como un nuevo enfoque de análisis contrapuesto a las tendencias desarrollistas que gestionaban la comunicación de manera vertical, pensaron a la comunicación como hecho cultural, pero también dotada de una dimensión política y liberadora de los sujetos. Se suman a este marco herramientas conceptuales de la investigación de la comunicación y de la planificación y gestión de procesos comunicacionales.

Ambas líneas le permiten a la autora pensar la comunicación como instancia de relación que dota de sentido a la experiencia y diferenciar los elementos de las situaciones de comunicación, entendidas éstas como hechos que conforman la cultura organizacional. Asimismo esboza como categorías centrales: la comunicación democrática y participativa, y suma a la investigación la articulación entre comunicación, arte y cultura, a fin de repensar esta relación y proponer nuevas acciones.

Pone el acento en el diagnóstico de la comunicación como un modo de proyectar acciones en función de la situación comunicacional que se lee, en ese sentido lo considera una forma de evaluación. Valora el diagnóstico participativo que releva y enuncia situaciones desde la perspectiva comunicacional y aunque lo reconoce como un esquema técnico, encuentra en sus antecedentes puntos de articulación con el método de Morin. Este proceso de conocimiento, en tanto proceso de aprendizaje implica la observancia de la indeterminación, la incertidumbre y el error, aspectos de lo real que crean las condiciones para el diseño de estrategias, las que a diferencia de los programas y planes pueden mutar, es decir que es posible su adaptación en función de las circunstancias.

Destaca que la misma noción de planificación refiere precisamente a la capacidad de operar sobre una realidad compleja, es decir susceptible de ser intervenida mediante una estrategia. De este modo cita a Morín cuando propone 
que la planificación es una formulación de estrategias más o menos flexibles, en relación con el diagnóstico.

Utilizando herramientas de la semiología, refiere luego a los estudios de comunicación organizacional que toman como elementos de análisis aquellos objetos que tienen un valor de uso y que son desbordados por su significación. Apela así a la búsqueda de los indicios que representan situaciones y procesos de comunicación, para ello utiliza clasificaciones ilustrativas de autores como Schvarstein, Etkin, Uranga, Villamayor.

Luego menciona una clasificación sencilla de los tipos de organización con los que trabajará en este marco, incluye las del Estado, las privadas y las de la Sociedad Civil, asociadas al campo cultural y del arte en México, entre las que se cuentan las autónomas y autogestionadas, caso de análisis de este trabajo.

El discurso de la organización presenta en sí mismo los rasgos de la cultura de la organización, define la misión y visión de la misma y le permite pensar al proceso dialéctico instituido/instituyente. Así como definir a las organizaciones como mediadoras entre las instituciones y los sujetos, le posibilita considerarla un sujeto enunciador para su análisis.

Toma de Michel Foucault la noción de poder en tanto relaciones de fuerza, entendidas como el predominio de unos intereses sobre otros en tanto posicionamientos en un esquema red. Foucault explica la adhesión al poder desde las periferias del mismo a partir de la ideología y de la institución, de modo que para trabajar un aspecto constitutivo de la ideología retoma la noción de espacio narrativo, constituido por aquellos metarrelatos que concilian versiones de la memoria tal como lo señala De Certeau.

La pregunta final de este apartado es en torno a la viabilidad del cambio en ese escenario y recurre a Schvarstein quien asegura que el sentido del cambio está en suspenso hasta que no se verifica la coherencia expresiva relacionada. Esta afirmación presenta al cambio como posible pero a través de distintas formas que pueden ser pensadas como parte de una planificación y como líneas de acción específicas. La construcción del significado implica también el reconocimiento de la posición del sujeto en relación con el objeto ya que las 
relaciones de poder inciden en las subjetividades. En este sentido siguiendo a Schvarstein recurre a la noción de mapa relacional para poner a los sujetos en relación según sus roles.

Otra de las características trabajadas y asumidas como clave de la organización es la autonomía y en ese sentido, la articulación entre la autonomía y la gestión de la comunicación está dada por un antecedente teórico ya mencionado que es el paradigma de la complejidad y la definición de la autonomía como parte de un sistema complejo con capacidad para auto organizarse y subsistir.

Por último en la articulación entre comunicación y arte, encuentra en trabajos de Romeu Araya (2008) en México la revisión del concepto de diálogo considerado en este marco como elemento ontológico de la comunicación y a la vez como enfoque, mientras que en el arte el abordaje es a partir del concepto de práctica artística en tanto suceso creativo, noción a la que se suma la de experiencia estética. El desarrollo de este autor le permite acercar una propuesta de trabajo en el marco de la planificación, dado que considera que el arte además de lenguaje -aspecto desde el que se encuentran la mayor cantidad de antecedentes de relación entre arte y comunicación- es una práctica social. Como tal tiene un componente comunicacional constitutivo, por tanto no considera a la obra de arte como soporte producto de la relación artecomunicación porque esto supone un posicionamiento en materia comunicacional de equiparar comunicación con información. En este desarrollo, el arte debe ser considerado como una relación social al interior del mismo proceso comunicativo y la producción artística aparece en ese proceso mediada por la interacción.

La oferta cultural o proyecto político del centro La Pirámide es entonces, al concretarse, un lugar de interacción, un espacio comunicativo en sí mismo y el arte que se entrega a los ciudadanos es la práctica al interior de ese proceso que tiene características específicas, las cuales desarrollará la autora en el diagnóstico.

Contexto socio-político en el que se ejerce la práctica 
Este capítulo da cuenta del sentido histórico que se ha dado a las políticas culturales en México; hace una breve descripción del aparato estatal en materia cultural en términos de su estructura; sintetiza las relaciones de fuerza en el campo del arte y la cultura y realiza una lectura crítica de las políticas aplicadas al momento de redacción de este trabajo. A esto se suman elementos condicionantes tales como el índice de la accesibilidad a Internet, costos comparativos en México y con otros países. La pertinencia de esta última información tiene que ver con la incidencia que las nuevas tecnologías podrían tener en el proceso de construcción de una ciudadanía participativa pero también con la necesidad de considerar sus limitaciones.

Las políticas culturales como estrategia de integración después de la Revolución de 1910 respondieron a la necesidad de lograr cohesión en torno a proyectos que reivindicaran la identidad mexicana. Con tal finalidad se creó la Secretaría de Educación Pública (SEP) en 1921, con José de Vasconcelos como titular, cuya apuesta fue un plan estratégico integral de la cultura y educación. El discurso nacional institucionalizó la enseñanza y propaganda de las artes y para eso tuvo lugar la construcción de una infraestructura cultural sin precedentes en Latinoamérica.

El Estado construyó una maquinaria cultural que tiene hasta nuestros días una fuerte injerencia en la definición de lo que es arte y de lo que es cultura. Dicha fortaleza no ha disminuido a pesar del período neoliberal en el que el Estado tras asociarse con grandes monopolios aseguró su adhesión a otro proyecto de control como es la industria del entretenimiento

Por otra parte, la falta de marcos legales para funcionar en condiciones de igualdad y fortalecer la propia oferta artística y cultural, ha sido un reclamo constante de la autogestión y otros sectores de la Sociedad Civil en México. Esta ausencia, contrasta con la fuerte presencia del aparato cultural estatal en la normativa y realza los conflictos y debates que se han suscitado históricamente alrededor de las leyes de medios. 
No obstante a pesar de la alternancia partidaria en la órbita nacional (dos presidencias del Partido de Acción Nacional -PAN-) la planificación de políticas de corte desarrollista no generó cambios significativos en los modos de hacer de la política cultural. De hecho el $94 \%$ de las concesiones que determina la ley mexicana están en poder de dos grandes monopolios, Televisa y Tv Azteca, productores que informan y entretienen a las audiencias en el país, con el mismo tipo de oferta cultural, cargada de condicionamientos y de representaciones.

De hecho el fin del Partido Revolucionario Institucional (PRI) en el poder central y en la ciudad, marcó un arco de expectativas entre los actores culturales, quienes esperaban una democratización de las expresiones artísticas. A pesar de que esa instancia de participación no llegó, la efervescencia sirvió de semillero para la diversificación de proyectos y producciones en espacios culturales independientes.

\section{El Estado y la cultura en las periferias}

La nueva administración en la ciudad (PRD) creó al principio de la década del 2000 las Fábricas de Artes y Oficios (Faros) para el reemplazo de las tradicionales Casas de Cultura del priismo federal. Pero el accionar no se inició a partir de una planificación original, sino del encausamiento de proyectos autogestivos y de la convocatoria a líderes que habían resultado de las huelgas que se sucedieron en la UNAM, en defensa de la educación pública.

Dicha visión incluyente de las periferias, que perteneció en principio a la Sociedad Civil y que fue luego considerada por el Gobierno de la ciudad, permitió que emergiera en el territorio capitalino una constelación de espacios culturales que, aunque más y menos fluctuantes, ofrecen desde entonces propuestas alternativas con espacios físicos y simbólicos de expresión libre. Es así como los faros se complementan con los espacios culturales autónomos y autogestionados.

Los espacios autónomos y autogestionados 
Fue parte del diseño metodológico de la tesista entrevistar a referentes de la autogestión que fueran reconocidos por sus pares, "creando de ese modo algo así como una lista de la autogestión por 'autorreconocimiento'".

Tras relevarlos y contactarlos, trazó un mapa -con referencia a la estación de metro más cercana- para identificar dónde se encuentra la autogestión reconocida por sus propios actores en la ciudad, priorizando los que tienen espacio físico para funcionar, que les permite ser identificados también tanto por autoridades delegacionales como por vecinos y comunidad en general.

Todos los referentes y líderes de las organizaciones aceptaron dialogar y le permitieron a la autora un acercamiento a las representaciones de la autogestión y de la autonomía.

La Casa Refugio Citlaltépetl nace como extensión del Parlamento Internacional de Escritores teniendo como fin la asistencia a intelectuales no mexicanos perseguidos por sus ideas en otros países. Cuauhtémoc Cárdenas (Partido de la Revolución Democrática 1997-1999) propuso la creación de un sitio de refugio para intelectuales exiliados siguiendo la política de su padre, Lázaro Cárdenas, quien décadas atrás había generado las condiciones para que migrara a México la mayor cantidad de extranjeros de la historia, en mayoría españoles que huyeron de la Guerra Civil.

Philippe Ollé Laprune, director del centro cultural explicó que a poco tiempo de ponerse en marcha el proyecto, la llegada de otro jefe de gobierno a la ciudad motivó la reducción del presupuesto y desde ese momento tuvo que volverse un gestor cultural. Opina que siempre hubo una relación especial entre los intelectuales y el gobierno y que el hecho de recibir apoyo no implica que interfieran en la producción. No obstante según sus concepciones, en la práctica la autogestión es un problema para el sistema, ya que él toma presupuesto oficial pero no le dicen cómo administrarlo. En torno a su visión sobre los modos de comunicar los proyectos políticos de la cultura sostiene que otra particularidad es que en México se invierte en producción pero no en difusión.

Otro de los actores El Circo Volador, un centro cultural que es reconocido en la ciudad como autogestivo, nació como una iniciativa privada que logró apoyo por 
el prestigio académico de su presidente quien elaboró la tesis de doctorado “ Juventud popular sus medios y sus efectos". El resultado fue la puesta al aire de un programa radial Ilamado Tolerancia Zero con el que se fueron ganando adeptos y la gestión logró apoyos locales e internacionales, lo que le permitió incorporar en su directorio a personas que habían estado involucradas con la lucha social, incluso en el zapatismo. Uno de ellos es Jovany Avilés, su actual director de proyectos, quien compartió que en la actualidad habría un perfil más asociado a lo comercial que a lo social en el espacio cultural.

Un dato clave es que el centro de arte y cultura se constituyó como Asociación Civil desde 1995 y potenció su costado más social a la hora de elaborar proyectos para pedir financiamiento. Esta combinación de estrategias, pareciera haberlo fortalecido, mientras que, por un lado se renta el espacio para conciertos de rock y se hacen negocios con productores musicales a la vez no se descarta la posibilidad de ofrecerse como lugar donde jóvenes encuentran algunas actividades tendientes a la inclusión.

Una mirada diferente es la de Ignacio Pineda del Multiforo Alicia, quien asegura que es posible sostener una ideología, una filosofía de la autogestión y de la autonomía en México. Es interesante remarcar que Pineda da la entrevista en la barra de ingreso al Multiforo y frente a sus compañeros, quienes escuchan atentos y completan algunos datos. También explica Pineda que la autonomía y la autogestión tienen como debilidad general el tema de los espacios. Incluso señaló que el alto costo de la renta es la principal debilidad para el Multiforo.

La misma necesidad de un espacio propio fue la que movilizó a la comunidad del Chanti Ollin, un espacio cultural que funciona en una casa tomada, en un barrio de nivel medio a alto (Chapultepec) en la ciudad de México. Allí, grupos de artistas independientes, zapatistas, integrantes de movimientos de los pueblos originarios, en mayoría jóvenes, realizan distintas disciplinas; organizan recitales de rock, hip hop, punk, cuentan con un horno de barro en el que hacen pan que canjean a productores por verduras, cuentan con una sala de medicina orgánica y tradicional, hay teatro, performance, y diversidad de propuestas ecológicas y 
de activismo urbano. El Chanti Ollin implica colaboración de varios grupos que están en red por la ciudad y en otras; que no habitan la casa en forma permanente, juntos han resistido a los juicios e intentos por recuperar el espacio por parte de sus propietarios originales. Una cualidad que valoran otros autogestionados es la capacidad de resistencia de quienes son parte de la organización.

Por su parte, la Central del Pueblo, también tuvo que resolver el problema de no contar con sede aunque sus líderes optaron por la vía de la negociación. Al ser desalojados por el gobierno delegacional de un edificio histórico (Teatro del pueblo) en el que trabajaban para su recuperación, acordaron con un comerciante del Centro Histórico de la ciudad el préstamo de una antigua vecindad que ahora arreglan, mientras realizan diversas actividades culturales, teniendo entre otros, el proyecto de obras de teatro ambulante en las periferias. Al igual que los anteriores su director remarcaba que para subsistir la autonomía, tiene que superar en primera instancia la dificultad que representa contar con un espacio propio para su funcionamiento. Luego, el paso siguiente es conseguir quien respalde el proyecto autogestivo, por lo que sus directores y coordinadores deben volverse gestores culturales.

Referente empírico. El caso La Pirámide

En este capítulo la autora caracteriza la organización, los actores, su propuesta cultural, los vínculos, productos y situaciones comunicacionales que le permiten profundizar y dar cuenta del conocimiento del caso abordado.

En torno a su ubicación destaca que La Pirámide está ubicada al suroeste de la Ciudad de México en la colonia San Pedro de Los Pinos; de la Delegación Juárez, que tiene alrededor de 385 mil vecinos. El sector cuenta con uno de los índices educativos más altos de la ciudad como también con un nivel económico de medio a alto. El área del centro cultural colinda con sectores de la delegación Álvaro Obregón, que presentan como contraste algunos cordones de pobreza. Su área de influencia no está circunscripta a la colonia (barrios en términos 
argentinos) ya que su oferta artística y deportiva es demandada por otros sectores de la ciudad que llegan por servicio de metro y metrobús.

Su diseño arquitectónico tiene forma triangular y representa una pirámide tal como su nombre lo indica y si bien es una construcción moderna, parece haber sido inspirada en la cultura prehispánica. Así lo explica la tesista que agrega que la localización se encuentra en una zona arqueológica y es el lugar donde vivió su infancia el escritor Octavio Paz, por lo que específicamente en esa zona de ruinas funciona una dependencia del Instituto Nacional de Antropología e Historia. Agrega que todos los relatos sobre su historia aluden al edificio y es reconocida en la misma la lucha que se desarrolló en el 2004 para la obtención a préstamos del mismo. También sirvió esta movilización denominada 'La Pira Lucha' para un pronunciamiento colectivo en torno a la recuperación de edificios abandonados como única vía de acceso a propiedades de acceso inalcanzable a la mayoría de los ciudadanos. La convocatoria la comenzó la Asociación de Escritores que contaba con una oficina allí, paralelamente la Jefatura de Gobierno de la ciudad llamó a las Delegaciones a vender o alquilar los edificios mencionados. Así fue que una vez recibido el citatorio, los colectivos y asociación mencionada organizaron la toma de las instalaciones que duró siete meses e incluyó otras acciones mediáticas y de intervención pública. Luego de ese período de resistencia las autoridades le otorgaron un permiso temporal revocable, que al haber expirado cambió en la actualidad el escenario de la negociación entre el gobierno y el colectivo cultural. A pesar de que La Pirámide integró redes de autogestión, esta lucha se fue debilitando con los años y en la actualidad no hay actividades que unifiquen a quienes continúan bregando por la autonomía y la autogestión. No obstante existen algunos convenios con el Gobierno para hacer actividades, y se ve muy lejana la posibilidad de que el espacio ocupado sea devuelto al Estado.

La autora enumeró luego los diferentes modelos de gestión en los que la organización basaba su sustento legal así como la conformación de un comité directivo e incluso un pronunciamiento sobre la propuesta artística, estética y política pensada como extensiva a un nuevo modelo democrático de país. No 
obstante la convivencia de la diversidad de los colectivos involucrados trajo aparejadas tensiones sobre todo en el tema de uso del espacio y mantenimiento. Fue por este motivo que se llegó a la figura de los coordinadores en la necesidad de resolver, entre otros, problemas de infraestructura. Menciona posteriormente la realización de un trabajo de relevamiento que derivó en un informe que fue desde los recursos materiales hasta las relaciones de los actores y colectivos de La Pirámide. Este documento no sólo marcó debilidades y diagnósticos de la dimensión comunicacional sino que sirvió para la realización de un proyecto ecológico inédito en la autogestión de la ciudad.

La propuesta cultural como proyecto político

Luego de realizar una caracterización de los actores, menciona los cinco coordinadores, todos con formación académica, dedicados a diferentes áreas de gestión mediante roles productivos. En cuanto a los colectivos, al momento de realizar esta tesis la autora manifiesta que funcionaban una decena de grupos que iban desde un laboratorio de experimentación de cine alternativo hasta acrobacia aérea y teatro callejero. Se sumaban otras actividades y festivales (adjunta documentación gráfica de talleres y eventos) así como una gran cantidad de productos comunicacionales, que a su juicio, definen el proyecto político y las especificidades de la organización. Al detallarlos sostiene que una mirada sobre ellos permite conocer los ámbitos de interacción y distribución de la información al interior y exterior de la organización.

Los soportes tradicionales fueron la cartelería y folletería, dado que los formatos en papel insumen costos difíciles de solventar. El proyecto para incrementar su posicionamiento pasaba al momento de la redacción de este trabajo por difundir en las carteleras del metro y conseguir un acuerdo para que jóvenes del Instituto Mexicano de la Juventud hiciesen una pasantía que colaborara con esta y otras estrategias de difusión e investigación. No obstante lo concreto para las actividades de 2011-2012 fue la difusión en formatos digitales a través de las redes sociales. A pesar de contar con 400 seguidores en la fan page y 2500 en el 
perfil de Facebook, no existía hasta ese momento una estrategia de seguimiento de la participación o de adecuación de formatos a cada propuesta de comunicación. Así como tampoco una sistemática difusión de los talleres lo que es marcado como una debilidad y enunciado como problema por sus mismos protagonistas.

Otra situación de comunicación analizada trata de la vinculación con los colectivos que quieran sumarse al centro cultural, para los cuales se plantea el establecimiento de una obligación contractual que asegure el cumplimiento de deberes para con el espacio. De acuerdo a lo planteado por la autora, estos modos de hacer comunicación aparecen en las estrategias de difusión que son vistas y formuladas como un proceso lineal. "De estos indicios y situaciones que a su vez conforman procesos, se desprenden modos de ver a la comunicación que inciden en cómo se piensa y planifica. Todo lo que se hace en pos de construir y distribuir mensajes parece estar escindido de la idea de que la comunicación equivale a un proceso complejo y de transformación, y que, precisamente por eso, tienen que ser considerados varios frentes. Uno de ellos puede ser la enunciación mediática, pero sin duda, otro indispensable son las relaciones intersubjetivas que permitirán conocer cómo se reproduce una cultura".

\section{Diseño metodológico}

El trabajo fue abordado desde una metodología cualitativa para indagar sobre los procesos de comunicación de la organización. En una primera etapa con la realización de un pre-diagnóstico que determinó la necesidad de elaborar un diagnóstico participativo para "construir una mirada comunicacional a partir de las representaciones de los propios actores, aunque también realizando un distanciamiento necesario para pensar analíticamente al caso y hacer propuestas que facilitaran procesos".

En estos abordajes se articularon técnicas de observación participante, análisis de documentos, realización de entrevistas y trabajo en grupo con los actores identificados como líderes de la organización. Destaca la tesista que las 
entrevistas semiestructuradas fueron la herramienta más significativa en el trabajo de campo, para conocer las percepciones de los actores y reconstruir algunas representaciones de la autonomía y sus procesos comunicativos. A la información obtenida se sumó la observación de situaciones de comunicación para inferir el modelo comunicativo que atraviesa a los distintos sectores de la organización, así como el diálogo con los actores acerca de la misión y la visión permitió pensar el tipo de gestión que se estaba desarrollando. De la consideración de estos aspectos recuperó información para esbozar un mapa de poder que le permitiera visualizar los flujos comunicacionales.

Asimismo se realizaron entrevistas a gestores culturales de la ciudad, funcionarios de la Secretaría de Cultura, diagnosticadores, referentes de centros autogestivos, autónomos y/o independientes; coordinadores de La Pirámide, presidentes sucesivos de la Asociación de Escritores de México A.C. e integrantes de colectivos indagando acerca de cuáles situaciones de comunicación podían ser mejoradas a fin de facilitar un reacomodamiento en el modelo hacia otro con mayor potencial participativo.

\section{Estrategias y técnicas}

Una primera estrategia fue la de relevar la comunicación desde afuera hacia dentro, interpelando a interlocutores externos, a fin de reconstruir el universo discursivo y de identificar corpus informacionales y representacionales que dialogan con lo particular.

En la estrategia 2 se buscó considerar la comunicación interna, teniendo como referencia el esbozo de un mapa de poder y actores identificados, sumando información sobre roles productivos y áreas de trabajo como también las percepciones que los actores tenían de su propia tarea. De ese modo se reconocieron alianzas, algunos oponentes señalados en la historia y discurso organizacional, y se tomó nota de rasgos provenientes de las subjetividades y tensiones. Asimismo, se efectuó una comparación entre el organigrama formal 
con el de roles productivos a fin de identificar el modo en el que se distribuyó el poder en la organización en el período 2010-2011.

Los materiales que destacó fueron: los espacios de comunicación, momentos comunicacionales; el contenido y la forma de los mensajes que produjo la organización; flujos y recursos comunicacionales de la organización, pero más que nada las interacciones entre coordinación con los colectivos, colectivos entre sí y modos de relación con los asistentes a talleres y otras actividades.

En cuanto a las técnicas, la propuesta fue pensar un mapa causal a partir de fortalezas y debilidades, identificar trayectos causales decisivos, (red de debilidades asociadas a necesidades) y determinar los nudos críticos es decir, los de mayor relevancia para la acción, considerando a los propios actores como los protagonistas de las lecturas pertinentes para detectar la mirada comunicacional en un contexto acotado.

Tras detallar la información relevada en las entrevistas a actores externos de la autogestión y de la autonomía, describió una taxonomía elaborada para considerar acciones u omisiones al comunicar desde Internet y una enumeración de los destinatarios de las 14 entrevistas realizadas.

Diagnóstico comunicacional del centro cultural La Pirámide

El aspecto central del diagnóstico tiene que ver con las contradicciones que manifiesta la autora haber detectado en el proceso del período analizado, teniendo como parámetro la participación y democratización del centro cultural. Las situaciones de comunicación enumeradas le permitieron inferir la presencia de una estructura piramidal con una comunicación más fluida entre integrantes de la Asociación de Escritores de México con los coordinadores y de manera descendente con los demás actores de la organización.

Como debilidades emergentes menciona que no se produjeron procesos de abajo hacia arriba, en parte por cuestiones de falta de espacios que lo propiciaran. También refirió a malentendidos entre roles y su asunción, a dificultades para comunicar el proyecto político y al desconocimiento de las necesidades de los interlocutores. 
Respecto de sus reflexiones acerca de estos indicadores menciona por un lado, la imposibilidad por parte de la organización para adecuar sus modos de comunicación a un proceso más participativo y la influencia del contexto estatal con un modelo más orientado a la reproducción que al cambio.

Al concebir la planificación como un momento del proceso integral de gestión, el análisis de los procesos comunicacionales analizados puso en evidencia la falta de la misma. También la distancia existente entre el concepto de autonomía y los resultados del relevamiento da cuenta de que los problemas de relación entre los niveles de la organización se alejan de la noción de construcción colectiva. No obstante la capacidad discursiva y de gestión son cualidades que diferencian a los actores líderes de los demás y es valorada por todos los coordinadores. Mientras que "la modalidad de producción de sentido está claramente asociada a la formulación de una gestión que puede recrear el mito de autonomía desde el discurso pero que a su vez ve a los colectivos como públicos. Los otros aquí y ahora no son sujetos que tienen las mismas capacidades que nosotros y pueden sucedernos, continuar el proyecto de autonomía, sino de públicos, es decir, receptores de nuestros mensajes e invitaciones a una propuesta cultural que ya no se diferencia de las del Estado porque el mismo gobierno, a través de los faros culturales ya diversificó su propuesta cultural y artística llevándola, aunque de modo insuficiente, a las periferias".

Si la representación comunicacional de los interlocutores es de públicos, los coordinadores por deducción, son prestadores de servicios y no miembros de una organización autónoma que tiene los rasgos condicionantes de la autonomía. Precisamente concebir a los sujetos con los que queremos comunicarnos como sujetos de decisión, es clave para el diseño de estrategias comunicacionales dentro y fuera de la organización. Aunque de las entrevistas realizadas se infiere que los talleristas y artistas a veces son vistos más como sujetos de necesidades y demandas.

En cuanto a los medios para comunicar el más utilizado por la organización es Internet y la publicidad impresa en carteles y volantes. Hay un desinterés 
particular en los medios masivos tradicionales y de las entrevistas se interpreta que además de las razones que exponen de falta de tiempo para explorar esas posibilidades, los actores tienen una representación definida respecto de los medios masivos en la sociedad mexicana.

En relación a la misión y la visión de la organización planteadas seis años antes de este relevamiento como la construcción de un proyecto alternativo a las políticas gubernamentales con vistas a autosustentarse mediante esas prácticas emancipadoras. Los cambios instrumentados implicaron más concentración en el proceso, la misión tiene hoy más que ver con lograr coherencia en el diálogo con los colectivos en tanto la visión implica redefinir la clase de organización deseada contrastando lo alcanzado con aquellos propósitos originales.

En este diagnóstico las prácticas refieren a un proyecto que no es del todo participativo en el que la noción de autonomía se relativiza, dando prioridad a la subsistencia de la organización como se encuentra, con sus autoridades y su modelo instituido.

En este sentido, un proceso reflexivo respecto de la organización que pretenden y la noción de autonomía, permitiría actualizar de modo colectivo la misión y la visión. Así como también la relación que se tiene con los interlocutores que implicaría modificar la representación de de ellos como público a pensarlos como componentes de un proyecto político y también como posibles futuros líderes.

Finalmente la autora plantea que este conjunto de debilidades formuladas en el texto -un esquema comunicacional vertical, falta de acuerdos entre actores en torno a roles y tareas; desconocimiento de los interlocutores y consecuentes representaciones - forma parte de un trayecto causal decisivo, en un mapa más amplio de debilidades asociadas y que no refieren en exclusivo a lo comunicativo pero que permiten ver una disociación entre gestión/proyecto político y comunicación.

En el presente diagnóstico planteó a modo de verdad epocal que existen debilidades asociadas que se corresponden con una necesidad de democratizar la comunicación en la organización previa reflexión. A lo anterior se suma que 
esa reflexión debe extenderse a los productos comunicacionales, que constituyen el proyecto político.

Planificación. Líneas de acción posibles para la autonomía y autogestión

El concepto de diálogo entre comunicación y arte aludido por la tesista es revelador para su aplicación a este caso dado que implica pensar el arte como una práctica al interior de un proceso de comunicación integral. A los fines de este trabajo le interesaba conocer lo que los actores consideran arte como propuesta política.

A partir de esto, propone una serie de líneas de acciones basadas en las especificidades de la organización, autonomía, autogestión, auto organización, comunicación participativa, etc., a fin de visualizar cuáles actividades podrían facilitar un proceso de democratización de la comunicación en la organización estudiada.

Y en las conclusiones destaca que la autonomía y la autogestión son construcciones sociales mediadas por procesos de comunicación. Por lo tanto para pensar un proceso de planificación de la comunicación participativa en la autonomía es necesario "repensar la autonomía y sus implicancias comunicativas, a fin de ajustar los nuevos cuerpos informacionales y trabajar sobre ellos hasta obtener una transformación en todos los niveles comunicativos. De este modo la evidencia del cambio podrá servir de incentivo para otras organizaciones de la Sociedad Civil".

c) Tesis Diego Pérez 01/10/2013

WIKI RADIOS EDUCATIVAS

Red de radios escolares 
El director de tesis fue el Dr. Carlos Giordano y el proceso se desarrolló en el marco del Programa Provincial de Lectura de la Provincia del Chubut y la FM Ciudad de Puerto Madryn de la cual el tesista es propietario, durante los ciclos lectivos 2010, 2011 y 2012. ${ }^{23}$

Índice de Contenido

1- Agradecimientos. Pág. 2

2- Índice. Pág. 3

3- Fundamentos Pág. 4

4- Bases epistemológicas y metodológicas Pág. 9

5- Puesta al día de las experiencias de radios escolares.... Pág. 33

6- Trayectoria de la capacitación en 2010 Pág. 40

7- La puesta en marcha de la propuesta actualizada en 2011 Pág. 55

8- Ciclo 2012, los proyectos. Pág. 93

9- Conclusiones y perspectivas de las wiki radios educativas. Pág.167 10-Bibliografía Pág.170

11- Anexo. Pág.172

"Esta tesis vincula el desarrollo de las Nuevas Tecnologías de la Información y la Comunicación "TIC" con un proceso de cambio pedagógico de los distintos niveles educativos que impactados por una realidad mediatizada necesitan readecuar las estrategias cognoscitivas en sociedades cada vez más interconectadas globalmente, pero fracturadas, complejas y culturalmente más diversas". El autor también sostiene que se basa en una mirada comunicacional de las instituciones educativas formales con la consciencia de que en la

\footnotetext{
${ }^{23}$ Al momento de redactar la presente capítulo, esta tesis se encontraba presentada en la FPyCS de la UNLP pero aún no se había organizado la mesa para su defensa y legitimación institucional.
} 
actualidad la generación y distribución de conocimientos y saberes, excede esos límites de formación. Este proyecto de trabajo conjunto se denominó Escuela al Aire Libre, como parte de la Asociación entre el Programa Provincial de Lectura y la FM ciudad de Puerto Madryn, en el segundo año de su desarrollo este tesista fue incorporado como docente en el equipo del programa, lo que le permitió extender el trabajo a toda la provincia del Chubut.

El objetivo planteado fue el de desarrollar procesos de inclusión de la radio en los contextos educativos, con el desafío de pensar la educación desde una mirada comunicacional y no solo desde la mediación tecnológica de la radio.

En los fundamentos el autor de esta experiencia destacó los rasgos más importantes que han impactado en el nuevo escenario educativo tanto desde el interior de las instituciones como desde el contexto social del país. Entre otros, el crecimiento exponencial de los usos de la tecnología particularmente en los jóvenes y la implementación del proyecto "Conectar Igualdad" del gobierno argentino (al momento de esta redacción, se habían distribuido cerca de 2 millones de netbooks a alumnos de las escuelas secundarias). La aprobación de la nueva ley $\mathrm{N}^{\circ} 26.522$ de Servicios de Comunicación Audiovisual que permitió la expansión de las ofertas radiales incluyendo a las radios de instituciones educativas y una creciente convicción de la crisis de sentido que provoca la desproporcionada creación de saberes por fuera de la escuela. La búsqueda de una importante cantidad de docentes que intentan sumar a los medios de comunicación como "recurso pedagógico" sin los horizontes de compresión que significa la difícil relación entre los campos disciplinares de la educación y la comunicación. Así como la aprobación del voto a los 16 años que en un contexto de re-politización de la juventud, replantea la cuestión del debate y la acción política dentro de las instituciones escolares.

En este marco esta tesis incluye una descripción sistemática y las reflexiones y conclusiones de un proceso de capacitación de docentes que integraron una experiencia como "Mediadores en la realización de proyectos institucionales de radio" desde un enfoque de procesos de planificación de la comunicación en los 
ámbitos escolares, logrando integrar experiencias de utilización de la radio en el aula con niños y niñas de establecimientos ubicados en diferentes sectores de la provincia, urbanos y rurales, con perfiles diversos, lo que configura una práctica extendida en actores, territorios y culturas.

Este espacio de encuentro y diálogo de saberes, con variados formatos de programas radiales en cada institución, se dio en tres grandes ciclos lectivos: 2010, 2011 y 2012.

El primero, en el año 2010 en la ciudad de Puerto Madryn, con un proyecto de trabajo conjunto entre el Plan Provincial de Lectura y FM Ciudad 105.1Mhz. Comprendió a ocho escuelas, cuyos docentes recibieron capacitación y fueron transmitiendo vía streaming distintos programas por internet hacia la radio del trabajo conjunto entre ambas. Estos programas fueron realizados por los alumnos desde salas de informática o desde las mismas aulas, tuvieron una rápida repercusión social y constituyeron la base de la experiencia que permitió el desarrollo luego de un proyecto más abarcador.

Durante el año 2011, con la incorporación de este tesista como docente al equipo del Programa Provincial de Lectura del Chubut - la experiencia se amplió a más de 100 docentes de 35 instituciones primarias y secundarias correspondientes a 11 localidades de la provincia. Se trabajó reflexivamente en el equipo del Plan de Lectura la experiencia del primer período de formación y se incorporaron nuevos conceptos e ideas que aparecieron en las conclusiones de los docentes y talleristas.

En el tercer ciclo del 2012, que culminó con un encuentro provincial de radio/escuela, se sintetizaron las experiencias realizadas hasta el presente.

\section{Características de esta experiencia}

El aporte original de este proceso es la utilización de la tecnología radial derivada de la Web 2.0 que se integró como un instrumento facilitador de la transformación del proceso tradicional de la enseñanza áulica.

La idea de esta experiencia pensada como una red de radios que crea contenidos de manera conjunta e interactúa con la comunidad desde los ámbitos 
escolares permitió proyectar un proceso más allá de las escuelas como transmisoras de conocimiento y las radios como difusoras de este saber. Wiki Radio fue planteada, puntualiza el autor, como la posibilidad de articular un nuevo proceso comunicacional que transforme tanto la creación de saber en la escuela como el concepto de radio tradicional comercial que informa pero no necesariamente comunica.

Las preguntas iniciales estaban dirigidas a indagar tres cuestiones básicas:

a) De qué manera la radio puede aportar a mejorar el proceso de aprendizaje escolar en general y la lectura en particular.

b) En qué condiciones la radio puede transformarse en un dispositivo que permita la transversalidad y multidisciplinariedad en los abordajes de las materias curriculares.

c) Si la radio desde el aula/escuela, en red con otras radios/escuelas puede mejorar el intercambio y el reconocimiento entre los contenidos curriculares y los saberes sociales y culturales de las comunidades que rodean la institución escolar.

Para una aproximación que colabore con algunas respuestas a estas cuestiones se decidió como actividad inicial, hacer en conjunto con los docentes, directivos y alumnos un proceso de diagnóstico institucional/comunicacional y elaborar un proyecto que tenga en cuenta estos interrogantes; pensando a la radio como un nuevo vínculo que ponga en diálogo los saberes escolares y los saberes más generales de la comunidad que la integra.

Para esta tarea se trabajó en la formación de "docentes mediadores" que permitieran llevar adelante la experiencia en el campo institucional. En conjunto con ellos se consensuaron algunas hipótesis sobre las radios/en/escuelas y su puesta en red, y los rasgos que las diferencian de las radios comerciales y las comunitarias.

Luego de exponer el autor, el complejo desafío de orientar el desenvolvimiento de la comunicación en la institución escolar y consciente de la provisoriedad de la reflexión y de su rol en un proceso que necesariamente continúa y se 
modifica, aborda esta articulación entre comunicación y educación para dar cuenta de esta experiencia.

Menciona inicialmente los antecedentes de la llamada "educación en medios" que se fue gestando para dar respuesta a la cantidad de saberes que circulaban por fuera de la escuela. En nuestro país se extendió la concepción dominante de pensar la práctica en las escuelas más como una cuestión instrumental ligada al periodismo tradicional o a la estructura de las radios comerciales que como un replanteo pedagógico que generara nuevas prácticas.

Es así que para proponer un comienzo de la experiencia se apeló a la Investigación/acción" un dispositivo teórico propio, validado desde el campo educativo que permitió trazar espacios de encuentro y similitudes con los fundamentos de la "Planificación y gestión de la comunicación". Ambas miradas contienen aspectos comunes relacionados con un punto de vista interpretativo, con herramientas etnográficas y de seguimiento de los procesos involucrados tanto en lo educativo como en lo comunicacional. Y ya dentro de este campo se centró la atención en los procesos discursivos - tanto escritos como orales - que relacionan las actividades escolares y radiales. Procesos discursivos en la escuela vistos desde una perspectiva sociocultural y en la radio, como estructurante de los procesos sociales de significación del espacio público. Este enfoque permitió conocer rasgos del discurso de una institución educativa y los discursos utilizados por la radio comercial o la radio comunitaria, para trabajar las diferencias.

Así como la nueva perspectiva de la Educación en Medios de Comunicación que pretende formar personas conocedoras de los nuevos lenguajes audiovisuales de nuestra sociedad, capaces de apropiarse críticamente de ellos y de emplearlos creativa y activamente como canales personales de comunicación. Los destinatarios de este nuevo «eje transversal» de la enseñanza pueden ser tanto maestros y profesores de todos los niveles y modalidades del sistema educativo y de todas las especialidades curriculares -con la función de cascada, de forma que ellos actúen después sobre sus estudiantes-, o bien directamente los niños y jóvenes, que ya están expuestos diariamente a una «dosis» audiovisual 
considerable, sin conocimiento ni análisis de estos nuevos códigos de interpretación y expresión del mundo.

Desde el lugar del gobierno menciona el autor el Programa Escuela y Medios del Ministerio de Educación de la Nación, que se creó con el objetivo de promover la Educación en Medios para todas las escuelas primarias y medias del país. Se implementó mediante acciones de formación docente: edición de materiales de capacitación sobre la lectura reflexiva de los medios de comunicación, certámenes, concursos y festivales que promueven el análisis y utilización de los medios de comunicación, etc.

La línea central de esta modalidad se basa en una perspectiva de construcción de un lector-ciudadano-crítico con aptitudes y capacidades de cuestionar la agenda de los medios y eventualmente de elaborar sus propios recursos de difusión. No aparecen, adelanta el autor, referencias directas al proceso más general de la escuela pensada como un "dispositivo de comunicación" que articula el Estado, la sociedad y las personas en el entramado cultural de una época.

Desde el punto de vista de la articulación comunicación/educación, destaca la importancia del trabajo Cultura Escolar, Cultura Mediática/intersecciones de Jorge A. Huergo y María Belén Fernández (Huergo y Fernández, 1999), que al partir de premisas comunes a este enfoque, explora ampliamente de manera teórica este vínculo, y aporta claves de interpretación del fenómeno que se desarrolla aún a tientas. Luego de unas cuantas referencias de estos autores que visualizan los rasgos característicos de este vínculo se puede sintetizar lo extractado en la siguiente cita "El obstáculo clave en la mayoría de los proyectos de educación en comunicación" [...] "ha sido, y es, naturalizar la dimensión escolarizante de la educación," y por lo tanto " «escolarizar la comunicación»". Más adelante citando a Ignacio Lewkowicz esboza su mirada en torno a estos tiempos y roles del Estado y los medios. "El sujeto/niño o niña formado en la subjetividad del mercado mass mediático no responde a "la normativa" y "el saber" derivado de los dispositivos de lógica estatal, sino que su anclaje está formado por conceptos de "imagen” y "opinión”. Está más cerca del "usuario" y 
"consumidor" que del tradicional estudiante y esta es la principal causa del desencuentro".

Y es a través de Cristina Corea que explica que el discurso mediático produce actualidad, imagen, opinión y que en el pasaje de un contexto estatal a un medio informacional varía la subjetividad porque varían las operaciones con las que se habita cada situación, pero también varía el mecanismo mismo de producción de las operaciones. "Tengo que leer un libro para la escuela o la universidad. Estoy obligado a subrayarlo, a identificar ideas principales, a relacionar las ideas de ese libro con las de otro, a realizar una ficha bibliográfica, a ubicarlo en el conjunto de una bibliografía o en el programa de la materia, a producir un resumen, a contestar consignas; he de someterme incluso a un ritual llamado examen en que se me evaluará en el desempeño de todas las operaciones anteriores: soy una subjetividad pedagógica". Necesito desarrollar "la memoria" y estar "concentrado", "quiero" en "un lugar, sin moverse" y "alejado de cualquier estímulo". En el caso del discurso mediático la construcción de subjetividad se da de una manera completamente distinta. "En vez de la interioridad y la concentración requeridas por el discurso pedagógico, el discurso mediático requiere exterioridad y descentramiento: recibo información que no llego a interiorizar, (y) debo estar sometido a la mayor diversidad de estímulos posibles: visuales, auditivos, táctiles, gustativos" concluyendo que "la subjetividad informacional se constituye a expensas de la conciencia".

\section{Particularidades del Chubut}

Posteriormente aborda la historia de los modelos educativos en esta provincia que están íntimamente ligados a la concepción geopolítica del estado nacional de ocupar supuestos desiertos habitados aquí y allá por salvajes improductivos, alguno de ellos venidos allende Los Andes con ánimo de robar tierras argentinas. Esta mirada que motorizó la llamada "Conquista del Desierto" marcó a sangre y fuego la actividad civilizatoria de las escuelas, sus designios y métodos. 
Una afirmación clave a la hora de repasar estos registros es que "la tradición oral no es considerada como transmisora de conocimientos". Partiendo del prejuicio "acerca de los pueblos considerados indios, que por naturaleza no deberían tener ni historia ni educación".

La educación que era en la época colonial una cuestión centralizada por la Iglesia católica, llega al Chubut recién en la segunda mitad del siglo XIX, de la mano de los galeses. Poco tiempo después llega la escuela nacional y posteriormente la salesiana con un proyecto en relación a la población originaria", destacando que en Chubut "se pasa de una educación propia de los pueblos originarios a la educación de la generación del 80". La situación provincial respecto de esa herencia multicultural pesa al momento de pensar un escenario de procesos educativos y comunicacionales, en particular por la incidencia que hoy tienen estas familias originarias en la composición de la matrícula escolar. Existen alrededor de 115.000 alumnos en la actualidad en todos los niveles de las escuelas públicas de la provincia del Chubut. De acuerdo a datos aproximados recogidos de varias fuentes a la fecha de elaboración de este trabajo un $7 \%$ de estos estudiantes pertenecen a comunidades originarias y un $3 \%$ a pueblos migrantes de países limítrofes especialmente de Bolivia.

Enfoque para el trabajo

La práctica de la comunicación en el campo de la educación implicó para el autor iniciar el camino mediante la investigación/acción que dé cuenta de la posible tensión entre los aportes de los proyectos institucionales y sus planificaciones pedagógicas por un lado, y de las posibles aplicaciones de los enfoques comunicacionales a la institución escolar por el otro. El enfoque de investigación sirvió para mostrar las zonas de conflictos y confluencias entre ambos, el aspecto de los lenguajes fue en este caso, el que más peso adquirió en la exploración. Así como al hacer dialogar estas corrientes de reflexión desde ambos universos generó el análisis de la primera etapa de implementación del proceso llamado Escuela al Aire Libre, donde confluyeron los distintos criterios de un modo pragmático y operacional. 
En la fundamentación que elaboró el equipo para el proceso de capacitación de los docentes como mediadores en el año 2011: “Elementos para un diagnóstico orientado a la incorporación de la radio como mediación en procesos de aprendizaje en ámbitos educativos de diferentes niveles y contextos socioculturales" (Silvia Contín y Diego Perez) se señalaron los primeros lineamientos, enriquecidos con el aporte reflexivo de los propios docentes, de los capacitadores y con la aparición a lo largo de este período, de algunas investigaciones que han tomado el mismo sentido de búsqueda, particularmente en América Latina y España.

La escuela desde la mirada institucional educativa y la comunicacional Los Proyectos Educativos Institucionales (PEI) correspondientes a cada institución son construidos en un proceso de debate entre el equipo docente y directivos de las instituciones teniendo en cuenta los Núcleos de Aprendizaje Prioritarios, los diseños provinciales y las realidades concretas de cada escuela en relación con su entorno sociocultural.

Es así que el tesista presenta algunas dimensiones desde las cuales los PEI construyen y expresan saberes específicos, parte del trabajo de construcción de escenarios desde los cuales los docentes basarán su trabajo de proyectar la creación de una radio como mediadora de los procesos educativos.

Mientras que desde lo comunicacional, se parte de una mirada multidisciplinar que pone en su centro los vínculos entre el conjunto de actores de la institución y las formas y mecanismos de dar sentido a sus prácticas internas y externas, buscando los indicios que permiten leer la institución desde esta perspectiva. Como existen varios rasgos comunes en los criterios que se utilizan para elaborar tanto diagnósticos institucionales-educativos como los comunicacionales, se trabajaron una serie de aspectos que integran ambas propuestas.

Desde el comienzo se percibió una tensión entre los preceptos de la llamada Educación en Medios, centrada especialmente en lograr una lectura crítica de los medios de comunicación y los conceptos de planificación y gestión de procesos 
comunicacionales, que contempla a la comunicación como una relación que se establece de manera múltiple, que incluye a los medios pero que es mucho más amplia.

La primera experiencia del año 2010

En la primera experiencia del año 2010 relata el tesista, a pesar de que en el proyecto se contemplan los procesos comunicacionales como un sistema amplio de referencia teórica, en la práctica y en la propuesta metodológica se notó fuertemente la influencia de los criterios de la educación en medios y una presencia dominante de recursos didácticos extraídos de la formación de profesionales de radio. Esto fue posible por la heterogeneidad de los participantes del equipo que llevó adelante la experiencia y el poco tiempo que pasó entre la gestación de la propuesta y su puesta en marcha (3 meses). También explica - en parte - las dificultades a la hora de consolidar los procesos en cada institución escolar.

El proyecto de Escuela al Aire Libre se extendió por seis meses, participaron 8 escuelas de la ciudad y finalmente 4 lograron hacer sus programas y micros, algunos fueron emitidos en directo por FM Ciudad y otros grabados y emitidos con posterioridad. Se planteó una nueva modalidad de interacción que en contraste con propuestas convencionales atendiera las problemáticas existentes desde dos ejes relacionados. La inclusión de la dimensión comunicacional como parte del proceso de enseñanza aprendizaje - implica considerar a los medios de comunicación no solo en su faz educativa, sino centralmente como articuladores de la construcción social de ciudadanía y opinión pública en la cual viven los estudiantes- y el cambio de "escucha" en relación a los conocimientos adquiridos por los estudiantes, ampliando el ámbito del aula por el de la sociedad más en general y provocando una resignificación de los conocimientos desde su valor socio-histórico y epocal.

En el desarrollo de la experiencia se presentaron contradicciones y desplazamientos respecto de la planificación original. Ante las dificultades de los docentes para hacer cumplir la primera consigna de realizar un documental 
radial, los capacitadores los acompañaron en el aula para colaborar con dicha producción, que se daba por el desconocimiento de la técnica de radio o de destrezas comunicativas. Esta decisión permitió además observar en el lugar las verdaderas dificultades que tenían los docentes para desarrollar este trabajo y aportar luego a una mirada más adecuada para acompañar la gestión de los proyectos. Los resultados finalmente en esta etapa han sido muy ricos y diversos y en general favorecieron la incorporación de los alumnos.

El cierre de año se formalizó con un encuentro en el laboratorio de informática de la escuela 750 de Puerto Madryn con la participación de 4 proyectos de radio y la acreditación de 10 docentes de 6 escuelas y contó con una radio abierta realizada el 24 de marzo del 2011 donde participaron casi 200 alumnos. Allí se fueron consolidando algunas primeras conclusiones de la experiencia del año 2010. Destacó el autor que participaron más de cincuenta alumnos de 8 escuelas involucradas en el Plan de Lectura y el Plan de Mejora Institucional, que los chicos de las instituciones que lograron hacer sus programas pertenecen a estratos socioeconómicos de barrios populares, de ellos: dos escuelas con cierta experiencia previa y otras dos sin contacto alguno con experiencias radiales.

Luego de presentar varios ejemplos testimoniales de la experiencia de los chicos en la radio, realizó un punteo de las conclusiones de Escuelas al Aire Libre (EAL) que le sirvieron de base para la continuidad del proyecto al año siguiente. Entre otros aspectos destacó la capacidad estructurante de las formas culturales para determinar el alcance de la experiencia educativa, sobre todo en agrupamientos con diversidad cultural identitaria; que tanto los docentes como los alumnos que participaron de la experiencia utilizaron de manera superpuesta los lenguajes formales escolares, los de los medios de comunicación comerciales y lenguajes sociales de su comunidad inmediata y que esa hibridación abre nuevos modos de interpretación del mundo adolescente. Producto de los efectos de la radio sobre la ampliación de la escucha, se readecuaron los procesos educativos; así como los alumnos evidenciaron un crecimiento en sus habilidades expresivas dando muestras, de que el trabajo con la radio, produce una recuperación del deseo de saber y de intervenir desde el propio lenguaje. Asimismo se 
manifestaron nuevos modos de vinculación de los alumnos con su familia, utilizándose la radio como mediadora de nuevos procesos de diálogo. En el caso de los alumnos bolivianos destacó, la importancia de la escucha del programa por parte de familiares y amigos en su país, así como el cruce entre la radio y las redes sociales para una interacción más estrecha entre la comunidad y la escuela. En otro orden de cosas, el reconocimiento del conflicto como parte del aprendizaje que provoca la argumentación de posiciones, conciliación frente a los extremos y la apertura a nuevos interrogantes, pone en cuestión a la gobernabilidad misma de la radio. Dejan de tener validez los sistemas jerárquicos tradicionales para comenzar a visualizarse procesos de gobernabilidad compartidos entre docentes, alumnos, padres y comunidad cercana de le escuela.

Finalmente como conclusión novedosa emergió una diferenciación notable entre los lenguajes utilizados por la radio escolar a diferencia de la radio comunitaria y la radio comercial.

Por último en relación a las enseñanzas que la experiencia dejó para el proceso de planificación y gestión de la comunicación aplicada a la de formación de mediadores en el desarrollo de proyectos institucionales de radio, el tesista destacó: la necesidad de asistir a las escuelas a reforzar el trabajo con alumnos y docente en la preparación de los programas, la elección de temas por fuera de las restricciones que imponía la cultura escolar y el impacto en los mismos docentes, acerca de la transformación que la experiencia ejercía, no sólo en sus capacidades y las de sus alumnos sino en el proceso más amplio de producción de saber social y escolar.

La puesta en marcha de la propuesta en 2011

Al año siguiente se produce el desplazamiento del equipo creador el EAL desde el área del Plan de Mejora Institucional al equipo del Plan Provincial de Lectura, incorporándose a la planta de capacitadores del Ministerio de Educación de la Provincia del Chubut y esta medida amplió las responsabilidades y las demandas. 
El tesista en su calidad de capacitador señala que la reedición de la experiencia desde este nuevo sector institucional no sólo respondía a los resultados de la misma, sino al escenario que se presentaba a nivel nacional y que impactaba directamente en este proyecto, como las licencias para radios escolares y la entrega de netbooks a los alumnos. Escenario que se consolida con la firma de un convenio entre el Ministerio de Educación de la Nación, la Autoridad Federal de Servicios de Comunicación Audiovisual (AFSCA) y la Comisión Nacional de Comunicaciones, previa a la instalación de 200 radios escolares en 6 meses. El proyecto EAL cobro entonces una nueva dimensión en varios aspectos: se extendió a toda la provincia del Chubut y en consecuencia se pasó de planificar la formación de docentes mediadores no solo en escuelas de ciudades sino también en escuelas rurales con características completamente diferenciadas y con dificultades operativas más importantes.

Al conocerse la oferta por los canales oficiales de formación docente, la convocatoria generó expectativas en todos los niveles educativos: primario, secundario, terciario, especiales y aún en organizaciones de la sociedad civil (en las cuales colaboran docentes).

Fue así como la extensión del proyecto permitió incorporar los contenidos y el seguimiento de los trabajo en la plataforma virtual TEKOA del Ministerio de Educación del Chubut. Se presentó entonces un nuevo punto de partida con otros desafíos teóricos y prácticos que se incorporaron a la capacitación y que obligaron a profundizar en sus implicancias en la formación de "mediadores en proyectos institucionales de radio" del año 2011.

\section{Curriculum escolar y lenguaje}

Adhiere el autor a las conclusiones de la Dra. Silvia Contín quien en su tesis de doctorado y luego de analizar los modelos de formación docente, considera al modelo hermenéutico reflexivo como la línea a seguir en proyectos y en consecuencia también en las prácticas de comunicación y gestión.

Derivado de este procedimiento se diagnosticó que la yuxtaposición de discursos tanto de los capacitadores como de los mediadores, entre los lenguajes de la 
escuela y los derivados de las prácticas de radio generalmente asociadas a las comerciales y aun a las comunitarias, más allá de las ventajas instrumentales, mostraron la necesidad de rever conceptos que diferencien cada modelo.

Un indicio fueron las dificultades que tenían las radios escolares ya instaladas en la provincia para mantener una programación continua y adecuada, una parte de ellas había cerrado sus instalaciones o se encontraban con pocos programas, realizados por personas ajenas a la escuela. Algunas, como la radio FM 98.1 de la Escuela No 108 Portal de los Andes en Lago Puelo, había sido cerrada temporalmente por no contar con una programación adecuada a la currícula ni docentes con asignación de horas especiales para realizar esta tarea.

En el caso de la radio ubicada en la escuela $N^{\circ} 87$ de Puerto Pirámides, ocurrió algo similar, aunque la radio continúa en el aire sin un plan específico de trabajo, sino con docentes que deciden "hacer radio" con los chicos en unas instalaciones que inclusive están fuera de la escuela.

La gran variedad de experiencias planteó la necesidad de discriminar entre distintas categorías: aquellas que tienen radio en la escuela; las que no tienen pero si cuentan con proyectos como radio en los recreos, programas grabados y emitidos en las aulas o grabados y emitidos en las radios; y finalmente las que no tienen pero desean construirlo.

Para la trasposición de esos textos literarios a imágenes sonoras, el equipo sistematizó el proceso en etapas, además de diseñar una guía con ejemplos que les permitieran vincular los textos con las realidades locales y las identidades.

En virtud de los nuevos desafíos y las características de los docentes anotados provenientes de diferentes lugares de la provincia, se dispuso la red virtual y el equipo planificó encuentros para la organización del proceso.

El primer encuentro, julio del año 2011 en Puerto Madryn

Asistentes: 48 personas. Instituciones: 28. Localidades: Trelew, Rawson, Puerto Madryn, Puerto Pirámides, Camarones, Gaiman, Dolavon, Esquel, Lago Puelo, Playas Doradas (Río Negro). 
Talleristas: Silvia Contín, Ignacio Lo Russo, Diego Perez - Colaboradora: Cecilia Cañas TEKOA (aula virtual)-.

Los encuentros favorecieron la reflexión con los intercambios y las puestas en común, pero la producción entre reuniones sufrió de varios contratiempos, entre las causales citadas por los docentes y observadas por las tutorías se destacan: la falta de horas dedicadas al trabajo de capacitación y de espacios adecuados de reunión, la dificultad para la comprensión de las consignas, para la lectura en voz alta y la síntesis y claridad conceptual.

Para la presentación inicial, los participantes preparan un pre-diagnóstico con algunas preguntas orientadoras que servirían de base para la elaboración de los posters en clase. Algunos datos que ayudaron a la caracterización de las comunidades y de los estudiantes realizados en las evaluaciones, fueron caracterizaciones como: la diversidad étnica y socioeconómica, de tipologías familiares, de participación comunitaria y de comunicación.

Intervención de los asistentes

De acuerdo a los protagonistas, la radio sostuvieron es entre otras razones, una herramienta para mover cosas que la estructura tradicional no puede, un espacio para que circule la palabra, una matriz escolar para mejorar la calidad educativa, para compartir y comunicarnos. Comunicar problemas de drogadicción, violencia, embarazo, lograr una apertura y un acercamiento a la sociedad en calidad de ciudadanos, entre otras tantas opiniones que surgieron de este relevamiento.

No obstante estas dificultades se realizaron seguimiento a las escuelas más accesibles que fueron preparando sus programas y entrenándose con vista al programa final integrado.

Luego de exponer el autor una síntesis de las actividades realizadas en las escuelas más cercanas, dado que el fracaso en la utilización de la plataforma virtual impidió acompañar la evolución de los trabajos en las localidades más alejadas de la meseta y cordillera, señala la dispersión y los distintos niveles de asimilación de los conocimientos. 
La propuesta de armar un proyecto de radio que implique revisar las propias prácticas comunicacionales/educativas, no solo choca con aspectos de la cultura institucional sino que pone en cuestión formas propias de cada docente a la hora de pensar el dispositivo radial como promotor de cambios más profundos del proceso educativo.

La práctica de radio situada permitió entrever que una parte importante de los docentes (cerca del 60\%) que manifiestan dificultad de los chicos y chicas para leer en voz alta, tienen dificultades para leer en voz alta.

Los docentes que se animaron a dar mayor protagonismo a las niñas y niños fueron los que más pudieron avanzar en el proceso de incorporar la actividad radial en la escuela.

Excepto los docentes de una escuela de Trelew, todos los demás tendieron a replicar los lenguajes escolares.

En el último tramo se les pidió a los participantes que respondieran consignas y preguntas para evaluar sus opiniones del proceso. Así fue como tiempos, espacios, técnica y apoyo institucional caracterizaron estas reflexiones de los equipos docentes. La mayor dificultad se siguió manifestando en la posibilidad de poner en palabras, de imaginar el cruce de los contenidos escolares con la agenda de la comunidad, como también el cruce de lenguajes y las dificultades de gobernar un medio de comunicación asociado con la escuela.

El cierre del año con la participación de 13 escuelas con pequeños micro programas que se realizó en la escuela 162 de Puerto Madryn, generó las condiciones para pensar nuevos proyectos al año siguiente tomando en consideración estas demandas y las nuevas realidades institucionales.

Ciclo 2012, los proyectos

En el año 2012 cambiaron las autoridades provinciales y por lo tanto se realizaron modificaciones en los diferentes equipos que conforman los ministerios. El Equipo del Plan Provincial de Lectura del cual depende el proyecto sufrió recortes en la cantidad de integrantes respecto del equipo original y se sumaron referentes en Comodoro Rivadavia y Esquel. Esto implicó alineamientos 
con el proceso político nacional de las nuevas autoridades que permitieron dar impulso a perspectivas locales que coincidían con la perspectiva nacional.

En la práctica continuaron las tareas planificadas y se encontró el espacio para la articulación inicial de las redes, para obtener más conocimiento del proyecto por parte de los docentes, mayores niveles de confianza institucional de directivos y supervisores y como consecuencia, mayores libertades para pensar y explorar diversos caminos. No obstante las experiencias pusieron en evidencia aún más las asimetrías que existen entre las distintas localidades y dentro de ellas sus barrios, como así también las distintas formas culturas escolares en las ciudades y en las zonas rurales.

Para darle respuesta a este diagnóstico en relación a la localización se crearon cuatro nodos:

a) Noreste: Puerto Madryn, Puerto Pirámides, Trelew, Rawson.

b) Cordillera: Esquel, Trevelin, Lago Puelo y localidades cercanas.

c) Comodoro Rivadavia y localidades cercanas.

d) Meseta central: Dique Florentino Ameghino y localidades cercanas.

La primera actividad significativa en redes se logró en el comienzo del año 2012 con la organización de un programa radial conjunto en conmemoración del 24 de marzo con la consigna: "Las niñas y niños tienen la palabra y la reparten por el aire de toda la provincia". Programa que se produjo en red a modo de "wiki radio educativa" con la participación de más de veinte escuelas chubutenses, transmitido en directo a través de internet y difundido desde cada localidad por FM locales.

El resultado fue alentador y gratificante para los participantes, pero por sobre todo mostró en la práctica la posibilidad real de llevar a cabo estas redes con la dedicación y entusiasmo que despertó en alumnos y docentes la interacción e integración regional.

La experiencia fue combinada con el uso de las redes sociales, lo que permitió generar un intercambio en el momento de realizar las acciones. Para esto se 
creó en el Facebook de FM Ciudad una página llamada "Red de radios escolares por la verdad, la memoria y la justicia" donde se pueden observar las imágenes de los nodos que trabajaron y escuchar el audio completo del programa.

Los nuevos procesos de formación de mediadores en proyectos institucionales de radio

En el año 2012 se experimentaron diversos cambios que dieron cuenta de procesos específicos de la comunicación dentro de la institución escolar. Entre ellos, aquellos que apuntaban a lograr mejores condiciones para debatir las propias prácticas docentes, en el marco de los proyectos radiales de cada una las instituciones.

Esto fue posible poniendo énfasis en el desarrollo de teoría y prácticas situadas geográfica y culturalmente. En esta nueva etapa, en la cual formalmente se replicó el taller preparado para el año anterior, se afianzó una lógica que se asentó en recuperar los saberes y los sentimientos de cada participante sobre el tema, y reflexionar sobre ese saber/sentir al momento de explicar las cuestiones teóricas y desde allí plantear los abordajes de la práctica. Este proceso tuvo en cada lugar puntos de divergencia y de secuencias diferentes de acuerdo a las realidades y escenarios particulares.

Equipos de trabajo por escuelas y nodos

Las variables de tiempo, espacio y cantidad de asistentes tuvieron un fuerte impacto en la elección de los caminos a recorrer en cada oportunidad, como así también las experiencias previas de trabajo con las técnicas de radio. Luego de la presentación del tema se dividieron las comisiones y se trabajó en el intercambio, con la consigna de dar cuenta del estado de situación de los proyectos en las escuelas participantes, la pregunta acerca de para qué una radio en el aula y cómo sería una radio en la escuela.

Luego de las memorias radiales y su radialización - es decir su transformación en micros dramatizados - los talleristas hicieron sus primeras aproximaciones a un diagnóstico - llamado pre-diagnóstico - desde las distintas escuelas y pensaron opciones para construir sus proyectos radiales. 
No todos los docentes llegaron a realizar el proceso de pre-diagnóstico /diagnóstico/proyecto. El orden elegido se relacionó con la densidad conceptual y metodológica, se comenzó por los planteos más acotados y terminó con un repaso del trabajo más amplio, el de los docentes de la escuela $N^{\circ} 56$ del Dique Florentino Ameghino.

\section{Encuentro Provincial de Wiki Radios Educativas}

Se convocó dicho encuentro, con el propósito de producir un intercambio y debate de saberes entre los protagonistas del proceso de construcción de los grupos de maestros mediadores y sentar las bases para la puesta en red por medio de internet a todos los proyectos de radios educativas en sus diferentes niveles en la Provincia del Chubut. Además se pensó en el aporte al debate y el encuadre que podrían brindar algunos referentes en el ámbito de la literatura como Juan Sasturain y del Radioteatro como María Mercedes Di Benedetto y los talleres de guion radial a cargo de integrantes del equipo del plan.

El evento que convocó a docentes, directivos, bibliotecarios, animadores culturales, comunicadores, agentes comunitarios de las instituciones que fueron parte de las acciones de capacitación del proyecto Escuela al Aire Libre, promovió el tratamiento de las funciones, lenguajes y sentidos de la radio en la escuela, su vinculación con la lectura, diferencias y similitudes entre radios comerciales, comunitarias y escolares.

Con los siguientes ejes de debate se realizaron mesas de actividad entre los concurrentes al encuentro que se desarrolló en escuela provincial 713 de la ciudad de Esquel:

- Diálogo de saberes entre la escuela y la comunidad

- La lectura y la oralidad mediadas por la radio

- Reconfiguración de los procesos de enseñanza aprendizaje en un nuevo contexto sociocultural/tecnológico

- Wiki radios

Pensar una nueva institución escolar para nuevos sujetos sociales. 
La intención de la convocatoria estuvo centrada en medir no solo el nivel de avance de los distintos proyectos de radios escolares, sino también producir una nueva reflexión e intercambio de experiencias que facilitara la vinculación de las escuelas, creando una masa crítica de actores que hagan propia la idea y la posibilidad de poner en red los proyectos de las wiki radios educativas. Una evidencia puesta de manifiesto ha sido que cualquier proceso de transformación y creación de nuevos dispositivos educativos no solo tiene un componente económico ligado al financiamiento, a la infraestructura y al sostenimiento de retribuciones acordes, sino que el motor de este dispositivo es la convicción de los educadores respecto al valor de su trabajo y a los efectos que produce en los niños y niñas y el reconocimiento de su tarea como creador de nuevos saberes.

Aportes y conclusiones del encuentro

Los docentes participantes asumieron en sus debates y conclusiones que las lógicas educativas y comunicacionales tienen muchos puntos de encuentro, que no basta con pensar la radio como un recurso didáctico, sino que pensar la radio en la escuela desde la mirada comunicacional, nos permite repensar la escuela en su contacto con sus propias prácticas y su comunidad.

Todo el debate giró en torno de los aportes a la consolidación del proyecto y los cuestionamientos solo orientados a la demanda de horas, de espacios y aun de equipamientos. Y a la necesidad, por ejemplo, de revisar la legislación escolar que prohíbe la actividad partidaria en las escuelas, para dar lugar al debate que puede surgir a partir de la nueva ley del voto a los 16 que rige en el país y su repercusión en las radios escolares. Así como a utilizar todos los formatos radiales y estilos, poniendo especial atención a la forma de trasmisión de información o noticias, mencionando explícitamente las fuentes de la información, los procedimientos de validación la capacidad de "problematizar" didácticamente estos hechos.

Conclusiones y perspectivas de las wiki radios educativas 
De acuerdo al punto de vista del autor, impulsor del proyecto, "los tres años de experiencias relevadas, comprobaron la viabilidad de proyectar una red de radios escolares en una modalidad colaborativa y que los talleres para la formación de mediadores y proyectos institucionales han sido el espacio adecuado para diseñar junto con docentes y directivos, un primer diagnóstico que deberá ser retomado y completado en las próximas etapas para poner en marcha las wiki radios educativas".

Destacó que 200 docentes de 80 escuelas pasaron por el proyecto de Escuela al Aire libre en los tres años de trabajo y que el equipo inicial del Programa Provincial de Lectura encargado del proyecto fue de 3 personas, que al promediar el segundo año (2011) quedó reducido a 2.

Las mayores dificultades para avanzar en este proceso fueron lograr el compromiso efectivo de la estructura educativa de los niveles superiores, así como desde el punto de vista de los procedimientos y las estrategias, construir el conocimiento compartido, dado que la evidencia indica que existe una gran dispersión en la concepción y en las prácticas docentes como causa de los pocos espacios reales y abiertos de reflexión sobre la misma.

Los talleres, en especial los distribuidos regionalmente, han logrado crear un núcleo docente más cercano e interesado en seguir adelante con este proceso, pero sin la organicidad ni disposición para constituirse en promotor, con lo que sigue siendo necesaria la participación institucional de la Provincia y de la EAL para continuar con el trabajo encarado. Los alumnos, especialmente del nivel secundario son actores destacados en la generación de actividades y vinculación de la escuela y la comunidad. Como consecuencia del trabajo desarrollado, desde el Ministerio de Educación se ha autorizado la creación en este año 2013 de un portal de Wiki Radios Educativas, gestionado desde las áreas del programa Conectar Igualdad que permitirá poner en red de manera permanente a un mínimo de 20 radios on line con el sistema de streaming y todos los proyectos de radio que aún no dispongan de estas posibilidades podrán enviar sus trabajos en modo Podcast para ser colgados en el sitio Web. Este portal será diseñado en su funcionalidad por el equipo de Escuela al Aire Libre y se podrá 
utilizar a modo de red de intercambio de audios, documentos y enlace de los chicos y chicas de la Provincia que trabajen en los proyectos de radios en las escuelas.

Consideraciones finales sobre la planificación y gestión de la comunicación

En este punto el autor destaca que desde la perspectiva teórica, metodológica y práctica encontró probadas razones para sostener la riqueza de la mirada comunicacional de los procesos, que le permitió articular saberes y disciplinas diversas, para construir y dar cuenta del estado de la cuestión en este campo específico.

Reflexiona que en esta experiencia le fue imprescindible sostener la tensión entre las miradas pedagógicas/educativas y la mirada comunicacional, que no fue solo epistemológica o teórica, sino que se expresó en los debates permanentes con la Dra. Silvia Contín, responsable del Programa Provincial de Lectura, con quien compartió el desarrollo de la experiencia. La trama de este trabajo se construyó en ese intercambio, en un debate que se dio en los propios talleres y que caracterizó las intervenciones de cada uno en estos espacios, como oportunidades y lugares de creación de saber.

La segunda cuestión que destaca tiene un valor metodológico y es que los aportes teóricos no se construyen de una vez y para siempre, que por lo menos en este caso- enfatiza- las propias dificultades de la práctica y la necesidad de dar respuestas cada vez más complejas obligan a buscar nuevos aportes realizando una búsqueda cada vez más específica de algunos temas que emergen del propio proceso de investigación. Lo manifiesta no solo por la necesidad de profundizar saberes relacionados con el campo educativo, sino por la dinámica y fluidez que tienen los debates en torno a las cuestiones comunicacionales y aún más su vínculo con la educación.

Esto hizo que, en cada ciclo de trabajo anual el autor incorporara algunos elementos de enfoque teóricos que explican de una manera genealógica como se producen los saltos del pensar y su relación con las lecturas y las prácticas. 
“Por último quisiera hacer una observación sobre la planificación. Es posible que sea difícil atrapar en un concepto toda la complejidad de un proceso y que hay que entender esta palabra en su red de significación. De todas maneras -y para ser sincero con lo que fui comprobando a lo largo de estos años de trabajoplantear objetivos y gestionar los procesos para llevarlos a cabo puede ser más una orientación de procesos comunicacionales que una planificación, sobre todo en las escalas que involucran a comunidades enteras y complejas historias de vida", concluye el autor.

\subsubsection{Las no tesis. ¿Naufragio?}

Entre las opiniones sobre los seminarios y los intentos de tesis, los otros maestrandos entrevistados forman parte del mapa que muestra diferentes matices de un mismo trayecto. Sólo Marcelo Hernández que abandonó la idea de graduarse, puede evaluarse en términos de ese tipo de resultado, pero de ninguna manera pensarse que su paso por PLANGESCO no le permitió un crecimiento académico que permeó en su cátedra Derecho a la Información y seguramente en su acceso la regularidad mediante el concurso reciente de la misma.

La lamentable pérdida de Kira Rakela no impide evaluar el objetivo cumplido que la Maestría encauzó, acerca de la reflexión que sobre la articulación que entre comunicación y educación ejerció desde el inicio de su práctica profesional.

Mientras que María Dilys Vales continúa su proceso de escritura y Daniel Pichl cursa el doctorado en la FPyCS de La Plata en donde seguramente confluirán sus intereses académicos despertados en PLANGESCO.

Marcelo Hernández

Respecto de los seminarios manifestó "que todos hicieron su aporte, no creo que haya uno que diga, no este no me sirvió para nada, todos aportaron en función 
del crecimiento concreto". Reconoció que hubo desmotivaciones como la gran cantidad de material para tan poco tiempo de lectura, las dificultades personales, "por ejemplo no participé en el de Alcira Argumedo porque justo estaba en Buenos Aires por el banco, y estas cosas también me desmoralizaban..." La llegada de Arroyo, de Uranga, de 'Marita' Mata, nos abrieron una expectativa diferente, organizaron ese pensamiento que uno tiene de lo social, así como la certeza acerca de "que hay cosas que se pueden hacer desde la estructura gubernamental", porque justo venían del gobierno, como el caso de Arroyo con el testimonio "que se estaban haciendo cosas en Desarrollo que uno no se imaginaba que se podían llegar a hacer".

En relación a la tesis fue yendo de un tema a otro, "recuerdo que la primera posibilidad era trabajar con una acción concreta en torno a un plan de gobierno, después busqué una asociación vecinal o los talleres que se impulsaran desde allí, luego traté acá en Rada Tilly de ver la relación de las escuelas y los medios". En otro momento se vio tentado luego de hablar con el profesor Giordano, de tomar el proceso de formación que se estaba haciendo en el banco, quien le sugirió que trate de construir algo a partir de ese lugar, porque se estaba cambiando el paradigma de las capacitaciones. De todas maneras reconoció que en ese entonces "ya no tenía tiempo ni ganas, yo creo que es un problema mío no de PLANGESCO, salvo eso del tiempo y las prórrogas, porque veo que de veinte alumnos no quedaron dos, quedaron dieciséis, diecisiete...".

Para Marcelo Hernández PLANGESCO era una oportunidad para crecer académicamente, pero con el paso del tiempo y la suma de obstáculos, comenzó a mermar su interés "no en la Maestría sino en alcanzar la titulación". Reconoció además que bajó los brazos cuando advirtió que no iba a poder tener participación directa en alguna acción social que le permitiera hacer la tesis sobre ella "y me parece que una tesis por fuera de eso, era como que no cubría las expectativas de lo que me estaba planteando PLANGESCO", expresó.

Kira Rakela, quien en el capítulo precedente aparece mencionada como una de las maestrandas consultadas, falleció repentinamente en el mes de mayo del 
corriente. Las respuestas que se extractan aquí son de la misma entrevista citada en el capítulo anterior y del resumen de la temática abordada para su tesis a través del proyecto entregado a esta coordinación, que ya había ingresado a la FPyCS de la UNLP para su tratamiento.

"Nos ha dejado cosas muy interesantes la Maestría, -decía Kira en cuanto a los seminarios de PLANGESCO- gente como Alcira Argumedo, 'Marita'Mata...que te transmiten inquietudes, una lectura que te permite mirar un poco más allá, uno como docente siempre necesita esa inyección de sabiduría, de conocimiento, de entusiasmo. Son las que más recuerdo así como a Nancy Díaz Larrañaga, Florencia Saintout desde su lugar, desde su juventud mostró una sencillez y un conocimiento impresionante".

Y con respecto a la tesis "yo ahora en realidad, lo único que tengo que hacer es ponerme a escribir porque por ejemplo, ya tengo las entrevistas hechas, el material con el cual organizar y mirar teóricamente ya lo he leído, me faltaría dar una vuelta de tuerca con algunos aspectos de las entrevistas, lo voy a hacer después, pero pasa que me tendría que poner a escribir y escribir a mí me cuesta". Reconocía Kira quien iba a abordar un tema al que se dedicaba: la Educación de Adultos a través del caso del PROSEPA- Programa Semi-presencial Polimodal de Adultos -en Comodoro Rivadavia mediante las biografías escolares de nueve alumnos. Era responsable de la coordinación de ese programa desde hacía siete años, la educación de adultos junto a la comunicación, eran los campos que deseaba cruzar luego de que su vida laboral se viera atravesada por esas dos áreas de conocimiento y práctica. Respecto de la tesis y su intención de consolidar esa intersección "la idea en todo momento fue esa -sostuvo- yo siempre quise tener más herramientas para trabajar bien educación de adultos y para poder transmitírselo a los profesores, a los docentes que están trabajando conmigo porque hay muy poca gente que ha hecho capacitación en este sentido, hay pocos docentes de adultos, yo si algo quisiera hacer posteriormente es empezar a trabajar en educación de adultos, en capacitación, en formación".

Finalmente y para alegría de esta tesista, amiga personal de su colega y compañera de maestría, ante la pregunta acerca de si este ensamble que 
lograba entre comunicación y educación, conseguía a través de la educación de adultos ponerle el broche a su carrera, respondió satisfecha "Si siempre ha sido eso, yo le encontré... todo este itinerario fue para pensar la comunicación y la educación".

\section{María Dilys Vales}

Nuestra compañera de PLANGESCO de la ciudad de Trelew, consultada con respecto a los seminarios dictados afirmó que "yo creo que todos aportaron, me gustó mucho Nancy Díaz Larrañaga y tal vez porque en ese momento yo estaba trabajando justamente en una organización que presentaba todo lo que ella había bajado con respecto a la organización, me gustó mucho Samaja, porque creo que fue uno de los más profundos". También se mostró satisfecha con los talleres, tanto el de Uranga como los de Claudia (Villamayor) "me pareció que eran bien prácticos y esto es muy importante... También el de Schmucler".

Luego se refirió al largo proceso que atraviesa con la redacción de la tesis y su dirección, "mi directora era Claudia Villamayor y no la culpo a ella ni nada, sino que son los tiempos de uno y de otro que no dan, y entiendo que cada uno prioriza sus necesidades. $Y$ yo no soy una prioridad en las necesidades de los tiempos de Claudia, así que para nada me ofendo ni nada, simplemente no se da entonces prefiero...la quiero terminar, es una cuestión de aprender a cerrar ciclos y toda mi vida fue así empiezo y lo quiero terminar". Después de esta experiencia, se encuentra aún en esa búsqueda, así como en la constitución de un nuevo tema de tesis, "en un principio había tomado una experiencia propia que fue la capacitación en comunicación en organizaciones como el ISSyS Instituto de Seguridad Social y Seguros- Chubut, tenía toda la práctica allí, sólo la debía bajar a papel". Con el cambio de gestión política y los vaivenes que esto genera resolvió, aconsejada también por su directora de aquél momento, no tomar esa sola organización, sino la unidad ejecutora que integraba para ese propósito. De este modo inició la segunda etapa con una estructura basada en la misma y el relato del surgimiento, sus características, las relaciones con la 
comunidad, el procedimiento para captar sus necesidades, etc. Agrega que enriqueció su trabajo al integrar desde la Facultad de Humanidades de la UNPSJB sede Trelew una ONG para conformar una gran red solidaria y que su aporte se encauzará en la misma línea de la capacitación que desarrolla en la administración pública.

En este momento se encuentra retomando dicha producción y en busca de un director que guíe su proceso hasta el cierre.

\section{Daniel Pichl}

Después de cursar el posgrado de Gestión Universitaria que se dicta en la Facultad de Ciencias Económicas de la UNPSJB por convenio con la Universidad Nacional de Mar del Plata, Pichl se recibe de especialista en el año 2001 pero no finaliza la tesis que le hubiese permitido alcanzar el título de magíster.

Al momento de iniciarse PLANGESCO "yo quería que me hicieran un reconocimiento de materias de la otra maestría, todo lo que era de gestión, mientras tanto cursé los seminarios de Schmucler, Argumedo, Giordano, Mata, me arrepiento de no haber hecho el de Washington Uranga". Destacó que le gusta la temática, que trabaja en el área de Prensa de la universidad por lo que considera central el tema de la gestión, así como la necesidad de formación permanente.

A la tesis la vincula con su trabajo de comunicación periodística en el área de Prensa de la Universidad, desde donde también aborda el tema de la divulgación de la ciencia de la Universidad de la Patagonia. "Y sigo con la lectura, mi idea es presentarla en PLANGESCO como tema de tesis y de ahí tratar de cerrar".

En este escenario dinámico Daniel se encuentra cursando el doctorado en Ciencias de la Comunicación de la UNLP y su lugar de trabajo en la UNPSJB cambió del área de prensa al sector editorial, seguramente estos desplazamientos influenciarán en el proceso mencionado. Así como en su momento del proyecto relacionado con el consumo de medios en la ruralidad y en situación de aislamiento, pasó al tema de divulgación de la ciencia por la experiencia que estaba desarrollando en su área de trabajo. Experiencia que 
también se cruzó con la gestión de esta coordinación local de PLANGESCO dado que se intentó gestionar desde el espacio, un plan de formación para la comunicación pública de la ciencia. (Proyecto de Especialización en Divulgación Científica, capítulo 2: 16).

\subsubsection{Entre tesis: TICs, Autogestión cultural, Radios educativas}

Tanto la tesis de Luis Sandoval "Tecnología, comunicación, ciudadanía. Una aproximación a los usos políticos de las tecnologías de comunicación en Argentina", cuanto la de Celina Salvatierra "Autonomía en la ciudad de México 2010-2011: Comunicación y gestión en el centro cultural La Pirámide" como la de Diego Pérez "Wiki Radios Educativas: Red de radios escolares", acudieron al tratamiento de temáticas fecundas del campo comunicacional. Lo hicieron no sólo en cuanto a la pertinencia de los mismos, sino a la implicancia que cada uno tiene en el terreno de los actuales debates. Aunque más allá de sus aportes al campo a través del planteo de las problemáticas científicas detectadas, se destacan las implicancias políticas del desarrollo de los procesos generados al abordarlas.

La tesis de Luis Sandoval tiene que ver con una cuestión de políticas públicas en la que confluyen lecturas, intereses teóricos y una práctica de muchos años en la Municipalidad de Comodoro Rivadavia, que fue cruzándose con su producción académica cuando empezó a trabajar en un programa de acceso a las TICs. Asimismo abona la consolidación del Grupo de Investigación sobre Internet, tecnología y cultura (FHyCS-UNPSJB), desde el cual se organizaron las Jornadas patagónicas de Estudios Sociales sobre Internet y Tecnologías de Comunicación en junio de 2011, un mes después de la defensa de su tesis en la FPyCS. Tanto como el 17 de junio del corriente en un acto en la Biblioteca Central de la UNPSJB presentó su libro, Tecnología, Comunicación y Ciudadanía que completa el ciclo de la tesis con la versión ampliada y publicada. Así fue como siente que 
en los últimos años logró consolidar un espacio más claro de preocupaciones académicas y reconoce que la Maestría fue parte de ello, el tema de su tesis tiene que ver con el proyecto de investigación que dirige y con lo que espera sea su tesis de doctorado que actualmente se encuentra desarrollando.

Celina Salvatierra quien defiende su tesis un año después, en octubre de 2012, con el tema de Autogestión y autonomía de proyectos culturales en México, se convierte en una de las primeras jóvenes graduadas de esta carrera de Comunicación de la FHyCS con título de posgrado. Ese título no sólo tiene el mérito de haberlo alcanzado, sino de hacerlo en su propia casa de altos estudios, con la mayoría de los que fueron sus profesores y algunos pocos compañeros, "de las fortalezas, -reconoce- la primera es que hayan hecho una extensión al sur" y de haber podido cumplir con su deseo de desarrollar la tesis en el exterior. Su intención era la de abordar el tema de comunicación alternativa en Latinoamérica y ese objetivo cumplido le servirá como base para sus estudios doctorales que continúa hoy en la FPyCS de la UNLP y como patrón de otras iniciativas en la región.

Por su parte Diego Pérez, de Puerto Madryn, inició una experiencia que no solo le permitió pensar la mediación de la radio en los procesos educativos, sino que puso su propia emisora al servicio del proyecto y se vio sorprendido por la magnitud del emprendimiento que hizo que pasara a la órbita del gobierno y alcanzara a una gran cantidad y diversidad de escuelas de toda la provincia. Así como dejó las bases para la constitución de una red de radios educativas en una modalidad Wiki.

Aunque atravesó una instancia frustrada de tesis anterior, cuando como referente del área comunicación de la Fundación Patagonia Natural tomó el análisis de los procesos comunicacionales de los conflictos ambientales y la formación de una red de periodistas que diera cuenta del vínculo comunicación/ambiente en la actualidad regional (Capítulo 2:14). Esa experiencia retrasó una etapa de su graduación, pero para la FPyCS de la UNLP 
posibilitó la apertura de la Especialización en Comunicación y Ambiente y para la FHyCS de la UNPSJB la oportunidad de su dictado en esta sede con recursos de la Fundación Patagonia Natural.

No obstante, Diego logró desarrollar esta última experiencia de tesis que no sólo representa su posibilidad de alcanzar un reconocimiento académico, sino que se posicionó como un referente en el tema de radios educativas en la provincia.

\subsubsection{Entre todos}

La pérdida de Kira Rakela dejó inconclusa la tesis- la Educación de Adultos a través del caso del PROSEPA mediante nueve biografías escolares- pero su trayectoria en el tema que era motivo de la misma, marcó una huella que es importante destacar. La vinculación entre educación y comunicación fue constitutiva de su práctica y en especial su interés por la educación de adultos. Fue una de las primeras egresadas del PROA un posgrado en formación de adultos a principios de los noventa que estaba orientado a transformar las prácticas a través de la puesta en marcha de nuevas estrategias pedagógicas. A la par de su actividad en la carrera de Comunicación seguía vinculada a la educación de adultos hasta que fue nombrada coordinadora del PROSEPAPrograma Semi-presencial Polimodal de Adultos -.

Tanto María Dilys Vales con el análisis de una unidad ejecutora para la capacitación en comunicación en la administración pública provincial, con proyección a una red de organizaciones comunitarias, como Daniel Pichl con el tema de la divulgación de la ciencia en particular en la Universidad de la Patagonia, se encuentran avanzando hacia la concreción de esta instancia final. Estas temáticas sin duda aportarán al campo de la comunicación desde diferentes perspectivas, pero ambas serán enriquecedoras, no sólo académicamente sino también profesionalmente por la implicancia que dichas reflexiones sobre esas prácticas aportarán. 


\subsection{Propuesta de convergencia ¿Un futuro posible?}

\subsubsection{La Convergencia: un futuro posible}

En el acervo social del conocimiento y de la experiencia (Berger y Luckmann, 1997) se encontraban los sentidos que posibilitaron que la Escuela de Periodismo y Comunicación Social de la UNLP adquiriera carácter de Facultad en 1994 y a la Maestría PLANGESCO que se creara en 1996. Quienes la promovieron, la vieron más como una posibilidad para contribuir a ese proyecto mayor, aunque la consciencia de su proyección la fueron adquiriendo como gestores y alumnos de un posgrado que se distinguía, no sólo por ser el primero en los estudios superiores de comunicación sino además por su asociatividad con una ONG como La Crujía.

Estos hechos fundantes empezaron a gestarse a mediados de los ' 80 cuando se discutía un nuevo proyecto político académico, así como la reforma curricular de 1998 que posibilitó luego la apertura de las cátedras a los proyectos de investigación y su articulación con la política general de investigación de Facultad. Estas decisiones promovieron el actual posicionamiento de una Facultad que no sólo sumó $600.000 \mathrm{~m} 2$ de construcción en la nueva sede sino que ofrece tres nuevas maestrías, siete especializaciones, un doctorado y una instancia posdoctoral. El alineamiento político de su decana, Florencia Saintout, hoy candidata a primera concejal por el Frente para la Victoria para la ciudad de La Plata, habla de su compromiso comunitario y una modalidad de educación militante ampliamente defendida por los referentes de esa Facultad. Las ventajas no sólo se capitalizaron en su interior, la sanción de la ley de Servicios de Comunicación Audiovisual, fue discutida y apoyada por la Redcom, la red de Carreras de Comunicación, de la cual la Facultad de la Plata es fundadora y uno de sus miembros más activos.

Nuestra alianza con esa Facultad adquirió pleno sentido en la suma de experiencias que nos vincularon. Primero con los profesores que trabajaron en la 
formación de docentes locales, con grados de involucramiento político que fueron más allá de su función, para convertirse en el respaldo que la carrera necesitaba para posicionarse con mayor fortaleza en nuestra propia Facultad. El dictado de PLANGESCO a partir del año 2003, contó con el entusiasmo de todos los involucrados aunque con la extensión de su cursada, los numerosos obstáculos producto de la falta de respaldo institucional y de lo complejo del proceso de autogestión, fue siendo soslayada de los relatos, hasta su reconocimiento en el año 2011 por la visualización que se produjo tras la graduación del primer magister.

Sostenerla en el tiempo tuvo que ver con el interés de cada uno de los alumnos en formarse pero también con el conjunto, como referentes y responsables de llevar adelante un proyecto del departamento de Comunicación Social. Un programa colectivo que no sólo fuera un espacio para la formación académica individual, sino que posibilitara la articulación con otros proyectos que necesariamente parten de esta instancia pero que posibilitan otros logros importantes para el conjunto de la carrera.

La decana de nuestra Facultad Claudia Coicaud, resignificó esos logros desde su rol de decana, midiendo lo del colectivo de maestrandos, no sólo como proceso de formación sino desde su dimensión política en términos de lo que la gente puede desarrollar en ese campo de negociaciones. En este sentido, puso el acento en la conformación de jurados para la regularización de la planta docente, aunque reconoció que existían dentro de Consejo Directivo cuestionamientos al contralor académico y a la dilatación de los plazos de finalización.

Esos cuestionamientos pasaron de acuerdo a su opinión por la falta de discusión acerca de "las condiciones académicas de sostén" que habría que haber puesto al momento de implementar el proyecto. Desde la interpretación de su perspectiva se infiere que la ausencia de esas condiciones hizo que su destino quedara puesto en el grupo autogestionado y en el rol de la coordinación. Pero el anclaje que ella refería como necesario era el de una figura diferente a la que se constituyó, de coordinadora y maestranda a la vez, que pudiera agregar valor en 
lo académico y no siempre en términos de reclamo. Recordó que cuando cursó en la UBA, el responsable de la maestría era un posdoc y a lo largo de la cursada recibían clase de maestrandos en proceso de tesis. Este fue uno de los ejemplos que utilizó para destacar que es necesario optimizar estos convenios y armar un esquema que permita "un valor agregado en términos académicos". "Nosotros necesitamos que alguna vez ellos inviten a nuestros maestrandos que están en proceso de tesis porque no se necesita que sean magisters para poder poner algo de lo que fue esta experiencia, porque si no el valor agregado en términos de posgrado y de acreditaciones se diluye" (Entrevista Claudia, 1/11/2011).

Este planteo de cuando "las universidades grandes ponen un proyecto a disposición de una universidad más chica" (Coicaud) y la idea de tratar de que sea efectivamente colaborativo es lo que planteó la decana de la Facultad de Humanidades. Por su parte Marcelo Brunet coordinador de PLANGESCO Jujuy de la UCSE- DASS -Departamento Académico San Salvador de la Universidad Católica de Santiago del Estero- consideró su experiencia como exitosa (Entrevista Brunet, 14/06/2012). Al reseñar el modo en que se llevó a cabo la misma en la sede de San Salvador de Jujuy, contó que finalizó en junio del 2011, luego de los dos años acordados de cursada, con un viaje por cada docente, exceptuando los talleres que requirieron dos. Que comenzaron veinticinco alumnos y hoy tienen seis proyectos de tesis presentados y dos tesis esperando el armado de la defensa. Puntualizó que la UCSE- DASS asumió todos los costos que involucra un proyecto de esta naturaleza, incluso los honorarios de dos personas en La Plata para tareas administrativas y de coordinación. Tiene claro Brunet que aquella Universidad "no hizo dinero con PLANGESCO, al contrario, aún hay estudiantes que no terminaron de pagar las cuotas" pero destacó que la idea de las autoridades fue clara desde su gestión "a mediano plazo poder armar un posgrado propio y apelar a recursos formados aquí" (Entrevista Brunet, 14/06/2012).

Esta idea que acompaña también al colectivo de docentes que atravesó PLANGESCO en Comodoro, no sólo colaborará con el proyecto de esta gestión de la Facultad cuyo desafío en su inicio fue "consolidar las áreas de investigaciones 
y el área de formación de posgrado o por lo menos dejar bases sentadas" (Coicaud) sino también con la postergada investigación en nuestro campo.

Cada docente que ha iniciado y continúa su formación permanente tiene en sus manos una herramienta de transformación y en este trayecto de posgrado en particular, colaboró con la idea de entender la teoría a partir de la sistematización de los propios aprendizajes.

\subsubsection{Una experiencia en clave PLANGESCO}

(GABRIELA CHAVEZ, Entrevista: 20/02/2012)

Gabriela Chavéz es tucumana, hizo la carrera de Ciencias de la Comunicación en la Facultad de Filosofía de la Universidad Nacional y fue la sexta egresada de la primera promoción. Pasaba su verano en Rada Tilly, una villa balnearia $15 \mathrm{~km}$ al sur de Comodoro Rivadavia, trabajando en la venta de tarjetas de estacionamiento en la costanera. Le interesó PLANGESCO cuando dos de sus compañeros empezaron a cursarla en Jujuy en la UCSE- DASS, por una cuestión de tiempos y costos no pudo concretar la experiencia allá y se mudó a La Plata. En este momento (Chavéz. Entrevista personal, 20/02/12) se encuentra cursándola en la Facultad de Periodismo y Comunicación Social de la UNLP, con compañeros de diferentes lugares del país y de Latinoamérica. Está entusiasmada con la experiencia y ya se encuentra desarrollando el proyecto de tesis dado que se sumó a la Unidad de Prácticas de Producción del Conocimiento, que dirige Cecilia Ceraso, actual directora de PLANGESCO. Se trata de un proyecto de Jóvenes y Participación Política en La Matanza, que comenzó con el dictado de talleres a chicos del Observatorio de Jóvenes y la Unidad de Prácticas, de manera tal que su tesis relevará el proceso de esta experiencia. 


\section{Conclusiones}

A finales de 2013, a treinta años de recuperación de la democracia, a pocos meses de los 80 años del nacimiento de la Escuela de Periodismo en la UNLP y de cumplirse los 40 años de la creación de la UNPSJB, recoger esta historia de cruce de sus saberes y prácticas es un homenaje a la memoria de quienes los construyeron, organizando y fortaleciéndolas.

En los antecedentes de la región patagónica, pesa tanto su condición de Territorio Nacional frente al status de Provincia que alcanzó setenta años después (1955), como también la instauración de la Gobernación Militar que tuvo a Comodoro como Capital y se extendió por los dos primeros gobiernos peronistas. En ese marco se gestaron numerosas iniciativas vinculadas a la educación, desde la Universidad Popular de la Patagonia hasta el Instituto Superior de Estudios Patagónicos y, aunque no prosperó, el no menos importante proyecto de ley para la creación de la Universidad Nacional. Este último encauzó el reclamo de una comisión vecinal que además de su constitución, promovía a Comodoro para su ubicación, movimiento que perseguía el fin reivindicativo de una zona que se consideraba a sí misma autónoma y con capacidad para forjar los destinos de la región. Algunas investigaciones sostienen que este protagonismo provocó un enfrentamiento entre valletanos y comodorenses que aún persiste y en el ámbito de la UNPSJB es posible rastrearlo en la escasa vinculación en torno a proyectos entre las sedes de Trelew y Comodoro Rivadavia.

La intención de institucionalizar los estudios superiores y que los mismos estén vinculados a los temas de interés regional y en particular al desarrollo de la zona, es recurrente en todos los proyectos mencionados. No obstante en 1959 con la puesta en marcha en Comodoro Rivadavia del Instituto Universitario de la Patagonia, se posiciona en los estudios superiores esa otra línea vinculada a la educación religiosa. Es impulsado en un momento propicio para su desarrollo 
dado que seguidamente se sanciona la ley de creación de universidades privadas y un año más tarde es reconocido como Universidad de la Patagonia San Juan Bosco, que con sus escuelas de ciencias y de humanidades marcará la orientación académica de la actual universidad.

Esos antecedentes permiten visualizar la gestación de la universidad nacional que surgió a principios de los setenta como resultado de protestas estudiantiles y del impulso estatal a su apertura. Esta intención de las políticas nacionales de promover la regionalización de los estudios superiores para descentralizar, se complementaba con la necesidad de la población de la zona interesada en evitar el éxodo de jóvenes y calificar recursos para la explotación de sus potencialidades productivas. A fines de la misma década, la unificación con la privada dio como resultado la creación de la Universidad Nacional de la Patagonia San Juan Bosco, un intento más de conciliar intereses para promover el desarrollo, arraigar a los jóvenes y a partir de conformarse Comodoro en sede del Rectorado, regionalizar el proyecto a través de sedes. Esta intención se concretó en la denominada etapa normalizadora, cuando se pudo completar con el impulso a las sedes de Esquel y Trelew, a las que se sumaron luego las de Ushuaia y Puerto Madryn, a modo de una oferta académica pensada en relación a la explotación económica de esas subregiones.

La necesidad de recuperar los antecedentes de su constitución, demandó una reconstrucción del proceso, con el fin de vincular los momentos que posibilitaron la consolidación de la educación pública y laica, en una sociedad con un fuerte acento religioso, producto de la también importante obra educativa de la congregación salesiana. No obstante las diferentes tradiciones perseguían los mismos intereses institucionales de fortalecimiento del desarrollo regional, pero distinta metodología política para alcanzar los resultados. Si bien la Universidad Nacional absorbió lo que quedaba de la Privada al momento de constituirse, las bases de su imaginario fueron gestadas en ese modelo y muchas de las dificultades para consolidar esta universidad joven y emergente de la Patagonia encuentra sus raíces en esos debates internos y en el reconocimiento de la hibridez de su formación. Por otra parte devela un modo de articulación que 
desde la dimensión comunicacional adquiere otro sentido y está relacionado con una de las hipótesis que persigue esta tesis, que es la de contar cómo los procesos de institucionalización posibilitan o desalientan las iniciativas en virtud de los momentos e intereses políticos coyunturales que atraviesan y por los que son atravesados.

La Universidad Nacional de la Plata nace a comienzos de siglo y con su impronta tradicional y reformista, promueve la escuela decana de los estudios universitarios del Periodismo, en asociación con el Círculo de Periodistas de la Provincia de Buenos Aires.

Amplía su campo a la comunicación en la década del setenta, pero en el marco de la Dictadura que diezmó su propia estructura. Recién con el retorno a la democracia modifica el Plan de Estudios entre otras cuestiones institucionales, incorporando nuevas concepciones de la comunicación, la cultura y las ciencias sociales en general.

La Universidad de la Patagonia SJB nace en la década del setenta, y en los ochenta la carrera de Comunicación, del interés del Departamento de Letras por ampliar su campo de acción. En el marco de las reuniones fundacionales se realiza una con periodistas de los medios locales porque estaba vigente el debate entre idóneos y profesionales, pero el origen de la formación del periodismo en el campo universitario, precisamente en la UNLP, fue un argumento contundente al momento de conciliar diferencias.

En la década del noventa, Periodismo y Comunicación Social de la UNLP, de Escuela se convierte a Facultad y cambia su perfil por el de una institución que no sólo recupera el espíritu asociativo de su origen ahora con la Crujía, una organización sin fines de lucro dedicada a la educación en comunicación, sino que en conjunto da apertura a PLANGESCO, la primera Maestría en Comunicación del país.

Mientras tanto es también en los noventa cuando la FHyCS de la UNPSJB decide la incorporación de profesores viajeros para elevar el nivel académico que, en el caso de Comunicación, da como resultado el acuerdo con la FPyCS de la UNLP. 
El proceso de construcción del vínculo con la FPyCS de la UNLP comenzó con esos profesores que son quienes encauzan el interés de los docentes por capacitarse e inician las gestiones con las autoridades para la suscripción del convenio que permite el dictado de PLANGESCO en la sede Comodoro de la FHyCS de la UNPSJB.

Al reflexionar sobre el modo en que esta experiencia fue atravesada por la cultura de ambas organizaciones se pusieron en evidencia los diferentes grados de involucramiento, que permitió concluir que el complejo proceso que atravesó la experiencia tuvo que ver con las propias dificultades de la Facultad de Humanidades y Ciencias Sociales de la UNPSJB para institucionalizar el área de posgrado.

La UNPSJB, que a fines de los '80, fue pionera en el primer programa de posgrado de Argentina en el campo de la formación de profesores universitarios para el ejercicio de la docencia, por los avatares de su proceso de constitución, consiguió una decena de graduados quince años después. Las mismas autoridades que afirman que la falta de un proyecto político de formación fue general en la Universidad, sostienen que en la FHyCS, el posgrado se inicia cuando comienzan a inscribirse los proyectos en las instancias nacionales de acreditación. Indudablemente todos los antecedentes previos al señalado año 2007 de apertura de la Maestría en Letras, también fueron parte de la historia de la organización pese su escaso reconocimiento y documentación. Hay razones de orden general, como el hecho de que la estructuración de los posgrados en las ciencias sociales fue tardía porque resultó el área más castigada por la última dictadura militar y otras particulares, relacionadas por ejemplo con la realidad de una universidad joven y emergente en el marco nacional.

En el terreno de lo macro también coincide la experiencia PLANGESCO Comodoro con una problemática que tuvo que afrontar la generación intermedia de profesionales que no accedió a las becas FOMEC para los pocos posgrados en ese momento en el país, como tampoco a la oferta que posibilitaba la misma en el extranjero. Hoy la realidad es otra, los docentes con formación de posgrado superan a los de grado (Jeppesen, Nelson y Guerrini, 2004) pero no en la FHyCS 
donde aún son muy pocos los magisters y doctores como para dar cuenta de una masa crítica, tal como lo reconoce la Secretaria del área, aunque pronosticando un buen resultado con los que están siendo acreditados en esta gestión.

Otro de los atravesamientos, parte de este proceso de casi una década de vigencia de PLANGESCO, lo constituyeron las perspectivas políticas de abordaje institucional de cada una de las tres gestiones del Decanato en ambas Facultades, la de Periodismo y Comunicación Social de La Plata y la de Humanidades y Ciencias Sociales de Comodoro Rivadavia. Así como también de la propia Maestría que de una concepción del desarrollo asociada a procesos latinoamericanos vinculada a la figura de Washington Uranga pasó luego de un período de transición, a una noción de planificación asociada a procesos de liberación nacional y social. Esta perspectiva se tradujo en un cambio en la dirección a manos de Cecilia Ceraso y German Rétola que también repercutió en la cohorte-comodorense.

En la historicidad de este proceso aparecen destacados momentos y sucesos que forzaron la creatividad de la gestión para continuar con la planificación más estructural y deseada de alcanzar en conjunto el final de la cursada. Desde un período de desfinanciamiento y pedido de becas a la FHyCS para los docentes de la Carrera, cuya respuesta institucional fue el otorgamiento formal de la mitad solicitada que nunca llegó a efectivizarse; hasta el reclamo por la falta de anclaje académico del proyecto frente al reconocimiento de la ausencia de una política institucional sobre el tema, son parte de este escenario complejo de desenvolvimiento del posgrado.

Por su parte, la FPyCS no impedía ningún desarrollo pero tampoco ofrecía iniciativa para sortear las dificultades, salvo por la predisposición de quien siempre actuó como coordinador solo reconocido por su labor efectiva y de otros profesores que pusieron su capacidad y contactos al servicio de esta experiencia en alguna etapa del proceso. Este respaldo se tradujo en una serie de actividades político-académicas que colaboraron con el posicionamiento del posgrado en el imaginario de la Facultad. No obstante motivado por la extensión de la cursada y la complejidad del proceso de autogestión recreado, PLANGESCO 
Comodoro fue soslayada de los relatos hasta el año 2011 cuando adquiere visualización con el primer egresado de la cohorte.

Esta graduación también se convierte en un aliciente para el resto de los alumnos que completaron la cursada y se encontraban, en diferentes etapas, pero con el reencontrado deseo de alcanzar ese objetivo. Este anhelo se pone de manifiesto cuando se abordan las apropiaciones y representaciones que tuvo esta Maestría para la cohorte de alumnos, en su mayoría docentes de la Carrera de Comunicación Social, dado que las motivaciones individuales tenían un común denominador, la necesidad de iniciar una formación de posgrado. Mientras que en lo grupal no se destaca la fortaleza del mismo, así como tampoco hay acuerdos en cuanto a percibir la transcendencia de este proyecto en lo colectivo, las razones que esgrime cada uno son de diferente origen aunque, también por distintas razones, se menciona la falta de respaldo institucional de ambas organizaciones.

La perspectiva del primer graduado se modificó una vez alcanzado el objetivo, es posible que ello se revierta en los siguientes porque se cerraría el ciclo pese a su complejidad.

Si PLANGESCO Comodoro significó para todos los participantes un aporte a su crecimiento provocó una consecuente transformación en la carrera de Comunicación Social y se constituirá en un antecedente acerca de la fortaleza de un proyecto colectivo que sobrevivió a su propia fragilidad institucional.

Que la contribución de este posgrado no fue sólo en términos de formación, sino también de intercambio, ya que permitió la conformación de jurados para la regularización de su planta docente, así como la transformación de los programas, las prácticas aúlicas y es posible que sedimente en la modificación del Plan de Estudios en largo período de gestación.

Que es factible encauzar estos resultados hacia proyectos superadores también desde un programa que fortalezca la carrera articulando lo político con lo científico, lo científico con lo comunitario, para que las líneas de investigación que comenzaron en esta instancia de posgrado se fortalezcan también en las tesis doctorales promovidas a través del PROSOC II - Proyecto de Apoyo a las 
Ciencias Sociales- a la que accedió entre otros, el primer egresado de PLANGESCO Comodoro.

Las tesis aquí relevadas son tan diversas como el proceso que las promovió, pero señalan el interés de los comunicadores por analizar los múltiples procesos comunicacionales que van desde vínculos sociales hasta organizaciones culturales, así como por la necesidad de reflexionar sobre los grandes desafíos de la tecnicidad o revisar los propios recorridos de formación. Esta versatilidad de los procesos comunicacionales señala la condición transdisciplinaria del área y la necesidad de orientar esta potencialidad hacia proyectos institucionales de mayor sentido.

Al compartir aspectos comunes y sensibles de la experiencia, el grupo se consolida en la resistencia de modo que PLANGESCO Comodoro constituyó una oportunidad para los que mantuvieron en alto esa motivación inicial y no hay frustración posible si finalmente las instituciones terminan posibilitando el cierre del proceso.

Por último, de todo el trabajo de reflexividad hecho, queda la certeza de que el desarrollo de la cohorte Comodoro de la Maestría PLANGESCO de la Facultad de Periodismo y Comunicación Social de la UNLP representa un caso paradigmático para interpretar y caracterizar la complejidad con que los posgrados han sobrevivido y crecido en nuestro país durante una década, donde las políticas de restauración de derechos han sido trabajosamente construidas, con convicciones personalísimas e instituciones que aún resisten en lógicas autoreferentes, aislantes, desmotivadoras de lo colectivo, herederas plenas del neoliberalismo que la precedió.

La inmersión voluntaria a partir del acuerdo por tratar como tema de tesis nuestra propia experiencia, no ha sido fácil ni meramente autorreferencial. Rastrear en la genealogía de las características fundantes de las Instituciones, enmarcar el desarrollo en las políticas nacionales confusas y contradictorias, advertir constantes y distinciones entre los recorridos individuales, no sólo refiere a la metodología sino que ha redefinido un campo de trabajo de indispensable planificación y gestión hacia el futuro inmediato. 
La formación de posgrado, en sus variables de actualización, complementación, capacitación puede remitir, sin ahondar mucho siquiera, a modelos eurocéntricos y con la internacionalización y la equidad como bandera, es necesario resignificarla a partir de nuestros propios análisis y elecciones.

La historicidad de la UNLP, de la UNPSJB, de la FPyCS, de la FHyCS, debe conmoverse con este relato, enfrentándose a una imagen tortuosa e inacabada, procesándola para incorporarla como parte de su propio proceso. Los casos son la oportunidad para enfrentar los sueños proyectados y hacerlos proyectos soñados. Nosotros somos testigos privilegiados de esta pequeña batalla por unos derechos que aparentemente no estaban más que en nuestra voluntad de aprender la comunicación como un proceso de conocimiento y realización colectivo.

Diciembre de 2013.-

\section{Bibliografía}

Restrepo, Mariluz (2003) Universidad como mediadora de Cultura. Pensar Iberoamérica. Revista de Cultura, OEl.

http://www.oei.es/pensariberoamerica/ric03a01.htm

Argumedo, Alcira (2003) Universidad y conocimiento en América Latina: un debate por el futuro. Prohistoria, Año VII, número 7. pp. 207-230.

Argumedo, Alcira, Quintar Aída: Argentina ante una encrucijada histórica en Estudios Sociológicos-Colegio de México, Vol. XXI, № 63. México DF. 2003.

Argumedo Alcira (200l) Argentina: los desafíos de un nuevo tiempo histórico en Ciudadanos, Año 2, № 2. Buenos Aires. 
Argumedo Alcira (1996) El Imperio del Conocimiento, Impacto de la Revolución Científico-Técnica. Encrucijada UBA, Año 2, nro. 4

Arias Bucciarelli (2010) Mario. La Patagonia Argentina como Territorio Nacional. Perspectivas de análisis. Dossier: Reflexiones en torno a los estudios de los Territorios Nacionales. UNCO

http://historiapolitica.com/datos/biblioteca/tn01.pdf//

http://historiapolitica.com/territorios/

Baeza Brígida (2002) La Universidad Nacional de la Patagonia San Juan Bosco como agente de desarrollo (1973-2002). Programa de Evaluación Institucional Permanente Secretaría de Planeamiento Universitario UNPSJB

http://autoevaluación.unp.edu.ar/wp-

content/uploads/2009/04/Historia_de_la_UNPSJB_Baeza.pdf

Barbero Jesús Martín. (1987) De los medios a las mediaciones, Comunicación, cultura y hegemonía, Gustavo Gilli, México

Barbero Jesús Martín. (2002) La educación desde la comunicación. EDUTEKA Tecnologías de Información y Comunicaciones para Enseñanza Básica y Media. Editorial Norma.

Barros, Sebastián (2007Anormalidad, inmadurez e historia de los Territorios Nacionales: el caso de Santa Cruz. Ponencia presentada en las XI Jornadas Interescuelas Departamentos de Historia, Universidad Nacional de Tucumán. http://www.ffyh.unc.edu.ar/archivos/modernidades_a/VII/DEFINITIVOS/Barros.htm

Beltrán, Luis Ramiro (2005) La Comunicación para el Desarrollo en Latinoamérica, un recuento de medio siglo. Documento presentado en el III Congreso Panamericano de la Comunicación en el Contexto de la Sociedad de la Información. Carrera de Comunicación de la UBA. 12 al 16 de julio, Buenos Aires. http://www.portalcomunicacion.com/both/temas//ramiro.pdf

Berger, Peter y Luckmann, Thomas (1997) Modernidad, pluralismo y crisis de sentido: la orientación del hombre moderno. Paidos. Barcelona

Berger, P. y Luckmann, T. (1994); La construcción social de la realidad, Amorrortu, Bs. As. 
Barsky Osvaldo (coordinador) (2005) Políticas y Mecanismos para fortalecer la articulación entre los posgrados universitarios y las cadenas productivas para mejorar niveles de competitividad, Convenio Consejo Interuniversitario Nacional (CIN) - Consejo de Rectores de Universidades Privadas (CRUP) - Universia.

Bonini, Elsa (2009) Discurso de la vicerrectora de la UNPSJB en el acto de entrega del título de Profesor Honorario al Dr. Cayetano De Lella.

http://www.ungs.edu.ar/areas/novedades_institucionales/171/

De Certeau, Michel (1996) La invención de lo cotidiano. 1 Artes de Hacer. UIA. México.

Bourdieu, Pierre (1990) Sociología y Cultura. Grijalbo. México D.F.

Bourdieu, Pierre (2000) Los Usos Sociales de la Ciencia. Ed. Nueva Visión

Buchbinder, Pablo y Marquina, Mónica (2008) Masividad, heterogeneidad y fragmentación: el sistema universitario argentino 1983-2007/ 1a ed. - Los Polvorines: Univ. Nacional de General Sarmiento ; Buenos Aires: Biblioteca Nacional http://www.academia.edu/2336222/Masividad_Heterogeneidad_y_Fragmentacion._El_sis tema_Universitario_Argentino_1983 - 2008

Buchbinder, Pablo (2005). Historia de las Universidades Argentinas. Colección: Historia Argentina. Director: José Carlos Chiaramonte. Editorial Sudamericana. Buenos Aires

Cano, Daniel (1985) La educación superior en la Argentina. FLACSO /CRESALC /UNESCO. Grupo Edit. Latinoamericano. Bs. As.

Cortés Carlos Eduardo (2001) La Comunicación al Ritmo del Pémdulo: medio siglo en busca del desarrollo. Bogotá

Carrizo, Gabriel.(2007) Saldando deudas. El peronismo en la Gobernación Militar. 1944-1955. Serie Voces y Argumento, director Dr. César Tcach. Documento $\mathrm{N}^{\circ} 11$, Córdoba, http://historiapolitica.com/datos/biblioteca/cean11.pdf

Castoriadis, Cornelius (1999) La Institución imaginaria de la sociedad. Vol. Tusquets Editores. Bs. As.

Chiroleu, Adriana; lazzetta, Osvaldo. (2005) La Reforma De La Educación Superior como capítulo de La Reforma Del Estado. Peculiaridades Y Trazos Comunes. En Risesi, E., Soprano, G., Suasnábar, C. Universidad: reformas y 
desafíos. Dilemas en la Educación Superior en la Argentina y el Brasil. Ed. Prometeo/UNGS, Buenos Aires

Chiroleu, Adriana; Marquina Mónica y Rinesi Eduardo, editores (2012) La Política Universitaria de los Gobiernos Kirchner: continuidades, rupturas, complejidades, Colección Educación, Universidad General Sarmiento, Bs.As

De la Fare, Mónica y Lenz, Silvia (2010) La política de posgrado en Argentina y la expansión de carreras a partir de la década del 90, Informe Final IECCONADU, Buenos Aires

De Lella Cayetano, Ezcurra Ana María y Krotsch Pedro (1994) Formación docente e innovación educativa Aique, Bs.As.,

Filmus Daniel, Kaplan Carina (2012) Educar para una Sociedad más Justa, editorial Aguilar, Bs.As.

Follari Roberto (2001) Argentina: el Acceso a los Posgrados como Urgencia Reglamentaria. Contextos de educación, Año 4, Nº 5

http://www.unrc.edu.ar/publicar/cde/05/Follari.htm

Giddens, Anthony Modernidad e identidad del yo, Ed. Península, Barcelona

Giddens, Anthony (1991) Sociología. Alianza. Madrid. Capítulo 9: Grupos y Organizaciones

Giordano, Carlos, Libro de los 70 años, 1934- 2004. Facultad de Periodismo y Comunicación Social, UNLP. Inédito.

Giordano, Carlos (2009) 23 Tesis sobre la Tesis: La Comunicación para la Transformación de la Gestión Educativa, La Plata

Giordano, Carlos. El Posgrado como espacio de formación político-académico y su articulación con los programas de becas y las tesis de grado.

Giordano, Carlos. El Bicentenario y la Universidad de cara al Siglo XXI. De riquezas, abandonos y oportunidades urgentes, Facultad de Periodismo y Comunicación Social, UNLP 
González, L, Ferretti E y Useglio, P: Compiladores.( 2009) Comunicar el Ambiente: una nueva experiencia pedagógica. $1^{\circ}$ edición, La Plata, Universidad Nacional de La Plata. ISBN: 978-950-34-0575-8

Huergo Jorge (1997) Comunicación/Educación. Ámbitos, Prácticas y Perspectivas. Ediciones de Periodismo y Comunicación. La Plata

Indicadores de Ciencia y Tecnología. Argentina (2009) Secretaría de Planeamiento y Políticas. Ministerio de Ciencia, Tecnología e Innovación Productiva, Presidencia de la Nación. Bs. As., 2009.-

Informe de Autoevaluación. Facultad de Humanidades y Ciencias Sociales. UNPSJB. (1996 y 2009)

Jeppesen Cynthia; Nelson Alejandra; Guerrini Victoria (2004) Diagnóstico y perspectiva de los estudios de posgrado en Argentina. IESALC - UNESCO

Krotsch Pedro; Suasnábar Claudio. Los estudios sobre la Educación Superior: Una reflexión en torno a la existencia y posibilidades de construcción de un campo. Revista

Pensamiento Universitario Nro. 10, Bs. As.

http://riepesal.ungs.edu.ar/articulos/Articulo\%20Revista\%20Pensamiento\%20\%20KrotsC h\%20Suasnabar.pdf

Luchilo Lucas, comp. (2010) Formación de posgrado en América Latina: políticas de apoyo resultado e impacto. - 1a ed. Eudeba, Buenos Aires.

Marquis Carlos, Spagnolo Fernando, Valenti Nigrini Giovana (1998) Desarrollo y Acreditación de los posgrados en Argentina, Brasil y México. Textos para una mirada comparativa Ministerio de Cultura y Educación. Secretaría de Políticas Universitarias.

Mata María Cristina, (1999) De la cultura masiva a la cultura mediática, DIALOGOS de la Comunicación № 56, Felafacs, Lima.

Najmanovich, Denise, La organización en redes de redes y de organizaciones http://www.denisenajmanovich.com.ar/upload/La\%20organizaci\%C3\%B3n\%20en\%20red es\%20de\%20redes\%20y\%20organizaciones.pdf

Plan Nacional de Ciencia, Tecnología e Innovación 2012-2015. "Construyendo Futuro, hacia una Argentina Innovadora". Secretaría de 
Planeamiento y Políticas en CTIP Ministerio de Ciencia, Tecnología e Innovación Productiva http://www.mincyt.gob.ar/multimedia/documentos/Version_Preliminar_PNCTI_20122015.pdf

Perez Lindo, Augusto (1985) Universidad, Política y Sociedad. EUDEBA, Bs. As.

Programa para el Diagnóstico, Planeamiento Estratégico y Evaluación de la Universidad Nacional de La Plata, Autoevaluación Institucional, aprobado por el Consejo Superior la coordinación de la Secretaría Académica de la gestión 1998-2000, y continuó en la gestión del período 2001-2004

Puiggrós Adriana (2007) Carta a los Educadores del S.XXI, Galerna, Bs.As http://books.google.com.ar/books?id=y1_tTKSIO50C\&pg=PA5\&lpg=PA5\&dq=adriana $+p$ uiggrós+cartas+a+educadores+del+siglo $+x x i \&$ source=bl\&ots=IDvul|Jm0Gf\&si

Puiggrós, Adriana (2003) Qué pasó en la Educación: Breve historia desde la conquista hasta el presente. Ed. Galerna, Buenos Aires.

http://lenguasvivas.org/campus/files/0_1/92536811-Adriana-Puiggros.pdf

Orozco Gómez, Guillermo. (2004) De la Enseñanza al aprendizaje: desordenamientos educativo-comunicativos en los tiempos, escenarios y procesos de conocimiento. Nómadas 21, 120-136. Universidad Central de Colombia.

Suasnábar, Claudio, Rovelli Laura (2011) Políticas universitarias en Argentina: entre los legados modernizadores y la búsqueda de una nueva agenda. (pp.21/30) Revista Innovación Educativa, ISSN: 1665-2673 vol. 11 núm. 57 - octubre-diciembre

http://www.autoriawcm.ipn.mx/wps/wcm/connect/229bca804b1f957384cced7b759ccbe e/57 Politicas universitarias_en Argentina.pdf?MOD $=A J P E R E S \& C o n t e n t C a c h e=N O N E \& C$ ACHEI $\mathrm{D}=229 \mathrm{bca} 804 \mathrm{~b} 1 \mathrm{f} 9573 \overline{8} 4 \mathrm{cced} 7 \mathrm{~b} 759 \mathrm{ccbee}$

Raffaele, Ana Clara (2012 la Construcción de Identidades Políticas durante el Proceso de Provincialización del Territorio Nacional de Chubut 1954-1955, UNLP.

Rosales, Elsa (2004) La Universidad Nacional de la Patagonia y el Desarrollo Regional, capítulo 6, pp 297-330. En Zárate, R y Artesi, L (coordinadores). Conocimiento, periferia y desarrollo. Los nuevos escenarios en la Patagonia Austral. Ed. Biblos. 
http://books.google.com.ar/books?id=GFFtxRuPfPsC\&printsec=frontcover\&hl=es\#v=on epage $\& q \& f=$ false

Samaja, Juan (1993) Epistemología y metodología. Elementos para una teoría de la investigación científica. Buenos Aires. Eudeba.

Saintout, Florencia (2003) Abrir la comunicación. Tradición y movimiento en el campo académico. La Plata. Ediciones de Periodismo y Comunicación Nro.23.

Sorrentino, Norberto. Discurso del Sr. Rector con motivo de su Asunción. http://www.bnm.me.gov.ar/gigal/documentos/EL000022.pdf

Wallerstein Immanuel, (1996) Abrir las Ciencias Sociales, Universidad Pedagógica Nacional, digitalizado por Red Académica. Traducción de Fernando Cubides. Universidad Pedagógica Nacional.

Vasilachis Irene (2007) Estrategias de investigación cualitativa. Gedisa, Barcelona

Uranga Washington (2003) Comunicar en y desde las Organizaciones. Bs.As

(2001) Gestionar desde la Comunicación. Gestionar Procesos Comunicacionales. Oficios Terretres. La Plata

(1999) Introducción a la planificación de procesos comunicacionales. Fac. de Periodismo y Comunicación Social, UNLP, Mimeo

Uranga, Washington; Bruno Daniela (2001) Diagnóstico desde la Comunicación-

La Gestión como Proceso Integral- Formación Académica e Imaginarios Profesionales del Comunicador y del Planificador de Procesos Comunicacionales. Tres Perspectivas para Comprendernos. Mimeo. Bs.As

\section{Ley 14557}

\section{Ley de Educación Superior $N^{\circ}$ 24521/95}

http://www.mec.gob.ar/index.php?option=com content $\&$ view=article\&id=203:le y-de-educacion-superior-nro-24521\&catid=110:leyes-nacionalesvigentes\&ltemid $=306$

Modificatoria de la 24521, Ley 25.754 de 2003 (arts.29c) y 39) 
Ley de Educación Superior. Proyecto de Modificación 2013

http://www.diputados.gov.ar/proyectos/proyecto.jsp?id=149818

Proyecto Ley Nacional de Educación Superior Comisión de Educación de la HCDN, http://www.diputados.gov.ar/

Ofertas Académicas de Universidades Extranjeras en la República Argentina.

Ley $26.793 / 12$. Decreto 2413/2012

http://www.hcdn.gov.ar/leyes/buscarNormasXNumLey.jsp?id_norma=60186 